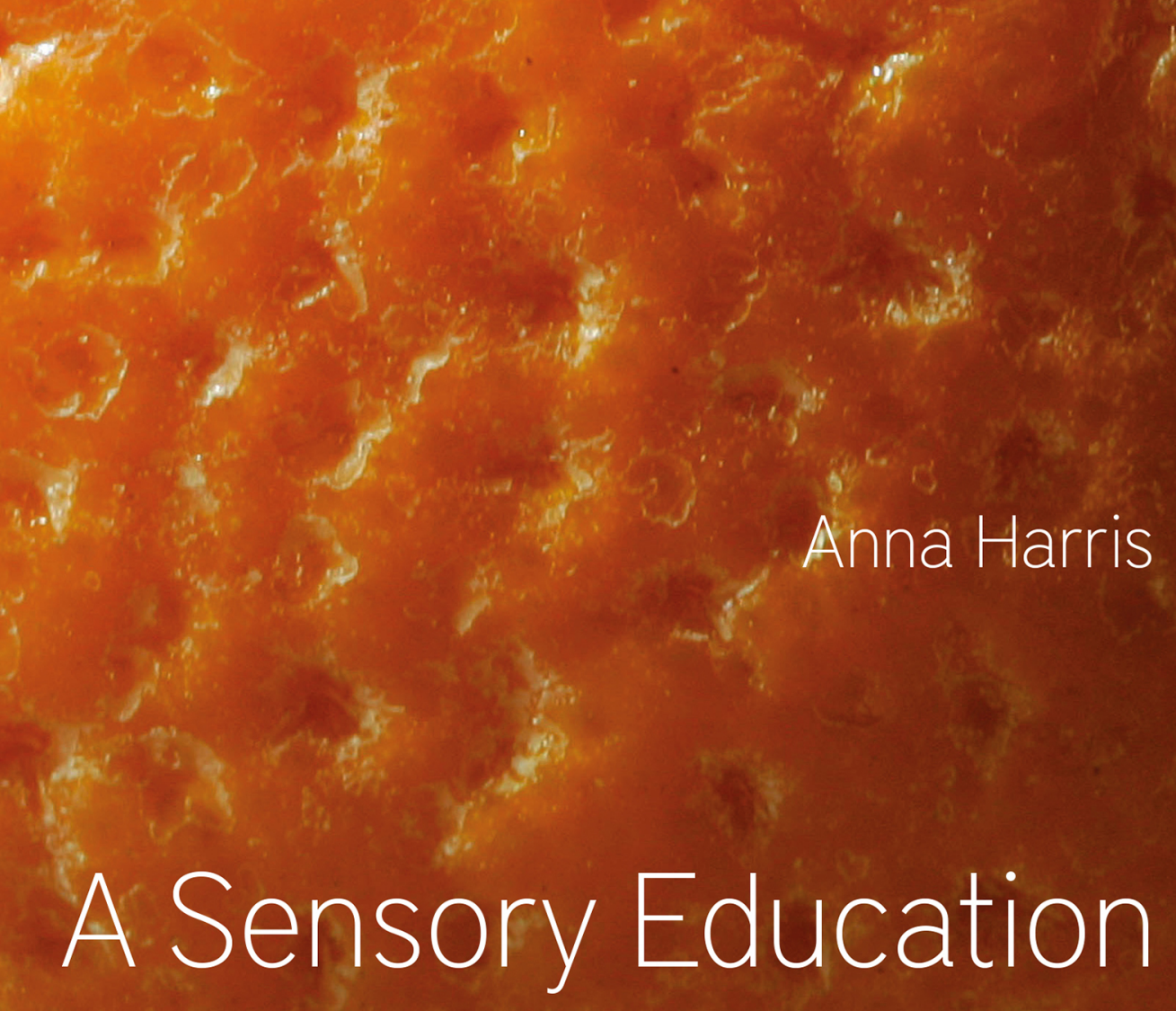

วิ 


\section{A Sensory Education}

A Sensory Education takes a close look at how sensory awareness is learned and taught in expert and everyday settings around the world. Anna Harris shows that our sensing is not innate or acquired, but in fact evolves through learning that is shaped by social and material relations. The chapters feature diverse sources of sensory education, including field manuals, mannequins, cookbooks and flavour charts. The examples range from medical training and forest bathing to culinary and perfumery classes. Offering a valuable guide to the uncanny and taken-for-granted ways in which adults are trained to improve their senses, this book will be of interest to disciplines including anthropology and sociology as well as food studies and sensory studies.

Anna Harris is an Associate Professor in the Department of Society Studies at Maastricht University, the Netherlands. 


\section{Sensory Studies}

Series editor: David Howes

This series comprises cutting-edge case studies and syntheses in the emergent field of sensory studies. It provides an invaluable resource for those involved in research or teaching on the senses as object of study and/or means of inquiry. Embracing the insights of a wide array of humanities and social science disciplines, the field of sensory studies has emerged as the most comprehensive and dynamic framework yet for making sense of human experience. This series offers something for every disciplinary taste and sensory inclination.

\section{Sensory Arts and Design}

Ian Heywood

\section{Food and Multiculture}

A Sensory Ethnography of East London

Alex Rhys-Taylor

Heritage Formation and the Senses in Post-Apartheid South Africa

Aesthetics of Power

Duane Jethro

\section{Race and the Senses}

The Felt Politics of Racial Embodiment

Sachi Sekimoto, Christopher Brown

\section{A Sensory Education}

Anna Harris

\section{Sounding Out Japan}

A Sensory Ethnographic Tour

Richard Chenhall, Tamara Kohn and Carolyn S. Stevens

https://www.routledge.com/Sensory-Studies/book-series/BLANTSS 


\title{
A Sensory Education
}

\author{
Anna Harris
}


First published 2021

by Routledge

2 Park Square, Milton Park, Abingdon, Oxon OX14 4RN

and by Routledge

52 Vanderbilt Avenue, New York, NY 10017

Routledge is an imprint of the Taylor \& Francis Group, an informa business

(C) 2021 Anna Harris

The right of Anna Harris to be identified as author of this work has

been asserted by her in accordance with sections 77 and 78 of the

Copyright, Designs and Patents Act 1988.

The Open Access version of this book, available at

www.taylorfrancis.com, has been made available under a Creative

Commons Attribution-Non Commercial-No Derivatives 4.0 license.

Trademark notice: Product or corporate names may be trademarks or registered trademarks and are used only for identification and explanation without intent to infringe.

British Library Cataloguing-in-Publication Data

A catalogue record for this book is available from the British Library

\section{Library of Congress Cataloging-in-Publication Data}

Names: Harris, Anna, author.

Title: A sensory education / Anna Harris.

Description: Abingdon, Oxon; New York, NY: Routledge, 2021. |

Series: Sensory studies | Includes bibliographical references and index. |

Identifiers: LCCN 2020024532 | ISBN 9781350056121 (hardback) |

ISBN 9781003084341 (ebook)

Subjects: LCSH: Senses and sensation-Psychological aspects. |

Senses and sensation-Study and teaching.

Classification: LCC BF233 .H278 2021 | DDC 152.1-dc23

LC record available at https://lccn.loc.gov/2020024532

ISBN: 978-1-350-05612-1 (hbk)

ISBN: 978-1-003-08434-1 (ebk)

Typeset in Times New Roman

by codeMantra

Research for this book has received funding from the ERC under the European Union's Horizon 2020 research and innovation program (grant agreement No 678390).
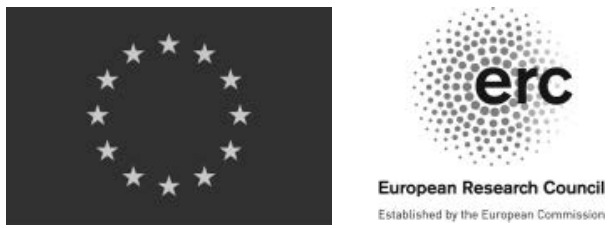
To Thomas and Bastian, who always notice 

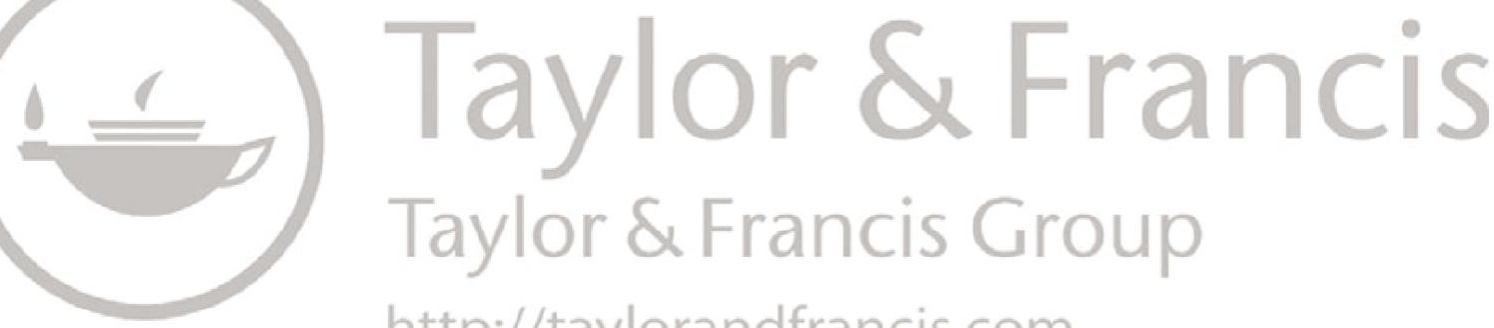

http://taylorandfrancis.com 


\section{Contents}

List of figures $\quad \mathrm{x}$

Acknowledgements xii

Author's note xiv

Making-reading, making-writing xv

The lessons xvii

Equipment guide xvii

Sound xix

Illustrations xix

Introduction 1

Cultivation 3

Noticing 4

Learning from others 6

How to percuss 8

Fieldwork this book draws on 21

What this book does not address 24

Summary of chapters 25

Lesson 1 How to make a cyanometer and other lessons in blue

1-10: Alice blue to duck egg blue 33

11-20: periwinkle to azure 34

21-30: Prussian blue to Egyptian blue 36

31-40: dark cyan to $7.5 B 1 / 238$

1 New vocabularies

New words 41

Objectivity machines 46

Reference sets 49

Metaphors 51

Knowing differently 55 
viii Contents

Lesson 2 How to teach medicine, with food

Eggs 59

Grapes 60

Tropical fruits 61

Oranges 62

Pear drops 63

2 Sensory school

Set-ups 69

Calibration 74

Creativity and improvisation 78

Lesson 3 How to knit a uterus

Equipment 84

Instructions 86

3 Sensory instructions

Instructional media 91

The sound of recipes 93

Designing expressive instructions 98

Sensory alignment 100

Lesson 4 Sensory food gatherings

106

Fried fish sandwich 108

Sahlep 108

4 Workshopping

A cooking class 112

Attention workshops for medical students 115

Hands-on learning 119

Skillshare 120

Lesson 5 Make your own lesson

5 Repackaging sensations

Sensory marketing 134

Old tastes, new tastes 136

Selling slowly 141

Dining differently 143 
Lesson 6 Observation exercises

Equipment 151

Instructions 152

6 Engineering noticing

Sensing and sensors 161

Design of our landscape 165

Bare feet and forest bathing 168

Something sensible by way of a conclusion

A final note on instructions 178

Index

180 


\section{Figures}

0.1 Pile of books xiv

0.2 Eraser xviii

0.3 Glue xviii

0.4 Pencil xviii

0.5 Ruler xviii

0.6 Scissors xviii

0.7 Headphones xix

1.1 Cyanometer, 1-40 33

$\begin{array}{lll}1.2 \text { Compass } & 35\end{array}$

1.3 Coffee cupping set-up with beans, spoons and cups 42

1.4 Pour over kettle used in a cupping session 44

$\begin{array}{ll}1.5 & \text { Glasses in a wine tasting }\end{array}$

$\begin{array}{lll}1.6 & \text { Smell kit } & 49\end{array}$

1.7 Pear drops $\quad 52$

2.1 Egg in cup $\quad 59$

$\begin{array}{ll}2.2 & \text { Bunch of grapes } \\ 2.3 & 60\end{array}$

2.3 Papaya 61

2.4 Oranges in socks $\quad 62$

$\begin{array}{lll}2.5 & \text { Pear drops } & 63\end{array}$

$\begin{array}{lll}2.6 & \text { Blackboard } & 65\end{array}$

$\begin{array}{ll}2.7 & \text { Ear model, Skills Lab (Maastricht) } \\ 2.8 & 70\end{array}$

$\begin{array}{ll}2.8 \text { Gloves containing water } & 79\end{array}$

3.1 Balls of wool $\quad 84$

$\begin{array}{ll}3.2 \text { Knitting needles } & 85\end{array}$

$\begin{array}{lll}3.3 & \text { Pacifier/dummy } & 88\end{array}$

$\begin{array}{lll}3.4 & \text { Cracked eggshells } & 91\end{array}$

3.5 Loaf of bread 96

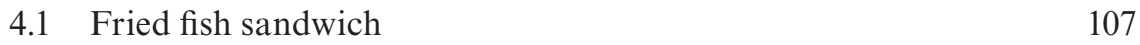

4.2 Farm basket for collecting herbs and vegetables 113

$\begin{array}{lll}4.3 & \text { Field binoculars } & 124\end{array}$

$\begin{array}{lll}5.1 & \text { Japanese teapot } & 132\end{array}$

$\begin{array}{ll}5.2 \text { Whiskey bottle and label } & 140\end{array}$ 
5.3 Tomato

5.4 New Nordic plate 145

$\begin{array}{lll}6.1 & \text { Smartphone } & 152\end{array}$

6.2 Notebook 153

6.3 Finding spices in the cupboard 158

$\begin{array}{lll}6.4 & \text { Smartphone } & 162\end{array}$

6.5 Promenade Plantée, Paris 166

$\begin{array}{ll}6.6 & 169\end{array}$

Note: All illustrations (C) Anna Harris, 2019. 


\section{Acknowledgements}

First and foremost, to all of the individuals who have shared their lives with me in some way, during the periods of fieldwork I have done researching this book - I have learned so much from you.

My sincere thanks also to ...

My dear Bastian and my dear Thomas, both exquisitely attuned to sensory detail, constantly inviting me to slow down more, and enjoy it;

At Bloomsbury, Lucy and Miriam, it was a pleasure to work with you and your team throughout much of the production of this book, and also the team subsequently at Routledge, who ensured a smooth transition. David Howes, you were an incredible series editor, encouraging me at all the right times, offering excellent feedback and literature suggestions, and also kindly inviting me to explore the book-in-the-making with your engaged students at Concordia. I look forward to our future collaborations on this theme. And to the anonymous reviewers for their enthusiasm and critical feedback which was so helpful in revising the text;

Valentijn Byvanck, for the generous collaboration over the years (including flying me to Aberdeen with a great crew to meet with Tim Ingold's group, when I didn't have a job) and for all that you have done to generate ideas through the public academic-arts lecture series Training the Senses, which I have been honoured to join and be part of;

Darryl Cressman, for reading and commenting on the instructions chapter and his inspiring tutorials on medial theory.

The European Research Council (ERC), for much of the research upon which this book is based received funding from the ERC under the European Union's Horizon 2020 research and innovation program (grant agreement No 678390);

Carla Greubel, what would I have done without you, in writing this book your research assistance and conversations over tea and cake, throughout the writing of this book to its moment of submission, were invaluable. Candida Sanchez Burmester, you joined our team at the end of this book project, but also came to the rescue with references at the end;

Marilys Guillemin, for offering not only an endorsement for the book proposal but also much-valued friendship and mentorship. You are my role model not only for academic work and how to strike a remarkable work/life 
balance but also, ever since we discovered our shared love of cookbooks, for how to enjoy the sensory pleasures of life, especially food and cooking classes;

At Maastricht University, my wonderful colleagues in the finance, legal and secretarial departments who helped with many of the bureaucratic arrangements related to writing a book - thank you especially Sanne and Cindy;

The fabulous Making Clinical Sense research team - including but not limited to Andrea, Rachel and John for sharing their insights from fieldwork and commenting on early chapters, Sally and Rachel for sharing their perfume making workshop experience, Andrea for recipe testing the oranges in class, Paul for making the gorgeous videos as part of the workshops and offering feedback on a chapter, and Harro for loaning me his office while I worked on the revisions;

My students in the Observing and Representing the Senses class over the years, thank you for the great questions and for constantly inspiring me;

My parents for raising me to make things, and for my whole family and my friends for always being interested and engaged in my work;

The Sonic Skills team, led by Karin Bijsterveld and funded by the NWO, also based at Maastricht University, greatly informed my own thinking about the senses, and I will always cherish this time we had working together;

Melissa Van Drie and Tom Rice, thank you for the collaborations over the years, I have developed much of my thinking about learning sound in medicine through writing with you both.

Considering that this book is a culmination of years of research and numerous research projects brought together, small sections of the text have been thought through in and reworked from previous publications. This includes the following: the discussion of percussion that appears in the Introduction chapter which was first developed in Body \& Society (Harris, Anna. Listening-touch, affect and the crafting of medical bodies through percussion. Body \& Society 22, no. 1 (2016): 31-61); Lesson 2 which first appeared as a photoessay in the quarterly food magazine The Gourmand (Harris, Anna. 'The culinary art of clinical simulation', The Gourmand 12 June 2019: 40-47); small sections of Lesson 3 which were developed in an article in Medicine Anthropology Theory (Nott, John and Anna Harris. 'Sticky Models: History as Friction in Obstetric Education': 7, no. 1 (2020): 44-65); Chapter 3 which includes reworked sections (those about baking bread) from an article in Gastronomica (Harris, Anna. The hollow knock and other sounds in recipes. Gastronomica: The Journal of Critical Food Studies 15, no. 4 (2015):14-17); Lesson 4 which has been reworked from a sound essay I published with friends and colleagues in the wonderful blog of the Centre for Imaginative Ethnography called Sound Dish (Harris, Anna, Thomas Fuller, Alexandra Supper, Joeri Bruyninckyx and Melissa van Drie. Sound Dish: What we hear, with our tongues. Centre for Imaginative Ethnography, Sounding, 5 February 2016); and the description of Sounds of the Sea in Chapter 5 first appeared in The Public Historian (Harris, Anna. Eliciting sound memories. The Public Historian 37, no. 4 (2015): 14-31). 


\section{Author's note}

Or,

\section{Possible ways to read and use this book: instructions, techniques and materials}

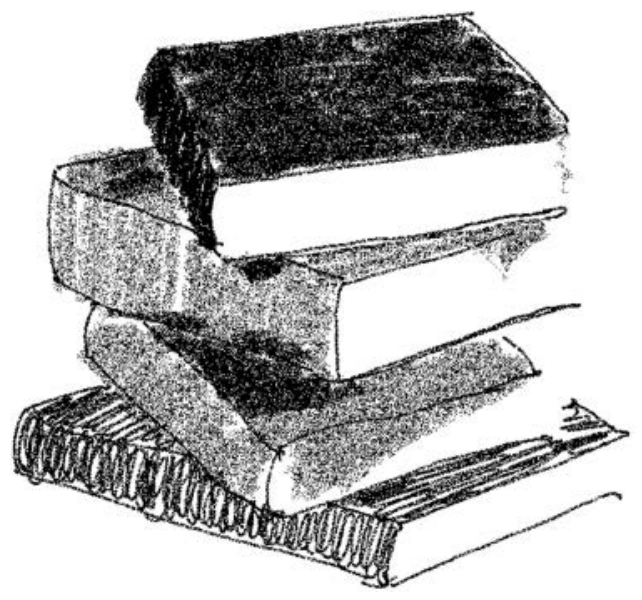

Figure 0.1 Pile of books.

This book has been written with several audiences in mind. First, it is intended to be of interest and approachable for curious readers interested in social currents of contemporary life regardless of academic background. The contemporary life that I write about is largely influenced by my own experience and life course. I am a middle-class white Australian woman with a Canadian and British parent/grandparent, raised in a small city in Tasmania and now living in a small city in the Netherlands. My experiences are largely those of privilege and based in Australia, Europe and North America. The observations I make in this book are of the attention to sensory education I see and have participated in around me, yet I acknowledge that this will not represent all readers' experiences. As an anthropologist I am highly aware of the cultural specificities of my cases, and try, whenever I can, to explore literature from outside of my own fieldwork and life opportunities. 
The book has also been written with mid-level undergraduate students in mind, with the hope that this manuscript not only offers theoretical and empirical insights into the topic of sensory education but also injects some practical lessons into the classroom, exercises that can be followed and which encourage a hands-on approach to education, one based as much on making as on reading and writing.

That said, reading books (Figure 0.1 ), I feel, has strangely become a luxury pursuit in teaching and learning institutions these days. Strange considering that writing and reading is often considered the cornerstone of academic life. Increasingly days are taken up with emails, meetings, and social media updates. Academics read what needs to be read - an article to review, a report to file - and settling into a comfy chair (where are those comfy chairs in universities?) for the day with a book seems like sheer indulgence. In fact, for many academics, tearing themselves away from the computer for anything other than for a meeting doesn't seem like work. I am revising this text after my university suffered from a cyber attack over the Christmas break, preventing access to emails until a few days into the new year. Most of my colleagues, including myself, were highly disoriented by this experience.

There are a bevy of books these days calling for various forms of digital minimalism ${ }^{1}$ and rethinking the ways in which we interact with screens. This book does not despise the digital. Far from it. In Chapter 6, for example, I delve into theories that enrich our understanding of sensoriality through digital engagements. That said, to the last audience I hope to address, the academic, this is an invitation to be luxurious in reading and to attend to its sensory nature, to notice how you read and to follow sensory instructions, sometimes quite literally. These instructions are intended as an invitation to try and read in a way that attends to the contents of the book, and to break some habits which might mean a new kind of sensory awareness in the process.

\section{Making-reading, making-writing}

If you wish to make an honest statement about the sensible, an epithet of Colette's is better than ten statements by a logician; as is a visit to, or better still the creation in detail of, a garden. ${ }^{2}$

Anthropologists, along with other social scientists and humanities scholars, make a lot of words - in the books sometimes luxuriously read, in the emails which wash in and out of inboxes, in lectures and seminars - but they rarely make wordless things. Artistic and creative researchers are one group who are pushing these boundaries, arguing that ethnographic research can have

1 Cal Newport, Digital Minimalism: Choosing a Focused Life in a Noisy World (New York: Portfolio/Penguin, 2019).

2 Michel Serres, The Five Senses: A Philosophy of Mingled Bodies (London: Continuum, 2008), 287. 
other outcomes than words. The anthropologist Tim Ingold ${ }^{3}$ has pursued an agenda for 'making' with the book by the same name. It is filled with ideas stemming from how he taught anthropology students in ways that engage with what it means to learn in practice, with things and materials. He held seminars in his classes where students and teacher did things - learned Alexander technique, made drystone walls, drew buildings - and considered that the quality of discussions had while doing things was unlike anything in an ordinary seminar. In his classes, students would collect objects, mess with materials, fly kites, make string, walk on the beach, forge signatures and at the same time read books and articles and attend lectures. In designing this course he asked, 'what difference does it make if discussion is grounded in a context of practical activity? ${ }^{4}$

This book takes inspiration from these attempts to think beyond the written word. It invites academics and students in particular to not only draw themselves away from the desktop computers and laptops to partake in the pleasures of sensory reading but also experiment with some making-reading. This is an invitation to head to the craft store on a trip to the library and to make things alongside reading each chapter. There are instructions specifically designed for this, to be followed, hacked, ignored and rejected (you can find more details below). Each instruction relates in some way to the chapter preceding it and the chapter following it. The instructions are always for how to make something from materials that are not too hard to find, and which can usually be pulled together from cupboards at home. Sometimes though you might want to make a trip out to the craft or hardware store.

The Lessons are inspired by the how-to books I studied for this manuscript. The very presence of this "author's note" and later the "equipment guide" is drawn directly from cookbooks for example. These authors' notes are wonderful examples of how cookbook authors attempt to set the tone of their sensory instructions through a beginning narrative or story that is also combined with instructions for techniques, methods and objects for cooking.

This is not a craft book though. Making-reading means not only working with your hands but also engaging with literature and theories at the same time - not literally at the same time, but in the same event of doing. Thus, I have written the instructions as narratives, which interdisperse academic arguments alongside the doing. This is about learning from doing as well as about it, learning from creation, in the words of Michel Serres quoted earlier.

For non-academics and those who make all the time already, the book is also an invitation to draw upon your own intellectual pursuits and consider these in relation to bodies of literature that you may or may not already be familiar with - experiments in psychology, developments in the neurosciences, histories of technology, for example. You will find much more of

3 Tim Ingold, Making: Anthropology, Archaeology, Art and Architecture (London: Routledge, 2013).

4 Ingold, Making, 9. 
this in the 'chapters' where these literatures are explored in conversation with fieldwork I have conducted for the book.

Because I wanted to explore the idea of making-reading, I also made while I wrote the book too - I engaged in what you might call making-writing. I designed, crafted and reconfigured objects which pertained to the arguments I was exploring as a form of "material thinking'. 5 This is something I have done in most of the fieldwork I have conducted, such as making quilts (during my fieldwork on migrant doctors) or embroidering (when studying genetic technologies). Some of these experiments have ended up as lessons in the book, others discarded in the UFO (unfinished object) pile. These lessons are sliced between the chapters, as outlined in the next section.

\section{The lessons}

Lesson 1 offers instructions on how to make an instrument called a cyanometer, designed in the eighteenth century to measure the blueness of the sky.

Lesson 2 invites the reader to experiment with food in demonstrating aspects of illness or how to train medical techniques.

Lesson 3 gives instructions for how to knit a uterus, a tool I found in medical schools, the instructions a narrative knitting pattern exploring the exploded history of the materials.

Lesson 4 gives advice for how to host a sensory dinner party, something which might make a nice reading group format, or just a way to explore issues of sensory knowledge with friends and colleagues interested in the topic.

Lesson 5 is an invitation for the reader to make their own lesson based on their own interests and observations. Some guiding questions are offered for considering when designing this lesson.

Lesson 6 is a set of observation exercises, inspired by the work of data graphic designers who encourage a particular kind of awareness during a week of your life.

In writing-making these lessons, I explored what it means to design instructions. I re-interpreted knitting instructions in Lesson 3 into a more academic narrative, for example, and remade a recipe for fish burgers in Lesson 4, as part of a sensory dinner party. I explored what it meant to make simple, abstract and generalisable illustrations.

\section{Equipment guide}

Overleaf you will find some basic equipment that can be used in the Lessons in the book. In her study of olfactory training, the sociologist Geneviève Teil ${ }^{6}$

5 Paul Carter, Material Thinking: The Theory and Practice of Creative Research (Melbourne: Melbourne University Press, 2004).

6 Geneviève Teil, 'Devenir Expert Aromaticien: Y a-T-Il Une Place Pour Le Goût Dans Les Goûts Alimentaires ?', Sociologie du travail 40, no. 4 (1998): 503-22. 
xviii Author's note

showed that care for one's sensory training tools was an important part of the process of learning. In her case she was using scent kits and smell charts, and the upkeep of these was vital to a shared communication between novices learning the craft. So, gather your materials and look after them, take care - this is an important part of the sensory lesson (Figures 0.2-0.6).

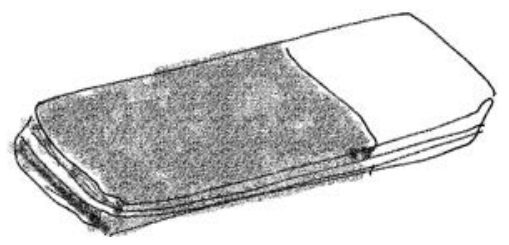

Figure 0.2 Eraser.

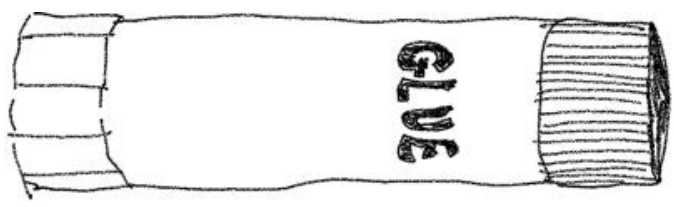

Figure 0.3 Glue.

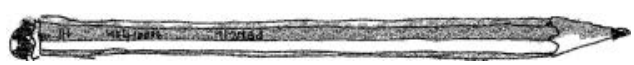

Figure 0.4 Pencil.

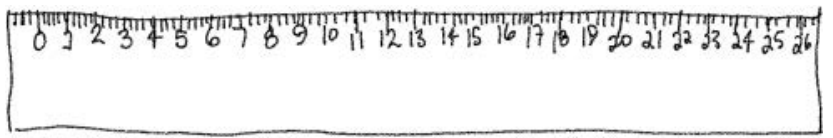

Figure 0.5 Ruler.

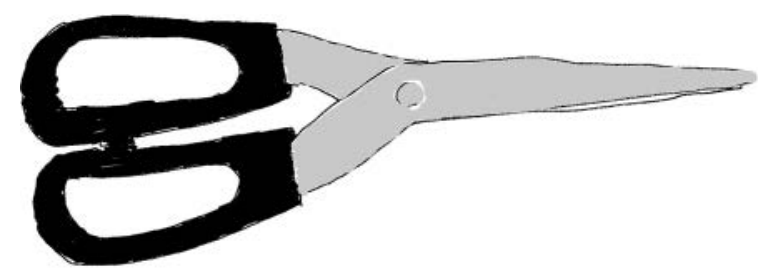

Figure 0.6 Scissors. 


\section{Sound}

What do you listen to when you read? How do you listen - with headphones, to create your own acoustic space, with records, to enjoy the feel and sound of vinyl, from the speakers of your computer or perhaps surround sound? All these ways of listening are bodily experiences whether solitary or social. How does this affect the reading experience? There is a recent trend in trade publishing to include soundtracks with novels and many ways to hack your own. Museums offer soundtracks to exhibitions. On the accompanying website for this book (www.makingclinicalsense.com/about-the-study/a-sensoryeducation/) you will find music or sounds which might interact with the words on the page (Figure 0.7).

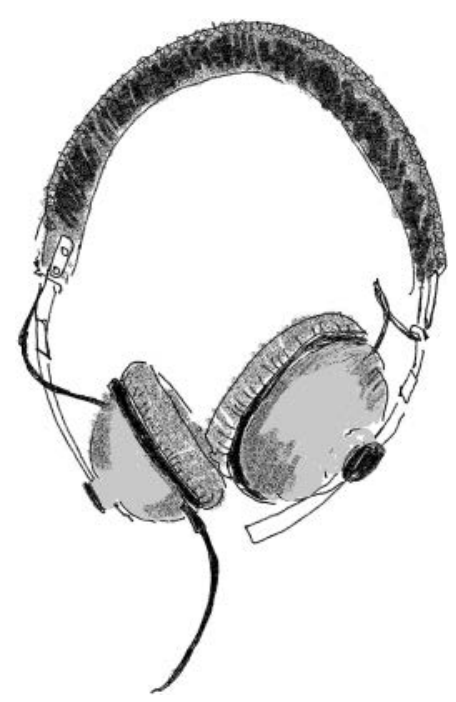

Figure 0.7 Headphones.

\section{Illustrations}

It is no coincidence that this book is replete with hand-drawn images. In making these drawings I wanted to explore and speak to the role of illustrations in instruction, whether that be a recipe, a birdwatching field guide, a knitting pattern, IKEA instructions or protocols for how to palpate a tumour. Illustrations allow for some kind of generalisations that photographs do not permit room for variation and abstraction and improvisation in the learning event.

I always make drawings when I make fieldnotes, as do many other anthropologists. These drawings may have appeared in classic ethnographic texts - illustrations of a range of tools to scale, for example - but then they disappeared for a while. There has been a more recent resurgence of interest 
in drawing in fieldnotes in anthropology, ${ }^{7}$ with Michael Taussig claiming that "photography is taking, the drawing a making". ${ }^{8}$ It thus fits with the idea of making-reading that I want to explore with this book, that in writing it I also consider what it means to illustrate instructions too.

\section{Bibliography}

Alfonso, Ana Isabel, ed. Working Images: Visual Research and Representation in Ethnography. Abingdon: Routledge, 2004.

Carter, Paul. Material Thinking: The Theory and Practice of Creative Research. Melbourne: Melbourne University Press, 2004.

Ingold, Tim. Making: Anthropology, Archaeology, Art and Architecture. London: Routledge, 2013.

Serres, Michel. The Five Senses: A Philosophy of Mingled Bodies. London: Continuum, 2008.

Taussig, Michael. I Swear I Saw This: Drawings in Fieldwork Notebooks, Namely My Own. Chicago, IL: The University of Chicago Press, 2011.

Teil, Geneviève. 'Devenir Expert Aromaticien: Y a-T-Il Une Place Pour Le Goût Dans Les Goûts Alimentaires?'. Sociologie du travail 40, no. 4 (1998): 503-22.

7 Ana Isabel Alfonso, ed., Working Images: Visual Research and Representation in Ethnography (Abingdon: Routledge, 2004).

8 Michael Taussig, I Swear I Saw This: Drawings in Fieldwork Notebooks, Namely My Own (Chicago, IL: The University of Chicago Press, 2011), 87. 


\section{Introduction}

One evening, during one of my knitting groups' regular gatherings, I wanted to learn a new stitch. I was struggling with the instructions described in the pattern I was following, printed from a free online website. The instructions seemed to make sense but I just could not get my fingers, the wool and the needles to work in harmony. I kept ending up with either knotted chaos or large holes each time I tried. Conversation was flowing amidst the endless tea, and literally, because they are all very good knitters, needles were click clacking. I piped up: how do I do this stitch? As always happened, a stream of excellent advice followed. The knitter next to me leaned over and took my needles, a little awkwardly as she tried to mimic how I held them rather than her own 'continental' style that she had learned as a child, and worked through the stitch several times. I tried to squeeze in close to her so I was not seeing the mirror image, but rather viewing it from her perspective, so I could best repeat the manoeuvre. I tried to notice carefully how she pulled the wool, to watch how she held the needles and take note of the various steps involved in the new stitch. She gave me my knitting back, to practice. The knitter on the other side of me leaned over. She had her iPad in her hand and had set-up an online video for me to watch, by one of her favourite knitting vloggers, of how to make that particular stitch. I could see a close-up of hands and wool in the freeze-framed image, with many comments below. I watched the video repeatedly, freeze-framing whenever I wanted to see something closely. Another of the knitters was watching this and when I stopped the video, she told me that she learned that stitch by unravelling a sweater - she watched how the wool went through the loops as she took it apart and then tried to recreate it herself. The fourth knitter in the group was quiet, for she was immersed in an extremely complicated numerical knitting pattern of the kind I would never have any hope of following.

Cradled within the lessons I learned that evening is the essence of this book, for it is a book about the social and material nature of sensory education. We learn things in life with others and with things. We learn in everyday encounters and in expert settings such as schools and other educational institutions. The knitting lesson offers just one example of the many different ways of going about, and the many different kinds of media involved in, 


\section{Introduction}

this sensory education - there are written instructions, videos and other demonstrations, lessons from others and learning from materials and memory. Sensory lessons demand the cultivation of a particular 'art of noticing'. All learning is sensory. Lessons in life and at school are bodily, sensory engagements with others and things and places whereby transformations, ideally, occur. It is these everyday and expert sensory lessons that I refer to when I talk of sensory education. The topic of sensory education is time-old. So why is this important to explore again, now, in a new book?

First and foremost, I need to point out who might consider this important, because most of the practices described in this book are those involving Western middle-classes, seeking a life of betterment, whether in their everyday life or through university education. Sensory education in these cases is a choice, not a matter of survival or getting enough to live by. Some of the practices that are described in much of the literature on sensory training, and that is included in this book, such as wine tasting and perfume making, could be considered as incredibly elitist activities that certainly wouldn't speak to all readers of this book. They are practices that individuals engage in because of certain conditions such as time (with more menial labour outsourced to others), ${ }^{1}$ gender, ${ }^{2}$ security, privilege and wealth. Some of the higher education I describe, such as medical school, is also not open to everyone in some parts of the world.

There is also certainly a very specific market, of those who are addressed in the marketing of sensory education tools, with a rather limited inclusivity entailed in many of the workshops, books and programs I found, whether through targeted groups or representation in advertisement. As I delve into throughout the book, sensory education is often seen as an antidote to digital maximalism, where through digital detoxing and digital minimalism, individuals can get back to their senses, Thoreau style. Yet as many STS scholars have pointed out, based on the work of non-use by Sally Wyatt, ${ }^{3}$ there are various ways in which individuals do not engage with technology and this might not always be through voluntary choice. That is, not all of the world needs to limit their engagement with digital tools - some would like to have more access. Discussing matters of sensory education would be vastly different in settings of social deprivation, in areas where economic and racial identities are different from those I encountered or where cultural and political contexts offer different conditions.

1 Travers, Mark, 'How Do the Very Wealthy Choose to Spend Their Time?', Forbes, 13 July 2019.

2 Criado Perez, Caroline, Invisible Women: Exposing Data Bias in a World Designed for Men (London: Chatto \& Windus, 2019).

3 Wyatt, Sally, 'How Users Matter: The Co-construction of Users and Technology', in Non-users also Matter: The Construction of Users and Non-users of the Internet, eds. Nelly Ourdshoorn and Trevor Pinch (Cambridge, MA: MIT Press, 2003): 67-79. 
Thus, in summary, this book speaks to a very privileged context, a context that I can mostly speak to, through my own experience and through my fieldwork. I encourage readers who have other experiences to critically engage with the text and think about what it might mean for situations of less privilege. In the conclusion, I discuss further areas of research, including a greater engagement with decolonial thinking, for example. Within the context of which I have researched and participated in, the topic of sensory education seems particularly pertinent for a number of reasons. First, because there seems to be a prevailing idea, amongst the Western middle classes, that sensory attention to the world around us has been lost or is seriously at threat, lost and threatened in an era of speed, distraction, automation and as I mentioned above, digital technologies and hence the need for recovery, for guidebooks, educators and instructions, to help guide the way back through sensory learning that is slow, mindful and intentional. This is a critical idea upon which this book rests: the sensory educators of our times are reliant on this notion of a loss of sensory awareness. Whether we have lost our sensibilities is not my interest or point, but rather what I explore in this book is the culture of sensory education that seems to be dwelling and springing up in the crevices of daily and work life.

As anthropologist Isabelle de Solier ${ }^{4}$ writes, post-industrial societies are focused on the individual self which is responsible for their own formation. This takes place through forms of consumption, as many argue, as well, she suggests, of leisure production, which can be a form of producing/consuming things as well as learning things. This leisure labour underscores many of the forms of sensory education we see outside the professional domain. Training the senses is a form of work, albeit pleasant, but labour nonetheless. And it is a form of labour which is becoming increasingly urgent. For alongside these discourses of productive leisure, sensory education is also wrapped up with concerns of sustainability and better ways to care for the planet. Noticing and seeing, attending to the world, requires new forms of sensibility that middle-class citizens, particularly urban dwellers, in Western places are urged to explore and cultivate.

\section{Cultivation}

Despite the cacophony of voices now studying sensory experiences in popular and academic literature, little is still known about how sensory education actually gets done in contemporary life. This book seeks to contribute towards this understanding of the various practices of sensory education. Knitting offers the first example of the complexity of this topic of sensory lessons. Part of a renewed craft movement, with knitting now celebrated 


\section{Introduction}

as offering time away from the computer, my knitting lesson showed that sensory practices are also deeply entangled with the digital. There are many other materials that come into play too - print outs and wool - as well as sensory memories. Learning is also something that happens with others, not only as a sole journey of self-transformation as might often be discussed in the self-help or psychologically orientated educational literature. It is social and it is material. Knitting will reappear as another example later in the book, as I talk more about my craft approach to research and delve deeper into some knitting instructions. The book itself, however, will draw mostly from sensory practices in two other distinct yet related fields: food and medicine. In doing so I work with my own ethnographic fieldwork over many years delving into the worlds of eating and doctoring, as well as the vast body of sensory anthropology literature researching these topics.

In doing so I forward one main and simple argument, which is that sensing is not something innate (i.e., you are born with it), cognitive/neurological (in the brain) or individual but rather cultivated through social, bodily, material practices. To cultivate something means to try to develop a skill. The words 'try' and 'skill' are crucial to the material I use to build my argument. Trying is different from achieving - it is the attempt that I want to foreground throughout the subsequent chapters, rather than the achievement of a particular sensory expertise. Thinking of sensing as a skill, rather than as a genetic ability, also helps to highlight the need to attend to the way it is learned and taught, to its education. The French origins of the word cultivate, colere, bring together these two important elements - trying and skill for colere means to inhabit. A sensory education means to inhabit sensing in social, bodily, material ways, through trying to learn skills and trying to teach them too. 'The senses' do not exist in and of themselves, as something to be made aware of in sensory education. Nor is sensory awareness a skill

to be 'trained'. Rather what I look at is how sensory education is an act of cultivation.

\section{Noticing}

I forward this argument with the work of Anna Tsing, whose recent work on the global politics of mushroom hunting offers a beautiful phrase for thinking with and for working further on, a study such as this one. She suggests that the work of mushroom hunters, just like the work of natural scientists and ethnographers, can be considered as the 'art of noticing, 5 She writes about how mushroom pickers develop this art when finding fungi in the forest and how anthropologists develop this skill through their ethnographies, just as natural historians do through fieldwork. It means 'looking around

5 Anna Lowenhaupt Tsing, The Mushroom at the End of the World: On the Possibility of Life in Capitalist Ruins (Princeton, NJ and Oxford: Princeton University Press, 2015). 
rather than ahead ${ }^{6}{ }^{6}$ something which Tsing ties into a broader politics of sensing.

I suggest that sensory education involves cultivation of the art of noticing. Cultivating the art of noticing is closely related to other concepts and phrases currently used by scholars studying sensory expertise and by popular writers. I will explore some of them briefly here, focusing on those that are most widely used and read in the popular literature. James Gibson and subsequently Tim Ingold have introduced into the academic literature an often-used phrase for describing learning in life, as an 'education of attention'. It is a phrase that I have used in my own work to examine the ways in which novices are guided in a rediscovery of their environment, yet now I find it somewhat too cognitive and individual, too focused on a cerebral engagement that involves attending. Latour develops from Gibson's work to look at how novice perfumers are 'trained to be affected'. In this process of learning to be affected by previously unregisterable differences 'body parts are progressively acquired.' ${ }^{7}$ For Latour the body is an interface that becomes further determined as it learns to be affected by more and more elements, whereby we become sensitive to what the world is made of. His theory goes that through such practices, the body is trained to sense, to be sensible, and that materials such as wine kits, wine labels, wine books are all part of this process. Latour's work is extremely useful for how it builds the materiality of education into the practices of sensing. Other related concepts which I do not go into but which very much inform the book are Berger and colleagues' Ways of Seeing, ${ }^{8}$ Howes and Classen's Ways of Sensing ${ }^{9}$ and Daston and Galison's ${ }^{10}$ 'trained judgement', all offering erudite analysis of what it means to develop sensory capacities.

Finally, a concept I don't use much in this book but which underpins my ethnographic approach is Marilyn Strathern's notion of 'learning to see', developed in her accessible Cambridge lecture series. ${ }^{11}$ It is a phrase which on surface appears to relate to the sense of sight but in fact encompasses the student of anthropology, and how they learn to build up a description and elucidate categories of thought. As Strathern writes, 'this is less an issue of how to arrive at an appropriate interpretation of particular [here she uses the word images] than how to make oneself (as the observer, ethnographer,

6 Tsing, The Mushroom at the End of the World.

7 Latour, Bruno, 'How to Talk About the Body? The Normative Dimension of Science Studies', Body \& Society 10, no. 2/3 (2004).

8 Berger, John, Sven Blomberg, Chris Fox, Michael Dibb, and Richard Hollis, Ways of Seeing (London: British Broadcasting, 1977).

9 Howes, David and Constance Classen. Ways of Sensing: Understanding the Senses in Society (New York: Routledge, 2014).

10 Daston, Lorraine and Peter Galison, Objectivity (Brooklyn, NY: Zone, 2010).

11 Strathern, Marilyn, Learning to See in Melanesia: Four Lectures Given in the Department of Social Anthropology, Cambridge University, 1993-2008 (Chicago, IL: Hau Books, 2015). 


\section{Introduction}

student) open to apprehending (some of) the effects such images may have'. ${ }^{12}$ My hope is that the format of this book works in a way to also offer probes and prompts in which anthropologists, as well as those outside the field, may learn other ways of making themselves open to new kinds of apprehension.

\section{Learning from others}

Throughout the book I tease out what I see as important elements of sensory education, the first being the shaping of new kinds of communication through the creation of new vocabularies (Chapter 1). I look at how sensing is calibrated as a collective social activity in sensory schools amidst materials (Chapter 2), and at how calibrated sensing is re-orientated with media in the form of different guides (Chapter 3). I show that at the core of sensory education is a socially cultivated awareness, something that becomes particularly evident in workshops (Chapter 4). I examine the role of industry in the commodification of sensory education by repackaging sensations (Chapter 5). Finally, I take these examples into natural landscapes and look at the design and engineering of sensory awareness as another form or act of noticing (Chapter 6).

In making these points I build upon others who have also argued for the social and material nature of sensing, in beautifully written papers and books, which are cited throughout this and subsequent chapters. I also build upon whole books exploring this topic from particular perspectives, such as Making Taste Public, ${ }^{13}$ which sees sensing not as passively shaped or impacted by culture, but looks instead at how taste (their focus) is a shared activity acquired by actively 'doing taste' - that is communicating, performing, manipulating, changing, sensing and embodying taste. This literature reiterates that focusing on sensory education offers excellent insights into places of sensory sociality, highlighting the key actors and key sites, the spaces of sensory exchange and the values that become attached in the process.

This book largely accesses English literature or literature that has been translated into English (with occasional forays in French and German, thanks to the incredible research assistant who helped with the book, Carla Greubel). But we only need to turn to other languages to see that nuances to the argument can be found. For example, in Dutch, learning and teaching are not separated into two words as they are in English. Rather, one word, leren, means both to learn and to teach. Leren encompasses practices of receiving, collecting, absorbing, acquiring, training, practicing, studying, teaching, educating, qualifying, mastering and familiarising. Moving

12 Strathern, Learning to See in Melanesia, 8.

13 Carole Counihan and Susanne Højlund, eds., Making Taste Public: Ethnographies of Food and the Senses (London: Bloomsbury Academic, 2018). 
across languages helps to problematise what it means to learn and what it means to teach, for the two are not so disconnected. As others have argued, education is not something that only occurs in schools. ${ }^{14}$ And as I explore later in the book, education is also something which is engineered and designed in non-school spaces too.

What I add to the body of literature I draw from is a closer look at this social labour involved in sensory cultivation - for example, the setting up of lessons, the care and maintenance of materials, the administration of protocols. This work of education is often forgotten or glossed over in education research that largely ignores the labour of those who do not take centre stage as experts, the behind-the-scenes work of creating the conditions for learning. In social studies of education, the focus is often on the learners. With some important exceptions, ${ }^{15}$ too often the work of teaching is neglected in the anthropologies of learning skills, perhaps because the novice is often taking a position alongside the other students (see more about that in the forthcoming methodological section of this chapter). I suggest that this neglects the work that goes into teaching sensory lessons ${ }^{16}$ and in this book I highlight the invisible labour not only of teachers but also of the other people and the infrastructures involved in teaching. Literature on sensory learning in anthropology also often sidelines many of the more mundane materials involved in educational practices - the ubiquitous role of how-to guides, for example, in the form of books and videos, these decoded ways of learning often dismissed as mere instruction. Anthropologists also do not pay as much attention to the work of curricula design nor the role of industry in how sensing is shaped [although many science and technology (STS) scholars are addressing this in work explored later in the book].

The book is also a timely scholarly account of sensory education in the midst of a popular book market that is literally being flooded by gurus and experts offering to guide people in their own sensory awareness. Marie Kondō's book sits near cash registers, offering to spark joy through decluttering (while selling more stuff in her new online store to replace what gets thrown away). ${ }^{17}$ Cal Newport urges a decluttering of digital lives through digital minimalism, speaking it seems only to a privileged elite in the US who have the choice and nothing better to do than to cut down on their

14 Jean Lave, Learning and Everyday Life (Cambridge: Cambridge University Press, 2019); Tim Ingold, Anthropology andlas Education (London: Routledge, 2018).

15 Lave, Learning and Everyday Life; Natasha Myers, 'Molecular Embodiments and the Body-Work of Modeling in Protein Crystallography', Social Studies of Science 38, no. 2 (2008): 163-99; Rachel Prentice, Bodies in Formation: An Ethnography of Anatomy and Surgery Education (Durham, NC: Duke University Press, 2013).

16 Anna Harris and Jan-Joost Rethans, 'Expressive Instructions: Ethnographic Insights into the Creativity and Improvisation Entailed in Teaching Physical Skills to Medical Students', Perspectives on Medical Education 7, no. 4 (2018): 232-38.

17 Marie Kondō, Spark Joy: An Illustrated Guide to the Japanese Art of Tidying (London: Vermilion, 2017). 


\section{Introduction}

digital habits. Jenny Oddell invites readers to 'do nothing', as a way of resisting the constant distractions and calls to divert our attention from what is important. ${ }^{18}$

As mentioned previously, the focus of this book is on educational practices related to food and medicine. Why these two domains? As the cultural theorist Tania Lewis ${ }^{19}$ writes, food is a generative space through which to understand the ways new technologies, such as the digital, get entangled into everyday life. Cooking and eating are both profoundly ordinary and in many ways invisible, tied into habit and ritual, but at the same time, inhabit a politicised and contested space, a space which has attracted anthropologists, historians and increasingly STS scholars. On the other hand, medicine offers us a glimpse into the world of sensory experts, offering a particularly rich example of materials in education considering the funding and resources put into training doctors. Both cooking and doctoring are practices supposedly threatened by digital technologies, which make them interesting sites in which to examine the call to 'get back to our senses', especially considering how entangled both are with the digital. Very pragmatically, these are also the sites where I have been conducting fieldwork for years, where I have access and have developed relationships, and where I find endless enjoyment and learning myself.

Before describing this fieldwork in more depth, I will unravel a few assumptions or myths that are commonly held with regard to sensory matters. I look at where these assumptions have come from and discuss the literature that dismantles them. To add some concrete examples to this section as I unpack each assumption I draw from one particular sensory practice that is taught in medical training: the skill of percussion.

\section{How to percuss}

Percussion is a tapping of the body performed by clinicians to understand more about potential pathologies and is often considered a fundamental part of what is called 'the physical examination'. It is a practice that doctors in particular have been doing for centuries, ever since they started physically engaging with patients rather than only listening to their stories. Percussion, like other bodily practices in healthcare such as pulse-taking, ${ }^{20}$ or the sensory techniques of bodyworkers such as reiki practitioners or masseuses $^{21}$ all deal with learning not only a new sensory vocabulary, but also

18 Jenny Odell, How to Do Nothing: Resisting the Attention Economy (Brooklyn, NY: Melville House, 2019).

19 Tania Lewis, 'Digital Food: From Paddock to Platform', Communication Research and Practice 4, no. 3 (2018): 212-28.

20 Valentine Daniel, 'The Pulse as an Icon in Siddha Medicine', in South Asian Systems of Healing, eds. Valentine Daniel and Judy Pugh (Leiden: Brill, 1984), 115-26; Elisabeth Hsu, 'Tactility and the Body in Early Chinese Medicine', Science in Context 18, no. 1 (2005): 7-34.

21 Ruth Barcan, Complementary and Alternative Medicine: Bodies, Therapies, Senses (Oxford: Berg Publishers, 2011). 
new techniques through which to elicit sensations, and by which to interpret them as well. It is an excellent example to help unpack five common myths about sensory education.

But first of all, for those who do not know what percussion is, but want to try it out while reading the next section, here are some simple instructions, adapted from a textbook called Clinical Examination by Nicholas Talley and Simon O'Connor (beware, these instructions, taken from a textbook I always had in my pocket as a medical student, assume right-handedness and may be difficult for the directionally dyslexic!):

First, raise your left hand to your upper chest wall and slightly separate the fingers (you can even align your fingers with the ribs if you can find them). Press the left middle finger firmly against the chest. Then, with the pad of the right middle finger, strike the middle phalanx (that's the second 'section') of the middle finger of the left hand. Quickly remove the percussing finger so that the note generated is not dampened. Try it again. The percussing finger needs to be held partly fixed, and a loose swinging movement should come from the wrist, not the forearm. Move around to different parts of your chest and see if you notice any different sensations. Try to remember this technique and the sensations (the sounds, the vibrations, your body movements), or keep practicing even, as you read the chapter, on different parts of your body, on a nearby table or arm of a chair. ${ }^{22}$

\section{Myth \#1: There are 'five senses' to be trained}

There are many examples to be found both in academic literature and in the public realm, which treat 'the senses' as separate entities with corresponding sensory organs, the ears which hear, the eyes which see, fingers which touch and so forth. Aristotle is the philosopher often credited with making this distinction between the five senses as discrete entities. These neat distinctions, however, have been problematised over time, with many philosophers, historians and anthropologists challenging such clear ordering. Anthropologists such as Kathryn Geurts and David Howes have explored sensory experiences not recognised in the five commonly listed, such as kinaesthesia, proprioception (knowing where your hand is in space and moving it along) and non-Western senses, ${ }^{23}$ as well as intertwined senses, ${ }^{24}$. Daniel Heller-Roazen ${ }^{25}$ also examines what is referred to as the common

22 Nicholas J. Talley and Simon O'Connor, Clinical Examination: A Systematic Guide to Clinical Diagnosis, Third ed. (Sydney: MacLennan + Petty, 1996), 110-11.

23 Kathryn Linn Geurts, Culture and the Senses: Embodiment, Identity, and Well-Being in an African Community (Berkeley: University of California Press, 2003).

24 David Howes, Sensual Relations: Engaging the Senses in Culture and Social Theory (Michigan: The University of Michigan Press, 2003).

25 Daniel Heller-Roazen, The Inner Touch: Archaeology of a Sensation (New York: ZONE Books, 2009), 44. 
sense, writing that in later modernity, the classic problem of the central sense gained new urgency, reinterpreted as an inner touch, a sense of one's vital movements, one's sense that they are alive. ${ }^{26}$ This was a sense that could not be easily placed or described, for some it was skin, others viscera, muscles or blood, for others all things in a single moment. ${ }^{27}$

The example of percussion highlights how the notion of the senses being discrete does not work in educational practice. In my fieldwork in Australian and Dutch medical schools, teaching clinicians quickly emphasised that percussion was about sound. It was not long, however, before other doctors declared that the practice was not about sound at all, but about touch. More teachers and students told me that percussion was about the feeling of the vibration, rather than listening to the sound, especially in noisy hospital wards. It was not only that touch produced the sound but also that practitioners feel the findings through touch too, through listening fingers. There was no agreement about whether percussion was about sound or touch, and in the end it did not seem important: 'We don't just say "Now you're listening. Now you're looking. Now you're feeling" it's ... it's all integrated!', one teacher in Melbourne exclaimed.

The clinical examination textbooks also emphasised the mingled nature of the sensory experience of percussion. For example, in a little yellow book stacked on top of many medical student's pile of digital devices, clipboards and papers, The Oxford Handbook of Clinical Medicine instructions for percussion were given as follows: 'Percuss all areas including the axillae, clavicles and supraclavicular areas. Listen and feel for the nature and symmetry of the sound, ${ }^{28}$

Teachers and learning materials promote percussion as a technique of both listening and touch. Other textbooks reiterate this: 'The feel of the percussion note is as important as its sound', say the Australian clinicians and educators Talley and O'Connor. ${ }^{29}$ 'Percussion results in a complex set of signals giving the examiner both the auditory information of pitch and the tactile information of vibration or resistance, and reflects the ratio of air to solid structures under the area being percussed', Cade and Pain ${ }^{30}$ further explained in the Essentials of Respiratory Medicine. Percussion also involved others sensory experience such as proprioception and kinaesthesia. The way in which the sounds produced are described is a sensory vocabulary that is learned in a particular way, as I explore in Chapter 1. But it also involves some kind of inner sense too, for medical students learn

26 Daniel Heller-Roazen, The Inner Touch, 250.

27 Daniel Heller-Roazen, The Inner Touch, 251.

28 R.A. Hope et al., Oxford Handbook of Clinical Medicine, Third ed. (Oxford: Oxford University Press, 1996), 28.

29 Talley and O'Connor, Clinical Examination, 111.

30 John F. Cade and M.C.F. Pain, Essentials of Respiratory Medicine (Oxford: Blackwell Scientific, 1988). 
to practice percussion on their own bodies. As I have written about elsewhere, ${ }^{31}$ learning sensory skills on your own body brings many different kinds of bodies into being: skilled bodies and anatomical bodies, but also affective bodies that resonate and pulse, as students tap out their breathing moving organs.

So in summary, the percussion example shows that one does not learn 'five senses' but rather that sensory education involves a sensing that extends beyond categories and organs. This involves the practitioner in an active engagement with their world, as a living breathing multisensory and intersensory body amongst other bodies.

\section{Myth \#2: Sensing is innate}

For many biologists, neurologists and cognitive scientists, sensing is a matter related to neurology and genetics, of cells and synapses and memories and bacteria formed from the very beginnings of life. While there is room for adaption, correction, breakdown and repair, there is nonetheless a largely shared understanding in these fields of study that sensing is an innate matter of the biological body. For example, Grunwald ${ }^{32}$ and Spence and Piqueras-Fiszman ${ }^{33}$ see the period of gestation as essential for the development of the senses, to the point where for Grunwald premature birth implies a lack of sensory training that is difficult to compensate with incubators. The approach to sensing is based upon learning models in psychol-

ogy, which assume that education is a form of 'information processing, ${ }^{34}$ and 'transmission'. ${ }^{35}$

Social scientists are more interested in social theories of learning. In regard to sensory experience such as taste, many anthropologists and sociologists such as Claude Lévi-Strauss, Mary Douglas, Jack Goody and Pierre Bourdieu saw this as a matter of socialisation. Social position and the habits of a class determined taste. These scholars viewed sensory knowledge as something 'acquired' in order to move between classes. ${ }^{36}$ While these social scientists interested in socialisation were showing the 'other side of the coin' in regards to the social nature of learning, they still often held the belief that

31 Anna Harris, 'Listening-touch, Affect and the Crafting of Medical Bodies through Percussion', Body \& Society 22, no. 1 (2016): 31-61.

32 Martin Grunwald, Homo Hapticus: Warum Wir Ohne Tastsinn Nicht Leben Koennen (Muenchen: Droemer Verlag, 2017).

33 Charles Spence and Betina Piqueras-Fiszman, The Perfect Meal: The Multisensory Science of Food and Dining (Chichester: Wiley-Blackwell, 2014), 1919.

34 Aradhna Krishna and Norbert Schwarz, 'Sensory Marketing, Embodiment, and Grounded Cognition: A Review and Introduction', Journal of Consumer Psychology 24, no. 2 (2014): 160.

35 Ingold, Anthropology andlas Education.

36 Geneviève Teil, 'Devenir Expert Aromaticien: Y a-T-Il Une Place Pour Le Goût Dans Les Goûts Alimentaires ?', Sociologie du travail 40, no. 4 (1998): 503-22. 


\section{Introduction}

there was something determined and resolved in sensing matters, this happened to people as a result of their circumstances their work suggested, or which people tried to change through a process of acquisition.

More recent scholarship on sensing has argued that sensing is not innate, nor a product only of class, but rather cultivated as an embodied experience, a line of reasoning I also adopt in this book. This means viewing the sensory learner as someone in formation through bodily, social and material practices, rather than as someone who is predetermined by biology or aspects of their environment. The body is enacted through sensing, and sensing is enacted through the body. ${ }^{37}$ The body emerges as a result, it is not a given reality, not as Teil and Hennion write, 'an autonomous and pre-existing physical body just needing a musical or gourmet training., ${ }^{38}$

My work relates to such concerns through theories of embodiment, a concept which refers to porous, visceral, felt, enlivened bodily experiences, in and with inhabited worlds. ${ }^{39}$ While anthropology has long had bodily concerns at its heart, issues of embodiment really became a central concept and object of study only in the mid-1980s, in the midst of a more general philosophical trend in the humanities and social sciences. A move was made here from studies of the body as object to taking the perspective of a bodily being-in-the-world as the starting point. While the history of this philosophical approach is highly complex and difficult to summarise, much of the embodiment literature in anthropology can be traced back to the work of French thinker Maurice Merleau-Ponty, ${ }^{40}$ someone I have been greatly influenced by too.

Merleau-Ponty was radical in his ideas at the time that human perception was not cognitive but rather embodied. He considered that the body opened one out upon the world and placed one in a situation there, a process that was in continual formation. Of the many who have engaged with MerleauPonty's work, several texts are notable for the ways in which they have theoretically advanced his ideas. Anthropologist Tim Ingold, ${ }^{41}$ for example, draws on ecological psychology to develop the notion of being-in-the-world that emphasises the body as a human organism in an environment. His work extends the theory of embodiment to look at enskillment, as a process of becoming skilled by living in and with the world. Rather than being passed

37 Annemarie Mol, The Body Multiple: Ontology in Medical Practice (Durham, NC: Duke University Press, 2002); Geneviève Teil and Antoine Hennion, 'Discovering Quality or Performing Taste? A Sociology of the Amateur', in Qualities of Food, ed. Mark Harvey, Andrew McMeekin, and Alan Warde (Manchaster: Manchester University Press, 2004), 19-37.

38 Teil and Hennion, 'Discovering Quality', 32.

39 Anna Harris, 'Embodiment'. In Oxford Bibliographies in Anthropology, ed. John Jackson (Oxford: Oxford University Press, 2016).

40 Maurice Merleau-Ponty, The Visible and the Invisible (Evanston, IL: Northwestern University Press, 1968).

41 Tim Ingold. The Perception of the Environment: Essays on Livelihood, Dwelling and Skill (London: Routledge, 2000). 
on through processes of transmission and acquisition, Ingold argues that skills are developed through practice, through the practitioner's active engagement with their surroundings. He differentiates his work from Michael Polanyi's notion of tacit knowledge, which is commonly used in discussions of skilled learning. Ingold suggests that Polanyi's ${ }^{42}$ dictum underlying the theory of tacit knowledge, 'we can know more than we can tell' adopts a narrow definition of telling, limited to words. If personal knowledge can be shared through gesture and other bodily means, Ingold posits it may not be so 'tacit' after all. Telling is possible, but articulating is hard.

For some time, literature on enskillment has drawn predominantly from examples of manual skills, such as learning how to ride a bicycle ${ }^{43}$ or to play the cello ${ }^{44}$. Much of this literature highlighted the implicit nature of skilled development, often citing Polanyi's ${ }^{45}$ work on tacit knowledge and sociologist Pierre Bourdieu's ${ }^{46}$ work on habitus. In the last decade, scholarly interest in other sensory skills besides a predominant focus on manual skills has resulted in studies of sonic skills, ${ }^{47}$ trained ears, ${ }^{48}$ skilled vision, ${ }^{49}$ skilled smelling, ${ }^{50}$ skilled tasting ${ }^{51}$ and sensory knowledge acquisition. ${ }^{52}$ Ethnographic studies have looked at sensory practices such as capoeira, ${ }^{53}$

42 Michael Polanyi, The Tacit Dimension (New York: Doubleday and Company, 1966).

43 Harry M. Collins, Tacit and Explicit Knowledge (Chicago: University of Chicago Press, 2010).

44 Ingold, Perception of the Environment; Richard Sennett, The Craftsman (London: Penguin Books, 2008).

45 Polanyi, Tacit Dimension.

46 Pierre Bourdieu, Outline of a Theory of Practice (Cambridge: Cambridge University Press, 1977).

47 Karin Bijsterveld, Sonic Skills: Listening for Knowledge in Science, Medicine and Engineering (1920s-present) (London: Palgrave Macmillan, 2019); Krebs, Stefan, “"Dial Gauge versus Senses 1-0": German Car Mechanics and the Introduction of New Diagnostic Equipment, 1950-1980', Technology and Culture 55, no. 2 (2014): 354-89; Krebs, Stefan and Melissa Van Drie, 'The Art of Stethoscope Use: Diagnostic Listening Practices of Medical Physicians and "Auto-Doctors"', Icon: Journal of the International Committee for the History of Technology 20, no. 2 (2014): 92-114; Bruyninckx, Joeri, Listening in the Field: Recording and the Science of Birdsong (Cambridge, MA: MIT Press, 2018); Van Drie, Melissa, 'Training the Auscultative Ear: Medical Textbooks and Teaching Tapes (1950-2010)', The Senses \& Society 8, no. 2 (2013): 165-91.

48 Alexandra Supper, 'Data karaoke: Sensory and Bodily Skills in Conference Presentations', Science as Culture 24, no. 4 (2015): 436-57.

49 Cristina Grasseni, ed., Skilled Visions: Between Apprentice ship and Standards (New York: Berghahn Books, 2009); Rebecca Ellis, 'Jizz and the Joy of Pattern Recognition: Virtuosity, Discipline and the Agency of Insight in UK Naturalists' Arts of Seeing', Social Studies of Science 41, no. 6 (2011): 769-90.

50 Latour, 'How to Talk about the Body?'.

51 Steven Shapin, 'The Sciences of Subjectivity', Social Studies of Science 42, no. 2 (2012): 170-84.

52 Honorata Jakubowska, 'The Sociological Analysis of Sensory Knowledge: Its Understanding, Construction and Acquisition', Society Register 3, no. 1 (2019): 121-36.

53 Greg Downey, Learning Capoeira: Lessons in Cunning from an Afro-Brazilian Art (Oxford: Oxford University Press, 2005). 


\section{Introduction}

Nihon Buyo dance, ${ }^{54}$ auscultation, ${ }^{55}$ cooking, ${ }^{56}$ scuba diving, ${ }^{57}$ cattle breeding, ${ }^{58}$ tea tasting ${ }^{59}$ and surgery, ${ }^{60}$ just to name a few. Scholars have also looked specifically at critical new pedagogical forms, calling for sensational pedagogies ${ }^{61}$ while the impressive collection of articles in a recent issue of the journal Senses \& Society examines embodied enculturation across time and place, through the lens of the history of education. ${ }^{62}$

Many of these scholars consider sensory learning practices not only from the lens of embodiment, but also the political and economic consequences of sensing practices and sensory training. Ella Butler ${ }^{63}$ looks at the food industry, for example, and Kunbing Xiao ${ }^{64}$ at the ways in which government policies impact tasting practices in Fujian mountain areas. This literature highlights the sensory politics of education; how governments, countries, non-profits all get involved in how local communities and individuals partake in sensory lessons.

There will be readers of this book who will see a large gap in my own analysis of the political and economic conditions shaping learning in many of the examples I give. The coffee cupping example in Chapter 1 is a striking instance of how colonial powers have shaped what coffee tastes like and how it is described. Medical schools are deeply tied into global markets and historical traditions that shape sensory knowing. And I only touch upon the capitalist tendencies of sensory marketing in Chapter 5. Highly cognizant of these gaps, I am working with a political economic historian to consider

54 Tomie Hahn, Sensational Knowledge: Embodying Culture through Japanese Dance (Middletown, CT: Wesleyan University Press, 2007).

55 Tom Rice, Hearing and the Hospital: Sound, Listening, Knowledge and Experience (Canon Pyon: Sean Kingston Publishing, 2013).

56 David Sutton, Secrets from the Greek Kitchen: Cooking, Skill, and Everyday Life on an Aegean Island (Oakland: University of California Press, 2014).

57 Stephanie Merchant, 'The Body and the Senses: Visual Methods, Videography and the Submarine Sensorium', Body \& Society 17, no. 1 (2011): 53-72.

58 Grasseni, 'Good Looking'.

59 Kunbing Xiao, 'The Taste of Tea: Material, Embodied Knowledge and Environmental History in Northern Fujian, China', Journal of Material Culture 22, no. 1 (2017): 3-18.

60 Prentice, Bodies in Formation.

61 Elizabeth Ellsworth, Places of Learning: Media, Architecture, Pedagogy (New York: Routledge, 2005), 27.

62 Joakim Landahl, 'Learning to Listen and Look: The Shift from the Monitorial System of Education to Teacher-led Lessons', The Senses \& Society 14, no. 2 (2019): 194-206; Geert Thyssen, 'Odorous Childhoods and Scented Worlds of Learning: A Sensory History of Health and Outdoor Education Initiatives in Western Europe (1900s-1960s)', Senses \& Society 14, no. 2 (2019): 173-93; Geert Thyssen and Ian Grosvenor, 'Learning to make Sense: Interdisciplinary Perspectives on Sensory Education and Embodied Enculturation', The Senses \& Society 14, no. 2 (2019): 119-30; Von Hoffmann, Viktoria, 'Learning (to) Taste: Food, Aesthetics, and Education in early Modern France', The Senses \& Society 14, no. 2 (2019): 131-47.

63 Ella Butler, 'Tasting Off-Flavors: Food Science, Sensory Knowledge and the Consumer Sensorium', The Senses and Society 13, no. 1 (2018): 75-88.

64 Xiao, 'The Taste of Tea'. 
how these threads shape sensory knowing, yet this work is still to come. What this book presents is a careful consideration of my work on sensory learning based on theoretical and ethnographic thinking over the last decade predominantly through concepts such as embodiment and enskillment.

Anthropological engagements with embodiment and enskillment have several characteristics, which distinguish them from other fields of study, such as the work of the psychologists and neurologists on sense perception. First, theoretical understandings of embodiment are stitched together from assembling and critically examining a key set of philosophies (predominantly phenomenology and practice theory), but also doing so in correspondence with insights from ethnographic fieldwork. This theoretical approach has developed largely in opposition to Western dualisms and static bodily categories, emphasising process and contingency. Anthropology is also characterised by embodied fieldwork, where the researcher's body is recognised as being deeply entangled in the process of study. If it is possible to generalise how I draw from the rich set of work mentioned above, it would be the insight that learning sensory skills has a profound effect not only on novices' sensing in that specific practice but also on their perceptive engagement with bodies (their own and others) as well as the world at large.

Returning to the practice of percussion, the work of phenomenologist Merleau-Ponty and other theories of embodiment and enskillment are important for highlighting the non-cognitive ways in which such skills are learned, not as a process of acquisition and transmission, as is often presented in the medical education literature, for example, but rather as an embodied process. ${ }^{65}$

When I studied the learning of percussion in medical schools, I did so through embodied fieldwork where I was constantly practicing on my own body and engaging with the movements of those around me. I had already studied percussion as a medical student. This is not a practice I had seen my parents perform (neither were doctors, though I had seen my father tap walls to look for studs). This was not a practice shaped in my mother's womb, or in my biology or genetics. Rather I learned it through repeated practice, by watching others perform percussion (teachers, other students), by improvising with my own technique, over and over again. This education was social and material, I learned percussion with others, in schools, from videos and textbooks and illustrations and sound recordings. Learning the skill of percussion was about my individual body and an ecological arrangement that included materials, places and talk. These practices of embodied cultivation were made most visible when there was some kind of communication about the sensory lessons, in the books or in the lessons, for example, and these were the moments which were easiest to study too as an ethnographer.

65 Kelly, Martina, Rachel Ellaway, Albert Scherpbier, Nigel King and Tim Dornan, 'Body Pedagogics: Embodied Learning for the Health Professions', Medical Education 53, no. 10 (2019): 967-77. 
So, in summary, this surveyed literature and this book argue that sensing is not a passive, innate activity, but one that is a learned, active practice and one that is formed in the act of education. Sensing is a process, shaped by a mutual interplay between individuals and others, materials, words and the worlds inhabited.

\section{Myth \#3: Sensory education is only for children}

Now that I have a toddler I see sensory training toys everywhere - paint kits in the craft store that attend to the five senses, set-ups for babies to lie on their backs and hear/see/feel the hours away, books which they can eat and squeak. Children museums that are interactive often promote sensory experiences and there are schools in the Montessori tradition that pride themselves on particular forms of sensory education using sensory materials. Even if a school does not adopt the Montessori tradition, they may have particular food training exercises (see Hojlund's ${ }^{66}$ work on the food training of Danish middleschoolers, or Terrio's ${ }^{67}$ work on the sensory alertness training in French elementary schools in the 1990s).

While some scholars lament that teaching particular aspects of sensory experience, such as smell ${ }^{68}$ or touch ${ }^{69}$ do not take place in many schools ${ }^{70}$ on the whole, nowadays children are often the target of sensory education. There is certainly a lot to say about the role of childhood in our sensory engagements with the world. In childhood we learn many new sensory words (see Chapter 1). Objects like toys become part of how we see the world (see Grasseni's ${ }^{71}$ work on how farmers' children employ plastic cow toys in their games and how these toys train a particular kind of 'professional vision ${ }^{\text {,72 }}$ in cow breeding). There is excellent recent scholarship, for example by historians of education such as Geert Thyssen and Landahl, on historical and contemporary sensory education programs and by others on sensory education for children in areas of social deprivation. I want to argue in this

66 Susanne Højlund, “'Listen! We Made these Potatoes Crispy!” Danish Adolescents Sharing Taste in a School Class', in Making Taste Public: Ethnographies of Food and the Senses, eds. Carole Counihan and Susanne Højlund (London: Bloomsbury Academic, 2018), 99-112.

67 Susan Terrio, Crafting the Culture and History of French Chocolate (Berkeley: University of California Press, 2000).

68 Teil, 'Devenir Expert Aromaticien'; Ilja Croijmans and Asifa Majid, 'Not All Flavor Expertise Is Equal: The Language of Wine and Coffee Experts', PLOS ONE 11, no. 6 (2016): e0155845.

69 Grunwald, Homo Hapticus.

70 Constance Classen, 'Other Ways to Wisdom: Learning through the Senses across Cultures', International Review of Education / Internationale Zeitschrift Für Erziehungswissenschaft/Revue Internationale De L'education 45, no. 3-4 (1999): 269-80.

71 Cristina Grasseni, 'Good Looking: Learning to be a Cattle Breader', in Skilled Visions: Between Apprenticeship and Standards, ed. Cristina Grasseni (New York: Berghahn Books, 2009).

72 Charles Goodwin, 'Professional Vision', American Anthropologist 96, no. 3 (1994): 606-33. 
brief section however, that it is necessary need to look beyond children and schools to expand an understanding of sensory education. As Jean Lave $^{73}$ writes, too often we equate education with schools, yet education is part of everyday life and occurs throughout it. For example, percussion is just one of many sensory skills which are part of university education, a formalised setting for learning. Learning to find a stud on a wall however is also a form of percussion, something you can learn about as you try to decipher the details of the walls of your home by being attentive to its materials.

In short, this book will show that sensory education is something that happens throughout adult life, in both expert and everyday settings, and that looking at the materiality of these practices reveals something insightful about the ways in which this is socially organised.

\section{Myth \#4: The only way you learn sensory knowledge is in person}

Many anthropologists interested in craft, tacit knowledge and sensory skills insist that there is one main way to learn skills: in constant practice, under the guidance of an expert or master. Classic works of tacit knowledge, such as Polanyi's The Tacit Dimension, reiterate this message over and over again:

Connoisseurship, like skill, can be communicated only by example, not by precept. To become an expert wine-taster, to acquire a knowledge of innumerable different blends of tea, or to be trained as a medical diagnostician, you must go through a long course of experience under the guidance of a master. ${ }^{74}$

Scholars of tacit knowledge and enskillment argue that it is difficult to codify or document skills: that they resist explication or formulae in a book, for example. ${ }^{75}$ Ingold, although not using terms like tacit knowledge (and in fact arguing adamantly against it $)^{76}$ also considers skills to be largely passed on through practice.

While I agree with many aspects of Ingold's theorisation of enskillment, as Melissa van Drie and I have argued in our work on sonic skills learning in medicine, ${ }^{77}$ this neglects the role of other matter in sensory educa-

73 Lave, Learning and Everyday Life.

74 Polanyi, Tacit Dimension.

75 Sara Delamont and Paul Atkinson, 'Doctoring Uncertainty: Mastering Craft Knowledge', Social Studies of Science 31, no. 1 (2001): 87-107.

76 Tim Ingold, Making: Anthropology, Archaeology, Art and Architecture (London: Routledge, 2013).

77 Anna Harris and Melissa van Drie, 'Sharing Sound: Teaching, Learning and Researching Sonic Skills', Sound Studies 1, no. 1 (2015): 98-117. 
tion. While learning in practice is an important aspect of skills learning, I disagree with these scholars' dismissal of words, photographs and other documented presentations as ways to teach and learn. I suggest that these resources have an important role not only in shaping what sensing is, but also demonstrating sensory skills and creating additional opportunities for the student to practice new techniques.

David Howes ${ }^{78}$ is also more lenient than those who consider that practice resists codification in representations, observing that many learn skills from how-to-guides. Sociologist Richard Sennett ${ }^{79}$ also proposes that one can learn from such remote direction, but that these instructions need to be 'expressive', linking technical craft to imagination.

Historians of science have recently become more interested in manuals and recipe books and how we might understand something more about how sensory knowledge is learned by looking at these sources. ${ }^{80}$ In the footsteps of these scholars, as well as STS scholars and media theorists, in this book I argue that sensory education is a process by which sensing is cultivated in a sociomaterial world that includes books and recipes and videos and other instructional media. Looking at contemporary examples, I argue that we learn with and through things that are not only rocks and leaves and footpaths (as Ingold uses as cases, for example), but also online videos, and knitting instructions and commercially produced smell kits, as well as from experts and non-experts alike.

Take percussion again as an example. This is a skill that is taught by example from teachers as well as through descriptions in textbooks, through illustrations and writing, through online videos and through sound files. This means that in the end the practice of percussion is inseparable from the field of technological relations which constitute it. In fact, these sources have been integral to the way this technique has travelled around the world. Auenbrugger was the first to document percussion. The adoption of the technique in medicine however was slow and uncertain before 1820, due in part to Auenbrugger's short, incomplete treatise, in Latin, which did not provide a clear explanation. It was only when Corvisart, a strong advocate of the clinical exam, translated Auenbrugger's work into French, that percussion was introduced, into an era of medicine where physical examination of the body had replaced hearing patients' stories. ${ }^{81}$

78 David Howes, 'Reply to Tim Ingold', Social Anthropology 19, no. 3 (2011): 318-22.

79 Sennett, Craftsman, 186.

80 Dupré, Sven, 'How-to Optic', in Perspective as Practice: Renaissance Cultures of Optics, ed. Sven Dupré (Turnhout: Brepols, 2019), 279-300; Hagendijk, Thijs, 'Unpacking Recipes and Communicating Experience: The Ervarenissen of Simon Eikelenberg (1663-1738) and the Art of Painting', Early Science and Medicine 24, no. 3 (2019): 248-82.

81 Alex Volmar, 'Sonic Facts for Sound Arguments: Medicine, Experimental Physiology, and the Auditory Construction of Knowledge in the 19th Century', Journal of Sonic Studies 4, no. 1 (2013). 
In summary, while this book does not ignore the learning that happens with experts and non-experts, with the environment and the world around us (see Chapters 4 and 6 on this in particular) - kindergarten teachers teach words for colours, grandmothers teach us to knit, fathers to cook and so forth - each chapter and lesson also shines light on the other material dimensions of sensory education which might be neglected in a study of sensory learning that focuses solely on guided rediscovery.

\section{Myth \#5: The digital kills the senses}

The example of percussion that I have used throughout this section of the book, has become somewhat emblematic of the kinds of sensory skills considered lost, in an era of technomedicine, ${ }^{82}$ as a result of the increasing use of digital technologies. Lament over the deskilling of doctors has a longer history, with the introduction of new machines often wrapped up in 'sensory politics ${ }^{83}$ Technologies are viewed as replacing the senses in contemporary medicine, with blood pressure machines, ultrasounds, echocardiograms, $\mathrm{X}$-rays and other investigations argued to replace practices involving touch, listening and more embodied approaches to care. ${ }^{84}$ As the historian Shigehisa Kuriyama wrote from a historical perspective, ${ }^{85}$ pulse taking has barely survived in Western medicine, and has become, what he describes, as a 'shrivelled, meagre science - mostly the bare counting of beats'. He sees the practice being replaced by machines, graphs, numbers, while 'classical tomes on the training of the touch gather dust ${ }^{96}$ Medical schools and other institutions are places where some of these sensory politics play out, as professions consider what kind of sensory skills their novices should learn.

This is not only an issue in medicine. Technologies are seen to be replacing sensory skills the world over, in an age of distraction and speed. For some, such as the philosopher Michel Serres, ${ }^{87}$ these are skills lost long ago, when we stopped hunting and gathering for our food:

Who now goes hunting first thing in the morning on an empty stomach, nostrils twitching at the slightest change in the wind? Who sits astern

82 Abraham Verghese, 'Treat the Patient, Not the Ct Scan', The New York Times, 26 February 2011.

83 Rice, Hearing and the Hospital.

84 Stanley Reiser, 'Technology and the Use of the Senses in Twentieth-Century Medicine', in Medicine and the Five Senses, eds. W.F. Bynum and Roy Porter (Cambridge: Cambridge University Press, 1993), 262-73; David Howes, 'The Senses in Medicine', Culture, Medicine and Psychiatry 19, no. 1 (1995).; Verghese, 'Treat the Patient'.

85 Shigehisa Kuriyama. The Expressiveness of the Body and the Divergence of Greek and Chinese Medicine (Cambridge, MA: The MIT Press, 1999).

86 Kuriyama, Expressiveness of the Body, 65.

87 Michel Serres, The Five Senses: A Philosophy of Mingled Bodies (London: Continuum, 2008). 
and listens to the sound of backwash, having been alerted by the first smell of leaves cutting through the thick wall of algae and salt? Who keeps their sense of distant sight and hearing so keen? Who today does not need to be notified by posters or messages of when to hear, feel, watch or taste? Frigid organs, empiricism in ruins, lost impressions, phantoms. ${ }^{88}$

I believe these critiques are too simplistic, that digital devices and other technologies are becoming, and have always been, part of our perceptive space and awareness, that we need to attend to this rather than shut ourselves up in sensory caves.

The work of post-phenomenology is helpful here. Drawing from the concerns of phenomenology as an alteration in a sense of being in the world, and what is significant and possible, scholars such as philosopher Don Ihde ${ }^{89}$ have argued for a reworking of phenomenology that attends much more closely to technologies and new articulations of bodies and objects. For Idhe, postphenomenology attempts to escape the subject-orientated nature of phenomenology. Instead, a greater emphasis is placed on objects and materiality. Merleau-Ponty began this project when he attended to the ways in which tools become incorporated into the body, his later work exploring the pre-experiential space that is formed at the meeting of body and world.

Postphenomenology can also be considered as an intersection of phenomenology and actor-network-theory, read through the work for example of Bruno Latour. ${ }^{90}$ Latour takes a look at how bodies come about through technologically mediated training of sensibilities. Grasseni, for example, builds on the work of Latour in her analysis of the mediating role of technological devices in the development of farmers' skilled vision. According to Grasseni, the farmers' acquisition of a skilled vision is both a matter of embodiment and of materials. ${ }^{91}$

What remains common across the work of these philosophers and social scientists is that they no longer assume that a body exists prior to experience, as the phenomenologists do, but rather that the body - the subject - comes about through experiences. Their aim is not to abandon phenomenology; rather, they seek to refigure and expand the boundaries. Anthropologists and scholars of STS are also contributing work on this subject which suggests that not only is sensing a 'social experience' but also that sensing is done through various socio-material practices which are technological and digital in nature. ${ }^{92}$ By looking at how food scientists learn to taste off-flavours

88 Serres, Five Senses, 198.

89 Don Ihde, Bodies in Technology (Minneapolis: University of Minnesota Press, 2002).

90 Latour, 'How to Talk About the Body?'.

91 Grasseni, 'Good Looking', 55.

92 Sarah Maslen, 'Layers of Sense: The Sensory Work of Diagnostic Sense making in Digital Health', Digital Health 3, (2017): 1-9. 
for example, Butler shows that sensing is in part a "precariously stabilized technoscientific achievement ${ }^{93}$

Hence, in summary, what this book shows is that digital technologies are so thoroughly enmeshed in our sensory practices that it is impossible to disentangle them - the digital shapes, is shaped by, sensing, but is not killing or killed by it. Sensing and sensate bodies come about through these engagements, rather than exist ahead of time.

\section{Fieldwork this book draws on}

Most of the scholars I have mentioned in the last section build upon an important body of work concerning the anthropology of the senses more broadly ${ }^{94}$ much of this work being collected in books such as David Howes and Constance Classen's ${ }^{95}$ Ways of Sensing: Understanding the Senses in Society and their other more recent texts. ${ }^{96}$ Anthropologists have always engaged their senses during fieldwork, although it is only recently that this has become a more explicitly articulated methodological practice, through forms of sensory ethnography. Sensory ethnographers advocate for an acknowledgment of the sensorality that remains fundamental to learning about others' lives. ${ }^{97}$ Sensory ethnography is a technique which has been advanced conceptually by scholars such as Sarah Pink ${ }^{98}$ and Mark Paterson, ${ }^{99}$ with Denielle Elliott and Dara Culhane ${ }^{100}$ in particular offering excellent methodological guidance. This section explores my own sensory ethnographic approaches in conducting fieldwork for this book.

First, a little background that informs my approach. In the mid-1990s I started medical school in Tasmania, Australia. Six years later I finished

93 Butler, 'Tasting Off-Flavors', 78.

94 Constance Classen, 'Museum Manners: The Sensory Life of the Early Museum', Journal of Social History 40, no. 4 (2007): 895-914; Constance Classen, 'Foundations for an Anthropology of the Senses', International Social Science Journal 49, no. 153 (1997): 401-12; Constance Classen, Worlds of Sense: Exploring the Senses in History and Across Cultures (New York: Routledge, 1993); Constance Classen, David Howes, and Anthony Synnott, Aroma: The Cultural History of Smell (London: Routledge, 1994); David Howes, 'Can these Dry Bones Live? An Anthropological Approach to the History of the Senses', The Journal of American History 95, no. 2 (2008): 442-51; David Howes, Empire of the Senses: A Culture Reader (Oxford: Berg, 2005); David Howes, The Sixth Sense Reader (Oxford: Berg, 2009); Howes, Sensual Relations; Howes and Classen, Ways of Sensing.

95 Howes and Classen, Ways of Sensing.

96 David Howes, 'Multisensory Anthropology', Annual Review of Anthropology 48, no. 1 (2019): 17-28.

97 Paul Stoller, Sensuous Scholarship (Philadelphia: University of Philadelphia Press, 1997).

98 Sarah Pink, Doing Sensory Ethnography (London: SAGE Publications, 2009).

99 Mark Paterson, 'Haptic Geographies: Ethnography, Haptic Knowledges and Sensuous Dispositions', Progress in Human Geography 33, no. 6 (2009): 766-88.

100 Denielle Elliott and Dara Culhane, eds., A Different Kind of Ethnography: Imaginative Practices and Creative Methodologies (Toronto: University of Toronto Press, 2016). 
my medical degree and started work in a hospital as a doctor. I can find material traces of what happened in those six years - anatomical drawings I made which hung on the ceiling above my bed for memorisation, piles of notebooks of drawings, diagrams and lecture notes, stacks of textbooks (recently donated to the local op-shop). I have photos of my friends, some in which we are dressed in white lab coats, presumably before a dissection class. I remember lessons at the blackboard with exquisite illustrations that facilitated an inhabitation of the body that the textbooks did not allow, ${ }^{101}$ learning techniques like percussion on my own body and classmates, ${ }^{102}$ visiting patients on the wards, so many stories sticking like plaster to my memories of what it meant to be ill and in a hospital; experiences that became more vivid when I became the patient, or the mother of one. But while I have snapshots of my time in medical school, it was not until I returned as an anthropologist that I could look at all of this learning, and particularly the teaching, in analytical ways, in ways which unpacked the educational process and which considered carefully the social and material relations involved in sensory lessons.

This book draws thus on my own experiences of sensory learning in medical school, as well as those as an anthropologist looking at medical school with fresh eyes. Thanks to funding from the European Research Council, I have also had the opportunity to collaborate with a research team of ethnographers conducting fieldwork in medical schools in Hungary and Ghana in a project called Making Clinical Sense. The book is deeply informed by this comparative collaborative fieldwork, although the fieldwork for these studies was only just completed at the time of writing.

Since 2013 I have been spending large chunks of time in medical schools in Australia and the Netherlands, and before that I conducted ethnographic fieldwork in hospitals with migrant doctors, looking at how doctors adjusted their practices in locations which I called 'unfamiliar strange', for they were migrant doctors working in Australia. ${ }^{103}$ In the medical schools in Melbourne and Maastricht I spent the majority of my time with medical students and medical teachers, although I also spent time with secretaries and technicians too.

During my more recent fieldwork I attended classes in the university and in the hospital, where I learned about physical examination education and saw how this happened on the wards, with patients. In Maastricht, I spent most of my time in a place called the 'Skills Lab', a teaching department in the medical faculty specifically designed for teaching medical students clinical skills, including those of physical examination. I observed lessons taught in Dutch and English, sometimes seeing the same lesson multiple

101 Anna Harris, 'The Blackboard Anatomist', BMJ: British Medical Journal 350 (2015): h345.

102 Harris, 'Listening-touch'.

103 Anna Harris, 'In a Moment of Mismatch: Overseas Doctors' Adjustments in New Hospital Environments', Sociology of Health and Illness 33, no. 2 (2011): 308-20. 
times. The Skills Lab changed location between two periods of fieldwork, and so I was able to see ways in which educational practices shifted across the settings. Each of the Skills Lab rooms, regardless of the new or old location, was 'set-up' in a standard way according to a lesson plan. In the older Skills Lab, a series of photographs on the walls indicated how tables should be arranged, how the 'beds' should be positioned and other equipment laid out. Each room also had a cupboard with a standard stock of tools that students used during the lesson. There were also whiteboards and projectors for PowerPoint (in the older Skills Lab) or smartboards (in the newer Skills Lab), and cloth curtains that students could use for privacy.

This medical school fieldwork is my starting point for most of the chapters to come, that is, a study of what it means to learn how to make clinical sense. However, as I stated earlier, I do not want to suggest that sensory education only happens in institutions and schools. So, to juxtapose material alongside the medical examples I also include my own fieldwork, and others', concerning very everyday and mundane practices: eating and cooking. It could be said I have been doing fieldwork on this topic whenever I have sat down at a meal, observed a friend make a dish, turned the pages of a cookbook or dined out. When I look at eating, I draw on both my everyday encounters with food and cooking and cookbooks, as well as concentrated periods of fieldwork in cooking classes and conducting ethnographic experiments with recipes.

While I re-enacted many of the lessons I observed in the medical schools, I did little participation in the medical school classes, mostly observing. When doing fieldwork on food I did a lot of participating alongside observing. Many social scientists of the body have drawn upon their own practical engagements to forward important theoretical insights about embodiment: Tim Ingold, ${ }^{104}$ Richard Sennett, ${ }^{105}$ Michael Polanyi, ${ }^{106}$ and Pierre Bourdieu ${ }^{107}$ all drew upon their own experiences of playing a musical instrument for example, to think about the minutiae of bodily practices. Many of the authors of studies I use in this book engage in the practices as novices to explore their own learning alongside others. ${ }^{108}$ As Ingold writes: 'Fieldwork is in truth a protracted masterclass in which the novice gradually learns to see things, and to hear and feel them too, in the ways his or her mentors do. 109

While I wasn't always able to be involved as a novice in my medical fieldwork, I nonetheless engaged in what I consider sensory ethnographies in

104 Ingold, Making.

105 Sennett, Craftsman.

106 Polanyi, Tacit Dimension.

107 Bourdieu, Outline of a Theory of Practice.

108 Downey, Learning Capoeira; Hahn, Sensational Knowledge; Rice, Hearing and the Hospital.

109 Ingold, Making, 2. 
specific ways. I conducted interviews with sensory awareness, ${ }^{110}$ I recorded sounds, videos and took photographs, as well as made drawings. I also conducted what I would term ethnographic experiments. These experiments involved setting up a proof-of-concept study for example, with the two other anthropologists in the Making Clinical Sense project, to explore how different methods such as video, photography and drawing may be used to trace learning a recipe. ${ }^{111}$ During our simultaneous fieldwork we also conducted experiments in which we did exercises each week, exercises, for example, that might have us recording smells of our sites, or drawing maps (read more about this in Lesson 6). ${ }^{12}$

\section{What this book does not address}

There are many topics that this book does just not have space to explore. It does not, for example, look at the fascinating, bizarre and growing world of animal sensing, and how animals are trained and teach humans about sensing. That said, animals are certainly challenging the way we think about sensory experience. Historians are now trying to re-enact life as badgers, philosophers are getting into the minds of squids and biologists are looking at how training pigeons to read mammograms might tell us something about training radiologists and designing medical equipment. All fascinating work.

This book also does not attempt to cover the vast field of sensory education aimed at those who identify with, or who have been identified with, sensory impairment. This includes practices such as echolocation which have been developed to teach those who have varying degrees of blindness how to position themselves in the world through self-produced sound, or odour training for those with anosmia. ${ }^{113} \mathrm{I}$ do not look at sensory training for children who are considered on the spectrum for autism, or who may have what is labelled as a 'sensory disorder', both involving highly attuned sensory awareness that parents, teachers, instructors, therapists and industry have found various solutions and trainings to mediate. It does not include the sensory training someone undergoes when they lose a limb, or when they receive a donated organ. Nor does it look at issues of regeneration, such as stem cell and gene therapy research looking at biological ways of retraining the senses.

110 Anna Harris and Marilys Guillemin. 'Developing Sensory Awareness in Qualitative Interviewing: A Portal into the Otherwise Unexplored'. Qualitative Health Research 22, no. 5 (2012): 689-99.

111 Anna Harris, Andrea Wojcik, and Rachel Vaden Allison, 'How to make an Omelette: A Sensory Experiment in Team Ethnography', Qualitative Research (20, no. 5: 632-648.).

112 Andrea Wojcik, Rachel Vaden Allison, and Anna Harris. 'Bumbling along Together: Producing Collaborative Fieldnotes', in Fieldnotes in Qualitative Education and Social Science Research: Approaches, Practices, and Ethical Considerations, eds. Casey Burkholder and Jennifer Thompson (New York: Routledge, 2020), 201-216.

113 Asifa Majid et al., 'What Makes a Better Smeller?', Perception 46, no. 3-4 (2017): 406-30. 
The book does not cover sensory training for older age. As we age, for example, we lose elements of our eyesight through macular degeneration and other normal visual defects. Grunwald ${ }^{114}$ writes that we lose our haptic sensitivities, while others see loss in smell, sound, movement and so forth. There are many kinds of training which attempt to address this so-called decline, whether a generalised sensory awareness training, ${ }^{115}$ or training that is more domain specific. ${ }^{116}$ Sensory training and practice is argued to counteract age-related decline in sensory skills. Not only is this body of work on age-related biological degeneration out of my scope, but I also believe that much of what I argue in this book counteracts this notion of decline in the first place. If sensory education is an awareness of the world through socio-material encounters with things and people and in events, then aging would only be seen to be grounds for some kind of improvement in sensory awareness. ${ }^{117}$

Finally, this book does not look at the growing interest in the senses of those exploring health promotion in schools and other communities. Many scholars are addressing the sensory nature of healthy eating and obesity, for, as Tracy writes: 'The politically charged issues of satiety and portion management, with their implication in diabetes, cardiovascular disease, and obesity, are also sensuous questions'. ${ }^{118}$ Many of the insights from this book, which concerns the role of materials and bodies in questions of sensory education appeal to and potentially address the concerns of those interested in health promotion, although as scholars such as anthropologist Emily Yates-Doerr ${ }^{119}$ remind us, these are topics where we also need to question what is being referred to by the term 'healthy' and the kinds of practices that are being reframed and educated deserve serious reflection and intervention.

\section{Summary of chapters}

What this book does look at though, can be summarised as follows.

The first chapter explores a fundamental and incredibly difficult aspect of sensory training: the learning of new vocabularies and how to find words for the sensate. For centuries, humans have struggled to find ways to articulate sensory experience. This chapter explores this issue first through the example of coffee cupping. Amidst flavour charts and beans, I learn new words for 'coffee'. The difficulties of articulation of smell are further examined through the cases of perfumers and amateur/expert wine tasters, who attach

114 Grunwald, Homo Hapticus.

115 Grunwald, Homo Hapticus.

116 Croijmans and Majid, 'Flavor Expertise'.

117 Majid et al., 'What Makes a Better Smeller?'.

118 Tracy, 'Delicious Molecules', 98.

119 Emily Yates-Doerr, The Weight of Obesity: Hunger and Global Health in Postwar Guatemala (Oakland: University of California Press, 2015). 
words to smells and tastes, with the help of odour kits for example. The final case takes the reader into medical schools where novice doctors are undergoing the same linguistic sensory training, learning to describe lung sounds, breath smells, microbiology slides and other pathologies. Through these cases, the chapter explores the ways in which the subjective experience of sensing is 'put into words', and the various strategies involved in the attempt to share experience.

While there are numerous everyday moments of sensory training that are explored throughout the book, the second chapter deals specifically with the training of sensory experts. There are many different kinds of professional sensory expertise, from the more obvious perfumer (or 'nose') and wine critic; to other professions such as doctors who rely on sensory information to make diagnoses. In order to learn more about their sensory education, I head into medical schools. Also reflecting further on my own medical student experiences, I look at the way in which medical education of the senses requires explicit 'setups'; arrangements which facilitate the sensory lesson. I look at the invisible labour of these set-ups - the care and maintenance of materials and settings. These involve, I argue, tools of calibration; however, I conclude by suggesting that teaching sensory skills requires skills also in improvising beyond the set-up.

The third chapter delves into the media that guides a sensory education. The focus in on instructions, different forms of which offer different ways of re-orientating sensory knowledge learning. I take some very concrete examples to work with, focusing again on food and medicine primarily. First, I look at the exploding world of cookbooks, where celebrity chefs and food writers must instruct the at-home cook in how to smell their food, touch their food, taste their food and occasionally, even listen to their food in the form of recipes. I then look at the steps that medical teachers are instructed to take when teaching sensory skills, which I argue offers insights into the expressivity of instruction. Finally, I explore the role of television and video in sensory training of both doctors and amateur chefs, particularly how multi-sensoriality is used to expand novices' imaginative space and re-orientate the senses.

In Chapter 4 I use workshopping as a way to deepen some of the explorations of this book so far, in particular what it means to attend and notice as part of sensory education. This chapter focuses on a particular aspect of the social nature of this experience, looking at learning in small groups and gatherings in workshops. The chapter begins by delving into the growing trend in cooking classes as a prime example of this, where participants are taught to better appreciate not only cooking techniques, but also tasting, smelling, feeling food as well. I also look at attention workshops for medical students, then at how insights from these might feed into ways to think about teaching and doing research in academia, how such sites could also be seen as sites of sensory lesson where art of noticing are cultivated as a transformative event.

Chapter 5 focuses on the products and objects which form part of this more elusive sensory training landscape, from wine labels to tasting diaries to menus. Multi-sensory experience has always been important in 
marketing, yet now increasingly marketing is trying to educate consumers to hone and tune their senses. It is not only the 'high end' culinary market where we find such sensory training. Sensory marketing also appears on supermarket shelves on wine label descriptions or packets of $100 \%$ dark chocolate which instruct buyers how to enjoy the bitter blocks. It appears on menus for many restaurants which describe what a diner will enjoy. In all of these cases commercial industries have repackaged 'the senses' and sold them back to their customers. The chapter looks at an important part of contemporary sensory education: at how sensations are extracted, isolated and re-inserted back into everyday sensory experiences.

The sixth chapter examines sensory education in "natural" landscapes. The chapter first treads into a very digital world, that of apps and self-tracking designed to better lives through facilitating sensory awareness of surroundings. These are technologies entangled in training to become more aware of individual experiences - our own symptoms and sensations, for example - as well as the environment. I then look at gardens and parks and forest walks and show that even when we head offline or take off our shoes, there is still design and engineering shaping sensory education. That is, there is no 'natural, unmediated' sensory lesson that exists outside of a socio-material learning context, no matter how far into the deep dark woods we go.

\section{Bibliography}

Barcan, Ruth. Complementary and Alternative Medicine: Bodies, Therapies, Senses. Oxford: Berg Publishers, 2011.

Berger, John, Sven Blomberg, Chris Fox, Michael Dibb, and Richard Hollis. Ways of Seeing. London: British Broadcasting, 1977.

Bijsterveld, Karin. Sonic Skills: Listening for Knowledge in Science, Medicine and Engineering (1920s-present). London: Palgrave Macmillan, 2019.

Bourdieu, Pierre. Outline of a Theory of Practice. Cambridge: Cambridge University Press, 1977.

Bruyninckx, Joeri. Listening in the Field: Recording and the Science of Birdsong. Cambridge: MIT Press, 2018.

Butler, Ella. 'Tasting Off-Flavors: Food Science, Sensory Knowledge and the Consumer Sensorium'. The Senses and Society 13, no. 1 (2018): 75-88.

Bynum, W.F., and Roy Porter, eds. Medicine and the Five Senses. Cambridge: Cambridge University Press, 2005.

Cade, John F., and M.C.F. Pain. Essentials of Respiratory Medicine. Oxford: Blackwell Scientific, 1988.

Classen, Constance. Worlds of Sense: Exploring the Senses in History and Across Cultures. New York: Routledge, 1993.

- 'Foundations for an Anthropology of the Senses'. International Social Science Journal 49, no. 153 (1997): 401-12.

. 'Other Ways to Wisdom: Learning through the Senses across Cultures'. International Review of Education/Internationale Zeitschrift Für Erziehungswissenschaft/Revue Internationale De L'education 45, no. 3-4 (1999): 269-80. 
. 'Museum Manners: The Sensory Life of the Early Museum'. Journal of Social History 40, no. 4 (2007): 895-914.

The Deepest Sense: A Cultural History of Touch. Champaign: University of Illinois Press, 2012.

Classen, Constance, David Howes, and Anthony Synnott. Aroma: The Cultural History of Smell. London: Routledge, 1994.

Collins, Harry M. Tacit and Explicit Knowledge. Chicago, IL: University of Chicago Press, 2010.

Counihan, Carole, and Susanne Højlund, eds. Making Taste Public: Ethnographies of Food and the Senses. London: Bloomsbury Academic, 2018.

Criado Perez, Caroline. Invisible Women: Exposing Data Bias in a World Designed for Men. London: Chatto \& Windus, 2019.

Croijmans, Ilja, and Asifa Majid. 'Not All Flavor Expertise Is Equal: The Language of Wine and Coffee Experts'. PLoS ONE 11, no. 6 (2016): e0155845.

Daniel, Valentine. 'The Pulse as an Icon in Siddha Medicine'. In South Asian Systems of Healing, edited by Valentine Daniel and Judy Pugh, 115-26. Leiden: Brill, 1984.

Daston, Lorraine, and Peter Galison. Objectivity. Brooklyn, NY: Zone, 2010.

De Solier, Isabelle. Food and the Self: Consumption, Production and Material Culture. London: Bloomsbury, 2013.

Delamont, Sara, and Paul Atkinson. 'Doctoring Uncertainty: Mastering Craft Knowledge'. Social Studies of Science 31, no. 1 (2001): 87-107.

Downey, Greg. Learning Capoeira: Lessons in Cunning from an Afro-Brazilian Art. Oxford: Oxford University Press, 2005.

Dupré, Sven. 'How-to Optic'. In Perspective as Practice: Renaissance Cultures of Optics (Techne: Knowledge, Technique, and Material culture, 1), edited by Sven Dupré, 279-300. Turnhout: Brepols, 2019.

Elliott, Denielle, and Dara Culhane, eds. A Different Kind of Ethnography: Imaginative Practices and Creative Methodologies. New York: University of Toronto Press, 2016.

Ellis, Rebecca. 'Jizz and the Joy of Pattern Recognition: Virtuosity, Discipline and the Agency of Insight in UK Naturalists' Arts of Seeing'. Social Studies of Science 41, no. 6 (2011): 769-90.

Ellsworth, Elizabeth. Places of Learning: Media, Architecture, Pedagogy. New York: Routledge, 2005.

Geurts, Kathryn Linn. Culture and the Senses: Embodiment, Identity, and Well-Being in an African Community. Berkeley: University of California Press, 2003.

Goodwin, Charles. 'Professional Vision'. American Anthropologist 96, no. 3 (1994): 606-33.

Grasseni, Cristina. 'Good Looking: Learning to Be a Cattle Breader'. In Skilled Visions: Between Apprenticeship and Standards, edited by Cristina Grasseni, 47-66. New York: Berghahn Books, 2009.

- ed. Skilled Visions: Between Apprenticeship and Standards. New York: Berghahn Books, 2009.

Grunwald, Martin. Homo Hapticus: Warum Wir Ohne Tastsinn Nicht Leben Koennen. Muenchen: Droemer Verlag, 2017.

Hagendijk, Thijs. 'Unpacking Recipes and Communicating Experience: The Ervarenissen of Simon Eikelenberg (1663-1738) and the Art of Painting'. Early Science and Medicine 24, no. 3 (2019): 248-82.

Hahn, Tomie. Sensational Knowledge: Embodying Culture through Japanese Dance. Middletown, CT: Wesleyan University Press, 2007. 
Harris, Anna. 'In a Moment of Mismatch: Overseas Doctors' Adjustments in new Hospital Environments'. Sociology of Health and Illness 33, no. 2 (2011): 308-20. . 'The Blackboard Anatomist'. BMJ: British Medical Journal 350 (2015): h345. . 'Embodiment'. In Oxford Bibliographies in Anthropology, edited by John Jackson. Oxford: Oxford University Press, 2016a. doi: 10.1093/obo/9780199766567-0151. . 'Listening-touch, Affect and the Crafting of Medical Bodies through Percussion'. Body \& Society 22, no. 1 (2016b): 31-61.

Harris, Anna, Andrea Wojcik, and Rachel Vaden Allison. 'How to Make an Omelette: A Sensory Experiment in Team Ethnography'. Qualitative Research 20, no. 5 (2020): 632-648.

Harris, Anna, and Jan-Joost Rethans. 'Expressive Instructions: Ethnographic Insights into the Creativity and Improvisation Entailed in Teaching Physical Skills to Medical Students'. Perspectives on Medical Education 7, no. 4 (2018): 232-38.

Harris, Anna, and Marilys Guillemin. 'Developing Sensory Awareness in Qualitative Interviewing: A Portal into the Otherwise Unexplored'. Qualitative Health Research 22, no. 5 (2012): 689-99.

Harris, Anna, and Melissa van Drie. 'Sharing Sound: Teaching, Learning and Researching Sonic Skills'. Sound Studies 1, no. 1 (2015): 98-117.

Heller-Roazen, Daniel. The Inner Touch: Archaeology of a Sensation. New York: ZONE Books, 2009.

Højlund, Susanne. “'Listen! We Made These Potatoes Crispy!” Danish Adolescents Sharing Taste in a School Class'. In Making Taste Public: Ethnographies of Food and the Senses, edited by Carole Counihan and Susanne Højlund, 99-112. London: Bloomsbury Academic, 2018.

Hope, Robert A., J. Murray Longmore, T.J. Hodgetts, and Punit S. Ramrakha. Oxford Handbook of Clinical Medicine. Third ed. Oxford: Oxford University Press, 1996.

Howes, David. Sensual Relations: Engaging the Senses in Culture and Social Theory. Michigan: The University of Michigan Press, 2003.

- Empire of the Senses: A Culture Reader. Oxford: Berg, 2005.

. 'Can these Dry Bones Live? An Anthropological Approach to the History of the Senses'. The Journal of American History 95, no. 2 (2008): 442-51.

- The Sixth Sense Reader. Oxford: Berg, 2009.

—. 'Reply to Tim Ingold'. Social Anthropology 19, no. 3 (2011): 318-22.

'Multisensory Anthropology'. Annual Review of Anthropology 48, no. 1 (2019): 17-28.

Howes, David, and Constance Classen. Ways of Sensing: Understanding the Senses in Society. New York: Routledge, 2014.

Hsu, Elisabeth. 'Tactility and the Body in Early Chinese Medicine'. Science in Context 18, no. 1 (2005): 7-34.

Ihde, Don. Bodies in Technology. Minneapolis: University of Minnesota Press, 2002.

Ingold, Tim. The Perception of the Environment: Essays on Livelihood, Dwelling and Skill. London: Routledge, 2000.

- Making: Anthropology, Archaeology, Art and Architecture. London: Routledge, 2013. . Anthropology andlas Education. London: Routledge, 2018.

Jakubowska, Honorata. 'The Sociological Analysis of Sensory Knowledge: Its Understanding, Construction and Acquisition'. Society Register 3, no. 1 (2019): 121-36.

Kelly, Martina, Rachel Ellaway, Albert Scherpbier, Nigel King, and Tim Dornan. 'Body Pedagogics: Embodied Learning for the Health Professions'. Medical Education 53, no. 10 (2019): 967-77. 
Kondō, Marie. Spark Joy: An Illustrated Guide to the Japanese Art of Tidying. London: Vermilion, 2017.

Krebs, Stefan. "Dial Gauge versus Senses 1-0”: German Car Mechanics and the Introduction of New Diagnostic Equipment, 1950-1980'. Technology and Culture 55, no. 2 (2014): 354-89.

Krebs, Stefan, and Melissa Van Drie. 'The Art of Stethoscope Use: Diagnostic Listening Practices of Medical Physicians and "Auto-Doctors". Icon: Journal of the International Committee for the History of Technology 20, no. 2 (2014): 92-114.

Krishna, Aradhna, and Norbert Schwarz. 'Sensory Marketing, Embodiment, and Grounded Cognition: A Review and Introduction'. Journal of Consumer Psychology 24, no. 2 (2014): 159-68.

Kuriyama, Shigehisa. The Expressiveness of the Body and the Divergence of Greek and Chinese Medicine. Cambridge, MA: The MIT Press, 1999.

Lahne, Jakob, and Amy Trubek. "AA Little Information Excites Us." Consumer Sensory Experience of Vermont Artisan Cheese as Active Practice'. Appetite 78 (2014): 129-38.

Landahl, Joakim. 'Learning to Listen and Look: The Shift from the Monitorial System of Education to Teacher-Led Lessons'. The Senses and Society 14, no. 2 (2019): 194-206.

Latour, Bruno. 'How to Talk about the Body? The Normative Dimension of Science Studies'. Body \& Society 10, no. 2/3 (2004): 205-29.

Lave, Jean. Learning and Everyday Life. Cambridge: Cambridge University Press, 2019.

Lewis, Tania. 'Digital Food: From Paddock to Platform'. Communication Research and Practice 4, no. 3 (2018): 212-28.

Majid, Asifa, Laura Speed, Ilja Croijmans, and Artin Arshamian. 'What Makes a Better Smeller?'. Perception 46, no. 3-4 (2017): 406-30.

Maslen, Sarah. 'Layers of Sense: The Sensory Work of Diagnostic Sense making in Digital Health'. Digital Health 3 (2017): 1-9.

Merchant, Stephanie. 'The Body and the Senses: Visual Methods, Videography and the Submarine Sensorium'. Body \& Society 17, no. 1 (2011): 53-72.

Merleau-Ponty, Maurice. The Visible and the Invisible. Evanston, IL: Northwestern University Press, 1968.

Mol, Annemarie. The Body Multiple: Ontology in Medical Practice. Durham, NC: Duke University Press, 2002.

Myers, Natasha. 'Molecular Embodiments and the Body-Work of Modeling in Protein Crystallography'. Social Studies of Science 38, no. 2 (2008): 163-99.

Newport, Cal. Digital Minimalism: Choosing a Focused Life in a Noisy World. New York: Portfolio/Penguin, 2019.

Odell, Jenny. How to Do Nothing: Resisting the Attention Economy. Brooklyn, NY: Melville House, 2019.

Paterson, Mark. The Senses of Touch: Haptics, Affects and Technologies. Oxford: Berg, 2007.

- 'Haptic Geographies: Ethnography, Haptic Knowledges and Sensuous Dispositions'. Progress in Human Geography 33, no. 6 (2009): 766-88.

Pink, Sarah. Doing Sensory Ethnography. London: SAGE Publications, 2009.

Polanyi, Michael. The Tacit Dimension. New York: Doubleday and Company, 1966.

Prentice, Rachel. Bodies in Formation: An Ethnography of Anatomy and Surgery Education. Durham, NC: Duke University Press, 2013. 
Reiser, Stanley. 'Technology and the Use of the Senses in Twentieth-Century Medicine'. In Medicine and the Five Senses, edited by W.F. Bynum and Roy Porter, 262-73. Cambridge: Cambridge University Press, 1993.

Rice, Tom. Hearing and the Hospital: Sound, Listening, Knowledge and Experience. Canon Pyon: Sean Kingston Publishing, 2013.

Roberts, Elizabeth. 'Bio-Ethnography: A Collaborative, Methodological Experiment in Mexico City'. Somatosphere, 26 February 2015. http://somatosphere. net/2015/02/bio-ethnography.html.

Sennett, Richard. The Craftsman. London: Penguin Books, 2008.

Serres, Michel. The Five Senses: A Philosophy of Mingled Bodies. London: Continuum, 2008.

Shapin, Steven. 'The Sciences of Subjectivity'. Social Studies of Science 42, no. 2 (2012): 170-84.

Spence, Charles, and Betina Piqueras-Fiszman. The Perfect Meal: The Multisensory Science of Food and Dining. Chichester: Wiley-Blackwell, 2014.

Stoller, Paul. Sensuous Scholarship. Philadelphia: University of Philadelphia Press, 1997.

Strathern, Marilyn. Learning to See in Melanesia: Four Lectures Given in the Department of Social Anthropology, Cambridge University, 1993-2008. Chicago, IL: Hau Books, 2015.

Supper, Alexandra. 'Data Karaoke: Sensory and Bodily Skills in Conference Presentations'. Science as Culture 24, no. 4 (2015): 436-57.

Sutton, David. Secrets from the Greek Kitchen: Cooking, Skill, and Everyday Life on an Aegean Island. Oakland: University of California Press, 2014.

Talley, Nicholas J., and Simon O'Connor. Clinical Examination: A Systematic Guide to Clinical Diagnosis. Third ed. Sydney: MacLennan + Petty, 1996.

Teil, Geneviève. 'Devenir Expert Aromaticien: Y a-T-Il Une Place Pour Le Goût Dans Les Goûts Alimentaires?'. Sociologie du travail 40, no. 4 (1998): 503-22.

Teil, Geneviève, and Antoine Hennion. 'Discovering Quality or Performing Taste? A Sociology of the Amateur '. Chap. 1 In Qualities of Food, edited by Mark Harvey, Andrew McMeekin and Alan Warde, 19-37. Manchaster: Manchester University Press, 2004.

Terrio, Susan. Crafting the Culture and History of French Chocolate. Berkeley: University of California Press, 2000.

Thyssen, Geert. 'Odorous Childhoods and Scented Worlds of Learning: A Sensory History of Health and Outdoor Education Initiatives in Western Europe (1900s-1960s)'. Senses and Society 14, no. 2 (2019): 173-93.

Thyssen, Geert, and Ian Grosvenor. 'Learning to make Sense: Interdisciplinary Perspectives on Sensory Education and Embodied Enculturation'. The Senses and Society 14, no. 2 (2019): 119-30.

Tracy, Sarah. 'Delicious Molecules: Big Food Science, the Chemosenses and Umami'. The Senses and Society 13, no. 1 (2018): 89-107.

Travers, Mark. 'How Do the Very Wealthy Choose to Spend Their Time?'. Forbes, 13 July 2019. https://www.forbes.com/sites/traversmark/2019/07/13/how-do-the-verywealthy-choose-to-spend-their-time/\#66c6f4c02cal (Accessed 1 January, 2020).

Trubek, Amy, and Maria Carabello. 'Teaching to Cook and Learning to Sense in Food Education'. In Making Taste Public: Ethnographies of Food and the Senses, edited by Carole Counihan and Susanne Højlund. London: Bloomsbury Academic, 2018: 139-152. 


\section{Introduction}

Tsing, Anna Lowenhaupt. The Mushroom at the End of the World: On the Possibility of Life in Capitalist Ruins. Princeton, NJ and Oxford: Princeton University Press, 2015.

Van Drie, Melissa. 'Training the Auscultative Ear: Medical Textbooks and Teaching tApes (1950-2010)'. The Senses \& Society 8, no. 2 (2013): 165-91.

Verghese, Abraham. 'Treat the Patient, Not the Ct Scan'. The New York Times, 26 February 2011. https://www.nytimes.com/2011/02/27/opinion/27verghese.html.

Volmar, Alex. 'Sonic Facts for Sound Arguments: Medicine, Experimental Physiology, and the Auditory Construction of Knowledge in the 19th Century'. Journal of Sonic Studies 4, no. 1 (2013).

Von Hoffmann, Viktoria. 'Learning (to) Taste: Food, Aesthetics, and Education in Early Modern France'. The Senses and Society 14, no. 2 (2019): 131-47.

Wojcik, Andrea, Rachel Vaden Allison, and Anna Harris. 'Bumbling along Together: Producing Collaborative Fieldnotes'. In Fieldnotes in Qualitative Education and Social Science Research: Approaches, Practices, and Ethical Considerations, edited by Casey Burkholder and Jennifer Thompson. New York: Routledge, 2020. 201-216.

Wyatt, Sally. 'How Users Matter: The Co-construction of Users and Technology'. In Non-users also Matter: The Construction of Users and Non-users of the Internet, edited by Nelly Ourdshoorn and Trevor Pinch, 67-79. Cambridge, MA: MIT Press, 2003.

Xiao, Kunbing. 'The Taste of Tea: Material, Embodied Knowledge and Environmental History in Northern Fujian, China'. Journal of Material Culture 22, no. 1 (2016): 3-18.

Yates-Doerr, Emily. The Weight of Obesity: Hunger and Global Health in Postwar Guatemala. Oakland: University of California Press, 2015. 


\section{Lesson 1 How to make a cyanometer and other lessons in blue}

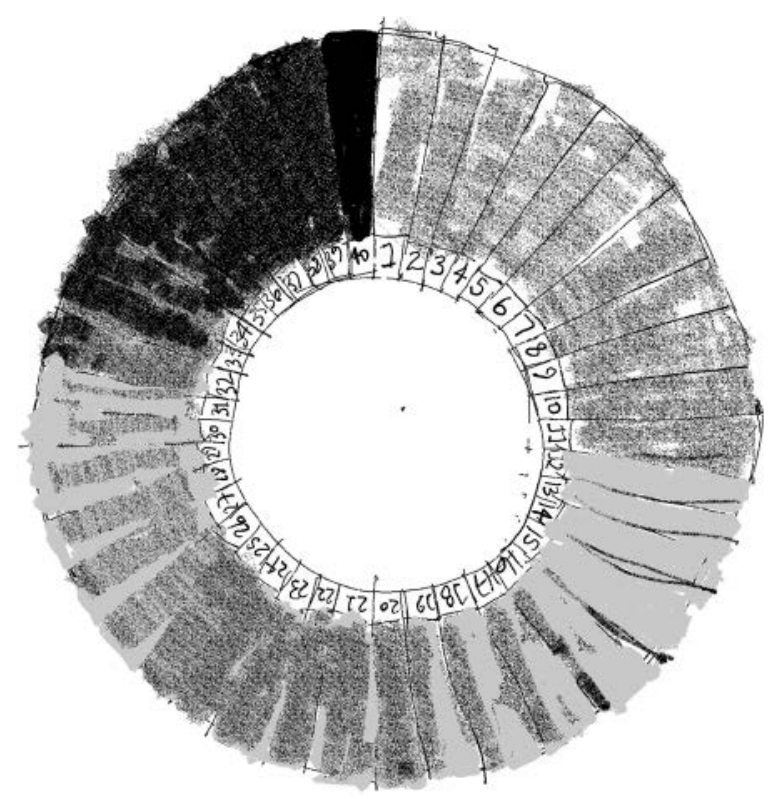

Figure 1.1 Cyanometer, 1-40.

\section{1-10: Alice blue to duck egg blue}

When children learn the names of colours, as they do pretty universally across the world, ${ }^{1}$ classic examples are often used and pointed to - in English, grass is green, roses are red and the sky is blue. Objects and phenomena in the world, which previously went unnamed, are given labels. This raises a lot of questions: 'Why is the sky blue?', is the time-old question from children.

1 Asifa Majid and Stephen C. Levinson, 'The Senses in Language and Culture', The Senses and Society 6, no. 1 (2011): 5-18. 
'What kind of blue?' (quoting Miles Davis), a chemist in eighteenth-century Europe might ask. 'Do all cultures name blue, and if they do, how many shades of blue are recognised?', linguists ponder. 'Why isn't the sky blue?', a historian enquires on a radio show.

These are some of the questions that arise throughout this first lesson of this book, in a lesson about how to make a cyanometer (Figure 1.1). By making a tool for measuring the blueness of the sky, the practical lesson serves as an entry point into the next chapter's theme of sensory vocabulary, the chapter focusing in particular on the cultivation of vocabulary in sensory education.

The cyanometer is a beautiful instrument invented by Horace-Bénédict de Saussure in the eighteenth century. ${ }^{2}$ It was invented at a time when measuring and objectifying the natural world seemed bursting with new possibilities. De Saussure, a Swiss geologist, meteorologist and explorer, was certain that the blueness of the sky related to its moisture content. He had no way of measuring this though, of proving his hypothesis. So, he invented a tool. Using various suspensions of Prussian blue, he dyed 53 paper squares every shade of blue he could manage, from white, to pale duck egg blue, to black, then assembled them in a numbered circle. The circle of blue was designed to be held up to the eye, so the viewer could match and measure the degree of blue in the sky.

\section{1-20: periwinkle to azure}

The central purpose of the cyanometer was to quantify something that was, until then, a subjective observation. The sky is a phenomenon that children don't even think of as having 'a colour' until it is pointed out to them. The tool not only highlighted the concept of varying blueness but also put numbers to each shade. The following chapter, Chapter 1, introduces sensory experts such as perfume makers and wine experts, who also create a sensory vocabulary of numbers. These vocabularies are used as standard sets or reference points in training novices or developing expertise. Unfortunately, little is known to the same degree about the practices of individuals who have used the cyanometer in the past, and what kinds of expertise it might have trained, but there is something to be learned in the making of the instrument, nonetheless.

These instructions for the cyanometer include numbers from 1 to $40-$ one being closest to white, 40 being closest to black. Making an instrument like the cyanometer helps to show the work that goes into constructing a numerical sensory vocabulary of blue, and of creating sensory standards or

2 Andrea Sella, 'Classic Kit: Saussure's Cyanometer', Opinion, Chemistry World, 28 September 2010, https://www.chemistryworld.com/opinion/classic-kit-saussures-cyanometer/3004936.article. 
reference points more generally. It shows how there is no 'natural' reference point at all. The tool is made up of whatever comes to hand - Prussian blue dye in de Saussure's case, or for the cyanometer you will make in this lesson, commercially produced paint sample cards available at your nearest hardware store (with all of their wonderful names such as 'periwinkle' and 'azure').

So, these are the instructions. Head out to the paint/hardware store and collect as many sample paint cards as you can, in all the shades of blue you can find. Then, after gathering some further supplies, you will be ready to make your own cyanometer.

\section{Equipment}

- Pens

- Scissors

- A compass (Figure 1.2)

- A sturdy piece of cardboard

- Glue

- White stickers

- Blue-tack (or white-tack)

- A music player to play Miles Davis' Kind of Blue.

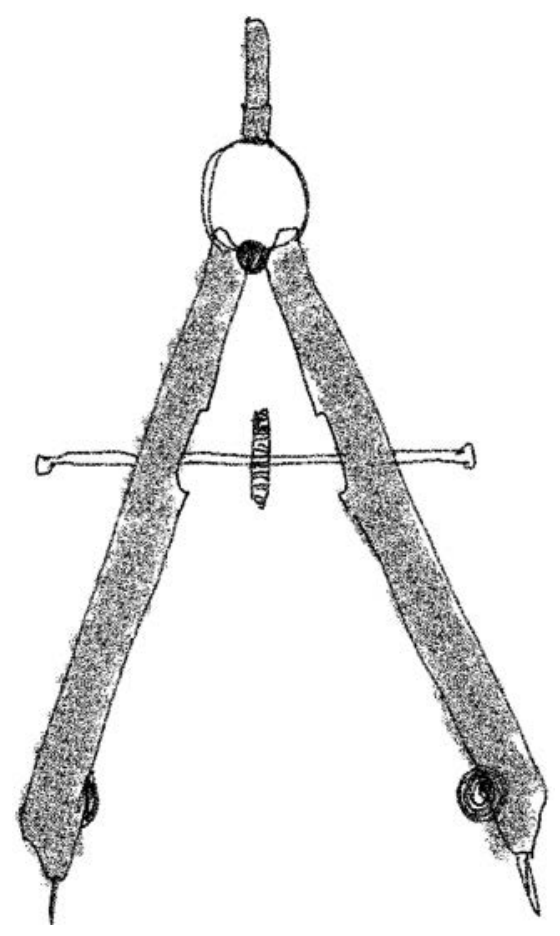

Figure 1.2 Compass. 


\section{Instructions}

1. Put music on, suggested listening being Kind of Blue. In 1959, jazz trumpeter Miles Davis assembled his ideal sextet. Using simple musical scales, instead of the complex harmonic progressions of their contemporaries, they attempted, in five mesmeric tracks, to redefine an art form and capture the essence of all that was blue. ${ }^{3}$

2. Take a compass and draw two circles on the sturdy card, one of approximately $30 \mathrm{~cm}$ diameter and the other of approximately $20 \mathrm{~cm}$ diameter. If you don't have a compass you can use dinner plates and saucers.

3. Fold the 40 colour sample cards in half and glue halves together, then cut in half again.

4. Put white stickers at the bottom of each colour card.

5. Arrange the sample cards in a circle, using blue-tack to hold into place so that the correct spacing can be achieved (10 cards should fit in one quarter).

6. Glue the cards in place.

7. Number the white stickers from 1 to 40 with a marker.

8. Take outside and measure the blueness of the sky. There is a blank page opposite for you to record your observations.

\section{1-30: Prussian blue to Egyptian blue}

It seems so simple. Hold the circle up to the sky, and measure blue. But what is blue? Is this a universally recognised colour name, not only for the sky, but also more generally? As the psycholinguistic researchers Asifa Majid and her colleagues ${ }^{4}$ from around the world have shown, many different cultural groups have different traditions in describing colours, including the number of words used for different shades and qualities of a colour. One cultural group they studied recognised many more shades of dark blue for example, than others in their cohort. These researchers also showed that there is a difference in the emphasis placed on giving words to colours in the first place. Studying sensory vocabularies of different cultural groups reveals what many anthropologists have argued for decades: that there is no 'set of senses', that there is no 'sensory hierarchy' and that sensory vocabularies are socially and historically constructed. ${ }^{5}$

Attending to the history of the colour shows that the sky has not always been blue either, something that is important to keep in mind when using the cyanometer you have made. In a podcast called 'Why isn't the sky blue' (which I would recommend listening to while working on your cyanometer,

3 Sella, 'Classic Kit'.

4 Majid and Levinson, 'Senses in Language and Culture'.

5 David Howes and Constance Classen, Ways of Sensing: Understanding the Senses in Society (New York: Routledge, 2014). 
Sky Observations

Date

Time

Location

Blueness 
alongside Miles Davis), the RadioLab team ${ }^{6}$ explore the historical situatedness of the link between skies and blueness. They retell the story of the British Prime Minister William Gladstone who did an exhaustive study of every colour reference in Homer's works, only to find that there was no blue. It leads to a conversation of how colour appears in historical texts in stages, and that blue always comes last. The suggestion is made that this was because there is little natural blue in the world, and that blue is hard to make. Without needing a word for it, blue isn't noticed. Gladstone deduced that if Homer had no word for blue, then the world for him was 'less blue'?

\section{1-40: dark cyan to 7.5B $1 / 2$}

Perhaps the question to ask, when making the cyanometer, is not what is blue, but rather what is cyan? For it is not a blue-o-meter you have just made, but a cyan-o-meter. The Munsell colour chart, a colour system which classifies colours according to hue, value and chroma, gives the colour blue a hexadecimal colour code of \#0093af, and considers it a medium dark shade of cyan. In her article in Cabinet, Lyn Hejinian describes cyan as follows: "Cyan (pronounced SIGH-ann) is the colour that emanates from a calm sea not far offshore on a clear day as the blue of the sky is reflected in salt water awash over yellow sand". ${ }^{8}$ She has a suggestion for how to make your own cyan:

To create a highly saturated cyan on your own, you might pour $1 / 4$ cup of Arm \& Hammer's Powerfully Clean Naturally Fresh Clean Burst laundry detergent onto the whites in your next load of wash (presumably Arm \& Hammer adds the pigment to its product in order to provoke association with what we imagine to be the pristine purity of tropical seas. $^{9}$

Or even better, for how to see cyan everywhere (without dying your clothes):

You can trick your mind into seeing cyan where it doesn't exist by forcing your mind first to see everything as red. Hold a red filter (candy wrapper, red glass, etc.) to your eyes so that your entire field of vision (including peripheral vision) is coloured for a minimum of one or two

6 Radiolab, 'Why Isn't the Sky Blue?', produced by Tim Howard, 21 May 2012, Podcast, 21:07, https://www.wnycstudios.org/story/211213-sky-isnt-blue.

7 Radiolab, 'Why Isn't the Sky Blue?'.

8 Lyn Hejinian, 'Cyan: Kind of Blue', Cabinet, no. 20/Ruins (2005-6), http://www.cabinetmagazine.org/issues/20/hejinian.php.

9 Hejinian, 'Cyan: Kind of Blue'. 
minutes - the longer the better. Then remove the filter and quickly look at a piece of white paper. ${ }^{10}$

Cyan has a rich cultural history. Doctors look for it when they perform a physical examination and check for the symptom of cyanosis. Cyanosis means that there is not enough haemoglobin in the blood supply, or there is a shutdown of the circulation system in the extremities. Learning what is cyanotic is a new way of describing blue for medical students, a special word for something which was once ordinary to them. Just like children naming the sky. Doctors need to learn ways of looking for cyanosis, to learn to make the connections between the word and the sign of illness in the body.

I have presented a few different ways of making and seeing cyan and for thinking about measuring it in skin and in the sky. Legend has it that de Saussare invented his cyanometer after hiking in the Swiss mountains, wanting to understand more about the world that he saw around him from these heights. The invitation is there - make and then take your cyanometer outside too. See what happens when you try and find blues; when you assemble and number your paint sample cards and make an arrangement in a circle; when you deconstruct and reconstruct the words and worlds of blue and cyan; when you hold up your cyanometer to the sky on a sunny summer day and try and find a clear patch of blue to measure; see what it opens up, you just might be surprised.

\section{Bibliography}

Hejinian, Lyn. 'Cyan: Kind of Blue'. Cabinet, no. 20/Ruins (2005-6). http://www. cabinetmagazine.org/issues/20/hejinian.php.

Howes, David, and Constance Classen. Ways of Sensing: Understanding the Senses in Society. New York: Routledge, 2014.

Majid, Asifa, and Stephen C. Levinson. 'The Senses in Language and Culture'. The Senses and Society 6, no. 1 (2011): 5-18.

Radiolab. 'Why Isn't the Sky Blue?'. Produced by Tim Howard. 21 May 2012. Podcast, 21:07. https://www.wnycstudios.org/story/211213-sky-isnt-blue.

Sella, Andrea. 'Classic Kit: Saussure's Cyanometer'. Opinion, Chemistry World, 28 September 2010. https://www.chemistryworld.com/opinion/classic-kit-saussures-cyanometer/3004936.article.

10 Hejinian, 'Cyan: Kind of Blue'. 


\section{New vocabularies}

The description is on the tip of our tongues, brushing the edges of our sensory memories, tingling in our fingertips. Often the sensory does not need description - a delicious meal eaten in silent appreciation, someone's pain written in the creases of their face. There are occasions, however, when there is some desire to articulate and put words to sensations. It might be a choreographer who wants to share with their dancers how to position their agile limbs, a wine critic who has to write about why this wine is so good or a doctor who needs to share the sounds that they heard in their patient's lungs with a colleague.

This chapter focuses on the problematics of sensory vocabulary and the cultural, geographical, historical specifics of its learning. Sensory education sometimes seems to be all about vocabulary, for people share sensations through words. Learning that the sky is blue, for example, means that there is a shared word for what blankets our lives from above and the shared word means people can be in conversation about it. As seen in the case of the cyanometer in Lesson 1 , these sensory vocabularies are culturally and historically constructed and are shaped by material conditions as well as sensory agendas.

As will be unpacked further in this chapter, generations of scientists and thinkers from psycholinguists, sociologists, historians, philosophers and beyond have tried to understand how the words used to describe sensory aspects of the world relate to how the world is experienced and perceived - and vice versa. This might mean, for example, trying to understand how feeling and touching is shaped by the words used to describe that touching, and how practices of touching shapes the words used to describe it. ${ }^{1}$ Throughout the chapter, I will explore this theme with a focus on the cultivation of sensory vocabularies, using examples such as coffee cupping workshops, olfactory training, wine tasting and medical school.

I suggest that sensory vocabularies are built up through, and utilised in, social and material practices where differences are constructed against reference points. I write about how these practices of building against a standard involve bodily techniques, metaphors and technologies. I examine some

1 Shigehisa Kuriyama, The Expressiveness of the Body and the Divergence of Greek and Chinese Medicine (Cambridge, MA: The MIT Press, 1999). 
key strategies that educators, whether in professional or everyday contexts, have developed for how to attend to sensory vocabulary training, strategies often shared across fields of learning. In doing so, I look at how these teachers try to accomplish the seemingly impossible: to share words for the ineffable.

Specifically, my examples include: What it means to learn new words in a public coffee cupping class; I look at the difficulties of articulation of smell through the cases of olfactory experts and wine makers and tasters, who attempt to attach words, and sometimes numbers, to smells and tastes. In addition, I go to medical schools where novice doctors are undergoing very similar linguistic sensory training, learning to describe lung sounds, breath smells, microbiology slides, lumps and other pathologies using metaphors, similes and analogies. In exploring these different forms of vocabulary learning, questions arise. How do mass produced tools like flavour charts, tools of measurement like the cyanometer and coffee cupping charts correspond to and shape sensory experience? How are these reference points constructed and used? In many fields where noticing is a core skill, such as natural history or archaeology, there are many reference points also used, charts, scales and other forms of measurement, including field guides or the Munsell chart to reference different colours of black dirt during an archaeological dig. ${ }^{2}$ Learning to sense, to notice, to see, involves working with such technologies.

In order to start exploring some of the questions raised above, I delve first into a coffee cupping class, and consider how novices learn to tell differences in what they sense, and how they learn to put words to these new sensations. Coffee cupping offers an excellent jumping off point into the theme of this chapter, for it looks at what was once a sequestered practice amongst experts, often at colonial sites of coffee export and import, that has now been taken into the public space. This shows how sensory vocabulary training exists in many realms of the everyday, not only behind closed doors. It also offers a nice array of examples of material strategies found to address the linguistic challenges of learning new vocabularies to describe coffee, whether through description charts, flavour wheels or workshop set-ups.

\section{New words}

It is a white-grey winter's day in Melbourne and I am in a popular inner-city coffee spot, attending my first cupping class. Mostly I am trying not to inhale coffee grounds up my nose. Fellow classmates are also sniffing the cups of freshly ground beans placed on the table before us. The instructor moves around the circular table quickly. He picks up a cup and holding it close to his neatly clipped moustache, inhales deeply. Looking momentarily off beyond the distant café tables, he turns back to the table and scribbles some 
notes on his clipboard. I look down at my own blank scoring sheet. How would I describe this aroma - flowery, fruity, spicy, earthy? There does not seem to be an option for 'smells like coffee'.

In this chapter, I look at the learning involved in going from 'smells like coffee' to a diverse vocabulary of a sensation that includes specific terms like 'spicy' and 'earthy'. As I have already introduced at the start of the book, as one of the central arguments of the manuscript, this work is social and material, something highly visible in the ritualistic practice of cupping.

Cupping is a practice designed to aid in the comparison and contrast of different aromas and tastes. It is a practice often undertaken by importers and roasters of coffee, rather than by producers within the country of origin (please do read Goldstein ${ }^{3}$ for a more elaborate ethnographic account of cupping rituals). Evaluating the quality of coffee started as a visual task where evaluators assessed the size and colour of green beans. At the end of the nineteenth century, as more coffee beans arrived from central America to the US, San Francisco coffee broker Clarence E. Bickford developed the 'cup quality test'. ${ }^{4}$ Around 1932, B.D. Balart, active in America's coffee associations, set out to formalise this evaluation procedure. With his article

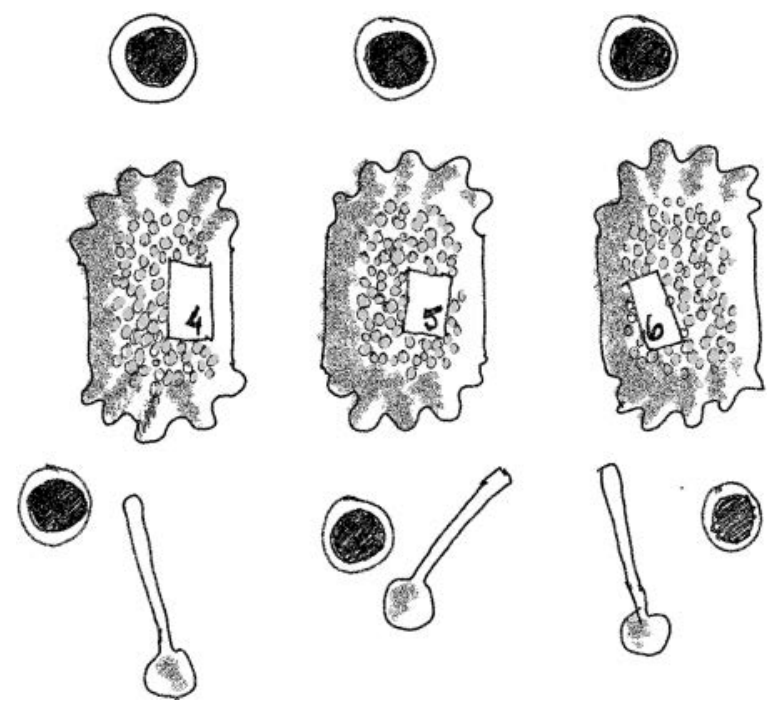

Figure 1.3 Coffee cupping set-up with beans, spoons and cups.

3 Jenny Elaine Goldstein, 'The "Coffee Doctors": The Language of Taste and the Rise of Rwanda's Specialty Bean Value', Food and Foodways 19, no. 1-2 (2011): 135-59.

4 Mike Ferguson, 'The Evolution of the Cupping Lab', Olam Specialty Coffee, 16 May 2017, http://blog.olamspecialtycoffee.com/2017/03/10/olams-new-cup-testing-facility-in-brazil/. 
claimed to be 'removing the guesswork from coffee cupping', he argued for developing more robust standards. ${ }^{5}$

Today's professional coffee laboratories and experts still use Balart's evaluation process, with his contribution to the field being seen as improving 'accuracy, control, and [offering an] expanded vocabulary'. ${ }^{6}$ Balart was striving for greater objectivity of the subjective nature of coffee evaluation. He introduced technological devices that attempted to improve accuracy and demanded control in contexts where external factors could potentially 'distract from a full sensory attention'. His expanded vocabulary meant training through the assistance of objects such as cupping forms, smell kits and different aroma and tasting vocabulary posters.

All of these material prompts are still present in cupping classes today (Figure 1.3). For nowadays, public cupping classes are not only expert affairs, but also increasingly popular in cafés from New York, London, Melbourne and other caffeine saturated cities, where coffee drinkers can enter the coffee laboratory. In these cafés, baristas and roasters share secret coffee business with their customers, opening up their backrooms to those who want to learn more about how to smell and taste coffee and receive instruction in the sensory arts of the brew. In a cupping class, instructors guide novices through the cupping process step-by-step, following Balart's principles of evaluation:

First look at the beans and assess appearance. Pick up a few, examine them and let them fall through your fingers. Then smell the freshly ground coffee with short sharp breaths (try not to redistribute too many grinds onto your face). [The instructor then pours boiling water over the coffee (Figure 1.4)] After three or four minutes you "crack" the crust which has formed with a little soup spoon. Put your nose as close as you can to the brew without dipping it in. Inhale. Remove the top sediment and after another ten minutes, when the coffee has cooled, slurp with a spoon. Swirl the coffee in your mouth. Spit out. Do not forget to take notes along the way. At the end of the session, the teacher reveals the mystery coffees and classmates compare impressions. ${ }^{7}$

Finding new ways to describe odours is an integral part of this coffee sensory education. It may be that there are new words or it may be familiar words appearing in a new context. In one class I attended the instructor picked up a cup: 'hmm, very chocolaty' he mused. I glanced at my notes and saw that I had hastily circled herbal and nutty for that one. I am not alone in the difficulties I had in describing the smell of coffee. Croijmans

5 Ferguson, Cupping Lab.

6 Ferguson, Cupping Lab.

7 Based on fieldnotes, Melbourne, 3rd July 2014. 


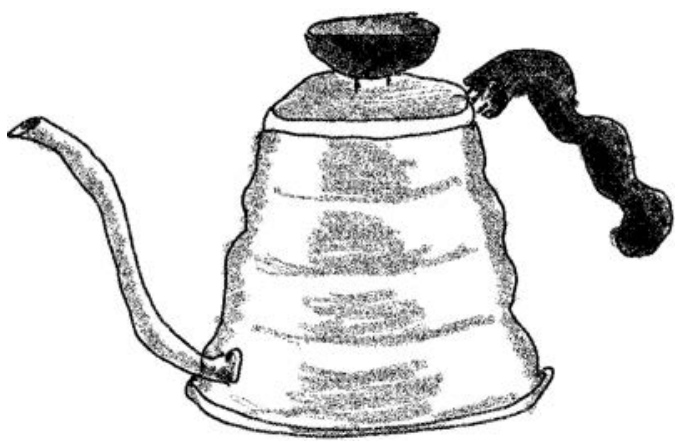

Figure 1.4 Pour over kettle used in a cupping session.

and Majid, ${ }^{8}$ two psycholinguists who have studied the development of the sensory vocabularies of coffee tasters discuss the difficulties in describing taste and smell as a WEIRD (Western, Educated, Industrialized, Rich and Democratic) affair, common to many in weird states. These psycholinguists argue that not everyone in the world finds describing smells difficult, however. Majid and her colleagues' research more broadly focuses on the links between words and perception in cultures across the world. They want to know how languages differ in their coding of the senses, specifically in the relative expressibility of perceptual domains.

There are certainly many linguistic limitations to sensory language. Majid and Levinson ${ }^{9}$ write that the meaning of colours, for example, cannot be easily linguistically expressed, something that arises when working with blue in Lesson 1. People learn colours, they say, through repeated sensory exposure, together with pointing or other techniques necessary to make connections $^{10}$ (using a cyanometer for example). Do many visual sensory cues available for colour learning lead to more stable sensory vocabularies, than say the olfactory vocabulary, which is often argued to be impoverished in comparison? Parents often point to the sky and say to their children 'blue'. They are much less likely to hold up a herb and identify its aroma. Asifa Majid, however, has worked tirelessly with colleagues to show how this is a culturally variable phenomena, that some languages have more extensive sensory vocabularies in specific domains than others. Jahai speakers in the Malay Peninsula, for example, have a very large olfactory range she

8 Ilja Croijmans and Asifa Majid, 'Not All Flavor Expertise Is Equal: The Language of Wine and Coffee Experts', PLoS One 11, no. 6 (2016): e0155845.

9 Asifa Majid and Stephen C. Levinson, 'The Senses in Language and Culture', The Senses and Society 6, no. 1 (2011): 5-18.

10 Majid and Levinson, 'Senses in Language and Culture'. 
argues. ${ }^{11}$ Others have also argued that there are different emphases in different cultures on particular senses, such as touch. ${ }^{12}$

The focus of study on culturally variable sensory vocabularies is fascinating for it points towards an assumption that researchers make in this line of research that the words used to describe the world, the codes people use to define something, reflect people's perception of the world. The psycholinguists see language as a bridge between private sensation and a shared sensory and cultural environment. Language is a way of verbalising what we sense. It means that sensing as a phenomenon is easier to study when actors make such vocalisation explicit, when communities construct rituals for articulation and when, as in training sessions, attention is paid to learning or relearning new terms.

The science and technology studies scholar Bruno Latour ${ }^{13}$ shares a fascination with the psycholinguists in sensory vocabulary but focuses much more on the bodily and material process of this learning, and what it means for a theory of the body. How we become bodies, is, he argues, a matter of this sensory vocabulary training. The more words we have to describe the world as we experience it, the more distinctions we can make between differences, the more bodies and social groups are articulated. The more you can describe, the more you can sense, the more you can experience the world. And all of this sensory training takes place amongst and with and as things. I will return to Latour's work in the next section when discussing the vocabulary of another kind of olfactory expert.

There is evidence of the materiality of sensory vocabulary training in a number of places in the cupping class. Take for example the scoring sheet, where participants are asked to comment on qualities of the coffee such as taste, aroma and mouthfeel. Some instructors hand out sheets with pages blank, leaving it up to imaginations and associations of pupils, while others provide prompts, such as those I found on my scoring sheet in Melbourne. One sheet in the class I attended, for example, had six coffee samples listed from A to F. In the next column, there was a prescribed list of aromas: flowery, fruity, herbal, chocolate, nutty, caramel, spicy, earthy and citrus. There was also a place which indicated 'other' - that is for the aromas that were not listed. The instructions on the sheet were to 'circle any aromas that you can smell'. The remaining four columns were titled 'sweetness', 'acidity', 'mouthfeel' and 'overall'.

The scoring sheets were not innocuous pieces of paper. They worked hard at the vocabulary training, offering words to help novices match new sensations. In her auto-ethnographic account of a sensory education class for

11 Majid and Levinson, 'Senses in Language and Culture'.

12 Paul Wenzel Geissler and Ruth J. Prince, 'Life Seen: Touch and Vision in the making of Sex in Western Kenya', Journal of Eastern African Studies 1, no. 1 (2007): 123-49.

13 Bruno Latour, 'How to Talk about the Body? The Normative Dimension of Science Studies', Body \& Society 10, no. 2/3 (2004): 205-29. 
food science students, anthropologist Ella Butler ${ }^{14}$ describes how the lab worksheets the students were given in their class worked in a similar way. 'The lab worksheet encouraged students to produce a descriptive vocabulary that could be shared and refined amongst their peers', Butler writes. ${ }^{15}$ In the case of food science students, however, it was learning a new vocabulary for describing 'off flavours' the customers might notice, which the food science students needed to attend to carefully.

Another seemingly innocent device in the cupping class is called The Flavor Wheel, a wall chart that helps coffee tasters find words to describe what they are smelling and tasting. Coffee Taster's Flavor Wheels decorated the walls of the cupping room in Melbourne. On the chart, aromas and tastes were splayed out like a multi-coloured seashell with enticing descriptors like tea rose and maple syrup, and others that didn't seem so attractive in coffee, like onion and garlic. The map was colour coded: yellows and greens for sour-y tastes, for example, and browns for aromas nutty and carmel-ly. These words were all in English, as they are in other coffee cupping contexts, such as in Rwanda, where local cuppers are trained to use this tool alongside little scented vials, to describe coffee flavours and aromas. ${ }^{16}$ As geographer Jenny Goldstein ${ }^{17}$ points out, these descriptions are not in the cuppers' native language, nor use words with which they are unfamiliar - blueberry or violet, for example, refer to flavours that are not available in East Africa in their natural states. The coffee wheel is a material form that becomes part of a new learned and at times imposed and limited vocabulary.

\section{Objectivity machines}

The coffee wheel used in both amateur and professional cupping contexts is inspired by the Wine Aroma Wheel: a copyrighted device invented by scientist and flavour chemist Ann C. Noble in the 1980s. ${ }^{18}$ Noble designed the wheel to facilitate the description of flavours perceived by ordinary wine drinkers. In unravelling the historical narrative of this artefact, historian of science Steven Shapin expands upon a new area of interest in science and technology studies (STS) related to issues of subjectivity. For decades, STS scholars have interrogated and questioned the ways in which objective knowledge is formulated in science and medicine, showing its inherently constructed nature. Shapin ${ }^{19}$ has pointed out that this focus on dismantling

14 Ella Butler, 'Tasting Off-Flavors: Food Science, Sensory Knowledge and the Consumer Sensorium', The Senses and Society 13, no. 1 (2018): 75-88.

15 Butler, 'Tasting Off-Flavors', 77.

16 Goldstein, 'Coffee Doctors'.

17 Goldstein, 'Coffee Doctors'.

18 Steven Shapin, 'A Taste of Science: Making the Subjective Objective in the California Wine World', Social Studies of Science 46, no. 3 (2016): 436-60.

19 Shapin, 'Taste of Science'. 
objectivity has left the issue of subjectivity largely untouched, and of presumed unquestioned relevance. His work on subjectivity, through the empirical case of wine tasting, works to dissect what it means to formulate subjective judgement; judgements such as how a wine is experienced. Shapin highlights that we need to look carefully at sensory vocabularies in all their historical and cultural complexity. The winemakers Shapin studied had their own particular (geographical, disciplinary, commercially orientated and historically specific) way of classifying sensations. Shapin has also looked carefully into the ways in which 'wine talk' has been developed over time. However, this chapter only focuses on a particular material manifestation of this new vocabulary in the twentieth century: the wine wheel.

Shapin is particularly interested in how 'soft' subjective judgements about wine (for example, concerning taste and odour), are transformed into 'hard' objective descriptions and evaluations. Like other scholars in the field of STS, he is not interested in what objectivity or subjectivity are per se, but rather, in the practices involved in the attempt towards their demarcation and accomplishment.

Wine tasting (Figure 1.5) is a practice that involves many sensations shaped by and shaping memory, imagination, emotions, beliefs and expectations. As John Ducker, a wine tasting teacher argues, taste experiences and memories depend on linguistic vocabulary 'to give them shape, precision, and context'. ${ }^{20}$ These articulations are also important for conversation and comparison. For Ducker it is crucial to understand 'what one
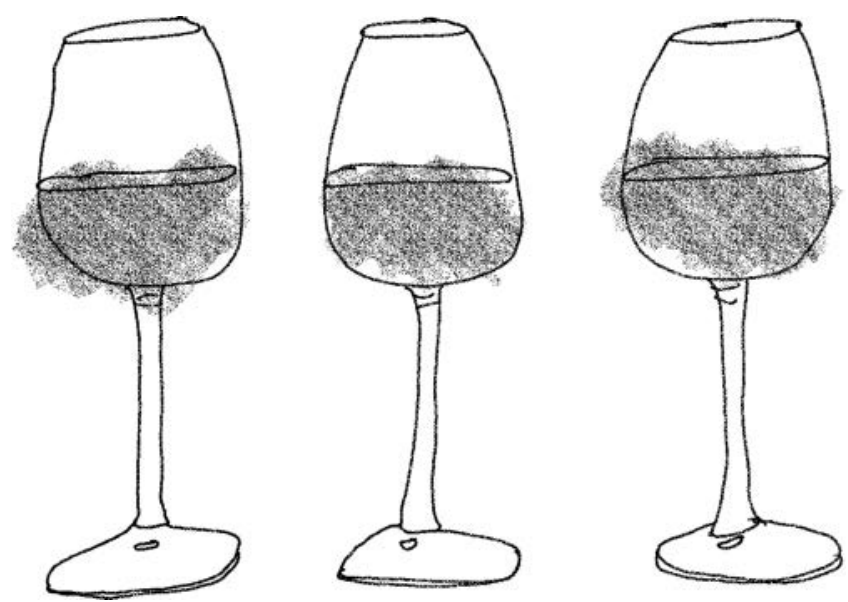

Figure 1.5 Glasses in a wine tasting.

20 John Ducker, 'Teaching Wine Tasting', in Educated Tastes: Food, Drink and Connoisseur Culture, ed. Jeremy Strong (Lincoln, London: University of Nebraska Press, 2011), 111. 
makes of those remembered sensations, ${ }^{21}$ The field of chemical science that Shapin studied was largely interested in developing a systematic vocabulary for these sensations, for the purposes of wine evaluation and also commercial success. This vocabulary was to separate out the objective (using 'scientific method', based on chemical properties of the wine) from the subjective (deemed 'untrustworthy' and 'unreliable'). It was problematic that individuals differed in their judgments of wine, and this difference in subjective judgement was something that needed repair. The solution was to be a shared vocabulary to describe the sensory properties of wine.

Shapin describes how the wheel that was invented was designed to allow users to assign stable descriptions to wine odours and tastes. The point of this wheel, Shapin argues, is not a matter of obtaining objectivity in taste, but rather 'taste intersubjectivity'. ${ }^{22}$ The wheel is, he suggests, 'a homespun intersubjectivity engine. Taste communities coalesce around practices like that - practices that refer to mutually accessible external properties as the causes of internal states'. ${ }^{23}$ Just like the coffee wheels, the wine wheel aims to create shared sensory experience. It also helps bring together communities of dedicated coffee and wine drinkers. Learning the vocabulary of coffee and wine tasting, whether as an expert or an amateur in a weekend class, brings together a social group; it is a social and material affair.

The scientists that Shapin followed in twentieth-century California developed other materials to help share vocabulary, including glossaries, guides and other instruments. As in the cupping class, sensory training in wine tasting, through particular material conditions, is a process by which not only are differences learned, but also calibrated to a standard, this standard then shaping sensory experience in return. I explore these practices of calibration further in the next chapter on sensory schooling. The interesting point is not that sensing is subjective and individual, but to try and understand more about how social groups try and tackle the challenge of how to share sensations with others. One solution is developing a particular sensory vocabulary, that is played out in how cupping sessions are arranged and in flavour wheels. Another solution is a material object often used in wine education which performs this task of sharing vocabulary: the smell kit. The smell kit sheds further light on how reference kits are used to train the sensory vocabularies of individuals entering into new communities of sensory practice. ${ }^{24}$

21 Ducker, 'Teaching Wine Tasting', 111.

22 Shapin, 'Taste of Science', 178.

23 Shapin, 'Taste of Science', 178.

24 Jean Lave and Etienne Wenger, Situated Learning: Legitimate Peripheral Participation (Cambridge: Cambridge University Press, 1994). 


\section{Reference sets}

A smell kit is a collection of little vials of essential odours, which a wine or coffee taster can smell to train their 'nose' (Figure 1.6). Here I want to look at how olfactory experts use the smell kit, and how in their training it becomes another reference point in learning new words. The French sociologist Geneviève Teil ${ }^{25}$ spent a lot of time thinking about the training of olfactory experts and how they used materials like the smell kit. From her fieldwork she suggests that sensing is not shaped through acculturation, as so many sociologists argued before her, but rather, through an emphasis on learning sensorial qualities of objects. An important part of learning new sensory vocabulary that Teil found, was the process of reformulating past vocabularies using the new reference standards.

We see this in the training of doctors as well - as they learn new words for sounds and other sensations, medical students must reconfigure their 'lay' or everyday terminology. This is also the terminology often used by the patients themselves, creating the often observed disconnect between how doctors and patients talk. I saw a striking example of this in a microbiology

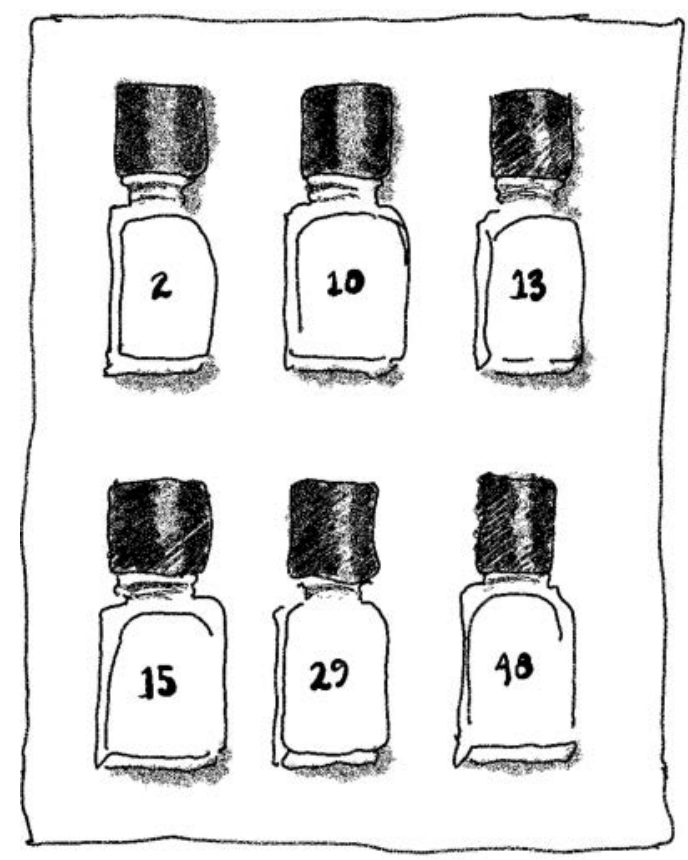

Figure 1.6 Smell kit.

25 Geneviève Teil, 'Devenir Expert Aromaticien: Y a-T-Il Une Place Pour Le Goût Dans Les Goûts Alimentaires?', Sociologie du travail 40, no. 4 (1998): 503-22. 
class I attended one day during my fieldwork in a Dutch medical school, when medical students were learning about a particular slide stain called 'orange'. Most students struggled with what this word was being used to describe, and indeed for me too the colour it referred to looked much more like purple. The teacher told them though 'please call this orange, if you have another opinion of orange, then don't, please use orange, then we know that you have done the training'. Later she reiterated, 'you have to agree with us, that this is orange - and the other is red purple - so join the club!' Archaeologists must undergo a similar training in colour labelling as part of their professional vision training, as sociologist Charles Goodwin shows. ${ }^{26}$ Archaeologists need to learn a standardised colour language in order to report the findings from their digs, reporting on the exact colour of dirt or other objects they find.

In smell training, novices are given scent kits with little vials of smells, as well as a coloured fan called 'Champ des Odeurs' with multiple coloured squares where each square shows one sensory descriptor. These tools must be carefully maintained, for they are the reference points upon which the new vocabularies are learned. They are designed in a way to be precise and to offer the 'correct' sensory evaluation. This means that, for example, the scent vials need to be stored away from light and in cool conditions. For they do not last forever. The danger is that if the tools are damaged in any way, that a correlation between odour and description become skewed. There is a fear that the shared language might get lost, as without the same reference standard, mutual understanding is not possible. ${ }^{27}$ Taking care of one's tools also means taking care of one's nose. Not inhaling poisons, for example. Caring for the materials of sensory education means looking after objects and things as well as one's body.

Anthropologist Rachel Vaden Allison, who also works on the Making Clinical Sense project with me, describes her own smell training in Amsterdam in a post on our project website.

Throughout the workshop, Sally [another member of our research team] and I both noted the difficulty we had in describing and naming the many scents presented to us. Frustrated by our inability to name and communicate, we noticed that we began to parrot our instructor, using the words he chose, to translate meaning between ourselves. ... [later] we found it better to draw upon our relationship with the smell- to describe the smell through memory or association ... By associating smell and memory, we had a better chance of not only communicating amongst ourselves, but of also remembering the scent of each oil. ... Lastly ... we were presented with three scents derived from the orange

26 Charles Goodwin, 'Professional Vision'.

27 Teil, 'Devenir Expert Aromaticien', 515-16. 
plant. I was sceptical at first as to whether, and how, these would be different. Indeed, they were different, and I was particularly able to detect the differences when recalling memories of my father's orange trees in bloom (neroli), a scent which I had all but forgotten until this workshop-once again illustrating the entanglement of scent and memory. However, I do wonder, without the introduction and naming of the scents, the degree of difference I might have detected on my own. ${ }^{28}$

The reconfiguring of language within these material conditions is important to be able to share words, so that sensory experts (and novices) can communicate with each other. As Teil puts it, through the social and material process of learning new sensory language, a transformation occurs where the novice moves further and further away from being an ordinary sensor. ${ }^{29}$ These new sensory vocabularies, with their structural classification systems, are not natural in any way - they need the novice to concentrate and attend to learning them, in order to discipline their perception. The new sensory vocabularies learned in sensory education help individuals to notice differences between their perceptions in new ways. It also means that they can learn to analyse and describe divergences from the standard set too.

\section{Metaphors}

In medieval Europe, doctors used a device that looked remarkably like a flavour wheel, to decipher the smell and taste of urine. ${ }^{30}$ In an illustrated, practical guide to urine diagnosis within the text Fasciculus medicinae (attributed to Johannes de Ketham and printed in Venice in 1500, although manuscript copies were circulated in the century prior) there are two pages devoted to urinanalysis. One of the illustrations is a wheel with 20 descriptions of the colour and characteristics of the urine samples, as well as little urine flasks. The UK Royal College of Physicians, who recently acquired the book, recount how 'the flasks fall into seven categories according to what they indicate about the patient's health. The central roundel gives the title of the diagram: "this is the method of diagnosing by the colours of urines". ${ }^{31}$ Urinalysis here is implied to be a visual skill, told through colour, something that anyone could learn, for the book was marketed to a broad audience. Sensing urine through smell and taste is a skill which has been practiced for thousands of years amongst healers. Sanskrit text, for

28 Allison, Rachel Vaden, 'Introduction to Parfumery', Making Clinical Sense, 17 May 2019.

29 Teil, 'Devenir Expert Aromaticien', 510.

30 Katie Birkwood, 'The Urine Wheel', Royal College of Physicians, 27 July 2015, https:/l www.rcplondon.ac.uk/news/urine-wheel.

31 Birkwood, 'Urine Wheel'. 
example, from 100BC shows that the taste of urine, particularly its sweetness, was seen as portent of disease. ${ }^{32}$

In medical schools today, students certainly no longer taste the bodily fluids but they may, as I observed, still be taught to smell a urine sample, as a fun way to start a lesson on urinanalysis. Educating a clinical sense of smell when making an initial assessment of patients remains important. Illnesses such as gangrene have their own particular odours, and doctors learn to become sensitive to these. In some medical schools, teachers still do train students to learn about pathological breaths. They use a simple mass produced sweet available in candy stores, the pear drop (Figure 1.7), which provides a perfect simulation for ketotic breath. One student sucks on the sweet and another smells their breath (see Lesson 2 for some other wonderful examples of food used in medical school). In the classroom away from patients, teachers need to find ways to simulate disease signs. The pear drop offers an analogy, a way of offering a sensation that is similar to the original, in an attempt to expand the students' smell vocabulary.

Metaphors are very important part of how medical doctors expand and reconfigure their sensory vocabularies (see also Sarah Maslen's work on this topic) ${ }^{33}$ Like the olfactory experts, learning to see, hear, touch and smell, in particular ways, enables doctors to become part of a community of practice with a shared understanding of terms and reference points. As we have

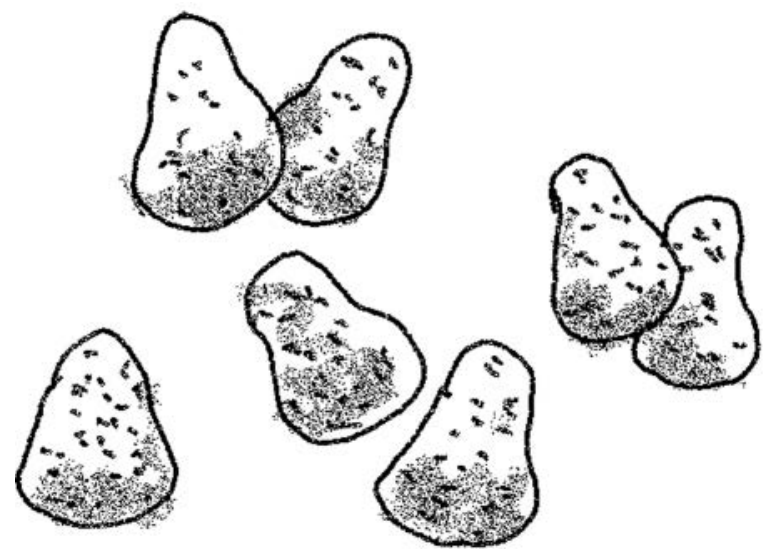

Figure 1.7 Pear drops.

32 J. A. Armstrong, 'Urinalysis in Western Culture: A Brief History', Kidney International 71, no. 5 (2007): $384-87$.

33 Maslen, Sarah, 'Researching the Senses as Knowledge: A Case Study of Learning to Hear Medically', The Senses and Society 10, no. 1 (2015): 52-70. 
already seen, this training means relearning lay and everyday vocabularies. In this section I look at how lay vocabularies remain important though in the creation of metaphors, analogies and similes, which mean that novices in a profession can refer to something they might already be familiar with (as we saw in the case of Rachel's father's orange trees).

Learning to listen to sounds offers some excellent examples of how metaphor is used in sensory education of doctors. The skills of learning to listen to sounds of the body are often learned when students discover the stethoscope for the first time. When medical students learn auscultation they first must begin to distinguish between categories of sounds and then use the specialist vocabulary associated with what they are hearing. They used a workbook in the medical school where I did fieldwork in the Netherlands, to encourage this: 'Describe your findings, try to use medical terminology' it read. Like wine tasting, this was about learning to be articulate, tying words to sensations. Novices were first introduced to these words (in English and Dutch) through whiteboard or smartboard teaching, and then teaching doctors would try to forge links with heard sounds. There were very technical words - like crackles and wheeze - but these often had to be compared to common words that one might understand. One method, in the tutorial room, was to use vocal mimicry, where a teacher would mimic a sound with their own voice - for example, they might inhale very hoarsely to imitate wheeze or make the sounds of a heart murmur.

While there are many different strategies for teaching medical students how to listen, metaphors, specifically simile and analogy, often arose as a solution to the linguistic challenge of articulating sensations. There is a long tradition of using similes and analogies, from the time of the invention of the stethoscope until today, when teaching sounds. René Laennec, the inventor of the stethoscope wrote, for example, of sounds being: 'like a metallic rattling, like a bellows blowing on the fire, like a musical tune containing these notes'. ${ }^{34}$ In fact, he drew analogies between stethoscopic sounds and a wide variety of phenomena from the sound environment, for instance, human and animal voices, natural processes, urban life, hospital practice or music. The STS scholar Jens Lachmund provides a list of examples drawn from the pages of Laennec's treatise:

The voice of Policinelle, the ventriloquist; high voices, silvery voices; trembling voices; the voice of a sheep, a voice transmitted through a metal trumpet; the bleating of a goat; the chirp of small birds; the coo of pigeons; the whistle of the wind in the lock of the door; the steady rustle of the sea; the noise of a coach rolling over the pavement; the tinkle of weapons during military exercises; the jingle of a small valve;

34 Jonathan Sterne, The Audible Past: Cultural Origins of Sound Reproduction (Durham, NC: Duke University Press, 2003), 132. 
the crackle of salt being dissolved in a bowl of warm water; the snoring of a sleeping man; the rattle of the dying; the sound produced by a piece of healthy lung-tissue filled with air, which one presses between one's fingers; the crepitation of a dry bladder which is being inflated; the rumble of a drum; the sound produced when a string of bass is beaten with a finger; the vibration of a metallic string which is rubbed with the tip of a finger. ${ }^{35}$

No matter how scientific Laennec's descendants attempted to be, they also fell back to analogy to describe sounds of the body. Although he made reference to "the duration of certain sounds, their continuousness or otherwise, their apparent nearness to or distance from the ear, ${ }^{36}$ the famous nineteenth-century physician and specialist in cardiothoracic medicine Austin Flint also noted their strong resemblance to other sounds, 'such as the bleating of the goat, the chirping of birds, etc'. ${ }^{37}$ Despite trying to be more systematic than Laennec, Flint concluded that sound could only be described by analogy.

Analogies are incredibly culturally and historically specific and seriously challenge the desire for a standard set of reference points. In many medical school tutorials where students learn to listen to lung sounds, medical sounds are compared to all sorts of familiar sounds in the local everyday soundscape. In the Netherlands inspiratory stridor was likened to the sound of someone being strangled on CSI Miami, the TV crime show. Pleuritic rubs were described as sounding like feet crunching in snow. In Australia though, where snow is not such a universal reference point, other analogies were used. One Professor of Respiratory Medicine in Melbourne commented to me on the ways analogies for lung sounds had also changed over time. For example, he no longer referred to pleural rub as sounding like squeaking leather, as Melbourne trams no longer used leather in their suspension, and thus students did not recognise the sound; however, he was still reluctant to use the more recent likeness of coarse crackles to Velcro. Long present in learning auscultation, analogies of this nature are ways that teachers attempt to bring novices closer to, or make them more conscious of, the sounds they need to learn in the particular local context that they find themselves in.

Learning new words through metaphor is one step, but associating them with sensory experiences is another. Just like in other forms of sensory

35 Jens Lachmund, 'Making Sense of Sound: Auscultation and Lung Sound Codification in Nineteenth-Century French and German Medicine', Science, Technology, \& Human Values 24, no. 4 (1999): 425-26.

36 Austin Flint, A Manual of Percussion and Auscultation (Philadelphia: Henry C. Lea, 1876), 32-33, quoted in Jonathan Sterne, The Audible Past: Cultural Origins of Sound Reproduction (Durham, NC: Duke University Press, 2003), 132.

37 Flint, Percussion and Auscultation, 32-33, quoted in Sterne, Audible Past, 132. 
education explored in this chapter, medical students try to learn how to match sensations to words and types of sounds. Medical students start to learn spatial differences: between right lung and left lung, but also the general kinds of sounds produced by lungs and livers, clavicles and stomachs. They then move on to sensations that are quite obvious or easy to contrast: dull and resonant and so on. As the students move through their education they learn smaller and smaller differences. Like novice perfumers, coffee drinkers and wine tasters, before their teaching, medical students cannot speak of the sounds of the body professionally, 'in a medical way'. In auscultation teaching, they learn to be affected by differences that they didn't have the words to describe before. In other kinds of training, such as the abdominal exam, I witnessed the students literally move from words such as 'liquidy' and 'slushy' to medically appropriate phrases. 'Learning to be affected means exactly that: the more you learn, the more differences exist ${ }^{38}$ Through and with the stethoscope, the medical student body becomes attuned to new sensations.

Metaphors, analogies and similes are used by these teachers in an attempt to bring novices closer to, and become more aware of, these sensations they need to learn. This, I suggest with my historian colleague Melissa van Drie, ${ }^{39}$ can be considered a form of 'sonic alignment', or what historians of science Lorraine Daston and Peter Galison may refer to as a 'collective sensibility' through standardising observing subjects. ${ }^{40}$ This is an intersubjective attempt towards a co-ordination of perception and definition of terms as we have also seen in the coffee, wine and smell kit examples (although in the case of the use of analogy and metaphor, there is a local alignment which is taking place, that defies usefulness as a more standard reference set). Certain kinds of bodies are learned in this medical training process, bodies that take shape through the vocabulary, and a vocabulary that is shaped by the understandings of the body. As the historian Shigehisa Kuriyama shows, however, through his focus on the sensory vocabulary of ancient Greek and Chinese physicians, this could be otherwise. ${ }^{41}$

\section{Knowing differently}

Kuriyama is interested in the divergences between Greek and Chinese medical cultures with regard to how they understood and imagined 'the body'. Kuriyama argues that conceptions of the body owe as much to uses of the senses as to 'ways of thinking'. ${ }^{42}$ In particular, he focuses on the

38 Latour, 'How to Talk About the Body?', 213.

39 Anna Harris and Melissa van Drie, 'Sharing Sound: Teaching, Learning and Researching Sonic Skills', Sound Studies 1, no. 1 (2015): 98-117.

40 Daston, Lorraine and Peter Galison, Objectivity (Brooklyn, NY: Zone, 2010), 63.

41 Kuriyama, Expressiveness of the Body.

42 Kuriyama, Expressiveness of the Body, 12-13. 
sensory ways in which physical examination of patients developed in each field, specifically pulse taking. Central to this learning was a difference in approach to vocabulary, the richness of vocabularies reflecting the perceptive skills of practitioners. He also suggests that differing ways of touching and seeing the body were intricately bound up with different ways of knowing bodies.

Kuriyama focuses on the grammar of the Greek and Chinese doctors' practices of pulse-taking and their sensory vocabularies. For the ancient Chinese doctors, there were four ways to judge a person's condition: gazing (wang), listening and smelling (wen), questioning (wen) and touching (qie). Kuriyama focuses mostly in his book on quiemo, which is palpating the mo (similar to pulse), for this is where he found all the historical resources were concentrated: upon how to interpret haptic signs.

While Kuriyama does not attend as closely to how these vocabularies are learned, he does offer a detailed linguistic and historical analysis of how they were used in these two medical realms. He shows that for the Greek physicians, anatomy 'shaped how and what the fingers felt'. ${ }^{43}$ Their object of study, the body, was formed through feeling and touching, and how the fingers touched was informed by their anatomical understandings of the body, principally through dissection. The Chinese on the other hand, had a much broader sensory vocabulary for $m o$ - they spoke of mos which were full (ying) and empty (xu), quiet (jing) and moving (dong), slippery (hua) and rough (se), floating $(f u)$ or sunken $(c h e n),{ }^{44}$ signs which helped inform of the origin of the patient's disease. Analogies were also used frequently, analogies such as 'like sawing bamboo', 45 'smooth succession of rolling pearls' and 'rain-soaked sand'. ${ }^{46}$ These, the historian suggests, were common in the Chinese 'allegorical style' of description which spoke to the imagination.

The Chinese haptic style, Kuriyama deduces from the images he sourced, demanded intense concentration. The Greek doctors were sceptical of the fanciful, the imaginative nature of the Chinese descriptions. Instead, the Greeks demanded lucidity and clarity. In an address to the Royal College of Physicians, the physician William Heberdeen, declared it 'highly unlikely' that any of the terms used to qualify the pulse 'are perfectly understood or applied by all to the same sensations and have in everyone's mind the same meaning. ${ }^{47}$ The Greek doctors wanted a secure science of the pulse, 'eradicating the betrayals of language. ${ }^{48}$ They were nervous about words, words that might blunt, distort, misrepresent what the fingers felt. We can

43 Kuriyama, Expressiveness of the Body, 32.

44 Kuriyama, Expressiveness of the Body, 48.

45 Kuriyama, Expressiveness of the Body, 50.

46 Kuriyama, Expressiveness of the Body, 72.

47 Kuriyama, Expressiveness of the Body, 69.

48 Kuriyama, Expressiveness of the Body, 70. 
reconsider this concern, and the quest for security, as a search for intersubjectivity through objectivity. It happens in medicine time and again, with the invention of every new instrument from the blood pressure machine to algorithms designed to detect abnormalities on CT and MRI scans. The Chinese doctors on the other hand embraced similes and metaphors in their imaginative style. While Kuriyama laments the loss of these styles of description, in fact the previous section of this chapter showed that they still exist in contemporary practices, and that there is an ongoing adaption in vocabulary training across time and place.

Returning to the central argument of this book, that sensory education shapes and is shaped by our sociomaterial conditions of learning, Kuriyama's conclusion from studying the texts of ancient Greek and Chinese doctors is integral to building this case. He posits that the different medical cultures 'knew the body differently because they felt it differently. The converse also holds, of course. We could also say: they felt it differently because they knew it differently' ${ }^{49}$ The sensory vocabularies that the doctors used where intimately interconnected with what the doctors knew about the body and with their styles of perceiving.

We return to this theme repeatedly in the subsequent chapters of the book. In the case of this chapter, and in the lesson that preceded it, the focus is on vocabulary. As Kuriyama argues, and as we have seen through countless examples so far, language sculpts perceptions and at the same time, what is felt, seen, smelled shapes the words we create. Without the word blue in our vocabulary, the sky is colourless. In fact, a kind of innocence is lost, as the RadioLab presenters point out, once the word blue is learned. Attaching names to colours or even numbers, offers not only a discourse to help individuals make sense of the world but also a language to share this knowledge with others. For styles of speaking are inseparable, Kuriyama reminds us, from styles of listening. We speak in a certain way to be heard in a certain way. Communication is central to how bodies, how the world, was and is known.

As Tei ${ }^{50}$ argues, sociality is not only a characteristic of sensory vocabulary training but also the goal of learning it - that is, the ability to share sensory impressions within a group. This can be disrupted, when analogies and metaphors are used, and has serious limitations, as philosophers and linguists also argue. The chapter has focused on vocabulary training but there is much more involved in sensory education. The next chapter explores how this occurs in institutional contexts, in schools and universities, where sensory education entails curricula, course material and other teaching tools.

49 Kuriyama, Expressiveness of the Body, 55-60.

50 Teil, 'Devenir Expert Aromaticien'. 


\section{Bibliography}

Allison, Rachel Vaden. 'Introduction to Parfumery'. Making Clinical Sense, 17 May 2019. http://www.makingclinicalsense.com/introduction-to-perfumery/ (Accessed 1 January 2020).

Armstrong, John A. 'Urinalysis in Western Culture: A Brief History'. Kidney International 71, no. 5 (2007): 384-87.

Birkwood, Katie. 'The Urine Wheel'. Royal College of Physicians, 27 July 2015. https://www.rcplondon.ac.uk/news/urine-wheel.

Butler, Ella. 'Tasting Off-Flavors: Food Science, Sensory Knowledge and the Consumer Sensorium'. The Senses and Society 13, no. 1 (2018): 75-88.

Croijmans, Ilja, and Asifa Majid. 'Not All Flavor Expertise Is Equal: The Language of Wine and Coffee Experts'. PLoS One 11, no. 6 (2016): e0155845.

Daston, Lorraine, and Peter Galison. Objectivity. Brooklyn, NY: Zone, 2010.

Ducker, John. 'Teaching Wine Tasting'. In Educated Tastes: Food, Drink and Connoisseur Culture, edited by Jeremy Strong, 105-18. Lincoln, London: University of Nebraska Press, 2011.

Ferguson, Mike. 'The Evolution of the Cupping Lab'. Olam Specialty Coffee, 16 May 2017. http://blog.olamspecialtycoffee.com/2017/03/10/olams-new-cup-testingfacility-in-brazil/.

Goldstein, Jenny Elaine. 'The "Coffee Doctors": The Language of Taste and the Rise of Rwanda's Specialty Bean Value'. Food and Foodways 19, no. 1-2 (2011): 135-59.

Goodwin, Charles. 'Professional Vision'. American Anthropologist 96, no. 3 (1994): 606-33.

Harris, Anna, and Melissa van Drie. 'Sharing Sound: Teaching, Learning and Researching Sonic Skills'. Sound Studies 1, no. 1 (2015): 98-117.

Kuriyama, Shigehisa. The Expressiveness of the Body and the Divergence of Greek and Chinese Medicine. Cambridge, MA: The MIT Press, 1999.

Lachmund, Jens. 'Making Sense of Sound: Auscultation and Lung Sound Codification in Nineteenth-Century French and German Medicine'. Science, Technology, \& Human Values 24, no. 4 (1999): 419-50.

Latour, Bruno. 'How to Talk about the Body? The Normative Dimension of Science Studies'. Body \& Society 10, no. 2/3 (2004): 205-29.

Lave, Jean, and Etienne Wenger. Situated Learning: Legitimate Peripheral Participation. Cambridge: Cambridge University Press, 1994.

Majid, Asifa, and Stephen C. Levinson. 'The Senses in Language and Culture'. The Senses and Society 6, no. 1 (2011): 5-18.

Maslen, Sarah. 'Researching the Senses as Knowledge: A Case Study of Learning to Hear Medically'. The Senses and Society 10, no. 1 (2015): 52-70.

Shapin, Steven. 'A Taste of Science: Making the Subjective Objective in the California Wine World'. Social Studies of Science 46, no. 3 (2016): 436-60.

Sterne, Jonathan. The Audible Past: Cultural Origins of Sound Reproduction. Durham, NC: Duke University Press, 2003.

Teil, Geneviève. 'Devenir expert aromaticien: Y a-t-il une place pour le goût dans les goûts alimentaires?'. Sociologie du travail 40, no. 4 (1998): 503-22.

Wenzel Geissler, Paul, and Ruth J. Prince. 'Life Seen: Touch and Vision in the making of Sex in Western Kenya'. Journal of Eastern African Studies 1, no. 1 (2007): $123-49$. 


\section{Lesson 2 How to teach medicine, with food}

Because it is difficult and not always appropriate for medical students to learn some diagnostic skills directly with patients, teachers often need to find imaginative ways to simulate bodies in their lessons. Many medical schools, particularly those with resources to spare, are becoming increasingly interested in highly advanced technologies for this. Some have virtual and augmented reality set-ups, others digital databases of sound recordings and photographs and computerised simulation mannequins, just to name a few. Despite all this sophisticated equipment though, there is one place educators return to time and time again for materials when teaching sensory skills: the kitchen. The following grocery list delves into this culinary art of clinical simulation. The final few examples have instructions to try yourself. ${ }^{1}$

\section{Eggs}

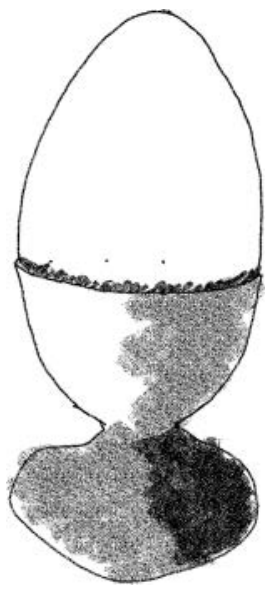

Figure 2.1 Egg in cup.

1 Harris, Anna. 'The Culinary Art of Clinical Simulation', The Gourmand, 12 June 2019, $40-47$. 
With their delicate shells and inner membranes, eggs (Figure 2.1) make the perfect food for neurosurgeons to practice using drill equipment. There are some tricky and complex areas of operation, such as the anatomical areas around the ear. These parts of the body require great precision in surgery, particularly when dissecting through bone and trying not to damage the fragile structures underneath. Surgeons use eggs to practice drilling with new robotic equipment. The equipment is designed to be highly sensitive to the tissues lying just ahead of its current position. Using the drills on eggs enables surgeons to develop their haptic techniques. It also means they can learn how much pressure to apply, and how to trust the sensitivity of the tool. New robotic drills will stop drilling once they have gone through the eggshell, only a few millimetres in thickness, but before they touch the membrane separating the shell from the egg white. This is a level of minute perception that humans alone are not capable of. As the anthropologist Neil Stephens writes when observing surgeons use these tools, ${ }^{2}$ practicing on eggs becomes a way of making the insensible quality of the drill sensible to the practitioners who will use it.

\section{Grapes}

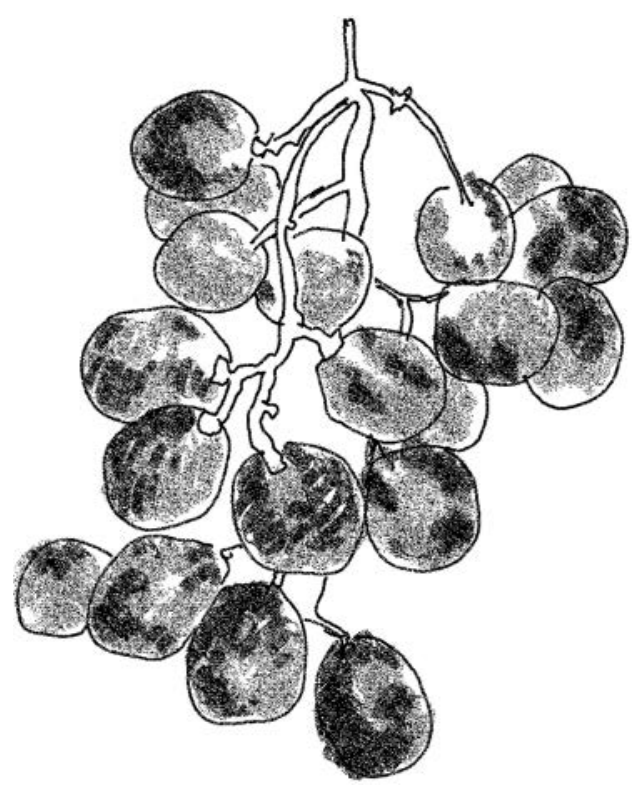

Figure 2.2 Bunch of grapes.

2 Neil Stephens and Jamie Lewis, 'Doing Laboratory Ethnography: Reflections on Method in Scientific Workplaces', Qualitative Research 17, no. 2 (2017): 202-16. 
Some doctors spend years training to become surgeons, including practicing one-handed knots on their bedposts and suturing banana skins. New techniques are now required as more and more robots enter the operating theatre. Manipulating robotic arms during a surgical procedure takes a specific set of finely tuned bodily movements, where surgeons and machine work together. Enter grapes. Their delicate skins mean that they are perfect for practicing on, as well as demonstrating the wonders of robotic surgery. A few years ago, a video made the rounds on the Internet showing how a robot called da Vinci could stitch up a small tear in a grape. It was only at the end of the video that you realised the grape was nestled in the base of a narrow-necked glass jar. No surgeon was visible except for the arms of the robot, meticulously sewing up the cut in the grape with knots of the finest thread. Some scientists are looking at how surgical robots can magnify the fine skills of humans into even finer parts, allowing for more precision that ever before. As millions are spent on developing these technologies, a simple bunch of grapes (Figure 2.2) is all it takes to show how magnificent the surgical robots might be.

\section{Tropical fruits}

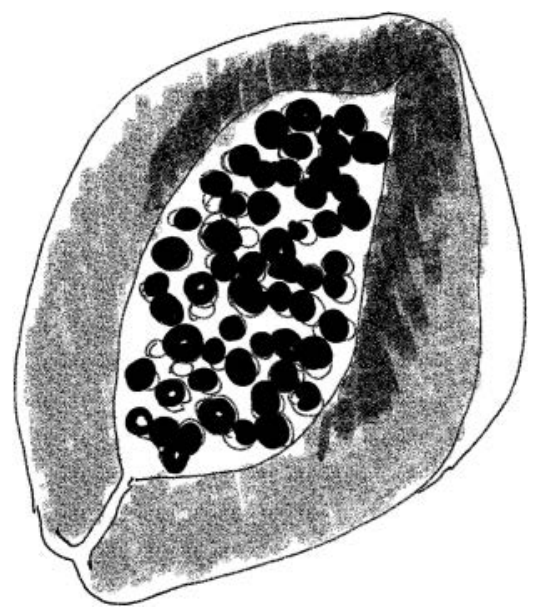

Figure 2.3 Papaya.

Since Hippocrates, fruits have been used to help describe disease - the yellowing of a patient's skin due to jaundice being likened to pomegranate peel, for example. As we saw in Chapter 1, teachers use metaphors to help students remember conditions and many of these are also food related: strawberry tongue for scarlet fever, raspberry tongue means late stage disease. 
When it comes to simulating body parts, pick almost any fruit from your local market and there is probably some body part it can be likened to. Soft ripe papayas (Figure 2.3) can help train gynaecological procedures, where students must learn to manipulate instruments through a small opening, reaching inside for the seed-filled cavity of the uterus. Bananas can be cut away to resemble a toenail resection. Peaches are perfect for resembling the skin of a child, so soft and delicate (though rarely so furry). Pregnancy is stereotypically likened to all of the round fruits, the latest stage usually being the watermelon. It may or may not be of some solace to women in late stage pregnancy, that some doctors also use watermelons to practice inserting epidurals.

\section{Oranges}
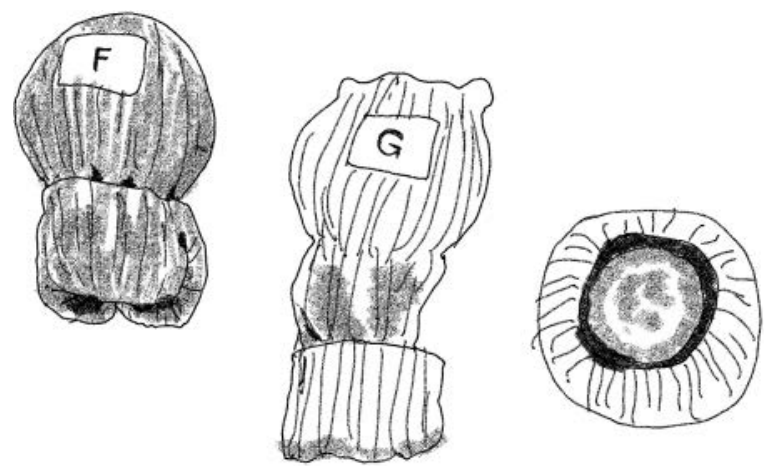

Figure 2.4 Oranges in socks.

Oranges are a particularly versatile fruit to teach doctors with. Their firm pocked rind makes them perfect to practice taking skin biopsies. Their juicy interior means that they are also fantastic replicas of joints for doctors to learn how to give injections. One of the most creative examples I came across of using oranges in medical education is their role in teaching students about delivering babies. Here are some simple instructions (adapted from Shea and Rovera) $)^{3}$ to try in the classroom or at home:

\section{Equipment:}

1 Three or more oranges of roughly the same size

2 Utility knife

3 Kathleen Shea and Edward Rovera, 'Vaginal Examination Simulation Using Citrus Fruit to Simulate Cervical Dilation and Effacement', Cureus 7, no. 9 (2015): e314. 
3 Compass and pen

4 Three or more exercise socks

5 Sticky labels

\section{Instructions:}

1 Draw circles of varying diameters between 1 and $10 \mathrm{~cm}$ onto the oranges using the compass and pen.

2 Carefully cut out the circle of peel with a razor blade or utility knife, keeping the pith intact.

3 Place oranges in sock, with the cut-out circle facing the opening. Roll up the remainder of the sock and leave a cuff (Figure 2.4).

4 Record on a separate piece of paper the diameters of each orange in the socks and place a sticker on each sock with the corresponding code.

5 Ask novices to feel inside the socks with two fingers, using gloves for better simulation, and assess the diameter of the hole inside by feeling the edge of the orange rind.

This technique helps train doctors' sensory memories so they can learn about different cervical dilation sizes - a crucial skill for determining how far a woman is in labour.

\section{Pear drops}

Smell has long been important in clinical diagnosis, with many illnesses leaving traces on the breath or in their urine. The previous chapter explained how in clinical practice doctors do not smell urine samples anymore but in

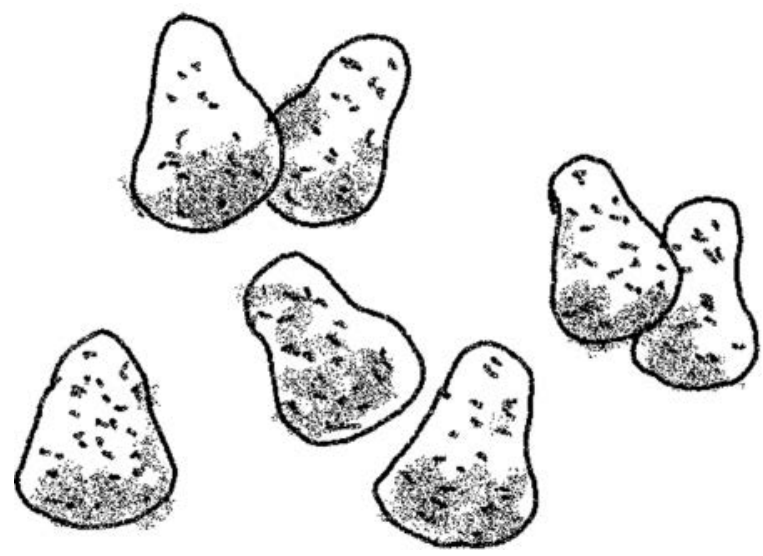

Figure 2.5 Pear drops. 


\section{How to teach medicine, with food}

medical school they are still trained to use their own noses. Take diabetes, for example. When someone's sugars are too high their breath takes on a sweet fruity smell. There is a simple way to simulate this condition, following the instructions below.

Equipment:

1 A bag of pear drops (Figure 2.5), found in most candy stores

\section{Instructions:}

1 Ask a student or friend to suck one pear drop.

2 Wait a minute and then ask someone else to smell the pear drop breath.

3 Repeat.

The odour released by pear drops mimics that of someone whose sugar levels are out of control. Patients' families and friends can be educated to recognise the distinctive pear drop aroma too (also likened to nail polish), so that they can get help for their loved one as soon as possible.

\section{Bibliography}

Harris, Anna. 'The Culinary Art of Clinical Simulation'. The Gourmand, 12 June 2019, 40-47.

Shea, Kathleen, and Edward Rovera. 'Vaginal Examination Simulation Using Citrus Fruit to Simulate Cervical Dilation and Effacement'. Cureus 7, no. 9 (2015): e314.

Stephens, Neil, and Jamie Lewis. 'Doing Laboratory Ethnography: Reflections on Method in Scientific Workplaces'. Qualitative Research 17, no. 2 (2017): 202-16. 


\section{Sensory school}

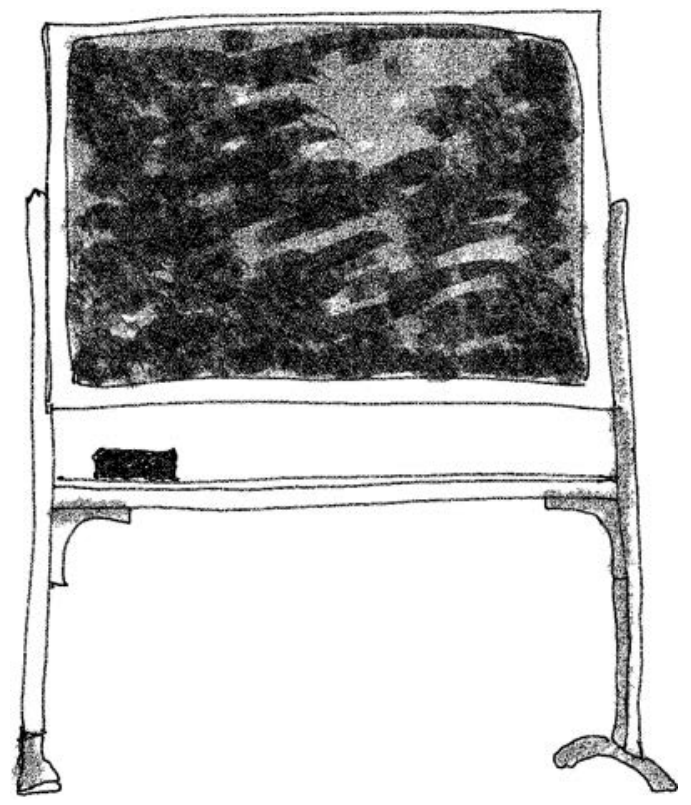

Figure 2.6 Blackboard.

When learning sensory skills, articulating words for a sensation is an extremely difficult task. Similarly challenging is the articulation required in teaching someone how to perform a sensory skill. Both these challenges are acutely highlighted in the act of designing training for novices in a particular field of expertise. The difficulty of teaching lies in finding ways to articulate practice and sensory experience. Conversely, the difficulty of learning skills and 'tuning' sensory knowledge involves embedding this instruction into one's own practice. ${ }^{1}$ This chapter focuses on how this conundrum plays

1 Richard Sennett, Craftsman (London: Penguin Books, 2008), 50. 
out in professional centres of sensory education - universities and institutes. It attends, once again, to the materiality and sociality of sensory education in these sites, where challenges and strategies manifest, for example, in curricula design, pedagogical tools and learning spaces.

The chapter builds upon the last, where I suggested that sensory vocabularies are cultivated through social and material practices, where differences are constructed against reference points, through bodily techniques, metaphors and teaching tools. In this chapter, there is a focus on how material conditions of learning in educational institutions are intimately involved in how sensing is learned and taught (Figure 2.6).

The subject of sensory schooling has interested social scientists from a range of disciplines for some time. Many of these scholars draw on theories introduced at the beginning of the book, such as enskillment and embodiment. Researchers have asked: How are professional habitus formed? How is sensory knowledge acquired? What are the tools that are instrumental to this? How are communities of practice formed around learning shared sensory skills and experiences? How are the skills and expertise of sensory professions reproduced, protected, threatened? What happens when curricula travel to other parts of the world?

Medical school has hosted a number of anthropologists and sociologists interested in such questions and produced some seminal studies exploring the education of sensory skills in institutional settings. An excellent contemporary example is Tom Rice's ${ }^{2}$ study of how London medical students learn to listen to heart sounds. His ethnographic study showed that students found listening practices such as auscultation extremely difficult. Rice recounts students' frustrations concerning first attempts to detect heart murmurs and how, through ongoing practice, they gradually acquire proficiency. In $C T$ Suite, Barry Saunders looks at how radiologists train skills needed to read images, such as CT scans. ${ }^{3}$ Paul Atkinson focuses on the skilled vision of doctors, looking at how pathologists learn to assess slides down a microscope. ${ }^{4}$ Janelle Taylor has looked at the ways in which medical students learn with simulated patients. ${ }^{5}$ More broadly, Sarah Maslen ${ }^{6}$ and

2 Tom Rice, Hearing and the Hospital: Sound, Listening, Knowledge and Experience (Canon Pyon: Sean Kingston Publishing, 2013).

3 Barry F. Saunders, CT Suite: The Work of Diagnosis in the Age of Noninvasive Cutting (Durham, NC, London: Duke University Press, 2008).

4 Paul Atkinson, Medical Talk and Medical Work: The Liturgy of the Clinic (London: SAGE Publications, 1995).

5 Janelle S. Taylor, 'The Demise of the Bumbler and the Crock: From Experience to Accountability in Medical Education and Ethnography', American Anthropologist 116, no. 3 (2014): 1-12.

6 Sarah Maslen, 'Layers of Sense: The Sensory Work of Diagnostic Sensemaking in Digital Health', Digital Health 3 (2017): 1-9; Sarah Maslen, 'Researching the Senses as Knowledge', The Senses and Society 10, no. 1 (2015): 52-70. 
Gili Hammer ${ }^{7}$ have offered excellent analysis of the role of sensory knowledge in medical practice.

In her research, Andrea Wojcik is focusing on how medical students in a Northern Ghanaian medical school learn techniques of touch. Her work develops from other scholars in the field, such as Rachel Prentice, who explores the tactile skills required in anatomy and surgery education, ${ }^{8}$ as well as the more historical work of scholars such as Shigehisa Kuriyama, who studies the vocabularies of touch using the example of pulse taking. ${ }^{9}$ She is also in conversations with scholars such as Claire Wendland, ${ }^{10}$ who point out that most social studies of medical school are conducted in the Global North, predominantly in British and North American locations. Wendland offers the first study of medical education in the Global South, focusing on the development of professional identity among students, whereas Wojcik uniquely tackles the question of sensory education in her careful elucidation of touch and its role in the training of doctors in Northern Ghana. Other examples of attention to the sensory training of doctors outside of the British and North American contexts can also be found in the work of Vania Smith-Oka and Megan Marshalla ${ }^{11}$ and Gavin Steingo, ${ }^{12}$ this literature highlighting how skilful practice in medicine is always cultivated within broader historical, cultural and political economies that are bound with class, race and gender, resulting in different power dynamics and vulnerabilities. ${ }^{13}$

In her research, Rachel Allison is exploring how medical students are trained to know the body through drawing, models and dissection in a medical school in Budapest, all of these materials shaping new kinds of sensory orientation and perception. Again, Central (and Eastern) Europe is another overlooked site of study in the social study of medical education, and is offering unique insights into what is often described as a 'traditional' site of training, where students are taught in ancient lecture theatres, through dissection and blackboard lectures taught by professors in white lab coats.

7 Gili Hammer, "You Can Learn Merely by Listening to the Way a Patient Walks through the Door": The Transmission of Sensory Medical Knowledge', Medical Anthropology Quarterly 32, no. 1 (2018): 138-54.

8 Rachel Prentice, Bodies in Formation: An Ethnography of Anatomy and Surgery Education (Durham, NC: Duke University Press, 2013).

9 Shigehisa Kuriyama, The Expressiveness of the Body and the Divergence of Greek and Chinese Medicine (Cambridge, MA: The MIT Press, 1999).

10 Claire Wendland, A Heart for the Work: Journeys Through an African Medical School (Chicago, IL: University of Chicago Press, 2010).

11 Vania Smith-Oka and Megan Marshalla, 'Crossing Bodily, Social, and Intimate Boundaries: How Class, Ethnic, and Gender differences are Reproduced in Medical Training in Mexico', American Anthropologist 121, no. 1 (2019): 113-25.

12 Gavin Steingo, 'Listening as Life: Sounding Fetal Personhood in South Africa', Sound Studies 5, no. 2 (2019): 155-74.

13 Smith-Oka and Marshalla, 'Crossing Bodily, Social, and Intimate Boundaries'. 
Together, Andrea, Rachel and I, in collaboration with the historian John Nott, are using medical schools as a place to help us describe, analyse, rethink and redesign the material conditions of learning sensory bodily skills. In our collaborative and comparative research project called Making Clinical Sense, we work from the premise that by attending to the everyday material practices of training doctors over place and time, we will gather insights into how the way people learn connects with what they learn.

Medical school certainly offers compelling cases of sensory education. It is a site that this chapter focuses on heavily; however, there are many other examples that could have been discussed. Other sensory professions that have already been introduced in this book such as wine tasters, perfumers and coffee makers. I could also list hundreds of more professions where there is some element of sensory training in their professional degree. Doctors for example are just one kind of body worker, healthcare alone a place where nurses, physiotherapists, acupuncturists and massage therapists undergo sensory trainings in tactility and other sensations. Archaeologists 'learn to see' in their first digs as students, using Munsell colour charts and other sensory aids at new vocabulary. ${ }^{14}$ Astronauts train their movements underwater ${ }^{15}$ while dancers' undergo a rigorous education in movement in dancing school. ${ }^{16}$ This chapter accounts for only some of these professions, focusing, as mentioned, on medical education, with the hope that insights from this extend out beyond to other examples.

These insights can be summarised as follows. First, sensory education in institutions requires explicit 'set-ups'; arrangements which facilitate the sensory lesson. This may be as simple as a bag of pear drops or elaborate as a computer simulation laboratory with one-way glass. In his work on wine tasting Bruno Latour ${ }^{17}$ has referred to the 'artificial set-up' of the wine tasting kit and its use, a set-up that helps novices develop 'a nose' through gradually noticing finer differences in smell that are arranged in little vials. This chapter expands Latour's (and consequently Teil's) ${ }^{18}$ work further, by looking at the invisible labour involved in the set-up. Working from the basis of the set-up, which often involves the use of reference sets and objectivity machines (Chapter 1), this chapter then looks at how novices' sensations are calibrated in sensory school. There is a focus in particular on tools of calibration, and how these are used in different contexts. Finally, the chapter

14 Charles Goodwin, 'Professional Vision', American Anthropologist 96, no. 3 (1994): 606-33.

15 Martin Grunwald, Homo Hapticus: Warum Wir Ohne Tastsinn Nicht Leben Koennen (Muenchen: Droemer Verlag, 2017), 136.

16 Tomie Hahn, Sensational Knowledge: Embodying Culture through Japanese Dance (Middletown, CT: Wesleyan University Press, 2007).

17 Bruno Latour, 'How to Talk About the Body? The Normative Dimension of Science Studies', Body \& Society 10, no. 2/3 (2004): 205-29.

18 Geneviève Teil, 'Devenir Expert Aromaticien: Y a-T-Il Une Place Pour Le Goût Dans Les Goûts Alimentaires?', Sociologie du travail 40, no. 4 (1998): 503-22. 
explores the theme of creativity and improvisation, qualities often seen as something to be emphasised in students, yet which are commonly ignored in teachers. The chapter makes the argument that teaching sensory skills requires skills in improvising beyond the set-up, and that future curricula design would benefit from allowing more room for making, tinkering and other creative processes when teaching sensory skills.

This chapter builds not only from the last chapter, the literature mentioned above and extensive fieldwork in medical schools, but also from my previous work with the historian Melissa van Drie, ${ }^{19}$ as part of Karin Bijsterveld's Sonic Skills project, ${ }^{20}$ in which I explored three aspects of learning sensory skill of listening in medical school: demonstration; repetition and mimicry; and finally, rhythm and improvisation. These are not, we suggested, discrete 'stages' of a delineated process, but are ways of skills teaching and learning that build upon, and continually refer back to, one another. As van Drie and I argued, no one strategy leads to the enskillment of novices in listening but rather through the co-ordination of practices of learning and teaching there is an attempt for 'sonic alignment'. ${ }^{21}$ While incorporating these insights Melissa and I developed together, this chapter expands upon them further by extending into new sensory settings. It also explores the notion of 'the set-up' further by looking closely at calibration tools and thinking further about the role of curricula design in this process.

\section{Set-ups}

For every lesson in the Skills Lab in Maastricht, where I have been doing fieldwork, following how medical students in the Netherlands learn the sensory skills of diagnosis, there is always a set-up: a particular arrangement of teaching tools, such as models, clinical instruments, workbooks and other necessary objects for the lesson. All of these things are placed on a central tutorial table in the middle of the classroom. The set-up extends further. Every tutorial room in the Skills Lab has roughly the same layout. There are five examination tables, upon which thin paper is rolled. There are cupboards stacked to the ceiling with models. As John Nott exclaimed, when opening the doors to these cupboards, inside these cupboards it smells like an old toy store. There is always a sink in every room, with hand disinfectant, nail clippers for cutting nails, paper towelling and cups for water. There are privacy curtains in the corner, a smartboard on the wall, blinds to block out the light. Every room the same.

19 Anna Harris and Melissa van Drie, 'Sharing Sound: Teaching, Learning and Researching Sonic Skills', Sound Studies 1, no. 1 (2015): 98-117.

20 Karin Bijsterveld, Sonic Skills: Listening for Knowledge in Science, Medicine and Engineering (1920s-present) (London: Palgrave Macmillan, 2019).

21 Harris and van Drie, 'Sharing Sound'. 
Before every lesson, the teaching tools are arranged. There is a special work folder that shows how this should be done, including black and white photographs and lists of equipment, and where the equipment can be found. The Skills Lab secretaries make this set-up, and if they have worked there long enough, no longer refer to the photographs and workbooks but know the set-up by heart. Occasionally a teacher will come in and modify the set-up somehow - add a favourite instrument for example or place a model on the table (Figure 2.7) - to introduce when they explain a technique. The secretaries set the lesson up very early in the morning or the day before if possible.

The work of the set-up goes back further than just prior to the lesson, however. Every summer, some of the secretaries in Maastricht lay all of the teaching tools on a table and see what needs repairing. Some models, such as the gynaecology mannequins made of leather, become hard and cracked, and these need massaging with leather conditioner. Others are brittle, or develop fissures through repeated use, and require hand-stitching with pieces of shammy cloth and left-over teaching supplies like discontinued surgical thread. There is an extraordinary amount of care put into the set-up, the kind of care that Teil described as necessary to keep a reference set intact, in order to attend to the sensory goals of the lesson. ${ }^{22}$

Set-ups seem similar to what a chef might call a mise-en-place: $:^{23}$ a particular arrangement of tools and instruments that mean chefs can cook

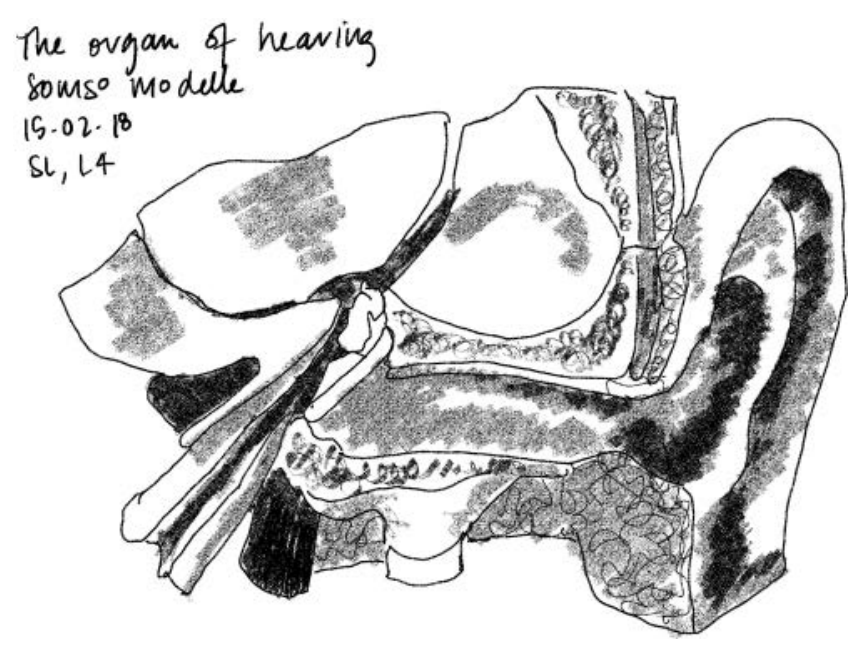

Figure 2.7 Ear model, Skills Lab (Maastricht).

22 Teil, 'Devenir Expert Aromaticien'.

23 Claudia Schlegel et al., 'Mise-En-place: Learning Across Disciplines'. International Journal of Gastronomy and Food Science 16, (July 2019). 
dishes and have what they need to hand. The surgeon and educator Roger Kneebone describes the similarities between a chef's mise-en-place and the set-ups of surgeons. Pedagogical set-ups serve a different purpose; however, the set-up is a way in which not only to have the right tools to hand but also to demonstrate sensory knowledge to novices, often in a desirable sequence. The set-up is arranged in a way that lends order to the lesson, so that learning techniques can be layered and certain aspects of sensations to be learned highlighted.

In fields such as science and technology studies and the history of science, demonstration is generally taken to mean the empirical demonstration of scientific fact, in many ways a very performative and theatrical set-up in order to offer scientific proof or evidence. ${ }^{24}$ In the case of sensory education, I consider demonstration as showing a technique to a novice, as part of the set-up. While in many ways demonstrations are about proving that there is something to sense, demonstration also involves highlighting a phenomenon or situation that enables the novice to get 'a feel' for the skill and sensations. Through this form of showing, the skilled practitioner can point out features of the environment, which the novice might otherwise fail to notice. Showing something to someone is about making it present for direct apprehension.

This is demonstrated beautifully in a lecture given by the famous cardiologist William Harvey, in the 1960s that van Drie writes about in her own work. ${ }^{25}$ While we do not know much about the invisible work and labour that went into assisting this teaching, we do know that Harvey used recordings of symphony orchestras to introduce students to the principles and techniques of aural identification and sound classification. Students were guided through repeated listening of the recording, much like a Schaferian 'ear cleaning' exercise, as set-up designed to help them learn to isolate a particular instrument from the more general orchestral background, before turning to similar analysis and descriptions of heart sounds. ${ }^{26}$ The premise is that before one can even begin to distinguish between 'normal' and 'abnormal' sounds one needs to be attentive to the sounds in that situation. When the novice first listens through a stethoscope, the amplification properties of the instrument reveal the polyphony of the body's sounds. The task of learning is to identify and analyse how specific sounds standout. As a student continues to learn the technique, they begin to recognise the qualities of a particular sound.

The lecture set-ups that Rachel observed in Budapest, and that I also had the chance to witness, were extraordinarily elaborate. It was the job

24 Steven Shapin and Simon Schaffer, Leviathan and the Air-Pump: Hobbes, Boyle, and the Experimental Life (Princeton, NJ: Princeton University Press, 1985).

25 Melissa van Drie, 'Training the Auscultative Ear: Medical Textbooks and Teaching Tapes (1950-2010)', The Senses and Society 8, no. 2 (2013): 165-91.

26 Van Drie, 'Training the Auscultative Ear', 166. 
of several technicians, all in white coats (theirs having short sleeves), to set the stage for the blackboard performance of the anatomy educator to come. This involved visiting the storeroom of the anatomy school and retrieving a selection of hand-painted posters that correlated to the anatomical region or theme to be explored in the lesson. The technicians would take these posters to the side of the blackboard and lower hooks upon which the posters were placed, and then hoisted up again for full display alongside the blackboard. At times there could be four, five, six posters decorating the walls. But these posters were not mere decoration. They were part of the lesson, creating an atmosphere of learning, reiterating the need for and the craft of drawing anatomy, as well as offering different perspectives to the teacher to use in their teaching.

Lectures continue to have an important role in medical education. However, most medical schools have now moved towards smaller group learning in the form of tutorials. In teaching sensory skills, tutors must be creative and resourceful, ${ }^{27}$ using the set-up that has been created for and with them, as well as their own skills and clinical experiences. In Maastricht and Tamale, for example, teachers used materials such as skeletons and models not only for showing anatomical landmarks, but also to demonstrate techniques such as auscultation. Double stethoscopes stored in the cupboards were used by two teachers in Maastricht so that they could tap out the sounds with the students as they listened simultaneously, correlating what they heard. PowerPoint and the smart board were used to show pictures, sounds and videos during a lesson. The teachers also brought in their own media too. They brought in CD and cassette players and accessed their favourite online sites such as repositories with recorded sounds. The teacher who used the cassette player had selected ten lung sounds to play to the students and he pointed out features of these sounds as he skipped through them. A teacher who used PowerPoint also had selected sounds from online to play: a pleural rub, played next to a sound of someone stepping through snow.

Sometimes the materials were not enough, and teachers used their own bodies to highlight an aspect of the lesson they were teaching. For example, in the gynaecology examination classes, teachers used their hands throughout the lessons. They demonstrated techniques such as bimanual examination, or how to use a speculum, as well as how to simulate different parts of the body that the students were examining. Fingers were fluttered as fimbria reaching out to ovaries, for example, demonstrating the anatomical structure of the female reproductive system. On another occasion a teacher scrunched her hands into a fist, making sure that there was only a small opening. This was to show the students what a cervix might look like. The teacher then gave a student a small brush that would be used in a papsmear

27 Tom Rice, "The Hallmark of a Doctor": The Stethoscope and the Making of Medical Identity', Journal of Material Culture 15, no. 3 (2010): 43. 
examination and showed the student how to rotate the brush in the small opening in her fist. Interestingly, some of the brushes used were no longer part of clinical practice. The teacher acknowledged the historicity of these artefacts, telling the students they needed to learn not only about the instruments currently used, but also those that were used in the past, so that they could feel the difference. It was not the first time I saw historical objects in use - in the obstetrics examination, students also used a monaural stethoscope, a wooden one which looks remarkably similar to that designed by Laennec. ${ }^{28}$ This 'ancient' stethoscope, the students in the Netherlands learned, is still used in some places in the world as a fetoscope. Indeed, the fetoscope has a lively and contemporary life in many maternal health settings, such as South Africa, as explored by Gavin Steingo. ${ }^{29}$

In a blogpost for the Making Clinical Sense project, Andrea Wojcik has also written about how in Ghana, teachers found the skeletons limiting in their movement for teaching some skills, such as knee examination, and used their own bodies instead. Andrea writes:

As the students worked their way from the neck and shoulder down to the knee and ankle learning to examine the musculoskeletal system, instructors pulled out anatomical models as teachers' aids, but the instructors relied on the models for much more than anatomical recall. They used them to help students better understand how to conduct a physical examination, that is how to "look, feel and move" so as to elicit musculoskeletal maladies. ... At times, however, even the models were too limited in their movement, and instructors would default back to the body, but not necessarily to the part of the body under scrutiny. For example, before going through the protocol for examining the knee, an instructor used a model of the knee to zoom in on two ligaments nestled in the hollow between the femur and the tibia.... After a few attempts, the instructor put the model down, made fists, and placed them against each other with one forearm running towards the floor and the other towards the ceiling, creating a model of the knee using hands and forearms. This model was easily able to demonstrate the abnormal movement of a dislocated tibia resulting from torn ligaments in the knee. ${ }^{30}$

In all of the cases, the purpose of demonstration and these set-ups is to guide the students in the art of noticing, to help them to learn how to see. ${ }^{31}$

28 Anna Harris and Tom Rice (forthcoming) Stethoscope. London: Reaktion.

29 Steingo, 'Listening as Life'

30 Andrea Wojcik, 'Modelling Movement in Medical Education', Making Clinical Sense: A Comparative Study of How Doctors Learn in Digital Times, May 16, 2017, http://www.makingclinicalsense.com/639/.

31 Anna Lowenhaupt Tsing, The Mushroom at the End of the World: On the Possibility of Life in Capitalist Ruins (Princeton, NJ and Oxford: Princeton University Press, 2015). 


\section{Sensory school}

Seeing here is not only visual, but a full sensory experience. Lessons are designed so that novices get a feel for something, through their teacher pointing out features of a sensation or skill they might otherwise have failed to notice. For Ingold the process of demonstration, as seen in these set-ups, is a very creative process:

We learn by doing, in the course of carrying out the tasks of life. In this the contribution of our teachers is not literally to pass on their knowledge, in the form of a ready-made system of concepts and categories with which to give form to the supposedly inchoate material of sensory experience, but rather to establish the contexts or situations in which we can discover for ourselves much of what they already know, and also perhaps much that they do not. In a word, we grow into knowledge rather than having it handed down to us. This is what Jean Lave (1990) means when she says that learning is a matter of understanding in practice, rather than acquiring culture. ${ }^{32}$

However, as I go on to examine in the next section, the lesson set-up is not only a way to guide the student through sensory discovery but also a way to calibrate the students - with each other, with the instrument, and with a standard.

\section{Calibration}

Calibration has a number of different dictionary meanings. One is adjustment to take into account external factors in the comparison of data. Another is the correlation of a reading of an instrument with a standard. ${ }^{33}$ The kind of calibration practices that take place in sensory schools encompasses both meanings of the term.

The first dictionary meaning, which is about calibrating to consider external factors, is seen vividly in the case of wine tasting training and here I want to turn to an example from food science briefly, where practices of calibration are brought to the fore in interesting ways which add insights into the medical education case. In his work on wine tasting, also in twentieth-century California, Shapin's colleague Christopher Phillips focuses on another aspect of sensory vocabulary sharing which is how sensory judgements in wine tasting could be aggregated and analysed statistically. In order to study wine tasting description as a phenomenon, Phillips describes the lengths that Amerine (see Chapter 1) went to try and create a 'context-free' setting for evaluation practice. The wine-taster goes into a

32 Tim Ingold, Making: Anthropology, Archaeology, Art and Architecture (London: Routledge, 2013), 13.

33 Oxford Dictionary of English, Calibrate (Oxford: Oxford University Press, 2010). 
booth fitting only one person with walls 'tall enough to block out anything else when its occupant looked forward'. ${ }^{34}$

The tests the sensory evaluators had to perform included identifying whether one sample was more intense than another, tasting a reference sample and finding the wine that best matched it, and then distinguishing difference between three wines (two of which were the same) and this is where sensory education by design comes in. The purpose of these tests, conducted in the 'context-free' environment, was not to assess the wine quality, but rather to train the judge's competence in evaluation. The tests were a way of calibrating the testers, to see whether they could reliably make distinctions. Small changes could be made to the wines, and then the evaluators tested again, to see if they could recognise these differences. ${ }^{35}$ The goal was to make the tasters as similar as possible. The researchers realised they could not eliminate for subjective difference so they calibrated the tasters' judgements against each other - the wine tasters became calibrated to themselves as instruments of measurement.

In the expert wine tasting example, experts are being trained to calibrate against each other in order to take into account external factors, whereas in other sensory school settings a different kind of calibration also takes place, attending to the second dictionary meaning of the term which implies the correlation of an instrument to a standard. I have already shown how reference sets such as wine wheels, aroma kits and flavour charts help to calibrate learning sensory vocabulary. In food science classes, students witness a lot of cooking demonstrations and from the very beginning are engaged in tasting exercises, designed so that they can learn to distinguish five basic tastes (sweet, sour, bitter, salty, umami) - the reference set that is calibrated to. ${ }^{36}$ In Chapter $1 \mathrm{I}$ also described how coffee growers and tasters in Rwanda also 'need' to have their tasting calibrated, often to reference sets that are very unfamiliar. In perfumery, students also calibrate to standardised protocols and through shared practices. ${ }^{37}$ The protocols used in teaching - how to smell, what to smell, etc. - create the standard. This means that individual differences can be controlled and comparisons made. Ultimately, olfactory students are learning to reproduce a classification system that is constructed by the teacher, where all scents have a particular relation to each other only allowing for descriptions that refer to a standard set and number of scents.

34 Christopher J Phillips, 'The Taste Machine: Sense, Subjectivity, and Statistics in the California Wine World', Social Studies of Science 46, no. 3 (2016): 462.

35 Phillips, 'Taste Machine'.

36 Amy Trubek and Maria Carabello, 'Teaching to Cook and Learning to Sense in Food Education', in Making Taste Public: Ethnographies of Food and the Senses, ed. Carole Counihan and Susanne Højlund (London: Bloomsbury Academic, 2018).

37 Teil, 'Devenir Expert Aromaticien'. 
In medical schools, reference sets can also be commonly found - some examples might include learning goals, textbook examples or online libraries of pathological sounds (see Bijsterveld ${ }^{38}$ and Bruyninckx ${ }^{39}$ for further examples of reference sets used in sensory calibration). One of the questions that often arose during my fieldwork in the Netherlands, was whether the technique the students were learning was a Dutch one or from 'somewhere else'. The students needed to learn the 'Dutch' method, which meant a method taught by the (almost exclusively) Dutch teachers (whom were all also clinical practitioners). This was also the method by which they had deemed would be the standard in the teaching resources, and most importantly, the assessment exam. Students were taught to learn the Dutch standard, and if the student travelled elsewhere to practice, they could always improvise later upon this. The communication scholar Ivana Guarassi studies this phenomena in the training of students in a clinical simulation laboratory, where she describes the education as one of training to the standard of assessment. ${ }^{40}$

Pedagogical tools in medical school also facilitate calibration to the sensory experience of others, through the creation of a shared sensing experience. Previously I mentioned the double-headed stethoscope, which meant that teacher and novice could 'listen together'. Learning auscultation is a form of bodily learning. Students may be instructed to nod with or tap the rhythm of the heart sound while listening through the double-headed stethoscope with their teacher, as well as draw the heart sounds and other forms of bodily mimicry. These are all ways to calibrate or align sensations. Tom Rice ${ }^{41}$ is also interested in how medical students 'learn together' and points out that it is difficult for students to establish common points of reference for what they are hearing.

In the fields of haematology and pathology, novice haematologists need to 'learn to see' pathological slides and become socialised into ways of looking, learning the vocabulary at the same time for ways to describe what they see. ${ }^{42}$ Instruments such as the two-headed microscope working in a very similar way to the double-headed stethoscope, are essential for this task. When working with such a stethoscope, the novice and the expert sit opposite each other, and the novice gradually learns to see the same thing as the teacher, including what words are associated with their visual impressions.

38 Bijsterveld, Sonic Skills.

39 Joeri Bruyninckx, 'Trading Twitter: Amateur Recorders and Economies of Scientific Exchange at the Cornell Library of Natural Sounds', Social Studies of Science 45, no. 3 (2015): 344-70.

40 Ivana Guarrasi, The Standard in the Body: An Ethnographic Reading of Standardized Patient Laboratory Simulations, Doctoral diss., University of California at San Diego (San Diego, 2017).

41 Rice, Hearing and the Hospital.

42 Paul Atkinson, Medical Talk and Medical Work: The Liturgy of the Clinic (London: SAGE Publications, 1995). 
In Maastricht I once used one of these microscopes with students that had three heads. We each looked on as one student tried to create a 'field of view'. The teacher showed us how to use a little arrow, so that we could speak to the same object in our descriptions. In Budapest, Rachel Allison watched students use digital microscopes, which achieved a similar kind of looking together. As the sociologist Paul Atkinson ${ }^{43}$ argues, this 'learning to see' pathological slides is a process of socialisation into ways of looking. The vocabularies of description and the tools of calibration are essential parts of the process, to the material conditions of learning.

Another commonly used tool in medical schools is the mannequin or model. Having an extensive history in medical education, models attempt to mimic the patient body and there has been a long running quest for fidelity in their manufacture, so that trainees can get as close as possible 'to the real thing'. For centuries model makers have experimented with fabrics, textures, bodily fluids and functionality. While they are used for many different reasons, such as cost-efficiency and safety, a strong case for their purchase is that all students can learn from the same model, and this might allow for some standardisation, and thus, calibration. Just as students learn to calibrate to the assessment requirements, they also learn to calibrate to the model, in some cases, this becoming quite an odd standard to be working with.

These models are potentially incredibly dehumanising. They also often perpetuate a Western white, often male body, regardless of the setting of medical education. Andrea Wojcik and John Nott's work goes deeper into these contradictions and forms of knowledge production in such cases. In my own observations I saw many attempts at calibrating to the models. One instance stands out in particular. It was an obstetrics class and students were learning how to measure the gestational age of the foetus. They were learning how to use their hands and to use measuring tapes, taking the pubic bone of the woman as a starting reference point, and then measuring 'upwards' so to speak. In a real woman, the pubic bone is very prominent and easy to feel. In the model, however, the bone was made of quite a soft material, whereas the inner structure of the model, made of harder material, was more pronounced in the pubic region. Thus, students continually used the hard structural detail of the model as their starting point, rather than the artificially made pubic bone. They were calibrating to the model.

As well as calibrating to tools, medical students also learn to calibrate to their own bodies. I saw that their own body was an ever-present source of learning and repetitive practice as they listened to themselves and tapped out organs. They only had to tap on their thighs to learn what a dull note was for example. As one teacher in Melbourne said, 'You always have yourself as a gold standard, use this! Excuse yourself to the toilet if you have to, tap away and remember that sensation'. I observed many instances of 
self-percussion during my fieldwork researching how listening to sounds is learned, taught and practiced. The students were sounding out their own bodies; practicing the technique while also feeling 'dull' or 'resonant' on their own body. This knowledge was then to be applied during their examination of patients, where dullness or resonance in the 'wrong' place or in uneven distribution, may indicate disease.

These examples across medical schools show that calibration is occurring in many different ways and forms - to reference sets, to teachers, to each other, and to the medical students' own bodies. In each case the standard or the reference shifts, and there is no universal basis to build upon, as many professional bodies wish. The standard is a moving target. Not only does the standard set-up take a lot of invisible labour, but the tools of calibration too, requiring care and expertise, maintenance and repair. Set-ups and calibration tools are used in sensory schools in many different domains and much attention is often given to them by curricular designers. Where less attention is paid, however, is in the creativity of teachers in working with these arrangements.

\section{Creativity and improvisation}

So far, this chapter has focused on standardised set-ups and different forms of calibration which are used in the sensory education of doctors as well as other professions such as wine tasting and perfumery. All these arrangements might seem rather stifling and constrictive. The conformity raises questions. Do these set-ups and calibration tools work so smoothly in practice? How does this account for the individuality and the creativity of teachers?

In the last section of this chapter I want to explore precisely this, what I believe is a neglected aspect of sensory education and education more broadly, which is the creativity and improvisation entailed in teaching students skills that are incredibly difficult to articulate. The literature on enskillment largely focuses on the role of improvisation in learning. As outlined in the introduction, enskillment means building a library of sensory knowledge and trying to master techniques. Enskillment also entails how to improvise creatively when encountering the new or unknown. Improvising is the act of developing one's own rhythm and ways of manoeuvring professionally in the world. Ingold discusses this as a 'continual sensory attunement of the practitioner's movements to the inherent rhythmicity of those components of the environment with which he or she is engaged' ${ }^{44}$ The novice seeks through repeated trials to achieve the kinds of rhythmic adjustments of perception and action at the heart of fluency. In this book I focus, in particular, on how materials, as well as bodies, are used in improvisatory ways, in this case in teaching rather than learning, particularly the sensory skills of diagnosis in medical school. 
I gave a taste of this kind of creativity and improvisation in Lesson 2, prior to this chapter, which detailed the wonderfully varied ways in which food is used in clinical teaching, from grapes for surgical techniques to oranges for childbirth. The teaching of obstetrics and gynaecology lends itself to all kinds of improvisatory teaching practices. This is because medical students are not often involved in actual deliveries, and also because of the centuries of creative ideas put into how to develop simulations to teach techniques in the field of midwifery and new parent education.

A particularly creative example I saw in my own fieldwork was the use of gloves when teaching the techniques of delivering a baby. One pair of gloves was filled with a lot of water, another with less (Figure 2.8). These were laid on the table next to another handmade teaching model: a knitted uterus covering a plastic baby doll. The teaching exercise proceeded as follows. The teacher pulled the baby's head out of the cuff of the knitting, to show how the cervix widened for birth. She then inserted the glove filled with a lot of water over the baby's head and within the knitting. A medical student was asked to feel the glove and was told that this is what it felt like if the membranes hadn't yet ruptured. The same exercise was repeated with the glove with less water, showing what it felt like if the membranes had ruptured, but were still intact over the cervix.

In the course of conducting oral histories for the Making Clinical Sense project, John and I talked with a charismatic medical teacher from Maastricht who spent a lot of time in medical schools around the world, both 'spreading the word' about the Maastricht model of education in the form of Skills Labs and problem-based learning, but also finding creative ways to share the resources she had at her disposal. For she also had a mission
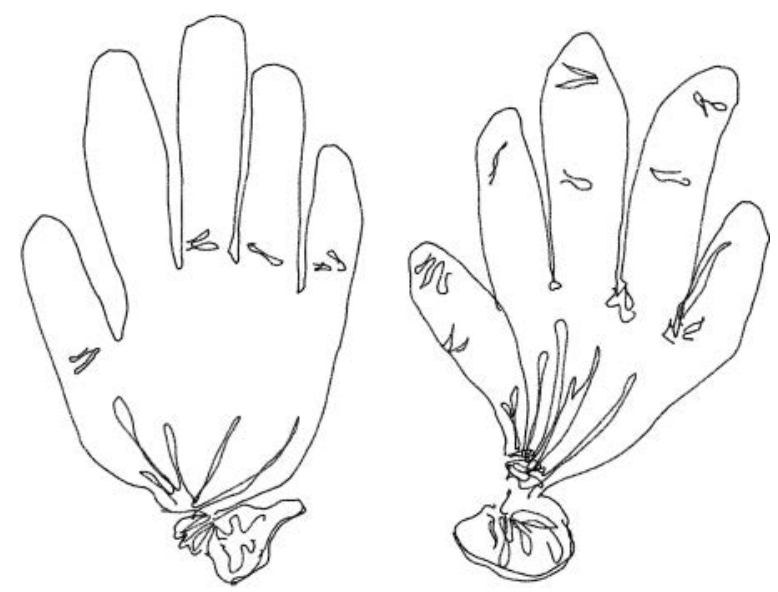

Figure 2.8 Gloves containing water. 
to try and help medical schools avoid unnecessary costs and buying expensive models, trying to facilitate conditions for the creativity and ingenuity that she encountered around the world with regard to model creations. She shared with us examples in her PowerPoint presentations, of homemade birthing suits made of old clothes and electronic simulations made from leftover electrical parts.

In these creative practices, the teachers are improvising with materials that come to hand. The set-up is tinkered with, adapted with attention to how the materials can simulate the body, and movements and sensations can be learned. These are practices which extend the photocopied pictures of how to lay out a room, or the designated materials to be included in a task. They go beyond calibration and notional reference points and allow room for experimentation. They allow for closer attention to the locality of medical training and the expertise of local trainers. When I presented on this topic during a medical education conference the question time was filled with examples from all around the world, of ways in which teachers creatively improvise with materials in their lessons.

The intense effort in instructional design in medical education has the potential to overlook these more mundane and yet incredibly rich practices of everyday design. Everyday design in medical schools is tinkering work involving adaption or making in creative acts of repurpose. Hardly a new practice in medicine - tinkerers and makers have often radically transformed the field with their inventions - these are skills, however, that can be lost as medical education strives for efficiency, standardisation, transparency and objectivity. These are also qualities which are seriously questioned by the challenges entailed in teaching sensory skills to students.

Improvisation, creativity, care, maintenance - these are all aspects of teaching which are often neglected in studies of education. As I have tried to show in this chapter, learning and teaching sensory skills in sensory schools is done through set-ups and calibration. Yet too often the focus of practitioners, and also social scientists analysing their practice, is on how the setups create conditions of standardisation and universality and objectivity. This overlooks the work that goes into the set-up - the care and maintenance and design. It also limits the space for creativity. In fact, sensory education only works through such set-ups because of the creativity involved in improvisation with materials. In the next Lesson, I offer a small celebration of everyday design and the craftsmanship of training healthcare professionals, by imploding ${ }^{45}$ an object I call the 'knitted uterus', which celebrates a playful attention to materials.

45 Joseph Dumit, 'Writing the Implosion: Teaching the World One Thing at a Time', Cultural Anthropology 29, no. 2 (2014): 344-62. 


\section{Bibliography}

Atkinson, Paul. Medical Talk and Medical Work: The Liturgy of the Clinic. London: SAGE Publications, 1995.

Bijsterveld, Karin. Sonic Skills: Listening for Knowledge in Science, Medicine and Engineering (1920s-present). London: Palgrave Macmillan, 2019.

Bruyninckx, Joeri. 'Trading Twitter: Amateur Recorders and Economies of Scientific Exchange at the Cornell Library of Natural Sounds'. Social Studies of Science 45, no. 3 (2015): 344-70.

Dumit, Joseph. 'Writing the Implosion: Teaching the World One Thing at a Time'. Cultural Anthropology 29, no. 2 (2014): 344-62.

Oxford Dictionary of English. Calibrate. Oxford: Oxford University Press, 2010.

Goodwin, Charles. 'Professional Vision'. American Anthropologist 96, no. 3 (1994): 606-33.

Grunwald, Martin. Homo Hapticus: Warum Wir Ohne Tastsinn Nicht Leben Koennen. Muenchen: Droemer Verlag, 2017.

Guarrasi, Ivana. The Standard in the Body: An Ethnographic Reading of Standardized Patient Laboratory Simulations. Doctoral diss., University of California at San Diego, San Diego, 2017.

Harris, Anna, and Tom Rice (forthcoming) Stethoscope. London: Reaktion.

Hahn, Tomie. Sensational Knowledge: Embodying Culture through Japanese Dance. Middletown, CT: Wesleyan University Press, 2007.

Hammer, Gili. "You Can Learn Merely by Listening to the Way a Patient Walks through the Door": The Transmission of Sensory Medical Knowledge'. Medical Anthropology Quarterly 32, no. 1 (2018): 138-54.

Harris, Anna, and Melissa van Drie. 'Sharing Sound: Teaching, Learning and Researching Sonic Skills'. Sound Studies 1, no. 1 (2015): 98-117.

Ingold, Tim. Making: Anthropology, Archaeology, Art and Architecture. London: Routledge, 2013.

- Anthropology andlas Education. London: Routledge, 2018.

Kuriyama, Shigehisa. The Expressiveness of the Body and the Divergence of Greek and Chinese Medicine. Cambridge, MA: The MIT Press, 1999.

Latour, Bruno. 'How to Talk About the Body? The Normative Dimension of Science Studies'. Body \& Society 10, no. 2/3 (2004): 205-29.

Maslen, Sarah. 'Researching the Senses as Knowledge'. The Senses and Society 10, no. 1 (2015): 52-70.

. 'Layers of Sense: The Sensory Work of Diagnostic Sensemaking in Digital Health'. Digital Health 3 (2017): 1-9.

Phillips, Christopher J. 'The Taste Machine: Sense, Subjectivity, and Statistics in the California Wine World'. Social Studies of Science 46, no. 3 (2016): 461-81.

Prentice, Rachel. Bodies in Formation: An Ethnography of Anatomy and Surgery Education. Durham, NC: Duke University Press, 2013.

Rice, Tom. "“The Hallmark of a Doctor": The Stethoscope and the Making of Medical Identity'. Journal of Material Culture 15, no. 3 (2010): 287-301.

- Hearing and the Hospital: Sound, Listening, Knowledge and Experience. Canon Pyon: Sean Kingston Publishing, 2013.

Saunders, Barry F. CT Suite: The Work of Diagnosis in the Age of Noninvasive Cutting. Durham, NC, London: Duke University Press, 2008. 


\section{Sensory school}

Schlegel, Claudia, Kirsty Flower, Jozef Youssef, Beatrice Kaeser, and Roger Kneebone. 'Mise-En-place: Learning across Disciplines'. International Journal of Gastronomy and Food Science 16, (July 2019): doi: 10.1016/j.ijgfs.2019.100147.

Sennett, Richard. The Craftsman. London: Penguin Books, 2008.

Shapin, Steven, and Simon Schaffer. Leviathan and the Air-Pump: Hobbes, Boyle, and the Experimental Life. Princeton, NJ: Princeton University Press, 1985.

Smith-Oka, Vania, and Megan Marshalla. 'Crossing Bodily, Social, and Intimate Boundaries: How Class, Ethnic, and Gender differences are Reproduced in Medical Training in Mexico'. American Anthropologist 121, no. 1 (2019): 113-25.

Steingo, Gavin. 'Listening as Life: Sounding Fetal Personhood in South Africa'. Sound Studies 5, no. 2 (2019): 155-74.

Taylor, Janelle S. 'The Demise of the Bumbler and the Crock: From Experience to Accountability in Medical Education and Ethnography'. American Anthropologist 116, no. 3 (2014): 1-12.

Teil, Geneviève 'Devenir Expert Aromaticien: Y a-T-Il Une Place Pour Le Goût Dans Les Goûts Alimentaires?'. Sociologie du travail 40, no. 4 (1998): 503-22.

Trubek, Amy, and Maria Carabello. 'Teaching to Cook and Learning to Sense in Food Education'. In Making Taste Public: Ethnographies of Food and the Senses, edited by Carole Counihan and Susanne Højlund. London: Bloomsbury Academic, 2018.

Tsing, Anna Lowenhaupt. The Mushroom at the End of the World: On the Possibility of Life in Capitalist Ruins. Princeton, NJ, Oxford: Princeton University Press, 2015.

Van Drie, Melissa. 'Training the Auscultative Ear: Medical Textbooks and Teaching Tapes (1950-2010)'. The Senses and Society 8, no. 2 (2013): 165-91.

Wendland, Claire. A Heart for the Work: Journeys through an African Medical School. Chicago, IL: University of Chicago Press, 2010.

Wojcik, Andrea. 'Modelling Movement in Medical Education'. Making Clinical Sense: A Comparative Study of How Doctors Learn in Digital Times, 16 May 2017. http://www.makingclinicalsense.com/639/. 


\section{Lesson 3 How to knit a uterus}

In the medical school where I did fieldwork in Maastricht, there was a small room filled with intriguing obstetric models designed for the purpose of teaching birth. It was like a cupboard of toys for grown-ups wanting to be real doctors. There were shelves of labelled leather legless trunks, with hollow spaces and zippered vaginas for cloth babies to squeeze through. These are the models that the secretaries at the Skills Lab lovingly cared for with leather conditioner and hand stitched repairs. There was a large plastic doll lightly coated in years-old glycerine, sticky from many attempted births; a globulous and veined placenta, more lifelike to handle than a cloth one, easier for moving through the models. But perhaps my favourite of all was the knitted uterus.

I first came across the knitted uterus lying innocently, flat, on a tutorial room table, part of the Obstetrics II class set-up. The set-up included all the tools and instruments that the secretaries had arranged for the teacher, to give the lesson about delivering a baby to second year medical students. I had absolutely no idea what it was or how it was used in teaching medical students the sensory skills they would need as a doctor. I was especially befuddled to find this object in one of the medical schools we had broadly labelled as 'high-tech', knowing that the Dutch were very progressive in the kinds of technologies they used in teaching.

Below you will find an implosion, ${ }^{1}$ or what I like to call an unravelling, of this mysterious teaching tool, written in the form of knitting instructions. There are many ways that you can instruct how to knit - using narrative or gridded patterns; in person from a parent, grandparent, instructor or friend; or via an online video to name a few. The instructions below are of the narrative variety.

1 Joseph Dumit, 'Writing the Implosion: Teaching the World One Thing at a Time', Cultural Anthropology 29, no. 2 (2014): 344-62. 


\section{Equipment}

\section{Wool or cotton ( $3 \times 50 \mathrm{~g}$ balls)}

The knitted uterus I found in Maastricht was made of coarse red wool, possibly synthetic, which was slightly matted and had started to pile. When making this pattern I tried to source the same wool but struggled to find a good match so ended up with a coarse red wool of 8 ply I had in my stash, purchased in Norway during a conference trip some years ago. I also added another material, a thin 2 ply pink cotton. The cotton was purchased by Andrea Wojcik, the anthropologist studying medical education in Ghana on the Making Clinical Sense project, during her fieldwork in Ghana's northern city of Tamale. When I first started asking about the knitted uterus in the Netherlands, I was told by some teachers that it 'probably came from Africa'. So, I asked Andrea, whether she could look for some wool on her next visit back to her field site. She doubted it, having seen very little knitting going on in Ghana. But she asked around and in the end found some pink cotton that was commonly used in braiding hair. The red wool from Norway and the pink cotton from Ghana, when woven together, made an intriguing combination of materials (Figures 3.1) in which to make and explore the sticky global connections of this teaching tool (Nott and Harris 2020).

Find whatever wool or cotton or any other kind of material you think appropriate to knit your uterus, and give some thought to where that wool came from, it's various global histories which brought it into your stash.

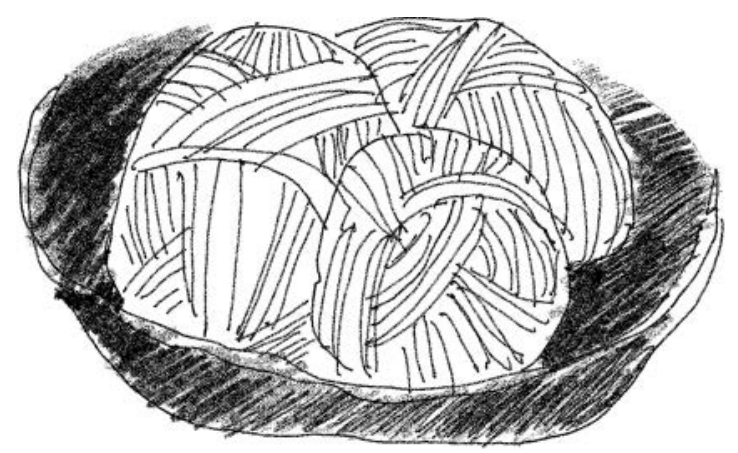

Figure 3.1 Balls of wool.

$2 x 6 m m$ knitting needles (or smaller or larger depending on your wool, see below)

Now I recommend you knit a gauge swatch. 
A gauge swatch allows a knitter to work out how their knitting will match the pattern. Every knitter works with a different tension, on the spectrum from loose to tight. Many patterns will have a gauge, a description of how many stitches horizontally and vertically the pattern assumes, to be a particular size. After knitting a gauge swatch you then measure and compare to the pattern. If it is too small, you can either adjust the wool, to be thicker, or you can use bigger needles (Figures 3.2) - both will increase the size of your knitting. This is a form of calibration, in this case, calibration to the pattern. It is a way in which the varied sensibilities of every knitter, from their wool preference to their knitting techniques, to the tension in their fingers, can be accounted for. It is also a way in which to train a knitter to be aware of these specifics, and also of the impact of the materials, whether needles or wool, that they use.

The gauge for this pattern is as follows, keeping in mind:

The size of the "uterus" should be appropriate to the size of the instructor's hands. A person with large hands or long fingers will use the large size; a person with small hands will find the smaller size more comfortable. ${ }^{2}$

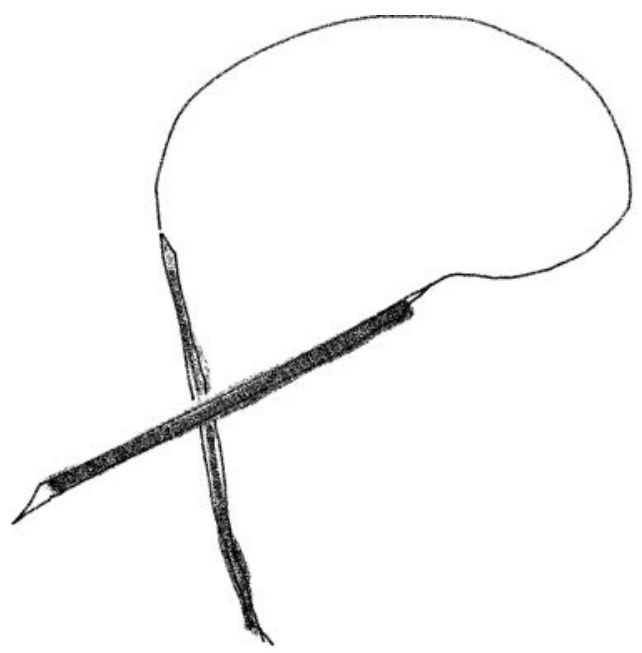

Figure 3.2 Knitting needles.

2 The Association of Chartered Physiotherapists in Obstetrics and Gynaecology. 'How to Make a Knitted "Uterus" for Teaching'. Briefs: Official Publication of the Maternity Center Association 26-30 (1962). Wellcome Library Archival, SA/CSP/R/2/4/3. 


\section{1 doll}

The knitted uterus needs a doll, for once knitted, the doll will be inserted into the uterus. In the lesson in which the knitted uterus is used, it is stuffed inside the woollen casing, with its head slightly protruding. The teacher then shows how the cervix (i.e., the ribbed knitted cuff) dilates as the head comes through, so that it not only gets wider but also stretches thinly. This helps to show the students something that they cannot see, as it is happening inside the body. It is also a way of showing the different positions the baby's head may take as it descends through the birth canal. The teachers I spent time with found using this model a much more dynamic and simpler way to teach these processes than the diagrams in the textbooks.

Find a doll in your local toy store, a kid's toy chest or online, that matches the purposes of your lesson and the size of your uterus.

\section{Instructions}

Cast on to your needles 48 stitches.

Ever since seeing this Obstetrics class for the first time, I have been captivated by the knitted model, more so as the myths and stories about it unravelled. As well as being told that the uterus was from 'Africa', I was also commonly told it was handmade by a teacher who no longer worked at the Skills Lab. The last theory I heard was that it was a ski hat that one of the previous directors thought would make a great teaching tool. Curiosity was cast.

\section{If working in the round, connect stitches and divide evenly on needles.}

John Nott, the medical historian on the Making Clinical Sense project, visited the Wellcome Trust archives in London where he found a 1960s pattern for a knitted uterus. It states that: 'Many fine teaching aids are available commercially for the teacher of parents classes: films, charts and records; but occasionally the instructor finds that she can construct something herself which will make interpretation particularly effective'. ${ }^{3}$

The knitted uterus is a fascinating teaching object, for how its materiality lends itself to a particular sensory lesson, simulating cervical dilation and effacement, the positions of the baby's head and ruptured membranes in a way that no other kind of model does. It is deliberately abstract, ${ }^{4}$ as the instructions found at the Wellcome state: 'Since this is merely a representation,

3 The Association of Chartered Physiotherapists in Obstetrics and Gynaecology, 'Knitted Uterus'.

4 Taussig, Michael, Mimesis and Alterity: A Particular History of the Senses (New York: Routledge, 1993). 
there is no attempt to make this visual aid lifelike in appearance. Actually, it may be more acceptable to the class if it does not appear to be too realistic. ${ }^{5}$

The knitted uterus is also insightful for all the imaginaries, histories, economics and politics knitted into the materials. In that red wool are medical educators who go on skiing holidays, travel to African medical schools to share techniques, and bring back materials with them. There are the ways that objects travel across different professional and non-professional spaces; physiotherapists, midwives, doctors, pregnant women.

And finally, there is the thinking through wool, a learning-in-making which lies at the heart of this book. Making the knitted uterus is a way in which to learn about how instructions are designed, by attending to their form. Following this pattern is in some ways a form of re-enactment, a material way of exploring how a teaching tool is used in sensory schools and also homes and clinics. Making the uterus is a way in which to understand about the scale and abstraction of teaching objects, and about the ways in which sensory lessons incorporate materials which attend to sensory imagination, as well as new perceptions and orientations.

Unravelling objects like the knitted uterus also teaches something about how doctors learn to make clinical sense in a material world. That learning sensing happens through handling objects, building a library of imaginary examples and layered sensory memories, feeling simulated replicas and translating instructions and analogies into future practices. The materiality of this learning is located and situated, bound up within the event and performance, while at the same time being tied into other places through sticky global connections to sites real and imagined - a European medical school or an Africa of low-tech solutions for example.

\section{Bibliography}

Dumit, Joseph. 'Writing the Implosion: Teaching the World One Thing at a Time'. Cultural Anthropology 29, no. 2 (2014): 344-62.

Nott, John, and Anna Harris. 'Sticky Models: History as Friction in Obstetric Education'. Medicine Anthropology Theory 7, no. 1 (2020): 44-65; doi: 10.17157/ mat.7.1.738.

Taussig, Michael. Mimesis and Alterity: A Particular History of the Senses. New York: Routledge, 1993.

The Association of Chartered Physiotherapists in Obstetrics and Gynaecology. 'How to Make a Knitted "Uterus" for Teaching'. Briefs: Official Publication of the Maternity Center Association 26-30 (1962): 107-8. Wellcome Library Archival, $\mathrm{SA} / \mathrm{CSP} / \mathrm{R} / 2 / 4 / 3$.

5 The Association of Chartered Physiotherapists in Obstetrics and Gynaecology, 'Knitted Uterus'. 


\section{Sensory instructions}

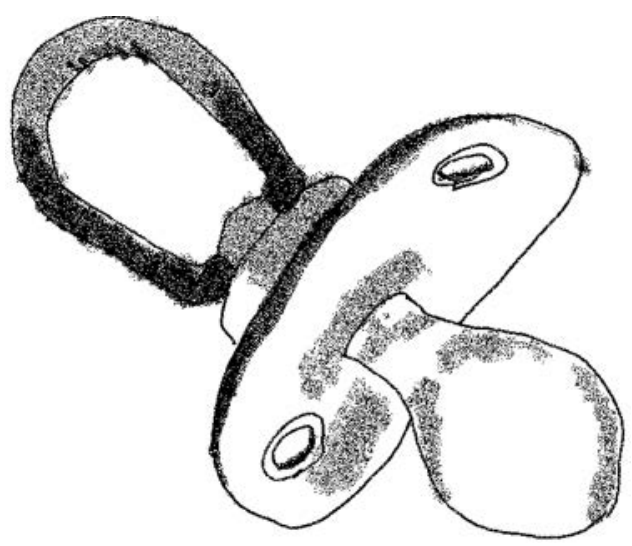

Figure 3.3 Pacifier/dummy.

Around the time I learned about the knitted uterus (see Lesson 3), I had, coincidentally or not, recently given birth myself. My husband and I were as flummoxed (and delighted) by the whole adventure as many new parents are. Both of us born in the 1970s, we did not seem to have the same trust and interest in social media parenting advice that we observed in our 'millennial' friends, who would show us how-to-videos, share tips from online fora and offer handy apps to download. Our younger friends were not alone. Figures show that $70 \%$ of millennials (a hard group to define) found their parenting advice online. ${ }^{1}$ We were instead, in some ways, 'old-fashioned', and bought a [paper] parenting book - The Baby Owner's Manual ${ }^{2}$

1 Andrew Arnold, 'How Millennials Use Social Media to Become More Competent Parents', Forbes, 5 March 2018, https://www.forbes.com/sites/andrewarnold/2018/03/05/theconnected-parent-how-millennials-use-social-media-to-become-more-competentparents/\#430200c070a3.

2 Louis M. D. Borgenicht et al., The Baby Owner's Manual: Operating Instructions, TroubleShooting Tips, and Advice on First-Year Maintenance (Philadelphia, PA: Quirk Books, 2012). 
which never left our dressing gown pockets in those early days. We could have asked grandparents for advice more often but as is the case for many modern parents who move away from where they have grown up, family was always a call away, and it felt difficult to juggle the time zones. We were happy with our one book. It felt like it limited the choices we had, at a time where there seemed too many. But we did notice that we were often targets of different tools designed to help train us as parents, and we could not help but view these with some kind of academic curiosity too.

One in particular was intended to train an important new sensory capacity of parenthood, almost as important as speedy reflexes: the sense of listening and recognising our baby's cries (Figure 3.3). Described as the Dunstan method after the Australian baby guru Priscilla Dunstan, the technique seemed simple. Parents just needed to learn to recognise five sounds their newborn would probably make - Neh, Eairh, Auw, Heh and Eh - and their associations - hunger, cramps, tired, uncomfortable and needs burping. It was, unsurprisingly, almost impossible to hone our sonic skills appropriately and decipher the different cries at $3 \mathrm{am}$ in the morning, juggling a crying newborn in one hand and the laminated language chart in the other. Was that a Neh, or an Eh? We were advised by a nurse to watch the instructional video that came with the chart carefully. With the volume down so as not to wake the baby, we perched the computer on our laps and watched as an incredibly poised Priscilla Dunstan not only worked out which cry was which but also showed techniques for how to sooth each one, burping a plastic doll over her shoulder without a spill.

Being instructed to learn baby language is just one example of the numerous everyday practices where media of many kinds - books, videos, charts and so forth - are designed to be part of our sensory education. It is difficult to divorce our parenting from media. ${ }^{3}$ However much parents such as my husband and I liked to think we were only using 'one book' we had been immersed in media environments since we grew up, our knowledge of baby cries forming from television shows, for example, or techniques for holding an infant seen in movies. As the media theorist Marshall McLuhan writes, 'I don't know who discovered water but it certainly wasn't a fish'. ${ }^{4}$ My life had already been awash with media shaping how I parent, just as my parents' lives had been too (this brings back a vivid memory of a book on my parents' shelf called How to Have Happy Children). Nowadays, digital technologies and sensory knowledge are intimately entangled as parents learn to read the sensory cues of their infant with the help of apps, videos and other online advice, similarly contributing to these online places too with their

3 Sarah Maslen and Anna Harris. Sensory and Digital Media Entanglements in Lay and Practitioner Diagnostic Work (under review).

4 Norm Friesen and Theo Hug, 'The Mediatic Turn: Exploring Concepts for Media Pedagogy', in Mediatization: Concept, Changes, Consequences, ed. Knut Lundby (New York: Peter Lang, 2009), 61. 
own sensory observations. This could be called a digital-sensory kind of noticing, a way of looking which stretches the cyborg concept more broadly to consider how the ways sensing gets imbued with the digital infrastructures.

In this chapter, I will look at the material and social nature of sensory education by zooming in specifically on instructions. I will suggest that the way sensory knowledge is learned is deeply embedded in and with media technologies, digital and non-digital. I focus in particular on instructions because I believe that it is through comparison of a particular form, such as instructions, that differences in media become more visible. It becomes easier to see what different media allow with regard to how information can be ordered and organised and how different media is engaged with by the people who use them. I will suggest that when it comes to sensory education, instructional media act in different ways to reorientate sensing. Marshall McLuhan famously argued that media has its own grammar and sensory ratio, where different senses are brought to the fore and become extensions of humans (see Friesen and $\mathrm{Hug}^{5}$ for a much more extensive and nuanced analysis of these points). Here I look at how media such as text and videos are part of sensory education in particular ways. In doing so I work a lot with media theorists like McLuhan, not only because this chapter deals with the materiality of instructions, but also because media theorists have spent a lot of time thinking about how technologies and sensing interrelate.

By now, readers of the book who have gone sequentially through the chapters will have already come across several explicit examples of instructional media in sensory training: Lesson 1 focused on the cyanometer, a tool designed for measuring the blueness of the sky, which gave insights into sensory communication and how words for blue might form; Chapter 1 looked at the role of flavour charts and smell kits in shaping sensory vocabularies, these vocabularies shaping the media too; Lesson 2 involved edible media used to simulate the human body, such as candy and fruit while Chapter 2 brought in pedagogical media used in classrooms such as protocols and textbooks, which aid calibration.

In this chapter, the book delves further into these media and other technological matter that is designed to instruct sensory education. Just like the media theorists, I will argue that this matter can never be separated from sensing, that it is embedded in the socio-material landscape that constitutes what sensing is, and how it is learned and taught. To understand more about sensory training, I take some very concrete examples to work with, focusing again on food and medicine primarily. First, I look at the exploding world of cookbooks, where celebrity chefs and food writers must instruct the at-home cook in how to smell their food, touch their food, taste their food and occasionally, even listen to their food in the form of recipes. Then, I explore the role of television and video in sensory training of both doctors and amateur chefs, particularly how multisensorality is used to expand novices' imaginative space. The chapter then goes deeper into the design of these instructions, exploring a red thread throughout this book: the social labour that goes into engineering sensory education. It

5 Friesen and Hug, 'Mediatic Turn'. 
focuses on the example of medical training again, exploring instructions for teachers and how they need to be 'expressive'. Finally, the chapter considers how such media experiences are involved in a specific form of reorientation that is common, I argue, in many kinds of sensory education.

The chapter develops from the previous chapters in a few different ways. It looks at how new vocabularies are shaped through written instruction and television shows, extending this by considering more carefully what these instructions do, not only in terms of sensing but also, extending from the media theorists, in orientating techniques of perception. I explore how media is not only used as a form of calibration, a concept I developed in Chapter 2, but also how calibration instruments are designed.

\section{Instructional media}

Anthropologists interested in craft, tacit knowledge and sensory skills insist that there is one main way to learn skills: in constant practice, under the guidance of an expert or master. This assumption underpins many ethnographies of enskillment, from the study of Japanese dancers to how cooking is taught in kitchens. ${ }^{6}$

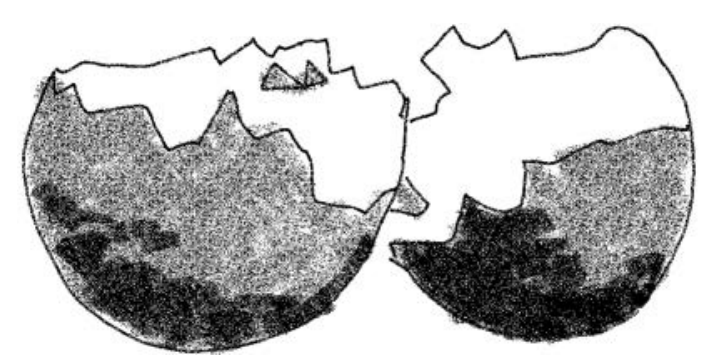

Figure 3.4 Cracked eggshells.

Tim Ingold is one of those who considers skills to be passed on through practice. ${ }^{7}$ In a lecture, he uses the example of cracking an egg, not an easy task, he states, for it is difficult to obtain that clean crack of sufficient extent to enable you to split the shell into two halves (Figure 3.4), and thus release the contents neatly in the bowl. The force cannot be too light or too great; either will mean an eggy mess. What adds difficulty is that no two eggs are

6 Tomie Hahn, Sensational Knowledge: Embodying Culture through Japanese Dance (Middletown, CT: Wesleyan University Press, 2007); David Sutton, Secrets from the Greek Kitchen: Cooking, Skill, and Everyday Life on an Aegean Island (Oakland: University of California Press, 2014).

7 Tim Ingold, The Perception of the Environment: Essays on Livelihood, Dwelling and Skill (London: Routledge, 2000). 
alike. How do you know the thickness of an egg's shell, to know how hard to hit it? There is a trick Ingold tells us:

First tap the egg lightly against the side of the bowl. Listen for the sound. This will tell you how hard to strike next time, so as to achieve a clean crack. Bum bum. Thick shells and thin shells sound differently when tapped. ${ }^{8}$

Ingold argues that such skills cannot be learned from cookbooks, but rather through learning by doing, through guided instruction by experts, with sensory awareness of one's material environment.

While Ingold does acknowledge in his later work ${ }^{9}$ the many different ways a novice may learn, whether from picking up habits from observation of what others do, to having them demonstrated or learning from rules or principles abstracted from the contexts of application, he is nonetheless still largely dismissive of or neglects the role of written and audiovisual media in sensory education. Historians are more attentive to such documents. Thijs Hagendijk ${ }^{10}$ for example looks at the role of 'how-to' books in learning crafts while Viktoria von Hoffmann ${ }^{11}$ looks at the role of etiquette books in learning taste. STS scholars John Law and Michael Lynch $^{12}$ examine fieldguides in learning birdwatching, as 'an aid to formulating a list of birds seen on the expedition', as a way of guiding the ordering of observations.

In order to look more closely at the role of media in learning sensing, I need a little help from media theory, a field that has drawn historically, amongst a number of disciplines, upon anthropology in its development, but which has received less attention from anthropologists in return. Media theory is a field which has typically studied print, film, radio and the Internet although now has quite an expansive definition of what media is. For example, John Durham Peters ${ }^{13}$ writes that if we think of media as not only a form of communication but rather as providing the con-

8 Tim Ingold, 'To Learn Is to Improvise a Movement along a Way of Life'. Lecture delivered at the LSE Department of Anthropology on 27 April 2010. www.youtube.com/ watch? $\mathrm{v}=1 \mathrm{DaaPaK}-\mathrm{N} 5 \mathrm{o}$.

9 Anthropology andlas Education (London: Routledge, 2018): 198-235.

10 Thijs Hagendijk, 'Learning a Craft from Books: Historical Re-enactment of Functional Reading in Gold- and Siversmithing', Nuncius 33, no. 2 (2018): 198-235.

11 Viktoria von Hoffman, 'Learning (to) Taste: Food, Aesthetics, and Education in Early Modern France', The Senses and Society, 14:2, 131-147.

12 John Law and Michael Lynch, 'Lists, Field Guides, and the Descriptive Organization of Seeing: Birdwatching as an Exemplary Observational Activity', Human Studies 11, no. 2/3 (1988): 271-303.

13 John Durham Peters, The Marvelous Clouds: Toward a Philosophy of Elemental Media (Chicago, IL: The University of Chicago Press, 2015). 
ditions for existence, we can look beyond only messages and channels and see media in infrastructure and all forms of life: 'Media are our infrastructures of being, the habitats and materials through which we act and are' ${ }^{14}$ This is the water the fish swims in. While I explore the ways in which sensory education is part and parcel of consumer society in Chapters 4 and 5, and the more elemental and environmental aspects of sensory awareness in Chapter 6, this chapter actually focuses on many of the more traditional interests of media theorists: printed matter, television and online content.

As already mentioned, McLuhan has been very influential, in thinking about the sensory qualities of media as well, as educationalist Norm Friesen ${ }^{15}$ points out, in thinking through the 'pedagogical enterprise'. McLuhan developed exercises for the classroom, but more generally, his theories of the sensory ratios of media have importance for thinking through instructions. Frustratingly for many scholars, McLuhan's work is perceived to be rambling and accused of being based on little empirical evidence. His theories also need to be considered within the historical time period and media technologies that existed when he wrote. However, McLuhan is good for thinking with, Peter ${ }^{16}$ points out, and encourages us to think more about how different instructional media attends to different sensory directions. I want to take Ingold's example about cracking eggs as a starting point, and explore the role of learning with media, and not only with experts. I challenged myself to find instances where the skill of listening (taking one sensory practice that entails all kinds of bodily engagement as well as touch and other sensations $)^{17}$ may be evident in written form. After extensive research I found a few delightful exceptions to what was an otherwise sensory dominance of instructions for taste, sight, touch and smell in cookbook instructions.

\section{The sound of recipes}

Cookbooks, the anthropologist Arjun Appadurai famously suggests, belong 'to the humble literature of complex civilizations ... They combine the sturdy pragmatic virtues of all manuals with the vicarious pleasures of the literature

14 Peters, Marvelous Clouds, 15.

15 Norm Friesen, 'Education as a Training of the Senses: Mcluhan's Pedagogical Enterprise', Enculturation: A Journal of Rhetoric, Writing and Culture, 7 November 2011, http://enculturation.net/education-as-a-training.

16 Peters, Marvelous Clouds.

17 Harris Anna. 'Listening-touch, Affect and the Crafting of Medical Bodies through Percussion'. Body \& Society 22, no. 1 (2016): 31-61. 
of the senses, ${ }^{18}$ For Appadurai, cookbooks are artefacts which offer insights into cultures in the making - and also maintain class hierarchies where cooking is a communicable form of expert knowledge (see also Jack Goody), ${ }^{19}$ especially as they 'sometimes move where people may not'. ${ }^{20}$ The cookbook, home of the written recipe, reveals cultural lore, norms and wisdoms of past and present communities. The cookbook is also, I suggest here, a perfect example of the role instructional media has in learning to sense.

Perhaps the idea we learn something from cookbooks is, again, 'old fashioned'. While Appadurai sees the cookbook as a manual, there has been some concern more recently, that the cookbook's instructional value has changed, that they have become adornments to beautify homes. ${ }^{21}$ As a cookbook publisher stated, in an interview in the UK newspaper The Guardian, 'there is no doubt that cookery books have become more beautiful and aspirational objects than the practical black-and-white cookbooks of yore'.22 Tim Hayward, a cookbook writer, muses that what many people regard as their most loved cookbook appeared just after the war, when writing about food was didactic, in regards to thrifty and efficient cooking methods, or about learning about exotic cuisines. ${ }^{23}$ While these publishers and writers may argue that cookbooks have lost their instructional purpose, and become more of a way to express identity, I found that a close look at recipes, even those in contemporary cookbooks, reveals that recipes still offer sensory lessons. Even cookbooks that eschew recipes that focus on the processes and technique of cooking, still invite sensory awareness.

Take bread making. ${ }^{24}$ Recipes for bread-making are abundant and cover many sensory details: there are instructions for recognising the sweet/sour smell of yeasty mixtures, the glutinous feel of kneaded dough, and the requisite 'hollow knock' on the bottom of the loaf at the end of baking. The hollow knock is an interesting example of sensory instruction that attends specifically to listening. For recipes are filled with sensory directions related to taste, appearance, texture and smell. 'Always taste as you cook',

18 Arjun Appadurai, 'The Capacity to Aspire: Culture and the Terms of Recognition', in Culture and Public Action, ed. Vijayendra Rao and Michael Walton (Palo Alto, CA: Stanford University Press, 2004), 3.

19 Jack Goody, Cooking, Cuisine and Class: A Study in Comparative Sociology (Cambridge: Cambridge University Press, 1982).

20 Appadurai, 'Capacity to Aspire', 7.

21 Caroline Davies and Nicola Slawson, 'Cookbooks' Key Ingredient Now Design Not Recipes, Says Food Writer', The Guardian, 18 August 2015, https://www.theguardian.com/ books/2015/aug/17/cookbooks-key-ingredient-design-recipes-prue-leith.

22 Davies and Slawson, 'Cookbooks' Key Ingredient'.

23 Yotam Ottolenghi and Tim Hayward, 'Does It Matter How We Use Cookbooks?', The Guardian, 22 August 2015, https://www.theguardian.com/lifeandstyle/commentisfree/2015/ aug/22/does-it-matter-how-we-use-cookbooks-prue-leith.

24 Anna Harris, 'The Hollow Knock and Other Sounds in Recipes', Gastronomica: The Journal of Critical Food Studies 15, no. 4 (2015): 14-17. 
the celebrity chefs proclaim. Sauté onions until translucent; bake a cake until golden on top. Rub flour and butter through your fingers until they feel like breadcrumbs. A pie is ready when you can smell it. But what about the sound of food cooking?

Let's start with a Madhur Jaffrey recipe, in any one of her Indian cookbooks. Before you know it you are waiting for a pop! as mustard seeds are heated in oil. Until they pop, mustard seeds give away nothing but bitterness, the pop releasing all their nutty goodness into the oil, just as a corn kernel is only a broken tooth waiting to happen until it pops into flower. Sichuan and Cantonese cooking also rely on the chef attending to sounds connecting hot oil and fresh ingredients, this time with a sizzle. Sizzles infuse Fuschia Dunlop's Every Grain of Rice, ${ }^{25}$ as hot oil is poured over dishes of blanched choy sum or chopped ginger and chili. She advises to ladle only a few drops at first: once you hear that the sizzle is 'vigorous' the rest of the oil can be poured over.

In The River Cottage Meat Book, Hugh Fearnley-Whittingstall ${ }^{26}$ dedicates a few paragraphs to the difference between the 'merry sizzle' and the 'gentle sizzle', sounds that can be used not only to test the temperature of a pan but also to determine how long a steak has been cooking. In the same carnivorous volume, Fearnley-Whittingstall ${ }^{27}$ shares techniques for roasting duck, one of which involves turning the duck breast-side down on a board and pressing 'hard on the middle of the backbone until you hear a crack'. Cracks and crackles can be heard in various recipes, although perhaps the crackliest of all, crackling, does not rely on the cook actually testing its sound qualities but rather looking to see if the pig fat is roasted adequately to cause some further dental destruction.

Similarly, recipes that instruct to cook vegetables so that they remain crunchy rely on a visual assessment of the sound, rather than the cook actually putting a boiling hot carrot into their mouth and listening in. Words such as 'sizzle' and 'crunch' are interesting to think about, for they defy easy categorisation as sounds, also including elements of touch and sight in their informative nature.

Making bread is a good example of the multi-sensoriality and sensibility required in cooking and baking. Starting from scratch involves skills in smelling yeast mixtures, kneading dough, watching for rise, and of course, the sound of a well-baked loaf: the hollow knock. Knocking on a loaf of bread to see if it is ready is another one of those rare times the novice cook is explicitly instructed to listen to their baking (Figure 3.5). Such a mysterious sound, this hollow knock! And one which divides the cookbook writers.

25 Fuschia Dunlop, Every Grain of Rice: Simple Chinese Home Cooking (New York: W.W. Norton \& Company, 2013).

26 Hugh Fearnley-Whittingstall, The River Cottage Meat Book (London: Hodder and Stoughton, 2004), 330-31.

27 Fearnley-Whittingstall, River Cottage Meat Book, 246. 


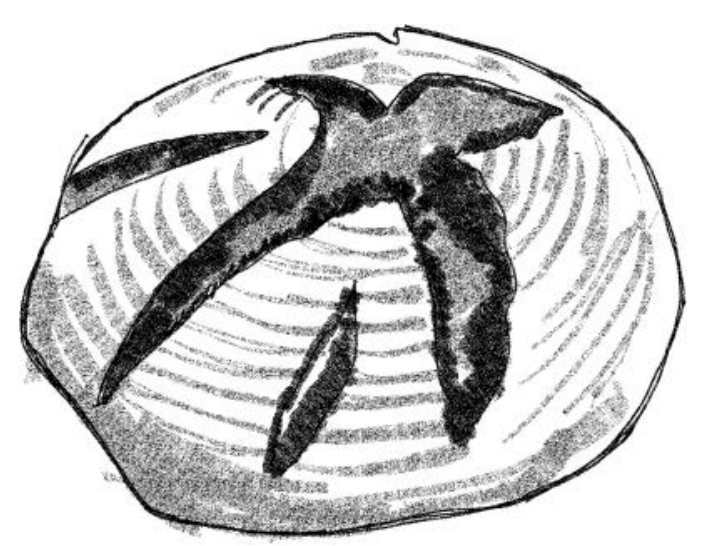

Figure 3.5 Loaf of bread.

Elizabeth David's ${ }^{28}$ instructions for her basic loaf in English Bread and Yeast Cookery suggest to tap the sides and bottom crust with one's knuckles, to test for a resonant sound that shows it is sufficiently baked. Nigella Lawson ${ }^{29}$ loves the knock too and recommends that budding domestic gods and goddesses check for the hollow noise. Others, however, find this instruction completely illogical. In Bread Matters, Andrew Whitely ${ }^{30}$ bemoans the technique: 'far too subjective', he writes, 'most loaves when tapped on the bottom sound "hollow"; other signs are more helpful'. Later he goes on:

There is hardly a recipe book that doesn't suggest tapping a loaf on its bottom to check whether it is properly baked. The hollow sound is supposed to be the clue. There is nothing wrong with this, and indeed I find myself doing it instinctively: after all, a gentle pat on the bottom is a satisfying gesture of intimacy and approval. The problem is determining what 'hollow' really sounds like. ${ }^{31}$

Indeed, this is a problem that has vexed many an online food forum discussant, with one motivated baker even trying to record some knocking sounds to help those completely unaware. ${ }^{32}$ Unlike meat thermometers or kitchen scales, there is no easy way to quantify sound on a scale of

28 Elizabeth David, English Bread and Yeast Cookery (London: Grub Street, 2010).

29 Nigella Lawson, How to Be a Domestic Goddess (London: Random House, 2012).

30 Andrew Whitely, Bread Matters: Why and How to Make Your Own (London: Fourth Estate, 2009), 102.

31 Whitely, Bread Matters, 122.

32 Freshly Baked, 'How to Know If Your Bread Is Properly Cooked', 11 May 2012, http:// www.homemadeloaves.co.uk/2012/09/how-to-know-if-your-bread-is-properly.html. 
'hollowness'. This is a dilemma of sharing sensory experience more generally. Many have attempted to address this conundrum by making recordings of sounds for pedagogical purposes, through visualising sound in graphs or pictures or trying to mimic or gesture sounds. It is difficult to be told, and to tell, what you are going to hear. The doctors I studied found it difficult to recognise lung sounds without listening to many examples, on CDs, online, in patients, as well as their own. Like doctors who learn by repeated practice, bakers also learn what hollow bread sounds like by knocking other hollow things and caressing many bread bottoms. The written instructions do not stand alone, but exist with other media. This also need to be tied into past and ongoing practical experience.

I remember my first hollow knock on bread. The oven alarm had shattered my afternoon doze. Stepping through the kitchen filled with soft smells, I peered through the splattered oven door. The loaf I had been caring for all day, my first ever, had risen to a majestic yeasty height. I was proud of my efforts so far. I had managed to keep my starter alive, kneaded and folded the dough according to the illustrations in the recipe, and now had a nice looking loaf glowing in the oven. Was it ready though? I had read in my cookbook about the knock and tried it. It was a disappointment. Besides a set of scorched knuckles I was none the wiser, and had trouble deciphering any difference each time the loaf was brought out of the oven. But I had begun to learn the gesture, and when learning to cook that is an important starting point. Learning to listen is not just about the sounds, but the techniques too.

This sonic exploration of cookbooks shows that while there are some wonderful examples, instructions for listening are scarce, and it may be, along the lines of McLuhan's sensory ratios, that recipes do not attend to listening in the same way as they do other sensory experiences. Perhaps sounds are considered 'too subjective' by cookbook writers as Whitely ${ }^{33}$ states, to provide information, compared to other sensory inputs. The hollow knock represents a particularly well-discussed case of the difficulties and controversies of listening to sounds of food, although other examples, such as the sizzle, crack or even tapping to hear for a dead oyster, may be less fraught. Perhaps English language speakers haven't learned the same kind of vocabularies for sounds in cooking, to describe what is heard, as for other sensory experiences. ${ }^{34}$ Ingold would claim that while the recipe might offer signposts for critical junctures in a process ${ }^{35}$ such skills cannot be written in cookbooks but need to be passed on in person. Or perhaps, as I go onto explore in the next section, it is just that the instructions are not expressive enough.

33 Whitely, Bread Matters.

34 Asifa Majid and Stephen C. Levinson, 'The Senses in Language and Culture', The Senses and Society 6, no. 1 (2011): 5-18.

35 Ingold, Anthropology andlas Education, 11. 


\section{Designing expressive instructions}

In the introduction to Julian Barnes' The Pedant in the Kitchen Mark Hix writes that 'it's not difficult to knock out a recipe, but being sympathetic to the reader is all too often overlooked, ${ }^{36}$

When a chef or cookbook writer instructs on how to make a dish, they must not only provide a clear guide to their student, with important steps and signposts, but they must also find creative ways in which to share and teach the tacit, bodily, sensory skills entailed in cooking. In his book The Craftsman, the sociologist Richard Sennett considers the teaching of skills through this example of recipes. ${ }^{37} \mathrm{He}$ shows that how to prepare one dish, Poulet a la d'Albufera (stuffed chicken), can be instructed in many different ways; from Julia Child's sympathetic illustrations to help the cook; to Elizabeth David's scenic narrative style that draws on historical references; to his own cooking class instructor's emphasis on metaphors. Sennett calls these different ways of sharing the recipe 'expressive instructions'. Relating this to the concept of noticing, it highlights the particularly lively and colourful instructions in the art of noticing, those which open up the learners' imagination in rich and vivid ways.

Designing instructions is not easy for most instructors of embodied skill. In the medical schools where I did fieldwork, there are teams of instructional designers, who help to redesign and design new curricula for teaching medical students. Many of these instructions are built upon cognitive learning models, which presume a transmission, or transfer, of knowledge by following a specific pathway. These theories and frameworks are then used to shape workbooks, the range of classes offered, and assessments for example. They also underpin teacher instructions. When anthropologists focus on how skilled learning happens in practice, between expert and novice, they often question the cognitive models in favour of theories of embodiment and enskillment. At the same time however, they often neglect the role of media and instructions that instruct the trainer. Here I suggest that a close examination of the protocols that teachers follow when giving their instructions in a medical school, looking at the steps that teachers are instructed to take when teaching sensory skills, offers insights into the expressivity of instruction. It also sheds light on how sensory lessons are being articulated, offering insight into some of the problems of protocols too. I take here the example of teaching the clinical examination method of palpation, which is an incredibly difficult technique to describe how to do. It is also difficult to describe the sensations that medical students must be aware of when they palpate.

The instructions I describe below were designed for teachers giving a tutorial where medical students needed to learn how to distinguish a tumour,

36 Mark Hix, 'Introduction', in The Pedant in the Kitchen, ed. Julian Barnes (London: Atlantic Books, 2003), $x$.

37 Richard Sennett, The Craftsman (London: Penguin Books, 2008). 
whether malignant, benign or the possibilities of. This is an incredibly important skill for a doctor to learn. While there will always be a gold standard test, a CT scan or a fine-needle biopsy, the doctors must also have tactile sensory knowledge, to assess which kinds of tests are required. Here are key sections of the instructions to the teachers running the class:

\section{B. Palpation}

Discuss that palpation means feeling. So, it is a technique the students have been using all their lives. You could ask the students how they think they can use this technique to obtain information about the patient or the patient's body.

Palpation provides information via the sensitive nervous system: touching, pressure, but especially the tension of your own muscles and the movement of your fingers will give this information and allow you to construct an image (feeling is watching with your fingers). But you can also feel temperature, or pulsations; and the patient can feel pain.

The students can explore this by using the materials available or by examining each other (e.g. palpation of the back of the hand with eyes closed, feeling a person's pulse).

Briefly discuss the technique of palpation: flat hand, front part of the fingers, calm, rotating movements of the skin in relation to the underlying layer (you can demonstrate this on one of the models). Explain that you can use this technique to find a tumour or to assess the surface.

\section{Examination of a swelling}

Take a moment to discuss the concepts swelling and tumour.

Discuss the confusion between a non-medical and a medical interpretation of these concepts. In this training, a tumour = a swelling. Also address the concepts normal, abnormal, benign, malignant. Remember that the students have very little or no medical knowledge.

This training mainly focuses on the skill of palpating a tumour. So use 'a clear mass' as example.

Ask the students to describe pictures of swellings. Which aspects could you describe? Use the students' suggestions and complete the list if necessary. The following qualities are assessed and described when you examine a tumour: Location; Shape; Size; Colour; Consistency; Surface; Mobility relative to the skin and underlying layer, dimpling; Delineation; Pulsation; Painfulness; Temperature.

Explain these concepts. It is most effective to do so after the students have already practised a little on the models, because the concepts will then be more tangible for them.

There is a lot going on in this instructional text for the teachers. First, the teachers are being instructed to retrain their students' vocabularies, to re-orientate the meanings of words so that they can exchange non-medical 
words for medical ones. The techniques are also put into context of what the students already knows but being reformulated for a clinical purpose. They are touching but searching for a different meaning, and in doing so are also re-orientating how they perceive the body. There are many materials to choose from in the lesson - objects at hand, models, each other, all offering different kinds of insights into the problematics of palpation. Each has their own possibilities, each their own limitations. The teachers are not instructed exactly how to 'discuss the technique of palpation' but it lends itself to bodily explanation, and indeed demonstration is suggested. The students need to make the concepts 'tangible'.

These instructions are not followed to the letter. There is much improvisation when it comes to how teachers guide students in medical school. Yet the protocol above is a wonderful example of attempts at greater expressivity, of how to give expressive instructions, with objects and materials which might simulate a sensation, with suggestions for demonstration techniques and for ways in which to bring the novices' sensing in closer alignment with those of the teachers' ${ }^{38}$ They also show the importance of training the medical students' sensory imaginations, so that they can 'construct an image (feeling is watching with your fingers)' through the sensory techniques they are learning. I explore this further in the next section, through audio-visual training materials.

\section{Sensory alignment}

So far, I have written a lot about written instructions; however, in this section I want to move to the role of audio-visual media in sensory education, such as television shows, as well as online videos and other multisensory media. As with cookbooks, television shows have evolved over time with regard to their role in instructing cooking. Historian Maggie Andrews ${ }^{39}$ argues, by looking at two UK cookery programmes from the 1990s, that there has been a shift in cookery programmes from an educational mode to a more sexual, lifestyle focus. Andrews writes that TV shows in the past were more like 'visual recipe books', encapsulated in Delia Smith's style which was a 'steady plodding attention to detail appropriate to a skilled domestic craft for which the correct tools were required'. ${ }^{40}$ As Andrews' argues, this shift is possible partly due to the many magazines and Internet sites that provide cooking recipes to the public, thus freeing television chefs from this task. ${ }^{41}$

38 Anna Harris and Melissa van Drie, 'Sharing Sound: Teaching, Learning and Researching Sonic Skills', Sound Studies 1, no. 1 (2015): 98-117.

39 Maggie Andrews, 'Nigella Bites the Naked Chef: The Sexual and the Sensual in Television Cookery Programmes', in The Recipe Reader, ed. Janet Floyd and Laurel Forster (Lincoln: The University of Nebraska Press, 2010), 187-204.

40 Andrews, 'Nigella Bites the Naked Chef', 188.

41 Andrews, 'Nigella Bites the Naked Chef'. 
Andrew's work implies that the instructional television shows of the 70s were devoid of sensory detail, yet once again, looking at instructional cookery shows of the time reveals exceptions to this. In the Making Clinical Sense project, we closely analysed one particular TV show of Julia Child's, instructions for how to make an omelette, in order to experiment with how to record the learning that takes place when watching a cooking show. Julia Child breaks all of Andrews' rules - she is demonstrative, loud and laughs often, and moreover, her instructions are filled with sensory details. In one video of making an omelette she describes listening to the sizzling butter, watching it brown, shows swift jerky movements required to bring the eggs together. Her instructions are intensely multisensory.

Media studies scholar Monica Mak $^{42}$ also suggests that cookery shows used some sensory details, such as sounds, in order to compensate for olfactory, tactile, and gustatory experiences in evoking the deliciousness of their dishes. She shows how kneading bread might represent texture and touch for example, drawing on bodily cues. There is a lot of invisible labour, just like the set-up of a medical school lesson. Not only are dishes premade but there is a lot of post-production editing which adds these sensory effects. Time is also manipulated: 'Through the dissolve, a long kneading process is deliberately completed in less than two minutes ... by so doing, the postproduction technique speeds up the passage of time in a subtle, unnoticeable manner and prevents viewers from becoming bored'. 43

For in all audio-visual instruction there is once again the challenge in how to share the sensory details of the skill being taught. The wine teacher Ducker $^{44}$ shares instances where this has been done unsuccessfully on the BBC's Food and Drink program. The time for example when participants were told the wines prior to training sessions with the idea that they could have them at hand already and taste the wines parallel to the presenter. Ducker criticises that the viability of such an approach is limited since the same type of wine can taste very different depending on bottle conditions, year, etc. Similar failures have been observed for example with smell-ovision cinema, where it is very difficult to 'match' sensations on a screen. Media theorist Laura Marks' work implies however that this might be a too simplistic view of sensory media. ${ }^{45}$ Marks is interested in the haptic qualities of video, and how the materiality of video for her, lends itself to a particular form of haptic visuality, one that attends to the bodily relation

42 Monica Mak, 'The Pixel Chef: PBS Television Cooking Shows and Sensorial Utopias', ed. Etta M. Madden and Martha L. Finch, Eating in Eden: Food and American Utopias (Lincoln: University of Nebraska Press, 2006), 258-74.

43 Mak, 'Pixel Chef', 267.

44 John Ducker, 'Teaching Wine Tasting', in Educated Tastes: Food, Drink and Connoisseur Culture, ed. Jeremy Strong (Lincoln, London: University of Nebraska Press, 2011).

45 Laura U. Marks, Touch: Sensuous Theory and Multisensory Media (Minneapolis: University of Minnesota Press, 2002). 
between viewer and image, inviting viewers into new kinds of bodily relations and experiences.

These shared sensory experiences are integral to attempts at sensory training that occur with television, video and the now more ubiquitous online video formats. Many medical students learn techniques from palpation, to percussion to suturing from videos available online. In making these video lessons, the video maker must attend to how to make the instructions expressive and how to attempt some kind of sensory alignment. The media needs to be used in a way in which the task is simplified enough for the learner, while opening it up to the complexities of what must be learned. Video allows for particular features of a lesson - replay and slowing down, for example, which are not possible in other kinds of lessons. In watching videos though, the learner must mirror the instructor, requiring a flip in their orientation which can potentially be confusing.

This echoed what I found in medical schools, particularly when there were instructions from multiple orientations, such a workbook with photographs from different angles then diagrams from another - medical students simply got confused. It came about particularly in watching videos, for this required a form of bodily mirroring which was not always easy for the students. When learning how to palpate from a video, for example, the student must perform the opposite manoeuvres than the instructor. Teachers told me however they could tell when a student had only seen a video and not come to class, just from their technique when assessed. Video works in a way, as with many other media, texts and resources, of re-orientating the senses through what it highlights, the perspectives it allows and the sensory and bodily engagements of the viewer and novice.

Some media theorists are concerned that digital media overrides and is irrelevant when it comes to the senses. Jussi Parikka, writes: 'The understanding of the senses becomes reshuffled when we realize how the digital is itself beyond the "threshold of the visible" (2008: 239), non-sensuous and mathematical'. ${ }^{46}$ He says that:

Software culture presents a new challenge in understanding the contemporary media sphere and its histories, and the way in which our cognitive and perceptive capacities are being trained anew in the midst of "smart environments" that measure, react to and survey us. ${ }^{47}$

Not too dissimilar from McLuhan's view of media manipulating the senses of populations, as if from a control tower, ${ }^{48}$ Parikka nonetheless helps to articulate a central idea of media historians and media theorists, which is that 
with new forms of media, we start to think about the world in new ways. He questions whether the digital brings a new phase of sensation.

One of the central arguments of this book and a myth I have tried to challenge is that materials are implicated in learning sensory skills, whether digital or non-digital, and that they do not compete with each other but co-exist. Instead of focusing on ruptures in sensory engagements with media, many such as historian of technology David Edgerton ${ }^{49}$ consider how old and new technologies intersect and overlap, and how, as Daniel Miller et al. ${ }^{50}$ write, we operate within polymedia environments. For as Katherine Kirkwood ${ }^{51}$ showed in their study of Australian households, individuals combine traditional and digital media when they learn practices such as cooking - sometimes an app, sometimes a cookbook, sometimes a TV show depending on what they are engaging with at the time. This is nothing new to the media theorists I introduced at the beginning of the chapter, who argue that media forms are all interrelated. Everyday and expert sensory education is a complex negotiation between explicit instructions that take the form of recipes, baby language charts, knitting patterns, cooking shows or protocols, in a world in which media has also had an enormous influence on the preconditions and characteristics of this learning, in regards to perceptions of time, space, attention and communication. ${ }^{52}$

In this chapter, I have tried to show that sensory education is a complex negotiation between explicit instruction and embodied learning, foregrounding in this case the role of media in this process. Media guides, instructs but also importantly, shapes and reshapes what we already know and how we learn to sense. At the same time, the design of instructional media involves sensory skills and imagination, something which I have not had the space to explore. The chapter has highlighted the role of instructions in learning, something which is often neglected by anthropologists interested in skill. Alongside others, such as de Solier ${ }^{53}$ and Hagendijk, ${ }^{54}$ I have tried to understand more about how media acts as a mediator in the ways people learn sensory things. This work also needs to be understood within the invisible economic logics underlying the various media forms I have discussed and where sensory education takes place more broadly, ${ }^{55}$ something which I explore further in the next two chapters.

49 David Edgerton, The Shock of the Old: Technology and Global History since 1900 (London: Profile Books, 2008).

50 Daniel Miller et al., How the World Changed Social Media (London: UCL Press, 2016).

51 Katherine Kirkwood. 'Integrating Digital Media into Everyday Culinary Practices', Communication Research and Practice 4, no. 3 (2018): 277-90.

52 Friesen and Hug, 'Mediatic Turn'.

53 Isabelle De Solier, Food and the Self: Consumption, Production and Material Culture (London: Bloomsbury, 2013).

54 Thijs Hagendijk, 'Learning a Craft from Books'.

55 Tania Lewis, 'Digital Food: From Paddock to Platform', Communication Research and Practice 4, no. 3 (2018): 212-28. 


\section{Bibliography}

Andrews, Maggie. 'Nigella Bites the Naked Chef: The Sexual and the Sensual in Television Cookery Programmes'. In The Recipe Reader, edited by Janet Floyd and Laurel Forster, 187-204. Lincoln: The University of Nebraska Press, 2010.

Appadurai, Arjun. 'The Capacity to Aspire: Culture and the Terms of Recognition'. Chapter 3 In Culture and Public Action, edited by Vijayendra Rao and Michael Walton, 59-84. Palo Alto, CA: Stanford University Press, 2004.

Arnold, Andrew. 'How Millennials Use Social Media to Become More Competent Parents'. Forbes, 5 March 2018. https://www.forbes.com/sites/andrewarnold/ 2018/03/05/the-connected-parent-how-millennials-use-social-media-to-becomemore-competent-parents/\#430200c070a3.

Barnes, Julian. The Pedant in the Kitchen. London: Atlantic Books, 2003.

Borgenicht, Louis M. D., Joe Borgenicht, Paul Kepple, and Jude Buffum. The Baby Owner's Manual: Operating Instructions, Trouble-Shooting Tips, and Advice on First-Year Maintenance. Philadelphia: Quirk Books, 2012.

David, Elizabeth. English Bread and Yeast Cookery. London: Grub Street, 2010. 1977.

Davies, Caroline, and Nicola Slawson. 'Cookbooks' Key Ingredient Now Design Not Recipes, Says Food Writer'. The Guardian, 18 August 2015. https://www.theguardian.com/books/2015/aug/17/cookbooks-key-ingredient-design-recipes-prue-leith.

Ducker, John. 'Teaching Wine Tasting'. In Educated Tastes: Food, Drink and Connoisseur Culture, edited by Jeremy Strong, 105-18. Lincoln, London: University of Nebraska Press, 2011.

Dunlop, Fuschia. Every Grain of Rice: Simple Chinese Home Cooking. New York: W.W. Norton \& Company, 2013.

Edgerton, David. The Shock of the Old: Technology and Global History since 1900. London: Profile Books, 2008.

Fearnley-Whittingstall, Hugh. The River Cottage Meat Book. London: Hodder and Stoughton, 2004.

Freshly Baked. 'How to Know If Your Bread Is Properly Cooked', 11 May 2012. http://www.homemadeloaves.co.uk/2012/09/how-to-know-if-your-bread-is-properly.html.

Friesen, Norm. 'Education as a Training of the Senses: Mcluhan's Pedagogical Enterprise'. Enculturation: A Journal of Rhetoric, Writing and Culture, 7 November 2011. http://enculturation.net/education-as-a-training.

Friesen, Norm, and Theo Hug. 'The Mediatic Turn: Exploring Concepts for Media Pedagogy'. In Mediatization: Concept, Changes, Consequences, edited by Knut Lundby, 61-81. New York: Peter Lang, 2009.

Goody, Jack. Cooking, Cuisine and Class: A Study in Comparative Sociology. Cambridge: Cambridge University Press, 1982.

Hagendijk, Thijs. 'Learning a Craft from Books: Historical Re-enactment of Functional Reading in Gold- and Siversmithing'. Nuncius 33, no. 2 (2018): 198-235.

Hahn, Tomie. Sensational Knowledge: Embodying Culture through Japanese Dance. Middletown, CT: Wesleyan University Press, 2007.

Harris, Anna. 'The Hollow Knock and Other Sounds in Recipes'. Gastronomica: The Journal of Critical Food Studies 15, no. 4 (2015): 14-7.

'Listening-touch, Affect and the Crafting of Medical Bodies through Percussion'. Body \& Society 22, no. 1 (2016): 31-61. 
Harris, Anna, and Melissa van Drie. 'Sharing Sound: Teaching, Learning and Researching Sonic Skills'. Sound Studies 1, no. 1 (2015): 98-117.

Hix, Mark. 'Introduction'. In The Pedant in the Kitchen, edited by Julian Barnes, ix-xiv. London: Atlantic Books, 2003.

Ingold, Tim. The Perception of the Environment: Essays on Livelihood, Dwelling and Skill. London: Routledge, 2000.

. 'To Learn Is to Improvise a Movement along a Way of Life'. Lecture delivered at the LSE Department of Anthropology on 27 April 2010. Accessed 10 August 2014. www.youtube.com/watch?v=1DaaPaK-N5o.

- Anthropology andlas Education. London: Routledge, 2018.

Kirkwood, Katherine. 'Integrating Digital Media into Everyday Culinary Practices'. Communication Research and Practice 4, no. 3 (2018): 277-90.

Law, John, and Michael Lynch. 'Lists, Field Guides, and the Descriptive Organization of Seeing: Birdwatching as an Exemplary Observational Activity'. Human Studies 11, no. 2/3 (1988): 271-303.

Lawson, Nigella. How to Be a Domestic Goddess. London: Random House, 2012.

Lewis, Tania. 'Digital Food: From Paddock to Platform'. Communication Research and Practice 4, no. 3 (2018): 212-28.

Majid, Asifa, and Stephen C. Levinson. 'The Senses in Language and Culture'. The Senses and Society 6, no. 1 (2011): 5-18.

Mak, Monica. 'The Pixel Chef: Pbs Television Cooking Shows and Sensorial Utopias'. In Eating in Eden: Food and American Utopias, edited by Etta M. Madden and Martha L. Finch. Lincoln: University of Nebraska Press, 2006: 258-274.

Marks, Laura U. Touch: Sensuous Theory and Multisensory Media. Minneapolis: University of Minnesota Press, 2002.

Maslen, Sarah and Anna Harris. Sensory and Digital Media Entanglements in Lay and Practitioner Diagnostic Work (under review).

Miller, Daniel, Elisabetta Costa, Nell Haynes, Tom McDonald, Razvan Nicolescu, Jolynna Sinanan, Juliano Spyer, Shriram Venkatraman, and Xinyuan Wang. How the World Changed Social Media. London: UCL Press, 2016.

Ottolenghi, Yotam, and Tim Hayward. 'Does It Matter How We Use Cookbooks?'. The Guardian, 22 August 2015. https://www.theguardian.com/lifeandstyle/ commentisfree/2015/aug/22/does-it-matter-how-we-use-cookbooks-prue-leith.

Parikka, Jussi. What is Media Archaeology? Cambridge: Polity, 2012.

Peters, John Durham. The Marvelous Clouds: Toward a Philosophy of Elemental Media. Chicago: The University of Chicago Press, 2015.

Sennett, Richard. The Craftsman. London: Penguin Books, 2008.

Sutton, David. Secrets from the Greek Kitchen: Cooking, Skill, and Everyday Life on an Aegean Island. Oakland: University of California Press, 2014.

Trubek, Amy, and Maria Carabello. 'Teaching to Cook and Learning to Sense in Food Education'. In Making Taste Public: Ethnographies of Food and the Senses, edited by Carole Counihan and Susanne Højlund, 139-53. London: Bloomsbury Academic, 2018.

Von Hoffman, Viktoria. 'Learning (to) Taste: Food, Aesthetics, and Education in Early Modern France'. The Senses and Society, 14, no. 2 (2019): 131-147.

Whitely, Andrew. Bread Matters: Why and How to Make Your Own. London: Fourth Estate, 2009. 


\section{Lesson 4 Sensory food gatherings}

Gathering around food is something that could be considered an almost universal pleasure. It is also a time-old technique for collaboration, brainstorming and experimentation in the social sciences, yet a surprisingly understudied methodology. Eating together has been used in all kinds of ways to help facilitate and study particular social effects, from historical re-enactments, ${ }^{1}$ to futurist and neo-futurist dinners ${ }^{2}$ to experiments in public participation, ${ }^{3}$ to ethnographic experiments. ${ }^{4}$ The Slow Food movement, which I discuss in the next chapter, had its origins in dinner parties held above a butcher shop. ${ }^{5}$

An eating event opens up opportunities for not only communality and sociality, but also for sensory education. It is a moment in which diners can learn from each other, from those who made the food, from those who are eating it and from those who have made something like it before. It is a chance to teach others about techniques, ways of eating, histories and foodways and politics of ingredients. This sensory education is part of everyday eating with others, but it can be made more explicit. In this lesson I suggest, in the spirit of a breaching experiment, to play with a particular sensory aspect of a food orientated gathering, highlighting it, adding rules and seeing what results. By extracting an element of a multisensory event (choosing, for example, to focus on one sensory modality) or by making guidelines,

1 Tristram Hunt, 'Dinner by Heston Blumenthal: A Taste of the Past', The Guardian, 3 February 2011.

2 Filippo Tommaso Marinetti, La Cucina Futurista (Milan: Viennepierre Edizioni, 2009).

3 Priya Parker, The Art of Gathering: How We Meet and Why It Matters (London: Penguin Business, 2019).

4 Anna Mann et al., 'Mixing Methods, Tasting Fingers: Notes on an Ethnographic Experiment', HAU: Journal of Ethnographic Theory 1, no. 1 (2011): 221-43.

5 Priya Parker, The Art of Gathering: Create Transformative Meetings, Events and Experiences (New York: Penguin, 2018); Harris, Anna, Thomas Fuller, Alexandra Supper, Joeri Bruyninckx and Melissa van Drie. 'Sound Dish: What We Hear, with our Tongues'. Centre for Imaginative Ethnography, Sounding, 5 February 2016. 
this focus may mean that many of the more invisible sensing practices are brought to the fore.

In 2015 I set out with my husband, friends and colleagues to hold such an event, one which in particular attended to sound. We were all scholars of sound of a sort, whether historians, ethnographers, artists and psychologists and currently working with that theme in our projects. Each participant was asked to create a dish which resonated with 'rich sonic qualities, whether in the making or eating of it'. These dishes then served as a starting point for the dinner party that followed, filled with stories, performances, observations and plenty of eating and drinking. In sharing these sensory dishes, we also educated each other about where we came from, our research findings, places we had visited. Each of us followed recipes in completely different ways - some of us learned instructions from family members over the years, others reconstructed dishes from written sources, cookbooks and online recipes, others from what they remember tasting on holidays. That was the case of the recipe, which I wrote with my husband and which you can find here, a memory of a holiday to Istanbul and some instructions to follow.

This recipe conjures a holiday memory of a winter spent in Istanbul. We wanted to evoke the sounds of sahlep seller's in the cold rainy streets with their hot thick and spicy drink; the sounds of cooking fish on the grill (Figure 4.1) in a poorly lit parking lot by the wharf inspired our fish sandwich recipe filled with crunchy lettuce, onion and tomato.

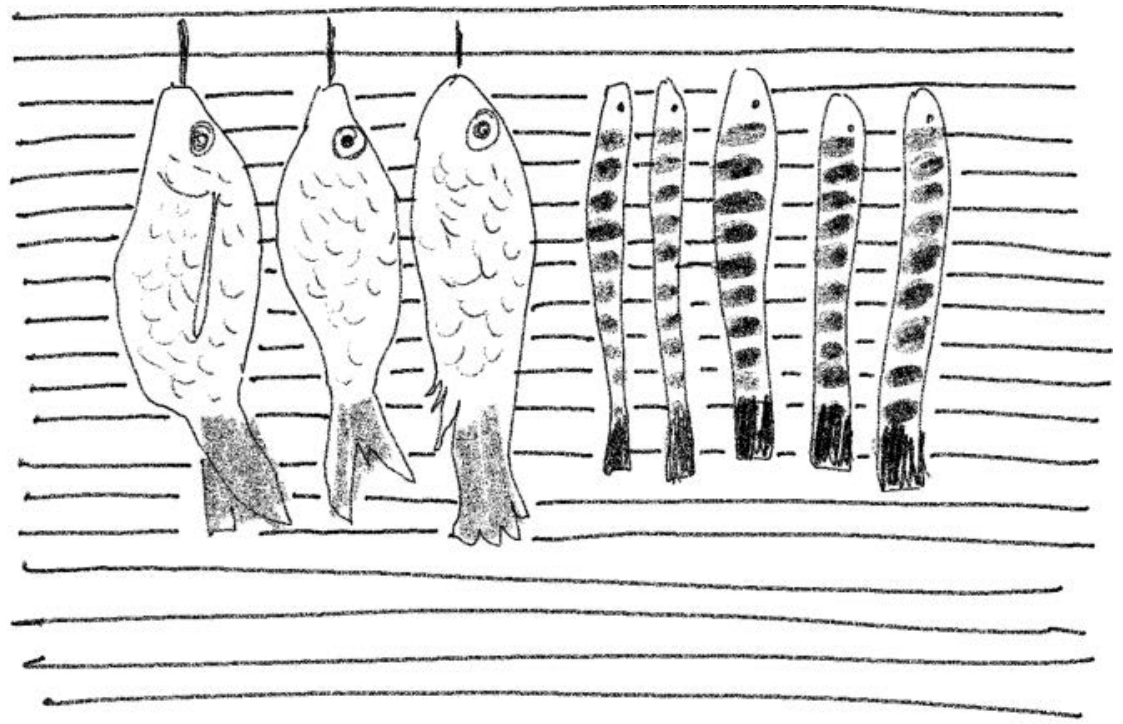

Figure 4.1 Fried fish sandwich. 
The recreated dishes are sensory impressions recalling the feel of the first warm styrofoam cup of the brew we drank by the Hagia Sophia, the huddled sociality of the parking lot, our bottoms balancing on the milk crates. For other friends at the dinner table it recalled dancing in a restaurant with a lively band. We all spent a lot of time laughing as bowls of onions and tomatoes were shared around the dinner table the night of the sound dinner. The style of instruction responds to the call for a more 'imagistic' anthropology, which uses 'image as method' to recall the ephemeral and elusive. ${ }^{6}$

Note: the two sound recordings for the recipes below can be found on the website for the book, on the Making Clinical Sense website: www.makingclinicalsense.com.

\section{Fried fish sandwich}

Olive oil melting: salt, pepper, paprika'ed fish, fresh from the Bosphorous that morning. Sizzle! On the plate. Fish bones extracted with swift precision. Tap, tap tap, fish tongs on the hot plate. Roughly cut the bread, crumbs fly. Lights flicker on in the car park. Brush bun with oil; add tomato, onion, mint, crunchy lettuce and lemon juice. Top with sizzling fish and munch while sitting on a milk crate or at dining table with friends.

\section{Sahlep}

Thick and sweet from the clattering urn, steaming in Styrofoam, drunk in the snow. The sahlep seller's cry through the cold streets - an improvised recipe in a cosy Dutch kitchen. Whisk cornflour and glug glug milk and water, while the sugar dissolves silently. Boil and thicken and whisk whisk. Pour into glasses and rest in a cold humming fridge. Make syrup of quiet sugar and water, crinkly bay leaf and vanilla pod. Pour on custard with shaved coconut and crushed pistachios.

6 Brian Goldstone, 'Image as Method: Conversations on Anthropology through the Image. Interview with Brian Goldstone', by Andrés Romero, Somatospehre, 14 August 2015, http://somatosphere.net/2015/image-as-method-conversations-on-anthropology-throughthe-image.html/. 


\section{Bibliography}

Goldstone, Brian. 'Image as Method: Conversations on Anthropology through the Image. Interview with Brian Goldstone'. By Andrés Romero. Somatospehre, 14 August 2015. http://somatosphere.net/2015/image-as-method-conversations-onanthropology-through-the-image.html/.

Harris, Anna, Thomas Fuller, Alexandra Supper, Joeri Bruyninckx, and Melissa van Drie. 'Sound Dish: What We Hear, with Our Tongues'. Centre for Imaginative Ethnography, Sounding, 5 February 2016. https://imaginative-ethnography. com/2016/02/05/sound-dish/ (Accessed 11 August 2020).

Hunt, Tristram. 'Dinner by Heston Blumenthal: A Taste of the Past'. The Guardian, 3 February 2011. https://www.theguardian.com/lifeandstyle/2011/feb/03/dinnerheston-blumenthal-history-menu (Accessed 1 January 2020).

Mann, Anna, Annemarie M. Mol, Priya Satalkar, Amalinda Savirani, Nasima Selim, Malini Sur, and Emily Yates-Doerr. 'Mixing Methods, Tasting Fingers: Notes on an Ethnographic Experiment'. HAU: Journal of Ethnographic Theory 1, no. 1 (2011): 221-43.

Marinetti, Filippo Tommaso. La Cucina Futurista. Milan: Viennepierre Edizioni, 2009.

Parker, Priya. The Art of Gathering: Create Transformative Meetings, Events and Experiences. New York: Penguin, 2018. 


\section{Workshopping}

The workshop is a classic site of study for those interested in craftsmanship. ${ }^{1}$ Knowing more about this site of learning deepens understanding of the craft lessons given by masters to apprentices, about the social nature of apprenticeship. The traditional image of a workshop conjures up a knot of well-loved tools hanging on specially designed hooks; long wooden workbenches and notched tables; dusty shelves of experiments and prototypes; boxes of cut-offs in corners. It is a cosy, sequestered space, where there is a quiet reverence to materials. The stereotype continues to encompass a site of concentrated work, where craft is learned through doing. There are rules and etiquette, cups of tea and coffee and a world outside.

In this chapter, I use workshopping as a way to deepen some of the explorations of this book so far, in particular what it means to notice as part of sensory education. This chapter focuses on a particular aspect of the social nature of this experience, looking at learning in small groups and gatherings in workshops.

Workshops have the cosy wooden stereotyped image I describe above, but they are also events. In the 'general public', a workshop is a time-bound activity where one can learn something. A short course, for example, in a specific place, often accompanied by a guide. In craft workshops of the kind you might enrol in for the weekend or at night, the traditional format is usually that people learn something about a skill, something about the materials involved and then have a discrete project to work on. In academia, where workshops are also common, a workshop is also a time-bound activity, although it is not always clear that it is a place to learn. In university settings, workshops are often run using traditional formula too - there is a presentation, perhaps a group activity, another presentation.

In all these cases of workshopping, participants learn about and through their senses. This chapter looks at what happens when a guide steps into the scene to explicitly take a group, whether a member of the public or a group of academics, through such a time-bound learning event. The chapter 
looks at the social labour involved in the lesson, as well as its material conditions. Workshops rely on what is often described as practical knowledge, or hands-on learning, that is, learning through engaging in practical activity under the guidance of a master. ${ }^{2}$ I look at how bodies get wrapped up into and articulated in such settings. Using again the concept of 'art of noticing' from anthropologist Anna Tsing, ${ }^{3}$ I try and unpack the noticing cultivated in the workshop setting. Tsing's work here offers an understanding of observation practices (she herself looks at mushroom hunting) that takes the task away from it being a mental activity, to embrace the more sensory and embodied dimensions too, activities, as she shows, that are imbued with environmental and political concerns.

The workshop of course is a site not only of romantic apprenticeship, but also of brutal labour and harsh conditions. I do not develop these aspects of workshopping though encourage others to seek out this work if it interests them, and to develop these sensory politics further. For the sociologist Richard Sennett, ${ }^{4}$ the authority invested in the head of the medieval workshop was paramount to the work that was done there. The head of a workshop set the standard and trained, and the inequalities inherent in the workshop drove that learning. These were also the reasons for its failings, Sennett argues. In the workshops I explore in this chapter, there are certainly guides or authority figures - cooking class instructors, medical educators, teachers of the social sciences and humanities. But at the end of the chapter, I want to explore what it means to have a workshop where there are no teachers or students - what does this do to the dynamics of learning?

There are many kinds of workshops for the public I could have focused on here as examples - mindfulness workshops, perfume workshops, yoga workshops. These are all part of the dazzling variety available for people to enrol in on their holidays, online, with friends in their local city. I want to stick with the interesting interconnections and interplay between food and medicine by exploring first a cooking class, and second workshops for medical students. In the final section, I look at how insights from these might feed into ways to think about teaching and doing research in academia, how such sites could also be seen as sites of sensory lesson where art of noticing are cultivated as a transformative event. This moves the goal of workshops away from learning 'something' to how attending in different ways, under the guidance of leaders and other workshop attendees, leads to new kinds of noticing.

2 Michael Polanyi, The Tacit Dimension (New York: Doubleday and Company, 1966); Jean Lave and Etienne Wenger, Situated Learning: Legitimate Peripheral Participation (Cambridge: Cambridge University Press, 1994); Tim Ingold, Anthropology andlas Education (London: Routledge, 2018)

3 Anna Lowenhaupt Tsing, The Mushroom at the End of the World: On the Possibility of Life in Capitalist Ruins (Princeton: Princeton University Press, 2015).

4 Sennett, Craftsman. 


\section{A cooking class}

I am heading to a cooking class, in the company of three friends - a doctor, microbiologist and sociologist. We are driving in a 4WD vehicle through the countryside of the southeast corner of Tasmania. The four of us have a shared love of all things related to food - we literally grow, read, talk, write about cooking all the time. For years we had heard of a cooking school that was turning novices into die-hard cooks, urban dwellers into gardeners and foodies into, well, just more intense foodies. We were in perfect company to try it out together.

After an hour of driving past swaying poplar trees, hop farms and barns, and small country towns, we followed the signs up the gravelly drive to our cooking school. Stepping out of the car I could smell it already: the rich, dark soil, the herbs sprinkled with dew, the pigs snorting through breakfast. Kookaburra calls rang through the eucalypts. The valley air was crisp. The cooking class had started.

We walked up to the farm door and the teacher, born in Sydney and migrated to Tasmania years earlier to set-up the school, greeted us with a warm smile and kitchen. The fire was blazing, and we were grateful, for this and the cakes and coffees laid out on the old wooden table. The cooking school was housed, appropriately, in an old country school, the kitchen and dining room converted from the two rooms used for teaching. Lining the dining room were hundreds, possibly thousands of cookbooks. As the cooking class members streamed in - Sydneysiders mostly, in Tasmania for a rural, culinary experience - they picked up a piece of the delicious almond tart and perused the shelves, finding their favourites and sharing recommendations with others. There was obviously a shared appetite for cooking classes and cookbooks amongst the group. The learners varied from teenagers with their mother having fun on a holiday, to bankers taking notes on their smartphones and social scientists interested in the senses.

As assistants prepared pots and pans and the rest of the set-up behind us, finding the right number of measuring jugs, the teacher introduced us to the cooking school and its central philosophy: that cooking is all about the food, and knowing where that food comes from. That is, to become 'good' cooks, cooks who do their job well and appropriately, we need to attend to the ground that our vegetables grow in, the air that our fruit trees sway in and the mothers and fathers of our meat. This was the first hint that our cooking lesson was going to have a broader landscape than I expected, but it was soon to continue over the next few hours as we stumbled through the school grounds in our oversized gumboots clutching umbrellas and wicker baskets (Figure 4.2).

We smelled herbs from the garden, herbs that the teacher loved, like apple mint and lovage. We tasted bitter salad leaves and smelled a local Tasmanian pepper berry, described by the teacher as the 'smell of Tasmania'. We spotted asparagus spears and pulled rhubarb stalks from the ground. We 


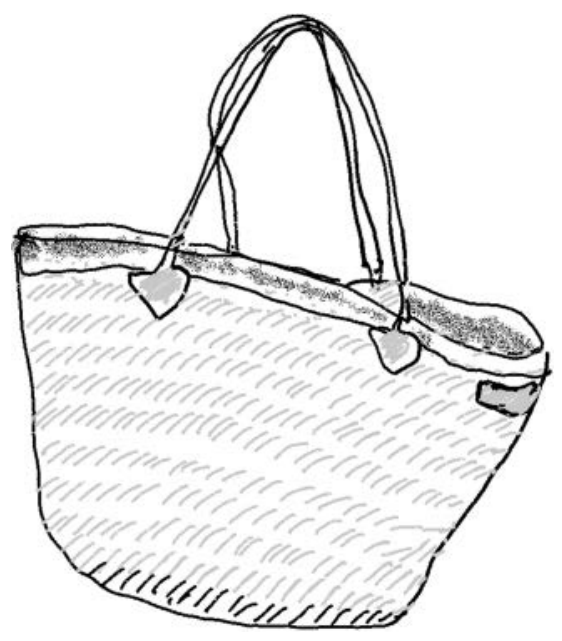

Figure 4.2 Farm basket for collecting herbs and vegetables.

met the farm's pigs and chicken, all who would be killed for future classes, for this was not a vegetarian school. We met the animals by name, learned of their heritage and breeding, saw the vegetable plots the pigs had dug completely for a beautiful harvest and were told that pigs taste better when they eat nice food and are treated well. We poked our heads in the smoking house where we smelled the remnants of the last smoke, using timbers delivered by locals after they cut down their trees. We were shown the grafted fruit trees, pruned heavily, and the empty plots ready for new plants.

This was not only a lesson in 'terroir', that is, where our food came from and the conditions of its growth, but a sensory lesson in environmental awareness and empathy, in connecting land and place to food. By smelling the herbs decked out in our gumboots, herbs grown from seedlings, we were taught about the cycles of growth, the specificities of local conditions, the importance of eating what comes from where you live, at particular times of year. If we had not already had herb gardens in our own homes, we were mentally plotting and potting them already. We had not even stepped into the kitchen yet, not picked up a wooden spoon, but we were already deeply immersed in learning the recipes. This was a living recipe that involved our immersion into the landscape of the workshop.

Eventually we would have paper recipes, with instructions listed to follow, ingredients to find. Our teacher had written them himself, an expert recipe writer who had written several cookbooks himself and also been a food writer and editor for some of Australia's leading food magazines. Over the lunch we enjoyed together, another important part of the lesson, he mused on these forms of recipes and their differences. How recipes in magazines and newspapers need to reach a broad audience of varied expertise, cookbooks 
allowing for less detail. How he thinks carefully about the steps that go into a recipe, about what is described. It was in a cooking class though that he felt he could attend to the sensory, material, physical details that are missing from the recipe. He could teach me how to slice the chives that I had picked and put in my basket, by demonstrating his technique, then watching me, guiding me, to use the incredibly sharp knife.

One of the difficult balances to achieve in a cooking class, is how to give the participants enough of an experience, without doing everything for them. I once took a local pie-baking workshop in Maastricht, learning how to make their famous vlaai, yet we mostly watched a sample dough being made (while the ones we were to work with were on our tables already). We saw the vats of filling pre-made for the pie, and then had fun making patterns on the casing. It felt hugely unsatisfying. Yet on the other end of the spectrum, my husband and I once took a cooking class with a famous chef and cookbook writer called Yotam Ottolenghi - with so many students vying for his time, we barely got a look in and although it was great fun we were largely left to ourselves to follow a recipe. We felt unguided and the lesson felt very similar to being in our own kitchen following one of his cookbooks.

In this class in Tasmania though, the balance was achieved. Part of the reason for that was that we were not working individually, or in pairs, but as a group. As we made each dish, we shared the making along the way. We handed around the flatbread dough that a couple were making, all instructed to feel and remember this wet rubbery texture, then we could determine how much water to use in the recipe when we tried it at home. We tasted when something was not seasoned well, seasoning being something which we were told helps to identify the more seasoned cook.

In the cooking classes we were not only learning individually through hands-on exercises and recipes, through the teacher's personal instructions, we were learning as a group, learning to sense together. We were not novices. Each student came with their own sensory knowledge. These had been influenced by media - the cooking teacher in Tasmania felt that the vocabularies used by the students in his class were changing as a result of cooking TV shows for example, as he now frequently heard that a student would be 'plating up' (a common term in TV shows like Master Chef). We shared techniques for chopping, and advice on the best mixer to buy to make meringue. We learned the lessons together, did parts of the meal and looked over shoulders to observe something we had not done before. And at the end of it all, we ate the meal together during which the lesson continued, as we mused over ingredients and newly learned techniques, passed bowls around complementing the cooks. Outside a warm glow started to descend on the garden, as we stayed a bit too late perhaps over our last glasses of locally produced wine.

In the workshop, we were being asked to notice together, notice the Tasmania that I had grown up in but a sensory landscape that I had, perhaps, always taken for granted. There was a lot of work behind the scenes - the 
recipe the teacher had selected and written himself, the assistants who were cleaning the pots and pans, the herbs that had been planted as seedlings, the wood that had been chopped for the smokehouse, the earth that had been tilled the day before. Our part of the lesson was to attend, through sensory observation, to all that these people and things had to offer.

In a continual effort for self-improvement, and in the midst of busy work and social lives, the consuming middle-classes are increasingly turning to dedicated workshops like this cooking class and similar experiences in order to 'get back to their senses'. In a cooking workshop, participants are told that they will better appreciate not only cooking techniques but also tasting, smelling, feeling food. Teaching cooking, once the domain of mothers in the kitchen, is now a task for Master Chefs and expert teachers who offer courses in a whole range of cuisines for small groups, often those on holiday. I must admit to being a total addict of cooking classes and have taken courses in Istanbul, London, Sicily, Paris, wherever I have had time to enrol. I have long abandoned the idea that I will learn something particular in these classes - a way of cooking or particular recipes. Instead I understand that in these workshops, just as Jean Lave ${ }^{5}$ points out in her work, I undergo a particular kind of transformative learning with a group, one that is enmeshed in the particular material conditions of the lesson. This was highlighted to me in the case of my Tasmanian cooking class, for these were material conditions, a landscape that I had taken for granted my whole life and discovered anew on that cosy Saturday in the countryside.

\section{Attention workshops for medical students}

Theoretically, doctors should be expert observers of sensory detail. Making diagnosis and caring for the patient throughout their treatment, requires ongoing skills of attention and observation. As we have seen so far in this book, however, such skills are incredibly difficult to learn, as well as to teach. It is a challenge to create learning environments in which novices learn to notice the big and small differences that are important for diagnosis, let alone the empathy by which to communicate this. ${ }^{6}$ In this section, I move away from cooking to look at workshops designed to address observational skills in medical students.

There has been a lot of interest recently in training the observational (mostly visual) skills of medical students, often within the remit of medical humanities. This often occurs through art classes for medical students, where medical students are trained to look at paintings in new ways. The theory is that better observational skills improve diagnostic ability as well

5 Jean Lave, Learning and Everyday Life (Cambridge: Cambridge University Press, 2019).

6 Alan Alda, If I Understood You, Would I Have This Look on My Face?: My Adventures in the Art and Science of Relating and Communicating (New York: Random House, 2017); Leslie Jamison, The Empathy Exams (New York: Graywolf Press 2014). 
as empathy, that is, being able to put themselves in another's shoes, something vitally important for their work as humanist doctors.

When I did fieldwork in Melbourne, looking at how doctors' train their sensory skills of listening to sounds, my colleague Eleanor Flynn (a medical educator and humanities scholar) and I found that teaching and learning sounds were indeed challenging. We also found that those who had studied music found it easier to be attentive to the frequency and rhythm of body sounds and find ways to describe them. This connection between musical training and physical examination skills is not new. Historians of medicine have long pointed out the musical abilities of the physicians who developed the skills of auscultation and percussion, Leopold Auenbrugger and René Laennec. ${ }^{7}$

What was most important in respect to this finding in our material was not so much whether music is beneficial to learning auscultation (see others such as Linda Pellico ${ }^{8}$ who are researching this), but rather that music training enhanced the students' skills in attentiveness. An important and beneficial aspect of musical training was a general education in sensory awareness that was also important in learning the sounds of the body. The attentiveness developed in musical training could also be of benefit in providing an ability to attend carefully to the sounds from the stethoscope in spite of being in a noisy ward. ${ }^{9}$ Learning to pay attention was integral to learning to listen to murmurs and pathological breathing, a process that required guidance by teachers. The clinical teachers needed to direct the students' attention towards what sounds to listen to, how to focus their attention. These skills in sensory awareness are vital to good medical practice, yet difficult to teach in medical school. As medical educators Alan Bleakley et al. write, 'how one may educate a perceptual attention, or close noticing, is a long-standing problem in medicine'. ${ }^{10}$

Eleanor and I suggested that more workshops in medical schools should explicitly focus on the sensory education of medical students. Attention is one of the bedrock goals of clinical teaching. Attention is also fundamental in all our daily interactions with the world around us. Ingold argues that

7 Pascal R. Vouhé, 'The Surgeon and the Musician', European Journal of Cardio-Thoracic Surgery 39, no. 1 (2011): 1-5; David C Bosanquet, James CD Glasbey, and Raphael Chavez, 'Making Music in the Operating Theatre', British Medical Journal 349 (2014): g7436; Peter Pesic, 'Music, Mechanism, and the "Sonic Turn" in Physical Diagnosis', Journal of the History of Medicine and Allied Sciences 71, no. 2 (2016): 144-72.

8 Linda Honan Pellico et al., 'Looking Is Not Seeing and Listening Is Not Hearing: Effect of an Intervention to Enhance Auditory Skills of Graduate-Entry Nursing Students', Nursing Education Perspectives 33, no. 4 (2012): 234-39.

9 Alexandra Parbery-Clark, Erika Skoe, and Nina Kraus, 'Musical Experience Limits the Degradative Effects of Background Noise on the Neural Processing of Sound', The Journal of Neuroscience 29, no. 45 (2009): 14100-07.

10 Alan Bleakley et al., 'Making Sense of Clinical Reasoning: Judgement and the Evidence of the Senses', Medical Education 37, no. 6 (2003): 545. 
it is through situated and attentive engagement that one becomes a skilled practitioner in daily life. The role of any 'tutor' in this process, he suggests, is to set-up situations in which the novice is instructed to attend to the particularities of what can be seen, touched, heard and to get a feel for it themselves. Similarly, Bleakly et al. ${ }^{11}$ discuss, drawing on the philosopher Michael Polanyi, the notion of a sensory connoisseurship in medical education, as an aesthetic and imaginative approach towards distinguishing differences.

For professionals such as doctors, there is much at stake in training the senses through attentiveness, just as there is for other sensory experts. Pellico et al. write that 'clinical competence begins by developing and sharpening skills that use the senses: observing, palpating, hearing, and smelling'12 and that

given that the skill of physical examination is multisensory, curricula that enhance the skills of observing, touching, and hearing logically have potential for improved competency. Development of these skills is critical since they are the basis for initial assessment, physical examination, diagnosis of a patient's needs and evaluation of treatment impact. $^{13}$

Eleanor and I proposed a series of practical activities focusing on sensory awareness which would assist students to gain these skills, suggesting that diagnostic skills can be better developed through workshops that cultivate sensory experience more broadly. ${ }^{14}$

One of our suggestions for a hands-on activities that could be developed and articulated into the existing curriculum was a cooking class. The aim of such a session would be to train the students to attend to differences (in sounds, sight, taste, smell, texture, movement, etc.), to guide them to notice aspects of their body, materials, their environment, they might otherwise not notice, to find ways to articulate these experiences and to reflect on the skills of observation and attentiveness to those observations that are required for their work as doctors. The workshops would have to be embedded in the clinical skills practical classes so the students could 'see' the connections. There would also need to be some encouragement of reflection before, during and after the sessions, through guided discussions with non-medical sensory expert and a medical educator and the documentation of the observations and reflections we argued was a necessary part of this learning.

Attention workshops in medical education are not new. There is a new trend in mindfulness classes, for example, but there is a long history of art

11 Bleakley et al., 'Making Sense of Clinical Reasoning'.

12 Pellico et al., 'Looking Is Not Seeing', 235.

13 Pellico et al., 'Looking Is Not Seeing', 238.

14 Anna Harris and Eleanor Flynn, 'Medical Education of Attention: A Qualitative Study of Learning to Listen to Sound', Medical Teacher 39, no. 1 (2017): 79-84. 
classes for medical students. There are also workshops on improving students' perceptive attention through the teaching of skills of close reading of literature and through creative writing. ${ }^{15}$ And finally, some have attended to musical training as well. ${ }^{16}$ Reports about art classes for medical students describe evidence of improved observational skills, which facilitate seeing in ways that improve diagnostic ability. ${ }^{17}$ Many of these studies find the importance of training observation skills to be based on better pattern recognition, viewed as a critical step in clinical reasoning. There is also a focus on how these courses train skills in empathy. Eleanor and I were much more focused on bodily, sensory learning.

Our research team had the opportunity to be involved in an event which meant we could experiment with how the workshops Eleanor and I had designed theoretically might play out in practice. The event was an elective for medical students at Maastricht University. The elective ran for some weeks across a number of art institutions in Maastricht. A particularly exciting aspect of the week we were involved in (with Marres) was that the students were encouraged to extend beyond the more traditional task of looking at paintings. Led by head arts educator Ilse van Lieshout and director of the space Valentijn Byvanck, students were not only encouraged to look, but also use other kinds of sensing, such as movement, through a number of moving exercises, or touch, through examination of various objects.

Our research team contributed with an exercise designed to train the students' skills of observation, through following a recipe of how to make an omelette. They were instructed to attend to how to read and interpret a recipe as well as how to observe others' cooking. While one half of the class cooked, the other half were taking fieldnotes, writing or drawing about that they were seeing, hearing, smelling in front of them. While being invited to attend to instructions and practices, it was from each other that the students learned the most. They also spent time in the gardens of Marres collecting herbs, exploring the space of the workshop in ways we did not anticipate. They were noticing aspects of their environment, of the workshop space, in the context of the small group lesson. The workshop facilitated articulations and expressions of these observations through fieldnotes, with the belief that attending to these art of noticing would have relevance for their work as doctors.

15 Caroline Wellbery and Rebecca A. McAteer, 'The Art of Observation: A Pedagogical Framework', Academic Medicine, 90, no. 12 (2015): 1624-30; Rita Charon, Nellie Hermann, and Michael Devlin, 'Close Reading and Creative Writing in Clinical Education: Teaching Attention, Representation, and Affiliation', Academic Medicine 91, no. 3 (2016): 345-50.

16 Pellico et al., 'Looking Is Not Seeing'.

17 Mark Perry et al., 'The Effectiveness of Arts-Based Interventions in Medical Education: A Literature Review', Medical Education 45, no. 2 (2011): 141-48; Mina Borromeo, Heather Gaunt, and Neville Chiavaroli, 'The Arts and Visual Thinking in Education at the Melbourne Dental School', in Creative Arts in Humane Medicine, ed. Cheryl L. McLean (Alberta: Brush Education, 2014), 40-54; Wellbery and McAteer, 'To See or Not to See'. 


\section{Hands-on learning}

The observation workshops for medical students were a way to highlight skills of attention that are fundamental to their work as doctors, yet the actual style of learning - that is hands-on through practical engagement with experimentation - is hardly new to medical students. They learn about anatomy through dissection, physical examination skills on each other, pathology through microscopy and community health through placements. Medical students are actually constantly working with their hands, more so than many other fields and disciplines in a university. In the field of social sciences, despite theoretically attending to the body through theories of embodiment and enskillment, there is little explicit attention given to sensory ways of learning. Students of the humanities rarely get their hands dirty on the stuff of history other than through texts, whether primary or secondary sources. The sensory and affective turn in the humanities, and the widespread recognition of sensory methods is changing this, yet university curricula are often bound within a particular form of education that sometimes forgets bodies and materials along the way.

In this section, I want to explore a growing and exciting series of experiments by educators that are calling out for greater attention to the sensory, to materials and to embodied learning, through workshops in academic teaching. This is taking learning back to the workshop, to a place where there is not a set body of knowledge to be learned, but rather materials to be tinkered with, and knowledge to be made with teachers.

Historians of science have led the way with these experiments, scholars such as Otto Sibum showing that scientific knowledge can be understood differently if students engage with the experiments they are reading about. ${ }^{18}$ Teachers guide in the way they facilitate discussion, and the way they replicate workshops for future students so that the learning that happens in these experiments is very much like that of an apprentice in a workshop. Further examples can be found in other areas of history, such as the history of leisure, where the media historian Kristen Haring asked her students to learn how to cook from Julia Child videos (this inspired our own experiment, which Kristen Haring also advised), as a way to understand about the role of television at the time, or make illustrations and notations for a manuscript, to understand more about text. ${ }^{19}$

Could the social sciences be more hands-on? Anthropology has traditionally taught students through doing fieldwork, but Tim Ingold takes this

18 Heinz Ottto Sibum, 'Working Experiemts: A History of Gestural Knowledge', The Cambridge Review 116, no. 2325 (1995): 25-37.

19 Erin Springsteen, 'Stanford Humanities Students Cook up Julia Child's Recipes, Study History', Stanford News, 8 April 2016, https://news.stanford.edu/2016/04/08/ kitchen-french-chef-040616/. 
further in his book Making, ${ }^{20}$ which is an example of how anthropology learns through education and how, as he explores in later work, anthropology is education. He looks at how reading anthropology can be a sensory education through guiding a close study of materials and the environment, in practical lessons (that complement readings).

Hands-on learning, as a phrase, might seem something of a tautology, for as I have argued throughout this book, sensory education is an embodied, socio-material happening, engaging bodies in an environment of relations. Yet it is not always taken for granted that one's body is involved in the processes of learning. There is also a risk in the authority given to knowledge by the hand. There might be seen to be magical, or even religious properties, that are given to the sense of touch, ${ }^{21}$ and the truthfulness of its practice. The same can be seen in the call for doctors to be more 'hands-on', that they may have lost their 'sense of touch'. ${ }^{22}$ However, what I am advocating is more for an attention to material thinking, ${ }^{23}$ a focus on construction of things that plays out in sensory ways.

In essence, I believe that the social sciences and humanities could be more hands-on. The university could in fact be more like a workshop as a place of experimentation amidst social rules, where the guiding principles are sensory exploration with others rather than knowing the answers ahead of time. This might help to train observers rather than followers. It would be an education of attention, that, following from Thomas $\mathrm{Csordas}^{24}$ might offer a somatic mode of attention exploring the culturally elaborated ways of attending to and with one's body in settings that include the embodied presence of others.

\section{Skillshare}

The final kind of workshop I want to explore in this chapter, the academic workshop, is a site where sensory knowledge is also often remarkably absent. In exploring its form and possibilities, I also want to rethink the academic workshop as a site of sensory learning.

In academia, the distinction between learning and teaching in events like workshops is often clear - a presenter gives a talk, the audience listens. There may be time for questions. The audience learns more about the presenter's research. These days the materials used may be a PowerPoint slide, perhaps a handout or poster. What if we rethought these knowledge-sharing

20 Tim Ingold, Making: Anthropology, Archaeology, Art and Architecture (London: Routledge, 2013).

21 Sennett, Craftsman, 61.

22 Abraham Verghese, 'Treat the Patient, Not the CT Scan', The New York Times, 27 February 2011, https://www.nytimes.com/2011/02/27/opinion/27verghese.html.

23 Paul Carter, Material Thinking: The Theory and Practice of Creative Research (Melbourne: Melbourne University Press, 2004).

24 Thomas Csordas, 'Somatic Modes of Attention', Cultural Anthropology 8 (1993). 
practices, and at the same time attended more closely to the materiality and sociality of the event? Workshops in academia are intended to be small scale events but sometimes there is little difference between the more passive talking/listening formats of the larger meetings. What if an academic workshop was more like a cooking class?

Just as the academic conference, the academic talk, the academic journal article, peer review and other aspects of academic tradition need to be, and are being, radically rethought, so too does the academic workshop. I suggest that if it becomes more of a site of sensory education, that this may be a way in which to bring back some of the creative possibilities of workshopping so that they are not only sites of social rituals and hierarchies, protocols and instructions, but also of the kind of experimentation that scientific knowledge (and cooking) flourishes on.

What are some important elements in rethinking the academic workshop? The first is place. As I introduced in the beginning of the chapter, workshops are places too, often with the romantic imagery of tools on the walls and wooden benches. What would be the tools and the benches of an academic workshop? What is the location in which the workshop will be housed, the landscape of learning?

Recently our research team organised a workshop on the role of materials in learning/teaching. We thought carefully about where to have the workshop and what materials would be in it; while scouting locations for our omelette experiments we came across some teaching kitchens at a local hospitality school. Located at the margins of the city, in a beautiful chateau, this was a place dedicated to education. The staff were all students training in hospitality, from those who waited in the restaurants to those who made the beds up in the morning. It was the ideal location for these academics to gather because the whole site was implicated in the workshop.

The hotel school had its own geographical, botanical, historical, architectural specificities, all materials which became part of our workshop arrangements sometimes explicitly, sometimes less explicitly. We played deliberately with the location in a number of ways, by asking many of our guests to run site-specific practical workshops for those coming to the small gathering (workshops within a workshop). In doing so we also learned from the site as well as from our guides. I will elaborate on our event as one example of a possible way to rethink the habitual traditional academic format of the workshop.

The workshop opened in a way we wanted to continue, through learning alongside each other. A historian and STS scholar Joeri Bruyninckx, who has written on the histories of listening to birds, ${ }^{25}$ hosted the first workshop

25 Joeri Bruyninckx, Listening in the Field: Recording and the Science of Birdsong (Cambridge, MA: MIT Press, 2018). 
on field guides. He sourced guides which may or may not speak to the local area, both written, digital as well as a human guide. As visitors arrived at the workshop Joeri invited them to explore the landscape and its inhabitants with others and with the guides. The guides were seen as ways of 'attuning' participants to each other, and to the ecological, geological and historical trajectories with we would be temporarily aligning ourselves during the workshop event. At the end, participants discussed what they learned in their meanderings, how the guides acted as ways of ordering sensory attention.

Later in the event one of the invited historians, Kristen Haring, ${ }^{26}$ ran a napkin folding workshop, a lesson in attending to the sensory details of folding and replication, through repetitive activity of folding linen napkins. We started at the breakfast table of the hotel, dirty napkins strewn around, and then moved to another space, where we folded many, many napkins. Next door the hospitality students were also folding napkins, these being for the lunch service. Through the exercise of folding we discussed hands-on learning in history and other fields. Rather than give a talk on how to bring hands-on exercises to bear on intellectual questions, Kristen worked cleverly with the location to give a sensory lesson, one which was remembered in the limbs of participants, as they listened and talked and reflected on what it meant to replicate lessons from the past.

The location played out in a different way in an outdoor workshop, run by an anthropologist Rachel Harkness. ${ }^{27}$ In this workshop Rachel attended to the notion of dwelling, and what it means to dwell in a space, by asking participants to work with clay and a site of their choosing in the grounds of the hotel. Working with their fingers in the cold clay, that hardened in cloying ways and changed colour as it dried, the participants of this workshop found themselves working on trees and trunks creating inhabitations, on the side of ponds and on window ledges. They needed to work not only with the clay but also with their surroundings, working in correlation with the academic readings and discussions that Rachel provided, thinking about architecture, scale and inhabitation.

Other workshops that were run by participants included an exercise in philosophical thinking using overhead projector drawings (a nod back to a visual teaching technology that demanded a kinaesthetic engagement that differs from PowerPoint), ${ }^{28}$ a science lesson replicated by Selase Dorledzi a teacher from the Practical Education Network ${ }^{29}$ in Ghana, a performative study of ancient recipes that imagined the historical workshop ${ }^{30}$ and a LED

26 Kristen Haring, Ham Radio's Technical Culture (Cambridge, MA: MIT Press, 2007).

27 Rachel Harkness, ed., An Unfinished Compedium of Materials, Knowing from the Inside (Aberdeen: University of Aberdeen, 2017).

28 Ludger van Dijk and Erik Rietveld, 'Situated Anticipation', Synthese (2018).

$29 \mathrm{https} / / / \mathrm{www}$. practicaleducationnetwork.com

30 By the ARTECHNE group, a project led by Sven Dupré, https://artechne.wp.hum.uu.n1/. 
light making workshop, ${ }^{31}$ where participants studied candlelight then tried to code it from open-source hardware. We also had discussions in groups and while walking. We brought objects to study and attend to in an activity led by the historian of loss Kate Smith. ${ }^{32}$ We conducted moving exercises throughout the day, with the anthropologist and artist Ulrike Scholtes ${ }^{33}$ exploring with the group how feeling techniques could be employed as tools to think and help researchers, write, think and work. In doing so, we constantly attended to objects and our bodies. There were also video making lessons for participants, given by medical historian and filmmaker Paul Craddock, ${ }^{34}$ who documented the workshops on site, drawing from his own work on embodied expertise.

In her book The Art of Gathering, ${ }^{35}$ Priya Parker argues that too often templates and staid old formats are used in gatherings. In doing so, she suggests, the possibility of creating something memorable, even transformative can be lost. Our research team is certainly not alone in wanting to make workshops more hands-on and many of the people we invited were also experimenting with the form of the workshop. We decided, in particular, that we would not only have rules for the workshop, but also try to dissolve some of the hierarchies which we thought were inherent in the presentation styles and group working formats of other workshops. We decided to call our workshops Skillsshare workshops after a program initiated as part of the Transition Town movement initiated in Totnes, the UK.

In Totnes, Rob Hopkins started Skillshare, as part of his broader goal towards transitioning into a sustainable community. Skillshare involves people sharing with others the skills they know, experimenting together with their hands and with materials. There is no clear teacher, no clear learner. Everyone tries to teach, everyone tries to learn. Sensory education come from others, not necessarily the workshop guide. Learning is a transformation, not an acquisition of a skill.

Perhaps one of my favourite moments of the whole workshop which exemplified this happened outside of the scheduled activities. We deliberately allowed for large chunks of unplanned time, so participants could make their own connections, or just attend to their work and surrounds in whichever way they wished. People knitted on the lawn, played charades in the evening and hosted movement classes on the lawns. I had struck up a conversation

31 Tom Igoe, Making Things Talk, 2nd ed. (San Francisco: O’Reilly, 2011).

32 Kate Smith, Material Goods, Moving Hands: Perceiving Production in England, 1700-1830 (Manchester: Manchester University Press, 2014).

33 'Research and Education in Moving Sensitivities', the website of Ulrike Scholtes. Accessed 27 May 2019, http://ulrikescholtes.nl.

34 Paul Craddock, Dragon in a Suitcase: A Cultural History of the Art of Transplantation (Penguin, forthcoming).

35 Priya Parker, The Art of Gathering: Create Transformative Meetings, Events and Experiences (n.a.: Portfolio Penguin, 2018). 


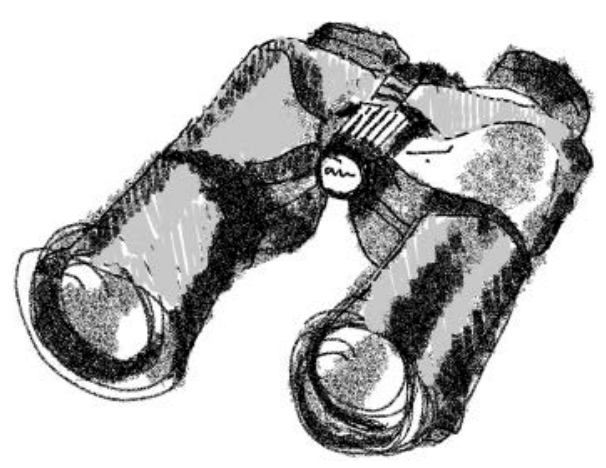

Figure 4.3 Field binoculars.

with one of the philosophers about our hobbies, and we realised we would love to learn what the other one knew about - Ludger had wanted to learn how to knit and I had always wanted to learn how to use a pair of binoculars I had been given recently as a gift (Figure 4.3).

Finding a quiet moment in the program, we headed outdoors into the sunshine, a couple of pairs of binoculars left over from field guide workshop to hand. It was a gorgeous July day, the grounds in full summer splendour. I immediately put the binoculars up to my eyes, but Ludger stopped me and said that first I needed to orientate my body towards the birds I wanted to watch, I needed to watch and observe these first. So, we looked around and he guided me to see birds I hadn't noticed before, sitting on trees and elements of the building architecture. I turned my body, re-orientated my feet, looked to where I wanted to look. Then Ludger taught me I needed to anticipate, to anticipate the direction the birds might fly - towards water, for example, or their nest. He knew about this from many hours watching birds and reading guides, ${ }^{36}$ but I might begin to learn it too, if I paid attention. Anna Tsing also describes this knowledge in the mushroom hunters, how they could find the fungi through feel alone, because they knew the spots where the mushrooms were likely to emerge. She writes that

this combination of intimate knowledge and feeling through the duff focuses [her] attention back on the here and now, the middle of things. We trust our eyes too much. I looked at the ground and thought, "there's nothing here". But there was.... ${ }^{37}$

36 John Law and Michael Lynch, 'Lists, Field Guides, and the Descriptive Organization of Seeing: Birdwatching as an Exemplary Observational Activity', Human Studies 11, no. 2/3 (1988): 271-303.

37 Lowenhaupt Tsing, The Mushroom at the End of the World, 277. 
Finally, I put the binoculars to my eyes, and adjusted the lens. It reminded me of pathology classes as a medical student, trying to find a 'field of view' and zooming in and out of focus quickly and inexpertly. I saw a bird, lost it, found it again. Time slipped away. I got lost in these moments, Ludger patient, quietly watching alongside me. We had had many conversations about skill and learning in the workshop and about our shared academic interests, but it was through this bodily engagement together in watching birds on that gorgeous summer day, that I understood something more about what it was we were learning together.

\section{Bibliography}

Alda, Alan. If I Understood You, Would I Have This Look on My Face?: My Adventures in the Art and Science of Relating and Communicating. New York: Random House, 2017.

Bleakley, Alan, Richard Farrow, David Gould, and Robert Marshall. 'Making Sense of Clinical Reasoning: Judgement and the Evidence of the Senses'. Medical Education 37, no. 6 (2003): 544-52.

Borromeo, Mina, Heather, Gaunt and Neville Chiavaroli. 'The Arts and Visual Thinking in Education at the Melbourne Dental School'. In Creative Arts in Humane Medicine, edited by Cheryl L. McLean, 40-54. Alberta: Brush Education, 2014.

Bosanquet, David C., James C. D. Glasbey, and Raphael Chavez. 'Making Music in the Operating Theatre'. British Medical Journal 349 (2014): $g 7436$.

Brown, David, Elizabeth Grierson, George Jelinek, Keely Macarow, Philip Samartzis, Tracey Weiland, and Craig Winter. Designing Sound for Health and Wellbeing. Melbourne: Australian Scholarly, 2012.

Bruyninckx, Joeri. Listening in the Field: Recording and the Science of Birdsong. Cambridge, MA: MIT Press, 2018.

Carter, Paul. Material Thinking: The Theory and Practice of Creative Research. Melbourne: Melbourne University Press, 2004.

Charon, Rita, Nellie Hermann, and Michael Devlin. 'Close Reading and Creative Writing in Clinical Education: Teaching Attention, Representation, and Affiliation'. Academic Medicine 91, no. 3 (2016): 345-50.

Craddock, Paul. Dragon in a Suitcase: A Cultural History of the Art of Transplantation. Penguin forthcoming.

Csordas, Thomas. 'Somatic Modes of Attention'. Cultural Anthropology 8 (1993): 135-56.

Haring, Kristen. Ham Radio's Technical Culture. Cambridge, MA: MIT Press, 2007.

Harkness, Rachel, ed. An Unfinished Compedium of Materials, Knowing from the Inside. Aberdeen: University of Aberdeen, 2017.

Harris, Anna, and Eleanor Flynn. 'Medical Education of Attention: A Qualitative Study of Learning to Listen to Sound'. Medical Teacher 39, no. 1 (2017): 79-84.

Harris, Anna, and Melissa van Drie. 'Sharing Sound: Teaching, Learning and Researching Sonic Skills'. Sound Studies 1, no. 1 (2015): 98-117.

Igoe, Tom. Making Things Talk. 2nd ed. San Francisco: O’Reilly, 2011.

Ingold, Tim. 'Situating Action V: The History and Evolution of Bodily Skills'. Ecological Psychology 8, no. 2 (1996): 171-82. 
. The Perception of the Environment: Essays on Livelihood, Dwelling and Skill. London: Routledge, 2000.

. Making: Anthropology, Archaeology, Art and Architecture. London: Routledge, 2013.

- Anthropology andlas Education. London: Routledge, 2018.

Jamison, Leslie. The Empathy Exams. New York: Graywolf Press, 2014.

Lave, Jean. Learning and Everyday Life. Cambridge: Cambridge University Press, 2019.

Lave, Jean, and Etienne Wenger. Situated Learning: Legitimate Peripheral Participation. Cambridge: Cambridge University Press, 1994.

Law, John, and Michael Lynch. 'Lists, Field Guides, and the Descriptive Organization of Seeing: Birdwatching as an Exemplary Observational Activity'. Human Studies 11, no. 2/3 (1988): 271-303.

Lowenhaupt Tsing, Anna. The Mushroom at the End of the World: On the Possibility of Life in Capitalist Ruins. Princeton: Princeton University Press, 2015.

Parbery-Clark, Alexandra, Erika Skoe, and Nina Kraus. 'Musical Experience Limits the Degradative Effects of Background Noise on the Neural Processing of Sound'. The Journal of Neuroscience 29, no. 45 (2009): 14100-07.

Parker, Priya. The Art of Gathering: Create Transformative Meetings, Events and Experiences. n.a.: Portfolio Penguin, 2018.

Pellico, Linda Honan, Thomas C. Duffy, Kristopher P. Fennie, and Katharine A. Swan. 'Looking Is Not Seeing and Listening Is Not Hearing: Effect of an Intervention to Enhance Auditory Skills of Graduate-Entry Nursing Students'. Nursing Education Perspectives 33, no. 4 (2012): 234-39.

Perry, Mark, Nicola Maffulli, Suzy Willson, and Dylan Morrissey. 'The Effectiveness of Arts-Based Interventions in Medical Education: A Literature Review'. Medical Education 45, no. 2 (2011): 141-48.

Pesic, Peter. 'Music, Mechanism, and the "Sonic Turn" in Physical Diagnosis'. Journal of the History of Medicine and Allied Sciences 71, no. 2 (2016): 144-72.

Polanyi, Michael. The Tacit Dimension. New York: Doubleday and Company, 1966.

Rancière, Jacques. The Ignorant Schoolmaster: Five Lessons in Intellectual Emancipation. Stanford: Stanford University Press, 1990.

Scholtes, Ulrike. 'Research and Education in Moving Sensitivities' (Website). Accessed 27 May 2019. http://ulrikescholtes.nl.

Sennett, Richard. The Craftsman. London: Penguin Books, 2008.

Sibum, Heinz Ottto. 'Working Experiments: A History of Gestural Knowledge'. The Cambridge Review 116, no. 2325 (1995): 25-37.

Smith, Kate. Material Goods, Moving Hands: Perceiving Production in England, 1700-1830. Manchester: Manchester University Press, 2014.

Springsteen, Erin. 'Stanford Humanities Students Cook up Julia Child's Recipes, Study History'. Stanford News, 8 April 2016. https://news.stanford.edu/2016/04/08/ kitchen-french-chef-040616/.

Van Dijk, Ludger, and Erik Rietveld. 'Situated Anticipation'. Synthese (2018): 1-23. Verghese, Abraham. 'Treat the Patient, Not the CT Scan'. The New York Times, 27 February 2011. https://www.nytimes.com/2011/02/27/opinion/27verghese.html.

Vouhé, Pascal R. 'The Surgeon and the Musician'. European Journal of Cardio-Thoracic Surgery 39, no. 1 (2011): 1-5.

Wellbery, Caroline, and Rebecca A. McAteer. 'The Art of Observation: A Pedagogical Framework'. Academic Medicine, 90, no. 12 (2015): 1624-30. 


\section{Lesson 5 Make your own lesson}

If you have worked your way through the book, especially the Lessons, by now you may have thought of some lessons of your own. I have made a box on this page to write down or paste in your own ideas, with the following two pages for any notes, jottings and literature you think relates to this lesson (if this is not a library book!). Hopefully this will give you a chance to tailor this book to your own interests and experience. If you lend this book to someone else, or you return to it later, you have an individually crafted edition which makes your book unique and adds your own sensory knowledge and curiosity.

When designing your lesson think about:

- Who is this lesson designed for? Your students? Your family members? Your local community?

- What materials are needed?

- How do you want to represent your instructions?

- What forms of notation will you invite in recording the observations? 
128 Make your own lesson

Notes:

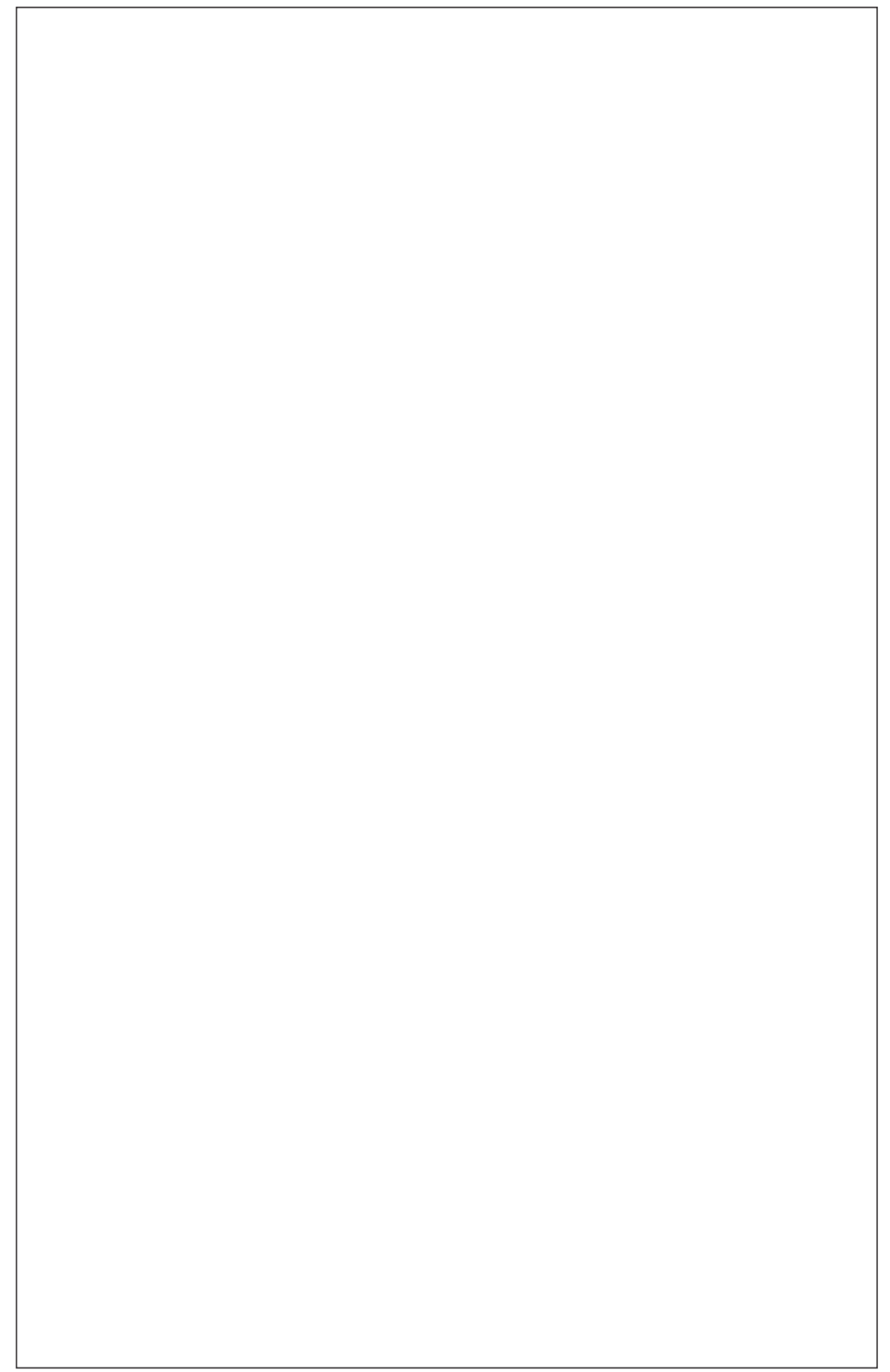




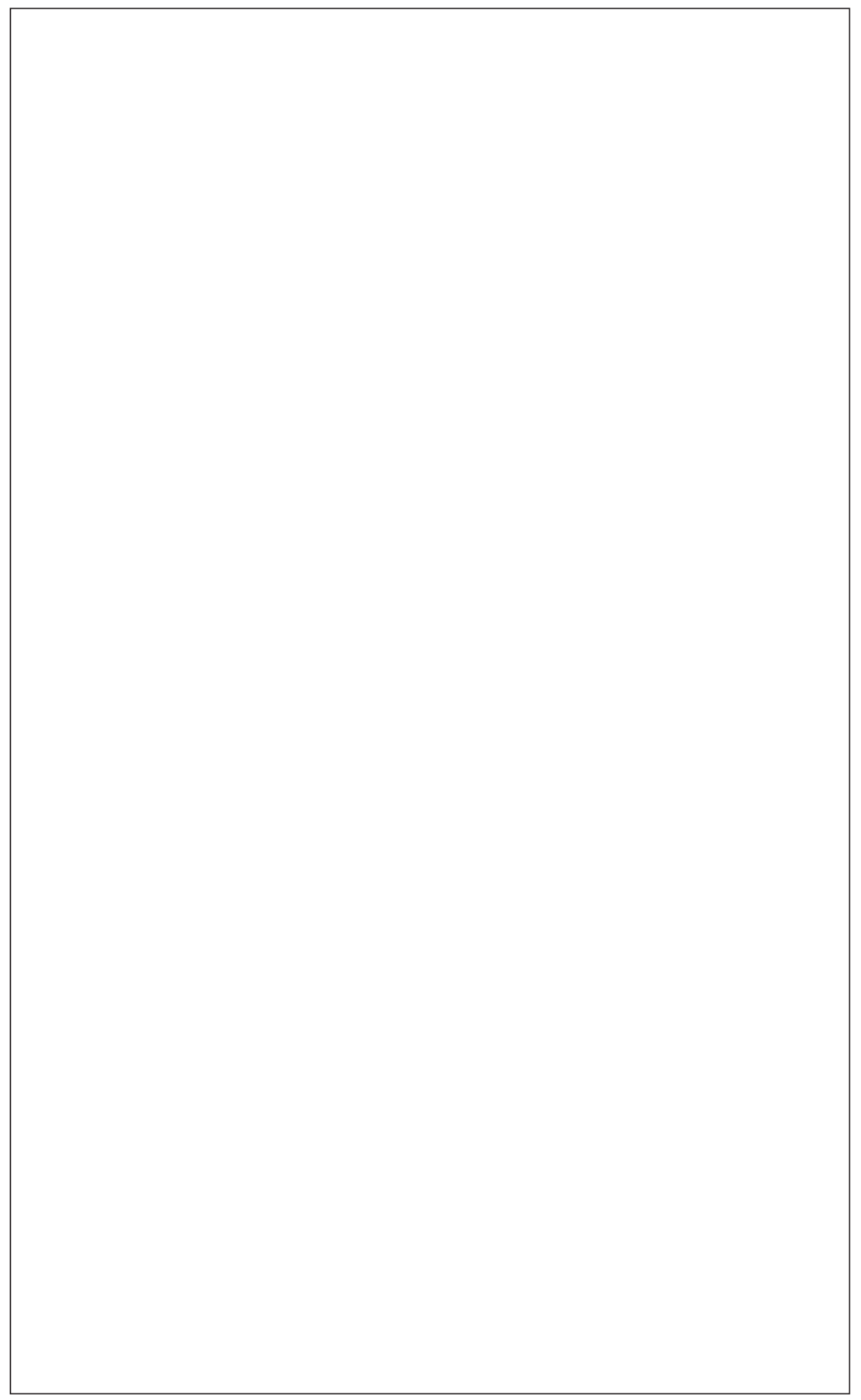




\section{Repackaging sensations}

'The senses' are used commonly today to sell a broad range of products. In a recent email newsletter from my yoga teacher she promoted a new range of teas which attend to 'the senses' - the website for the product suggesting that consumers should be: 'Paying attention to yourself, taking a moment, opening yourself to the present and truly experiencing it with all your senses.' ${ }^{1}$ This is the inspiration for - TEA $®$ For the Senses.

The TEA ${ }^{\circledR}$ For the Senses are likened to 'an evening hug', 'a day of sunshine', 'a sea breeze' or 'a trip to Provence', all sensory experiences that extend beyond that of smelling, drinking, and holding a tea-cup, and, in a commercialised Proustian moment, extend out not only to one's past but also to possible future sensory memories that could be evoked from a simple cup of tea (Figure 5.1).

In this chapter, I explore the ways in which commercial industries have repackaged 'the senses' and sold them back to us. This I argue, is also a form of sensory education. While institutions and universities, books and TV shows are all involved in very explicit sensory lessons, I suggest that the lessons that come with commercial products are often more implicit and ubiquitous.

I have already offered glimpses of some of these hidden lessons in food (which is again the focus of this chapter) - the patented wine-tasting wheel, for example, which helps to train novice wine palates and helps to sell wines. There was the wine tasting kit which is available in a range of quantities and prices. There were the coffee cupping classes which helped to sell expensive coffees, for as Jenny Goldstein writes: 'Consumers maintain the demand [created by producers, of quality] only once they are introduced to and convinced of the coffee's value; only then are they willing to pay a premium price for those embedded values'.

1 YOGI TEA ${ }^{\circ}$ For the Senses, accessed 27 May 2019, https://www.yogitea.com/en/senses/.

2 Jenny Elaine Goldstein, 'The "Coffee Doctors": The Language of Taste and the Rise of Rwanda's Specialty Bean Value', Food and Foodways 19, no. 1-2 (2011): 143. 


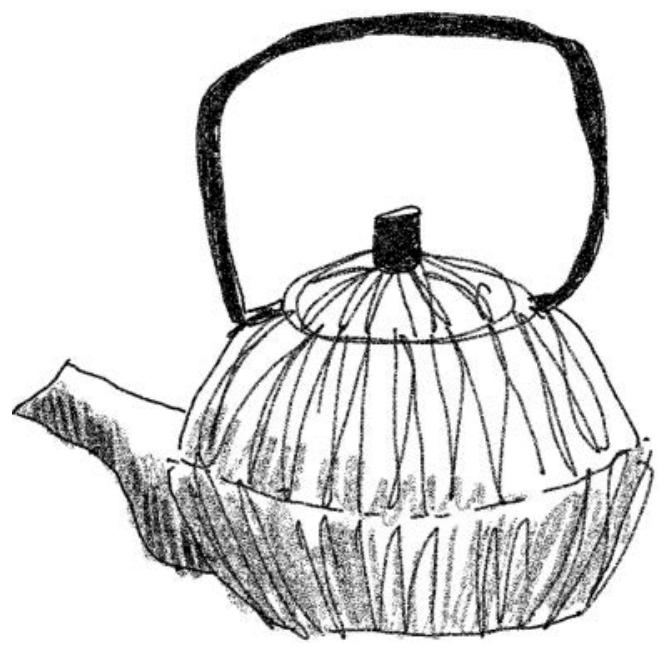

Figure 5.1 Japanese teapot.

Recognising that how sensory practices are cultivated cannot be divorced from commerce and industry, in this chapter, I look at how sensations are extracted, isolated and re-inserted back into sensory experiences. The best analogy I have for describing this is likening it to a bizarre dish I was once served at a restaurant. The chef had pulped celery sticks, put them in a piping bag and recreated a little sliver of celery on a large white plate, in the exact shape of a celery stick. The celery had been repackaged, to heighten a sensory experience. Instances abound, as I explore throughout this chapter, of how commercial industries repackage sensory experiences for sale. With so much focus nowadays on avoiding distraction through intentional, mindful, minimal and slow living, it is hard to deny that 'the senses' have become a significant experiential commodity in contemporary life, infiltrated by capitalism.

Anthropologists have long been interested in the commodification of bodily experience, ${ }^{3}$ and from the 1990s onwards have turned their attention to how the body has been an object or commodity that could be bartered, stolen or sold. Often drawing from Marxist discourses, these scholars were interested in the capitalised economic relations between humans in which bodies are the token of economic exchange, a theme that could also be seen to have its roots in topics such as slavery, magic, and cannibalism. Anthropologists interested in commodification and embodiment have explored

3 Nancy Scheper-Hughes and Loic Wacquant, eds., Commodifying Bodies (London: SAGE Publications, 2002). 
sites where the body becomes objectified. ${ }^{4}$ Sites of sensory experience are key here.

Anthropologists interested in the commodification of the senses have looked at topics such as sensory marketing and sensory museums with scholars David Howes and Constance Classen offering erudite analysis of the historical and contemporary use of the senses to entice customers and visitors. ${ }^{5}$ Other anthropologists have explored the commodification of other sensory training, such as teaching Eastern movement forms like yoga, meditation and tai chai, for example, which require new kinds of training of the body. ${ }^{6}$ Anthropologists with an interest in science and technology studies, have looked at how sensing is enacted and constructed through particular flavours (e.g., unami) ${ }^{7}$ or food products, such as bottled water ${ }^{8}$ and chocolate, ${ }^{9}$ focusing on how the material, economic and political get enmeshed. Consumers can be active participants in this process, as cultural theorist Tania Lewis ${ }^{10}$ shows in her study of how food is shared via social media, through making and watching cooking videos online. These are practices that require, she argues, not only media literacy but awareness of the commercial logics underpinning information and communication ecologies. But as STS scholars Christy Spackman and Gary Burlingame, ${ }^{11}$ and Ella Butler $^{12}$ show, consumers can also be ignored in sensory politics that favour experts and machines over novices.

Contributing to this work on the commodification of embodiment and the literature in anthropology and STS on commercialisation of sensing, I consider the commodification of sensory education, suggesting that examples of this can be found throughout everyday life. Training sensing has

4 Lesley Sharp, 'The Commodification of the Body and Its Parts', Annual Review of Anthropology 29 (2000): 287-328.

5 Constance Classen, The Museum of the Senses: Experiencing Art and Collections (London: Bloomsbury Academic, 2017); David Howes and Constance Classen, Ways of Sensing: Understanding the Senses in Society (New York: Routledge, 2014); Laura Spinney, 'Selling Sensation: The New Marketing Territory', NewScientist, 11 September 2013, https://www. newscientist.com/article/mg21929340-400-selling-sensation-the-new-marketing-territory/.

6 David Brown and Aspasia Leledaki, 'Eastern Movement Forms as Body-Self Transforming Cultural Practices in the West: Towards a Sociological Perspective', Cultural Sociology 4, no. 1 (2010): 123-54.

7 Sarah Tracy, 'Delicious Molecules: Big Food Science, the Chemosenses and Umami', The Senses and Society 13, no. 1 (2018): 89-107.

8 Christy Spackman and Gary A. Burlingame, 'Sensory Politics: The Tug-of-War between Potability and Palatability in Municipal Water Production', Social Studies of Science 48, no. 3 (2018): 350-71.

9 Susan Terrio, Crafting the Culture and History of French Chocolate (Berkeley: University of California Press, 2000).

10 Tania Lewis, 'Digital Food: From Paddock to Platform', Communication Research and Practice 4, no. 3 (2018): 212-28.

11 Spackman and Burlingame, 'Sensory Politics'.

12 Ella Butler, 'Tasting Off-Flavors: Food Science, Sensory Knowledge and the Consumer Sensorium', The Senses and Society 13, no. 1 (2018): 75-88. 
become an industry that sells a 'slow' way of life, a new focus of awareness of products, and a new way of partaking in practices such as eating which brings particular sensations to the fore. As de Solier ${ }^{13}$ has written in her book on foodie culture, learning new skills, training, is a way of forming identity in contemporary life, especially for the middle classes living in relative comfort who can afford to turn their attention to such concerns.

Using examples that anthropologists have studied in the food industry, as well as new dining experiences and the Slow Food movement, I focus less on identify formation, as others $\mathrm{do}^{14}$ and more at how the commodification of sensory education both reiterates and highlights social norms through what it packages back to us. That is, by paying attention to how industry is teaching us how to look and what to notice, we can learn more about the values of our times. The next section treads into this territory by looking at the histories and anthropologies of sensory marketing which foregrounds many of the practices I discuss, and how industries are deeply entangled in what sensory knowledge gets to matter and be sold back to consumers.

\section{Sensory marketing}

Sensory marketing is marketing which 'engages the consumers' senses and affects their perception, judgment and behaviour'. ${ }^{15}$ While many marketers claim that sensory marketing is a new phenomenon, ${ }^{16}$ David Howes and Constance Classen show that the practices have much deeper historical roots. They argue that sensory marketing was important in the eighteenth century for example in department and variety stores. Later in the twentieth century, according to Howes and Classen, there was less focus on the senses, although there were certainly exceptions to this. Nonetheless, most scholars agree that attending to the senses in advertising has now regained new importance. ${ }^{17}$

Howes and Classen list a host of examples of contemporary sensory marketing in their work. They write about Salem cigarettes announcing that they can 'stir the senses', coffee that 'awakens the senses', or the claim in some

13 Isabelle De Solier, Food and the Self: Consumption, Production and Material Culture (London: Bloomsbury, 2013).

14 Brown and Leledaki, 'Eastern Movement Forms as Body-Self Transforming Cultural Practices in the West, 123-54; De Solier, Food and the Self.

15 Aradhna Krishna, 'An Integrative Review of Sensory Marketing: Engaging the Senses to Affect Perception, Judgment and Behavior', Journal of Consumer Psychology 22, no. 3 (2012): 333.

16 Howes and Classen, Ways of Sensing.

17 Martin Grunwald, Homo Hapticus: Warum Wir Ohne Tastsinn Nicht Leben Koennen (Muenchen: Droemer Verlag, 2017); Howes and Classen, Ways of Sensing; Charles Spence and Betina Piqueras-Fiszman, The Perfect Meal: The Multisensory Science of Food and Dining (Chichester: Wiley-Blackwell, 2014). 
automobile advertisements that the car can stimulate even a sixth sense. ${ }^{18}$ Perhaps one of my favourite examples of sensory marketing is the Trappist brewery in the Netherlands called La Trappe. Set in a gorgeous monastery, which customers can tour after their beer samplers and cheese plates, the slogan of the site is 'taste the silence'. There is a sonic terroir which is incited through this slogan, that drinking the Trappist beer would bring one close to a monastic life that values silent and simple ways of being.

This marketing which evokes listening, or rather silence, shows a more expansive sensory trend in marketing. Sensory marketing specialist Aradhna Krishna $^{19}$ and psychologist Martin Grunwald ${ }^{20}$ for example argue that there has been a shift in the last 20 years from a focus on visual material in marketing to other sensory experiences. Krishna and Schwarz ${ }^{21}$ trace this back further, seeing a shift in consumer research from the 'cognitive revolution' in the 1970s to the recent interest in the senses and their role in human perception and thus in consumer behaviour. For Grunwald this is particularly evident in haptic marketing, what he argues is in some way 'an answer to the digital age' in that consumers touch advertising as well as see it online. ${ }^{22} \mathrm{He}$ writes that there was a realisation among marketers that consumers are so overloaded with information that their attention could be better captured with physical haptic advertisements. Howes and Classen also describe how physical stores need to compete against online retailers and do so with advertising products in particular where tactile, olfactory or gustatory aspects are prominent. The opening of physical stores for online retailing sites shows new iterations of this phenomena. ${ }^{23}$

For Howes and Classen sensory marketing has no small influence on the world, but rather, they write, 'is taking charge of fashioning the sensory imaginaries of the twenty-first century'. ${ }^{24}$ The pedagogical enterprise is all about fashioning imaginaries. Consumers need to be trained to recognise the product's qualities in order to buy them. ${ }^{25}$ This was evident in the coffee cupping example, where the classes are a way in which consumers can learn about why they need to spend so much money on their beans. It appears again in the next section when consumers in France needed to be trained to appreciate dark chocolate. A new sensory awareness is necessary to sell products, sensations becoming something of an experiential commodity for

18 Howes and Classen, Ways of Sensing, 125.

19 Krishna, 'Review of Sensory Marketing'.

20 Grunwald, Homo Hapticus.

21 Aradhna Krishna and Norbert Schwarz, 'Sensory Marketing, Embodiment, and Grounded Cognition: A Review and Introduction', Journal of Consumer Psychology 24, no. 2 (2014): $159-68$.

22 Grunwald, Homo Hapticus, 237.

23 Howes and Classen, Ways of Sensing.

24 Howes and Classen, Ways of Sensing, 151.

25 David Parisi, "Fingerbombing, or "Touching is Good": The Cultural Construction of Technologized Touch'. The Senses and Society 3, no. 3 (2008): 307-28. 
the modern-day self-improving consumer in many middle-class Western settings.

This review of the historical and anthropological literature on sensory marketing shows that while multi-sensory experience has always been important in selling products, industries are trying harder than ever before to educate consumers to hone and tune their senses to appreciate and buy their products. Krishna ${ }^{26}$ makes an important distinction between sensory marketing as a managerial practice, where it is used to create triggers that help define consumers' perceptions of a product, from the practice of companies to better understand sensing as a practice as it applies to consumer behaviour. It is the latter I now want to explore, through the case of chocolate, water, unami and off-flavours, where not only are consumer preferences attempted to be better understood, but also how industries attempt to change consumer needs, wishes and tastes, through their products.

\section{Old tastes, new tastes}

Who has not been tempted by those free samples in supermarkets, crying out to the hungry and vulnerable doing the pre-dinner shop. Samples are an excellent example of how companies must do work to train their customers, to tempt their taste buds and to offer a little explanation at the same time about a product that might be otherwise unfamiliar. Sometimes sellers have to work a bit harder, as was the case with chocolatiers in the 1980s in France.

In her book Crafting the Culture and History of French Chocolate, anthropologist Susan Terrio ${ }^{27}$ explores the lengths that French chocolate makers had to go to guide consumers to like dark chocolate, in order to distinguish the French chocolates from the white sweet Belgian concoctions flooding the market. Terrio shows the work that went into an embodiment of a new chocolate taste standard, through a concerted campaign to educate taste vocabularies. Calling this a 're-educating of French palates' that had been 'deformed' by exposure to foreign fakes, ${ }^{28}$ the campaign aimed to re-establish an image of French chocolate as a luxury good that carried cultural authenticity. Terrio shows how the campaign involved travel guides, newspaper editorials and TV interviews, school visits by chefs, guided tastings and books such as Le Guide des Croqueurs de Chocolat (1988). Stores showed craft chocolatiers making chocolates behind glass so that customers could see the work involved, while cookbooks described the history of production and techniques. Just as Geneviève Teil appreciated perfumes more after her olfactory lessons that taught her about the technical difficulties of

26 Krishna, 'Review of Sensory Marketing'.

27 Terrio, Culture and History of French Chocolate.

28 Terrio, Culture and History of French Chocolate, 40-1. 
production, ${ }^{29}$ these practices also aimed to facilitate appreciation, through sensing, of the technical skills of making an object. This is important in craft industries, which require the consumer to appreciate the extra challenges of making that also add more to the price tag. As Terrio writes,

one of the explicit goals of the gastronomic texts is to enhance consumers' knowledge about production, both industrial and artisanal. Consumers must be able to authenticate the rare craft version from the ubiquitous industrial one. However, this information about production remains incomplete and highly controlled. ${ }^{30}$

While this knowledge was important in taste formation, a new taste standard for chocolate eating also needed to be cultivated. Terrio herself underwent a small lesson, with one of the master chocolatiers. As she tastes she recalls the lessons she learned in Le Guide, where readers are invited to

marshal their senses ... "to look for a shiny coating, to smell the deep and power chocolate bouquet, to feel the creamy texture on the palate, and to taste the subtle combination of bitter and sweet notes in the composition". 31

Milk chocolates are given the lowest rating in the guide, and Terrio is made aware, in her guided tasting, that she should like the dark ones.

Because milk chocolate attended, the chocolatiers in France believed, to base pleasures, they needed their customers to focus on the dark chocolate to appreciate its value, with suggestions of silence, closed eyes and clear palates for tasting. ${ }^{32}$ Tricks were shared in public lectures such as blocking and unblocking your nose, 'a little insider's trick to allow the initial bitterness to give way to the sublime aftertaste' one chocolatier stated. ${ }^{33}$ Terrio is a little shocked at how her own taste profiles change through this process, showing 'how consumers, chocolatiers, and even anthropologists acutely aware of the processes at work can be drawn into mastering, displaying, and ultimately replicating taste protocols, ${ }^{34}$ These protocols were protocols of social distinction for the rising urban middle classes, a mark of cultivation, the craft chocolate industry having a very heavy hand in this cultivation.

Similar trends can be seen in the wine industry, and in fact Terrio believes that the chocolate industry was often following suit in France. For

29 Geneviève Teil, 'Devenir Expert Aromaticien: Y a-T-Il Une Place Pour Le Goût Dans Les Goûts Alimentaires?', Sociologie du travail 40, no. 4 (1998): 515.

30 Terrio, Culture and History of French Chocolate, 59.

31 Terrio, Culture and History of French Chocolate, 50.

32 Terrio, Culture and History of French Chocolate, 51-54.

33 Terrio, Culture and History of French Chocolate, 54.

34 Terrio, Culture and History of French Chocolate, 55. 
Shapin, the consequences of the objectification efforts by the wine chemists Amerine and his colleagues, were that they changed the way wine writers and marketers talked about wine. It also changed, he suggests, how ordinary wine drinkers talked about, categorised and ultimately had their wine tasting experiences. For Shapin, the new wine odour vocabulary is also a sign of globalisation. He calls this the 'aesthetic-industrial complex'. ${ }^{35}$ The philosopher Michel Serres would agree:

Anyone who drinks one of those industrial concoctions which are flooding the market and the planet, is swallowing terminology; and is fully aware of what they are drinking. It moves through the mouth like a language: written on a small label. ${ }^{36}$

Today, people drink wine all over the world. Consequently, a familiarity of the wine drinker with the specific characteristics of a wine territory cannot be presumed any longer. It is ironic that the descriptions of wine that Amerine and his collaborators developed are now used in the mass market, language that was originally trying to replace the 'fanciful language' of arbitrarily subjective, evocative wine descriptions.

Today consumers are being educated to extend their palates, not only through craft industries but also with big brands. On my supermarket shelves every week I see the marketing of an inexpensive $99 \%$ pure dark chocolate. Like the French craft chocolatiers, this particular company recognises the need to educate the customer and give them lessons in tasting the packaging offers 'important tasting advice':

To fully appreciate all its flavours, we recommend that you progressively develop your palate through our range of high cocoa content chocolate bars, starting with Excellence $70 \%$, then $85 \%$ and finally $99 \%$. The best way to experience EXCELLENCE 99\% Cocoa is to break off a small piece and allow it to melt slowly in your mouth. To taste the full bouquet of cocoa aromas, try accompanying your tasting with some coffee.

Wine labels and chocolate labels educate, not about the exploitations of chocolate workers in the Global South but rather how to taste. This goes beyond the 'the mere exposure effect' documented by psychologists in sensory marketing, meaning that our liking of things increases the more we are exposed to them. ${ }^{37}$ The case of chocolate and wine highlights how consumer taste is cultivated through sensory education that is part of the project. Aspects and features of the product are highlighted, explanations and

35 Steven Shapin, 'The Sciences of Subjectivity', Social Studies of Science 42, no. 2 (2012): 179.

36 Michel Serres, The Five Senses: A Philosophy of Mingled Bodies, Athlone Contemporary European Thinkers (London: Continuum, 2008), 221-22.

37 Krishna and Schwarz, 'Sensory Marketing', 161-62. 
instructions given, new tastes introduced. Sometimes however, the aim is not to cultivate or marshall the senses but rather to ignore them.

Science and technology scholars and historians of science have become increasingly interested in the potential of materials and practices to generate intersubjectivity and the sensory politics behind many consumer products. Shapin urges scholars to attend to how markets might try to transform subjective preferences into objectified facts, and many are contributing important insights into the politics of sensing in this way.

There is room to only give a brief overview of their work here but some important examples include Kane Race and Christy Spackman who both look (separately) at the politics of water. Their work show how publics are sold water in bottles as a necessity, ${ }^{38}$ and how sensory science shapes consumer perception. Spackman's work, in particular, shows how water experts override the sensory knowledge of consumers in assessing water quality. ${ }^{39}$ Sarah Tracy ${ }^{40}$ looks at the politics of MSG and unami, developed in the early twentieth century as an inexpensive product to make bland food tasty. Tracy argues that scientists of the chemical sense of taste and smell worked to define eating as something sensuous and molecular at the same time, and in doing so, that they cultivated pleasure in eating using molecular techniques and sensory engineering. Howes and Classen ${ }^{41}$ look historically at how Listerine invented a condition, bad breath, in order to create a market for their product. And Ella Butler's work looks at how food scientist are trained to picture a consumer that is 'hypersensitive', and that their ultimate aim, in their training is to make standardised consumer products.

These scholars, and others, ${ }^{42}$ invite a closer analysis of the ways in which industry produces pleasurable foods, and the close connections between food, science and politics. They show that there is more behind contemporary sensory education through food than instruction on labels (Figure 5.2) and in advertising campaigns. Industry shapes who gets to speak about sensing, and what sensing matters. As more anthropologists engage with sensory science, ${ }^{43}$ ethnographic studies reveal more about the practices of those who design what we eat. Work such as Ella Butler's on how food scientists learn not only about flavour but off-flavour is highly insightful for understanding more about how sensing is repackaged and how taste is managed. In

38 Gay Hawkins, Emily Potter, and Kane Race, Plasitc Water: The Social and Material Life of Bottled Water (Cambridge, MA: MIT Press, 2015).

39 Spackman and Burlingame, 'Sensory Politics'.

40 Tracy, 'Delicious Molecules'.

41 Howes and Classen, Ways of Sensing.

42 Emily Yates-Doerr, The Weight of Obesity: Hunger and Global Health in Postwar Guatemala (Berkeley: University of California Press, 2015); Heather Paxson, "The "Art" and "Science" of Handcrafting Cheese in the United States', Endeavour 35, no. 2-3 (2011): 116-24.

43 David Howes, 'The Science of Sensory Evaluation: An Ethnographic Critique', in The Social Life of Materials, ed. Adam Danzin and Kuechler Susanne (London: Bloomsbury Academic, 2015), 81-97. 


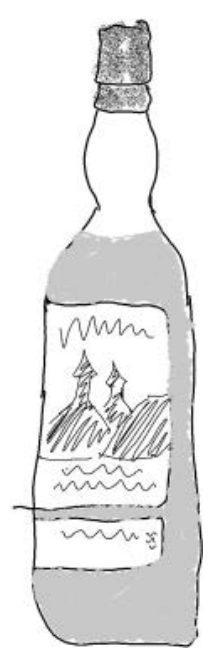

Figure 5.2 Whiskey bottle and label.

water, in MSG, in wine, the senses are extracted and reinserted, just like the culinary celery construction. It is still celery, but it has been repackaged for a novel experience. As Butler writes: 'Food commodities are carefully tuned and calibrated to produce sensory pleasure, but much of the scientific work invested in them is done so with a keen awareness of the sensitivity and perceptivity of the consumer sensorium'. ${ }^{44}$ The food industry is deeply entangled, she argues, in the engineering and managing of eating, practices entangled with knowledge and commodity production.

There are lessons to be taken from these analyses of the food industry, for medical education, also a global marketplace too. In teaching sensory skills of diagnosis, often sensations are also extracted, inserted back into materials such as mannequins and other teaching tools, and repackaged back for the student. The extraction is necessary to highlight what it is about the sensory lesson that must be learned, that must be, as industry is interested in, appreciated. The results are returned to the students in the form of 'a lesson'. For example, in the gynaecology class in Maastricht, students learned about cervical dilation during birth from plastic models of vaginas, housed in boxes, which had different centimetre dilations. A company had manufactured these boxes in various stages of labour, so that students could learn this specific haptic technique. The lesson was extracted and plasticised. In Lesson 2 there was a much more affordable way of attending to the same technique, through using oranges. As well as being creative this example questions the kinds of products which are sold to medical schools, and their 
necessity, particularly in areas of the world where funding for such technologies is sparse. Sensory repackaging, as the STS scholars I have reviewed in this section show, is not neutral. It is bound with political concerns, with Western values, with social norms that are white and heteronormative. In the next section I discuss one social movement's involvement in the engineering of sensory education, a movement that does not shy away from its political agenda.

\section{Selling slowly}

At first glance the Slow Food movement seems to sit uncomfortably in this chapter, a food movement that promotes attention to locality, quality and tradition, that tries to work against commercial enterprises such as fast food outlets and large supermarkets. Yet, as many scholars have argued, slow food is deeply entrenched in capitalist practices. I explore Slow Food in more detail here, as it is a movement which claims and connects to sensory awareness and is a movement which politicises a particular kind of sensory education. This plays out not only in the official university of the Slow Food movement, but also in the advertising, the slogans and increasingly common, the products, cookbooks, supermarkets and restaurants that operate under the brand.

The Slow Food movement has its origins in an association of Italian gourmets and consumers concerned with the support of food quality, local food traditions and a slow pace of life (as opposed to fast food and the acceleration of life) (Figure 5.3). This first Slow Food association called Arcigola,

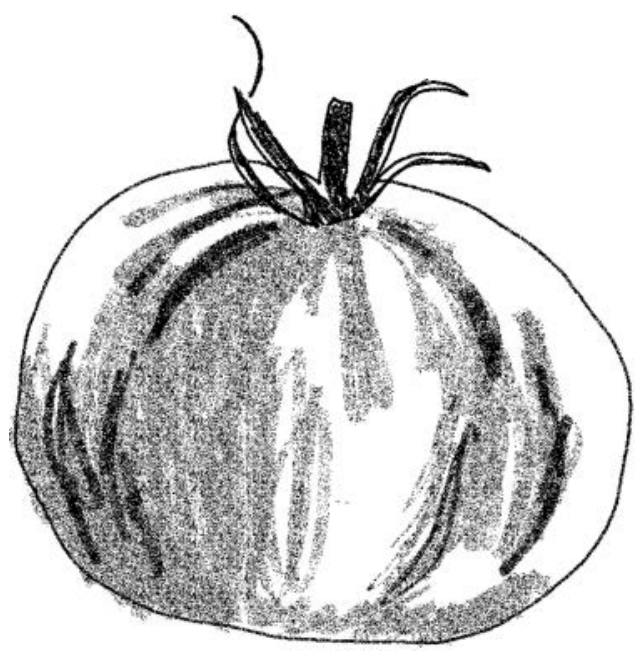

Figure 5.3 Tomato. 
founded in 1986 as a branch of the Associazione Ricreativa e Culturale Italiana, a group of leftist and anti-fascist clubs dating back to $1957 .{ }^{45}$ For the founder of the movement, Carlo Petrini, a well-known food and wine writer, pleasure is a central part of drinking and eating well and a pillar of the movement's philosophy. The manifesto emphasises that pleasure is not an individual but a collective, shared and, importantly, a unifying element of the movement.

Numerous anthropologists have spent time in slow cities and in Slow Food groups, in order to understand more about the practices behind the manifestos and claims, to look at how slow is done. ${ }^{46}$ In regards to the educational aims of slow food, Bruce Pietrykowski ${ }^{47}$ has explored how proponents of slow food seek to educate taste through exposure to local and regional food stuffs and through a particular kind of appreciation. The Slow Food movement also creates, as Carole Counihan and Susanne Højlund ${ }^{48}$ point out, sharp distinctions between bad and tasteless food, producers and non-discerning eaters, and good local producers, products and discerning consumers on the other hand. These distinctions are used to resist globalisation and preserve national identity, and also to market products, eateries and cooking classes. They are, as Siniscalchi ${ }^{49}$ argues also used as a tool of inclusion and exclusion.

Slow Food mixed business with politics from the very beginning, and in fact Alison Leitch ${ }^{50}$ believes that the organisation never set out to be anti-capitalist. They have developed a successful commercial wing publishing books and travel guides, starting taste education programs in primary schools, as well as the gastrouniversity. Like the chocolate campaign, slow food utilised a network of journalists and writers and sponsored a food award that recognised commitment to food diversity. With offices across Europe and North America, this is no small enterprise. As Leitch writes, this is not a story of "invention of tradition" ... but of its commodification ... The cultural politics of the Slow Food movement are not slow. They are fast, concerned as much with the proliferation of images, as with the marketing of memory'. ${ }^{51}$ As Leitch writes, the fact the movement is engaged in

45 Valeria Siniscalchi, 'Political Taste: Inclusion Ad Exclusion in the Slow Food Movement', in Making Taste Public: Ethnographies of Food and the Senses, ed. Carole Counihan and Susanne Højlund (London: Bloomsbury Academic, 2018), 186.

46 Siniscalchi, 'Political Taste'; Alison Leitch, 'Slow Food and the Politics of Pork Fat: Italian Food and European Identity', Ethnos 68, no. 4 (2003): 437-62; Carole Counihan and Susanne Højlund, eds., Making Taste Public: Ethnographies of Food and the Senses (London: Bloomsbury Academic, 2018).

47 Bruce Pietrykowski, 'You Are What You Eat: The Social Economy of the Slow Food Movement', Review of Social Economy 62, no. 3 (2004): 307-21.

48 Counihan and Højlund, Making Taste Public.

49 Siniscalchi, 'Political Taste'.

50 Leitch, 'Slow Food'.

51 Leitch, 'Slow Food', 448, 57. 
promotional activities which have consequences on food producers means it is important not to neglect addressing the kind of politics that slow food advocates.

Recently I walked into a supermarket manifestation of the Slow Food movement in Stockholm, Sweden, called Eataly. At first I thought it was a small local market, in the middle of the bustling town - perfect for the snack I was craving as I wandered the city streets a little lost. But as I stepped beyond the market façade I soon realised I was in a glittering and enormous supermarket. Yet it wasn't an ordinary supermarket - all the produce on the stalls were expensive Italian goods. It was an extremely upmarket deli, but it didn't stop at the supermarket shelves. With a stunningly tall ceiling and theatrical balustrades, the products soared overhead. It was a contemporary realisation of Le Bon Marché, which revolutionised supermarket shopping by taking away the sensory distractions of the market place. ${ }^{52}$

But here in Eataly, the sensory had been piped back in, in a way which was glitteringly moderated. Not only did the information about the products educate consumers on why slow food was important, but there was also a restaurant, where they could eat and try this out for themselves, and even better, a cooking school where customers could train their senses by professional chefs. I didn't have too much time to contemplate this as I waited for my slow pasta to arrive at my table, for the service was fast and the clatter from the long queue of hungry customers that wound down the staircases loud. But I did take pause to wonder exactly what kind of lesson this slow meal was giving me, thoughts I took with me to the cash register as I bought some dried handmade linguine to take home.

\section{Dining differently}

Restaurants have long served to educate the palates of consumers and have attempted to reflect the kinds of consumer trends which enable them to stay afloat. Yet arguably, there is observable heightened attention to the multisensory experience of diners nowadays, particularly in high-end restaurants.

Take for example a dish called Sounds of the Sea, invented by the chef Heston Blumenthal, in a restaurant called the Fat Duck. On a little glass box he (and later his many minion chefs) crafted a beach of tapioca, fried breadcrumbs, ground ice cream cones and crushed fried baby eels. Upon this 'sand' tumbles an ocean of abalone, razor clams, sea urchins, oysters and edible seaweed, fringed by shellfish juice foam. The dish is served with a large conch shell, out of which trail the ear-buds of an iPod. Diners are instructed to place the buds in their ears. In swim the sounds of waves lapping at a shore, overlaid with the odd squawk of a seagull. Blumenthal engineered a sonic spiral seashell to accentuate memories of the seaside and 
enrich the dish. He took the sounds from the sea then inserted them back into the seafood for the 'heightened effect'. He boasts that the effect is extraordinary, with diners overcome with emotion, engaging in passionate discussions with one another about which beach they find themselves in, as they become immersed in the culinary experience:

The wonderful thing about this dish is that the sounds of the sea and the occasional seagull act as a fantastic memory trigger, being generic enough to enable everyone around the table to relate to it. Anything more specific, like say a photograph, would just not have the same effect. ${ }^{53}$

Blumenthal argues that hearing is the most undervalued sense in terms of food and tries to reinsert it back in. In the introduction to his cookbook Heston Blumenthal at Home, ${ }^{54}$ the chef advocates for making food that appeals to the senses more generally, and describes some of the ways in which the amateur cook can use sound to enhance the flavours of their lovingly prepared meal: a crackling fire to accompany Christmassy dishes for example, or recordings of the sounds of cicadas to enhance a BBQ.

While Blumenthal 'adds' sensory experience to the restaurant, diningin-the dark restaurants take it away, intending to also focus one's concentration on the sensory dimensions of the food through blindfolding diners. Dining in the dark began in a restaurant in Zurich called Blinde Kuh (Blind Cow) in 1999. ${ }^{55}$ For the first time, a restaurant did not just offer dining by candlelight, but now in complete darkness. In 2001, a restaurant opened in Germany and since then dining-in-the-dark restaurants have emerged in Europe, North America and Asia. The idea behind dining in the dark has its origins in an attempt to come closer to the sensory experiences of the blind. However, as Spence and Piqueras-Fiszman ${ }^{56}$ argue, nowadays it is clear that the experience of dining in the dark is very different from the experience a blind person has when dining. The designers' imaginations of blindness meant they thought that subtracting light would create the same experience and teach customers to taste their food in different ways.

I have not eaten at the Fat Duck or a dining in the dark restaurant but did have a dining experience at a New Nordic restaurant in Copenhagen which attended very explicitly to the senses (Figure 5.4). I was with my husband

53 Heston Blumenthal, Website 'The Fat Duck', quoted in Anna Harris, 'Eliciting Sound Memories', The Public Historian 37, no. 4 (2015): 14-31.

54 Heston Blumenthal, Heston Blumenthal at Home (London: Bloomsbury, 2011).

55 Spence and Piqueras-Fiszman, The Perfect Meal.

56 Spence and Piqueras-Fiszman, The Perfect Meal. 


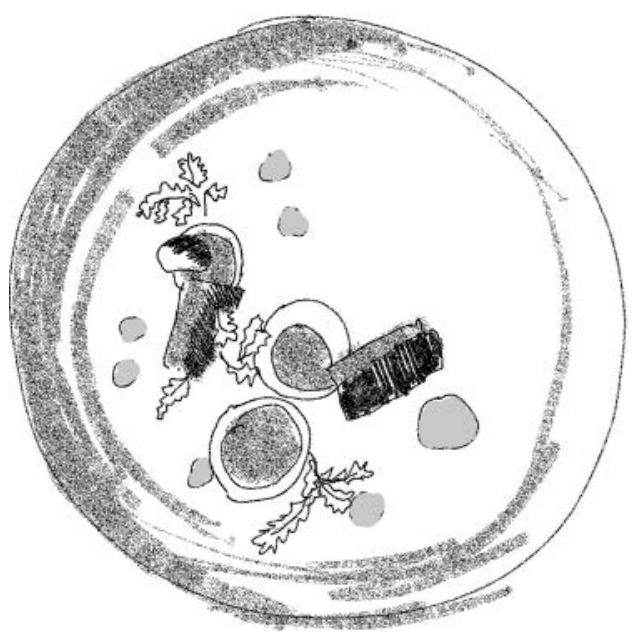

Figure 5.4 New Nordic plate.

and friends and colleagues, as we celebrated the end of an academic project together. 57 The 'sensory course' menu went as follows:

- Kingcrab, beach herbs, sour cream and bouillon

- $\quad$ Fresh cheese, kale, cabbage, pine oil and paradise apple

- Jerusalem artichoke, sorrel and black truffle

- $\quad$ Brisket of beef, 'beef jerky', milk skin and sauce on nettles

- Duck breast, pickled unripe currants and beetroot wine sauce

- Gravel, apple, milk and rosemary

- Wild berries, moss and parfait on juniper bush

Each course was served on a particular chosen plate, ingredients proudly sourced 'locally'. The menu was not meant to trigger sensory memories in the way that Blumenthal's dish did, nor take away any senses like the dark dining experience, but rather to attend to local food politics in Scandinavia through sensory awareness. Much like the Slow Food movement, New Nordic cuisine in Scandinavia celebrates foraging, local food producers and slow cooking methods. In order for the customer to appreciate the (very) expensive sensory experience (thank you Susan and Sally, for this was a present from them!), the chefs highlighted particular sensory qualities of the food - unusual juxtapositions on the plate, the unusual texture of the milk skin, the smell of smoking wood. The forests and seas of Denmark dia (London: Routledge, 2016). 
were brought to and artfully arranged on our plate, extracted, highlighted and repackaged.

These techniques of drawing attention to sensory qualities of food in restaurants is not new, nor is the attention to the dinnerware of the food and how this might enhance the dining experience (one just needs to think of Japanese dinnerware, for example, for serving close attention to the sensations of eating on particular plates - see also Ferran Adria's experiments in plating up). ${ }^{58}$ However, there is now a growing industry of sensory experience dining for an elite public of diners willing to pay the price, which seeks out "novelty and surprise'. ${ }^{59}$ Charles Spence, a neuroscientist who conducts experiments into multisensory eating experiences is a researcher closely tied with industry, the experimental results helping companies enhance the sensory potential of their products, or the sensory experience of their restaurants. Spence also looks at what he describes as the many non-food-related factors that shape the sensory perception of the diner. Spence and Piqueras-Fiszman argue that designers of restaurants and food should aim to simulate as many of the consumer's senses as possible. ${ }^{60}$ For them, whether it is the surprising experiences of the food, or the dining atmosphere, the processes at play are cognitive, and the multisensory nature of eating neurological:

We believe that the delivery of novel culinary experiences that diners find both satisfying and multisensorially stimulating is increasingly going to be facilitated by our rapidly growing knowledge about how the diner's brain integrates the various sensory and conceptual elements in a dish, by understanding that taste and flavour resides in the mind (and not the mouth) and, of course, by taking this science to the table. ${ }^{61}$

Yet what I have shown in this section, this chapter and this book is that the sensory education that occurs through such practices is incredibly social, material and political, and cannot be reduced to cognitive effects.

The STS scholar Anna Mann ${ }^{62}$ does a good job at taking terms such as Spence's notion of multisensory dining and looking at how they actually play out in practice. She considers the multisensory experience of dining as a term mobilised by cooks, to guide consumers towards attention and perception of dishes, as well as to organise the space of the restaurant and its infrastructure. Rather than taking for granted that the meal is multisensory,

58 Richard Hamilton, Ferran Adria, and Brett Littman, Notes on Creativity, The Drawing Papers (New York: The Drawing Center, 2014).

59 Spence and Piqueras-Fiszman, The Perfect Meal.

60 Spence and Piqueras-Fiszman, The Perfect Meal, 217.

61 Spence and Piqueras-Fiszman, The Perfect Meal, 9.

62 Anna Mann, 'Ordering Tasting in a Restaurant: Experiencing, Socializing, and Processing Food', The Senses and Society 13, no. 2 (2018): 135-46. 
like others such as Teil and Hennion, ${ }^{63}$ Mann looks at how tasting happens in everyday practices. This means to approach and study tasters not as passive subjects, and their taste determined by the object or social factors, but to see them as active and reflexive amateurs.

This is certainly something to remain cognizant of in such an analysis of the food industry, for there is a risk that looking at sensory marketing, selling new products, slow food and restaurant experiences as sites of education reiterates a passive view of consumers, that their sensory experiences are being manipulated, rather than cultivated through engagement and participation. As Teil and Hennion write, this is the approach of the neuroscientists and marketers mentioned in this chapter, but less so of anthropologists:

Compared to anthropological and sociological studies, experimental and interdisciplinary research have the merit of considering the body as a central mediator that articulates material individual and collective determinations. But, paradoxically, this body is nothing more than a receptacle shaped entirely by education or by stimuli given out by the product. From that point of view, food is reduced to a juxtaposition of causalities to which individuals are subjected. ${ }^{64}$

If we consider sensory education as a practice of learning, where the learning is not just what is taught, but a transformative experience that emerges in a situation where some form of noticing is being invited, then the consumer becomes less passive. Sensory education takes place in encounters with commercial objects through the knowledge of others in relation to objects, techniques and one's own body. It emerges from and is situated in a context rather than belonging to either objects or humans. As Teil and Hennion write in relation to taste:

Different people in different situations bring into play a collective knowledge of which taste is a result. In other words, taste is a way of building relationships, with things and with people; it is not simply a property of goods nor is it a competence of people. ${ }^{65}$

In this chapter, I have looked at the sensory lessons offered in commercial sites, looked at how differences get highlighted and noticed, and how consumers are taught to notice in particular ways through the extraction and

63 Geneviève Teil and Antoine Hennion, 'Discovering Quality or Performing Taste? A Sociology of the Amateur', in Qualities of Food, ed. Mark Harvey, Andrew McMeekin, and Alan Warde (Manchaster: Manchester University Press, 2004), 19-37.

64 Teil and Hennion, 'Discovering Quality or Performing Taste?', 22.

65 Teil and Hennion, 'Discovering Quality or Performing Taste?', 25. 
reinsertion of sensory experience. In the next Lesson and Chapter I explore observation and noticing in landscapes, in the worlds around us.

\section{Bibliography}

Blumenthal, Heston. Heston Blumenthal at Home. London: Bloomsbury, 2011.

Brown, David, and Aspasia Leledaki. 'Eastern Movement Forms as Body-Self Transforming Cultural Practices in the West: Towards a Sociological Perspective'. Cultural Sociology 4, no. 1 (2010): 123-54.

Butler, Ella. 'Tasting Off-Flavors: Food Science, Sensory Knowledge and the Consumer Sensorium'. The Senses and Society 13, no. 1 (2018): 75-88.

Classen, Constance. The Museum of the Senses: Experiencing Art and Collections. London: Bloomsbury Academic, 2017.

Counihan, Carole, and Susanne Højlund, eds. Making Taste Public: Ethnographies of Food and the Senses. London: Bloomsbury Academic, 2018.

De Solier, Isabelle. Food and the Self: Consumption, Production and Material Culture. London: Bloomsbury, 2013.

Goldstein, Jenny Elaine. 'The "Coffee Doctors": The Language of Taste and the Rise of Rwanda's Specialty Bean Value'. Food and Foodways 19, no. 1-2 (2011): 135-59.

Grunwald, Martin. Homo Hapticus: Warum Wir Ohne Tastsinn Nicht Leben Koennen. Muenchen: Droemer Verlag, 2017.

Hamilton, Richard, Ferran Adria, and Brett Littman. Notes on Creativity. The Drawing Papers. New York: The Drawing Center, 2014.

Harris, Anna, Susan Kelly, and Sally Wyatt. Cybergenetics: Health Genetics and New Media. London: Routledge, 2016.

Harris Anna. 'Eliciting Sound Memories'. The Public Historian 37, no. 4 (2015): $14-31$.

Hawkins, Gay, Emiliy Potter, and Kane Race. Plasitc Water: The Social and Material Life of Bottled Water. Cambridge, MA: MIT Press, 2015.

Howes, David. 'The Science of Sensory Evaluation: An Ethnographic Critique'. In The Social Life of Materials, edited by Adam Danzin and Kuechler Susanne, 81-97. N.p.: Bloomsbury Academic, 2015.

Howes, David, and Constance Classen. Ways of Sensing: Understanding the Senses in Society. New York: Routledge, 2014.

Krishna, Aradhna. 'An Integrative Review of Sensory Marketing: Engaging the Senses to Affect Perception, Judgment and Behavior'. Journal of Consumer Psychology 22, no. 3 (2012): 332-51.

Krishna, Aradhna, and Norbert Schwarz. 'Sensory Marketing, Embodiment, and Grounded Cognition: A Review and Introduction'. Journal of Consumer Psychology 24, no. 2 (2014): 159-68.

Leitch, Alison. 'Slow Food and the Politics of Pork Fat: Italian Food and European Identity'. Ethnos 68, no. 4 (2003): 437-62.

Lewis, Tania. 'Digital Food: From Paddock to Platform'. Communication Research and Practice 4, no. 3 (2018): 212-28.

Mann, Anna. 'Ordering Tasting in a Restaurant: Experiencing, Socializing, and Processing Food'. The Senses and Society 13, no. 2 (2018): 135-46.

Parisi, David. 'Fingerbombing, or "Touching is Good": The Cultural Construction of Technologized Touch'. The Senses and Society 3, no. 3 (2008): 307-28. 
Paxson, Heather. "The "Art" and "Science" of Handcraftign Cheese in the United States'. Endeavour 35, no. 2-3 (2011): 116-24.

Pietrykowski, Bruce. 'You Are What You Eat: The Social Economy of the Slow Food Movement'. Review of Social Economy 62, no. 3 (2004): 307-21.

Scheper-Hughes, Nancy, and Loic Wacquant, eds. Commodifying Bodies. London: SAGE Publications, 2002.

Serres, Michel. The Five Senses: A Philosophy of Mingled Bodies. Athlone Contemporary European Thinkers. London: Continuum, 2008.

Shapin, Steven. 'The Sciences of Subjectivity'. Social Studies of Science 42, no. 2 (2012): 170-84.

. 'A Taste of Science: Making the Subjective Objective in the California Wine World'. Social Studies of Science 46, no. 3 (2016): 436-60.

Sharp, Lesley. 'The Commodification of the Body and Its Parts'. Annual Review of Anthropology 29 (2000): 287-328.

Siniscalchi, Valeria. 'Political Taste: Inclusion Ad Exclusion in the Slow Food Movement'. Chapter 12 In Making Taste Public: Ethnographies of Food and the Senses, edited by Carole Counihan and Susanne Højlund, 185-98. London: Bloomsbury Academic, 2018.

Spackman, Christy, and Gary A. Burlingame. 'Sensory Politics: The Tug-of-War between Potability and Palatability in Municipal Water Production'. Social Studies of Science 48, no. 3 (2018): 350-71.

Spence, Charles, and Betina Piqueras-Fiszman. The Perfect Meal: The Multisensory Science of Food and Dining. Chichester: Wiley-Blackwell, 2014.

Spinney, Laura. 'Selling Sensation: The New Marketing Territory'. NewScientist, 11 September 2013. https://www.newscientist.com/article/mg21929340-400-sellingsensation-the-new-marketing-territory/.

Teil, Geneviève. 'Devenir Expert Aromaticien: Y a-T-Il Une Place Pour Le Goût Dans Les Goûts Alimentaires?'. Sociologie du travail 40, no. 4 (1998): 503-22.

Teil, Geneviève, and Antoine Hennion. 'Discovering Quality or Performing Taste? A Sociology of the Amateur'. Chapter 1 In Qualities of Food, edited by Mark Harvey, Andrew McMeekin and Alan Warde, 19-37. Manchaster: Manchester University Press, 2004.

Terrio, Susan. Crafting the Culture and History of French Chocolate. Berkeley: University of California Press, 2000.

Tracy, Sarah. 'Delicious Molecules: Big Food Science, the Chemosenses and Umami'. The Senses and Society 13, no. 1 (2018): 89-107.

Yates-Doerr, Emily. The Weight of Obesity: Hunger and Global Health in Postwar Guatemala. Berkeley: University of California Press, 2015. 


\section{Lesson 6 Observation exercises}

How do you observe the world around you? Do you ever document your observations? If you do, what are your habits? Do you have tools and techniques? Use words or pictures? This Lesson is designed to offer some ways in which to explore fieldnoting your observations, an exercise that I suggest may help to offer its own sensory lesson. It is inspired by the work of two graphic designers Giorgia Lupi and Stefanie Posavec, who identify themselves as natural cataloguers of the natural world. ${ }^{1}$

Lupi and Posavec's work as information designers means that they attend very explicitly to the visualisation of worldly observations in the form of what they call 'data'. While they spend their days trying to communicate observations in diagrams and so forth, they realised, through a surprising friendship, that it might be interesting to explore sharing their own daily observations in other ways, specifically, through postcards. They wrote a blog, then a book called Dear Data, which documents their experiment in correspondence. Rather than send postcards about random elements of their lives, or holiday anecdotes, the designers set a theme for each week, about which they were to collect data. These were often sensory themes the sounds they heard around them, when they had physical contact with others, what they saw. For 52 weeks they collected data along with these themes, then created postcards of the results.

Sensory experiments in anthropology are not new, and there are a number of fine publications with examples for research and teaching, standouts in this category being some of the sensory ethnography literature outlined in the introduction such as Denielle Elliott and Dara Culhane's $A$ Different Kind of Ethnography. ${ }^{2}$ What is particularly interesting about the Dear Data exercises for what I am considering in this book, is the way the experiment worked as a sensory training exercise, and the effect digital technologies in particular have on the process.

1 Giorgia Lupi and Stefanie Posavec, Dear Data (N.p.: Particular Books, Penguin, 2016).

2 Denielle Elliott and Dara Culhane, eds., A Different Kind of Ethnography: Imaginative Practices and Creative Methodologies (New York: University of Toronto Press, 2016). 
Lupi and Posavec describe how they gathered data 'that only computers couldn't', raising interesting questions about the generation of sensory knowledge. As the experiment went on the designers describe how: 'We soon found we were also becoming more in-tune with ourselves as we captured the life unfolding around us and sketched the hidden patterns we discovered in the details. By noticing our behaviour, we were influencing our behaviour'. ${ }^{3}$ They were learning through their observations and importantly, through the process of documenting and sharing them. The week of smells and scents, for example, reminded them of how data can help to grasp the 'ordinary moments of our lives: they are the backgrounds of our habits and journeys through our days'. 'To draw is to remember' was their moto. ${ }^{4}$

The two designers considered their project as more of a 'personal documentary' than a project of self-data collection that might align with say a quantified-self exercise. As they write in their introductory instructions, they consider this a novel methodology:

We see data as a creative material like paint or paper, an outcome of a very new way of seeing and engaging with our world. We hope this book will inspire you to see your world through a new lens, where everything and anything can be a creative starting point for play and expression. ${ }^{5}$

Data here are being used as an innovative way of seeing the world; however, the novelty of this claim is easy to dispute, since observation has been a mediated practice from the dawn of tools. Also, observation is not an exercise limited to data designers, nor anthropologists, but the very foundations for going about life and also studying it. That said, exercises which jolt awareness of this can be informative, exercises which highlight the observational work going on and which invite some kind of communication about it. The postcards are a contained, social, material form that lends itself very nicely to sensory education. Thus, while I doubt the novelty the data designers seek to express I nonetheless take inspiration from their exercises in this Lesson and outline below a modified form of their instructions for how to see the world as sensory data collectors along with my own comments and additions, for you to follow and further adapt as you wish.

\section{Equipment}

Blank cards, postcard size

Colouring pens

Pencils and eraser 


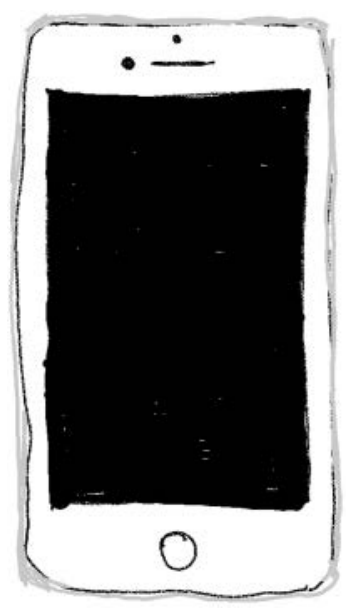

Figure 6.1 Smartphone.

\section{Instructions}

1 Begin with a question

The designers suggest beginning with considering the sensory details about life you want to know more about and explore. They offer sensory experiences and emotions for example, but you might also want to consider objects, animals or other things. For those interested, the anthropologist Joe Dumit offers related and further advice for how to go about this in his implosion project, adapted from the teaching of his mentor Donna Haraway. Both of them offer questions about an object which implodes all possible meanings you might initially have about it. Start with a cup of coffee Haraway and Dumit suggest, it takes you into some interesting places. ${ }^{6}$

\section{Gather the data}

Now you go out into the world and observe explicitly for this exercise, for one week, recording your observations. How to record? First, the designers used paper notebooks to make their notes, a preferred tool of many anthropologists (although one rarely discussed). Then they switched to their smartphones for ease - 'thank goodness for modern technology', they write. ${ }^{7}$ While mobile phones make data gathering easier for some, particularly those who are used to using phones to

6 Joseph Dumit, 'Writing the Implosion: Teaching the World One Thing at a Time', Cultural Anthropology 29, no. 2 (2014): 344-62.

7 Lupi and Posavec, Dear Data, 287. 
communicate and store information, think about how you gather data affects what you gather. Do you record the same kind of sensory details on your phone as you do in your notebook? What if you limited yourself to drawing and not words? Experiment across different days with different techniques and tools (Figures 6.1 and 6.2).

3 Spend time with the data

Ethnographers hardly need to be instructed that it is important to spend time with your data, but if this kind of observational exercise is new for you, here is a simple instruction: wallow in your observations. For the designers this is something that happens after data collection. For many other anthropologists of course, wallowing is something that happens during fieldwork as well.

4 Organise, categorise and find the story

How will you pull you sensory information together to make a story? The designers suggest that the story will help decide the layout of the drawing. Here social scientists who are used to analysing their material in a particular way are invited to think of their story in terms of a postcard image, rather than a written narrative.

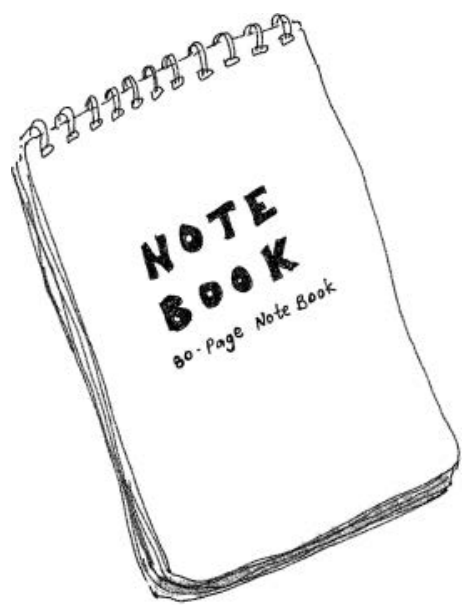

Figure 6.2 Notebook.

5 Sketch and experiment with first ideas, find visual inspiration around you, then draw the final picture

Drawing has experienced somewhat of a renaissance in anthropology. Michael Taussig has written about his use of fieldwork drawings in which he dwells on their ability to capture something 'invisible and auratic' stating that 'they [drawings] are intimate, they are sketchy, 
they are suggestive, and they are metaphysical. ${ }^{8}$ This is an invitation to use drawings in an analytical way, as a way of representing the story through diagrams, pictures and codes, colours and symbols that make patterns of the observations.

\section{Draw the legend}

The designers suggest asking yourself a simple question: 'What does someone need to read my data-drawing?'9 This is the code to analysis and in making it, often forces a kind of classification which may not have been at all visible at the time of making the observations.

The lesson is designed to be done in pairs, where each of the data collectors chose the same question to begin with. So, in effect the Lesson becomes a way of thinking about sharing sensory vocabularies too. While the designers want their participants to open out to the world, Ingold offers a similar exercise in his anthropology, archaeology, art and architecture course that instructs students to attend to the world, although in this case through one object. ${ }^{10}$ He instructs students to spend one hour with a chosen thing every week, focusing on a specific aspect, and to make notes on what had been observed or discovered. Students are asked to attend to the thing's history, whether it was finished or still growing, how people moved in and around it, what it sounded like and felt like at different times of day. They had to draw it or sketch it and reflect on how their drawing affected their observations. I have tried Ingold's exercise and Dumit and Haraway's implosion and also experimented with some of the sensory exercises in the literature with students I teach. I find these insightful and refreshing ways to approach my research too.

Last year my husband and I also did a Dear Data exercise with some friends of ours. Our instructions were to record 'beauty'. All of us were interested in scientific methodologies and enjoyed the craft of correspondence, so this project appealed to us, as a quirky and fun exercise, despite quite vast differences in our disciplines and areas of research. We distributed blank postcards and set a week to collect 'our data'. With a young toddler in our own house, my husband and I decided that it would be most practical to split the week into two, so that we recorded beauty on different days of the week, rather than both recording the whole week as our friends did. My husband recorded these details in a little notebook he carried with him, while I used a smartphone to make the recordings, taking notes and pictures and once, a video.

When it came to analysing the results, it became a beautiful exercise in intersubjectivity, where my husband and I had to qualify why something was

8 Michael Taussig, I Swear I Saw This: Drawings in Fieldwork Notebooks, Namely My Own (Chicago, IL: The University of Chicago Press, 2011).

9 Lupi and Posavec, Dear Data.

10 Tim Ingold, Making: Anthropology, Archaeology, Art and Architecture (London: Routledge, 2013). 
beautiful to each other. It meant we recounted details in our day we would otherwise not have shared over the evening dinner table - the way the sun fell on our bicycle on the ride to our son's daycare or the plants growing in a kitchen at work. It was an explicit way of attending too, to our shared aesthetic, for after ten years of being together, we had melded our sensibility of the beautiful. Finding similar things beautiful had also drawn us together. In the early years of childrearing it had become easy to focus mostly on the beautiful moments of our son's life, whereas the exercise forced us to look elsewhere too, during the working day or after he had gone to sleep.

What was beautiful for us was intensely emotional, bound up in things and in people. Beauty for us was aesthetic, something we tried to represent in our final design, which reflected the pattern for a rug we had carefully chosen together, a rug which paid homage to craft instructions in the form of an enlarged stitch sampler. Beauty was also intensely pleasurable, a sensation that made us prickle, yet, without the homework to write it down, would have not been catalogued in such a way. We also found much wonder, often by looking through our child's lens onto the world, and this made us realise the sensory education that he was offering to us, as he learned and attended to it anew. Beauty was also a break in habit, although we appreciated that habits can be beautiful too, in their quiet unthinking rhythm. It was everyday beauty we found, in objects, places, people and singular moments.

In the Making Clinical Sense project our research team also created activities to shake up our observations in the field. We wanted to find a way to make fieldnotes that shared our bodily and sensory experiences of fieldwork with the other team members, providing them with a window into our daily life as ethnographers but also enabling us to play and experiment with shared themes in our own field sites. Inspired by the Dear Data project, as well as other sources, we designed our activity set-up. The activities were to be a weekly exercise, taking only five-ten minutes to complete. We wrote the instructions for each other, ways to explore the field sites from new perspectives, breaking our own habits as ethnographers.

This Lesson has offered instructions in sensory observation, based on these projects and experiments. There are many other forms to experiment with too. You are only limited by your imagination! Take inspiration from exercises of observation you have already engaged with in the past - diaries you've kept, lab notes you've made in a chemistry class, fieldnotes for your ethnographic research - and play with this form, to break habits and see the world afresh, through new instructions.

\section{Bibliography}

Dumit, Joseph. 'Writing the Implosion: Teaching the World One Thing at a Time'. Cultural Anthropology 29, no. 2 (2014): 344-62.

Elliott, Denielle, and Dara Culhane, eds. A Different Kind of Ethnography: Imaginative Practices and Creative Methodologies. Toronto: University of Toronto Press, 2016. 


\section{Observation exercises}

Ingold, Tim. Making: Anthropology, Archaeology, Art and Architecture. London: Routledge, 2013.

Lupi, Giorgia, and Stefanie Posavec. Dear Data. N.p.: Particular Books, Penguin, 2016.

Taussig, Michael. I Swear I Saw This: Drawings in Fieldwork Notebooks, Namely My Own. Chicago, IL: The University of Chicago Press, 2011. 


\section{Engineering noticing}

Emile Peynaud, author of Handbook of Enology, describes what could be the underlying mission for a dedicated sensory education:

We have to set out on a 'scent-hunt', exploring every season, with our nose as a guide, the garden, meadows, heath and prairies; crumple of a leaf, smell of a flower, squeeze a fruit, sniff the range of spices and condiments in our cupboards, breathe in the scent of the herbs used in cooking, the herbalist's medicinal plants, the liqueur-maker's essences; carefully inhale a cologne, or a soap, recognize the perfume a woman is wearing. ${ }^{1}$

In this 'sense hunt', no crumpled leaf must be left unsniffed, no fruit unsqueezed, no perfume unrecognised (Figure 6.3). This is slow, mindful attention to the world, with all of one's senses. It puts the individual in a constant state of awareness, hunting down the sensory experiences that will educate in life. The novelist George Eliot offers a warning though:

If we had a keen vision and feeling of all ordinary human life, it would be like hearing the grass grow and the squirrel's heart beat, and we should die of that roar which lies on the other side of silence. As it is, the quickest of us walk about well wadded with stupidity. ${ }^{2}$

The hunt is exhausting and near impossible. Too heightened a sensory awareness drowns us, too little leaves us stupid. How to manage the balance, to open ourselves up to sensory engagement with life, to wander and wayfare and not die of the roar? In this chapter, I explore attempts of addressing these questions, through looking at purposeful engineering of sensory experiences of the landscape. Again, I focus on the social and material aspects of sensory education, in this case, ways in which the roar of landscapes are

1 Emile Peynaud, testimonial, cited in Jean Lenoir, 'Le Nez Du Vin', (n.a.: n.a., 2005), 53.

2 George Eliot, Middlemarch (London: Penguin, 1994), 162. 


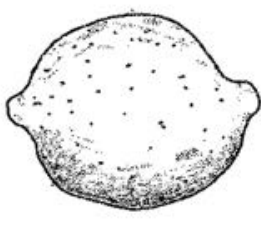

lemon peel

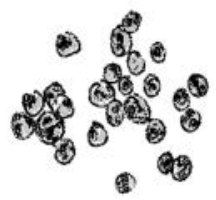

peppercorins

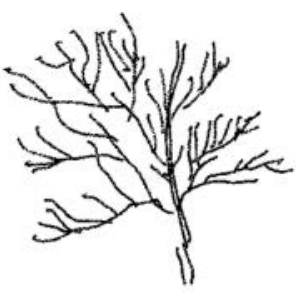

dill

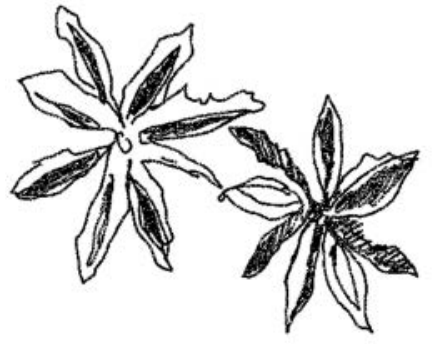

duise

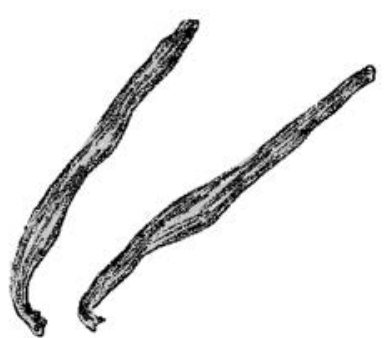

vanilla bean

Figure 6.3 Finding spices in the cupboard.

tamed. In doing so, I suggest, that this is yet another domain of sensory awareness where engineers, designers and technologies get entangled in sensing practices and how we learn them.

In examining this aspect of sensory education, I wander from my usual examples of medical practices and eating to look in this chapter at what I have been referring to as the landscapes in which we live. These could include what some refer to as 'nature' - for example, the forests I discuss in a later section - or urban environments - what some call 'culture'. Like many others I do not make a clear distinction between nature and culture here, the two are thoroughly entangled. I also recognise that landscapes are places which become part of food and medicine in much broader ways with regard to how we think about food, health and living.

In the chapter I concern myself with instructional examples which seek to bring individuals and groups 'closer' to the landscapes they live in. I build from other scholars who suggest that middle classes are attempting to create and maintain 'a sense of self in a runaway world' through various kinds of sensory learning practices. ${ }^{3}$ My examples engage with arguments in pop-

3 Isabelle De Solier, Food and the Self: Consumption, Production and Material Culture (London: Bloomsbury, 2013), 6. 
ular and academic literature which suggest we are disconnected from nature, ${ }^{4}$ living in polluted environments that affect our sensory perception, ${ }^{5}$ distracted $^{6}$ and always online. ${ }^{7}$ In previous chapters, I discussed the call to attend to the lost details of the 'terroir' of food, terroir as Amy Trubek ${ }^{8}$ reminds us, referring not only to climate and landscape but also skills, traditions, human and animal relationships involved in making food. There are numerous other examples I could have drawn on which cry out for sensory awareness - mindfulness and yoga classes for example - many of which claim to 'empower' the senses of those who participate. In bookstores there are stacks of self-help guidebooks that offer the same steps towards personal empowerment and notebooks on sale, to help guide making observations of the world. Almost all of them call for sensory attention of one's self and of the world, as part of daily practice, for a 'better' way of living:

Immerse yourself in your senses. Let this task be the one thing you are thinking about, the sole purpose of this moment. Are you hanging out the laundry? Instead of planning dinner or thinking about tomorrow's meeting or what you will do when the kids wake from their nap, focus on: the fresh scent of the wet, clean clothes; the coolness of the damp fabric in your hands; the snap of the pegs on the line; the way the sunlight hits the linen. ${ }^{9}$

Authors cry out for digital minimalism, ${ }^{10}$ to turn off our phones and get outside. ${ }^{11}$ Scholars argue that 'only through attentive and continuous perception will humans develop the sensory activity that will help them understand more fully their connection with the natural world'. ${ }^{12}$ Such mindfulness urges a "paying attention in a particular way: on purpose, in the present moment, and non-judgementally', ${ }^{13}$ espoused by gurus such as Professor of Mindfulness Jon Kabat-Zinn.

4 Nina J. Morris, 'Dalziel and Scullion, Tumadh: Immersion', The Senses and Society 10, no. 2 (2015): 261-66; Florence Williams, The Nature Fix: Why Nature Makes Us Happier, Healthier, and More Creative (New York: W. W. Norton, 2017).

5 Asifa Majid et al., 'What Makes a Better Smeller?', Perception 46, no. 3-4 (2017): 406-30.

6 Brooke McAlary, Destination Simple: Everyday Rituals for a Slower Life (Carlton: Nero, 2017).

7 Cal Newport, Digital Minimalism: On Living Better with Less Technology (New York: Penguin, 2019); McAlary, Destination Simple.

8 Amy Trubek, The Taste of Place: A Cultural Journey into Terroir (Berkeley: University of California Press, 2008).

9 McAlary, Destination Simple, 22.

10 Newport, Digital Minimalism.

11 Williams, The Nature Fix.

12 Morris, 'Dalziel and Scullion, Tumadh', 264.

13 Jon Kabat-Zinn, n.d., quoted in Ronald Purser et al., eds., Handbook of Mindfulness: Culture, Context, and Social Engagement, Mindfulness in Behavioral Health (Cham: Springer International, 2016), vi. 
Yet as I try to show in this chapter, even when we head offline, or wander in gardens, when we go into forests or take off our shoes, there is still design and engineering shaping sensory education. That is, there is no 'natural, unmediated' sensory lesson that exists outside of a sociomaterial learning context, no matter how far into the deep dark woods we go.

I offer then two main arguments in this chapter, based on this observation. The first is that I do not think it matters that places sold as 'natural' are in fact engineered and designed. For there is still a lot of work in learning noticing that happens in these sites. In fact, I suggest that sensory learning may even be heightened in such environments. My second argument is that it is in moving between states of noticing, between different specifics of the landscape, whether a small detail or the general atmosphere, that we might learn the most.

To help explore these themes, I draw from two anthropologists, Anna Tsing and Marilyn Strathern, who both consistently interrogate the complexities of the world we live in with creative, insightful, fieldwork led theories. Again, I use Anna Tsing's ${ }^{14}$ notion of the 'art of noticing'. Tsing is interested in different practices of noticing, particularly in landscapes. Her case is the set of mushroom-human relations that assemble through feeling and learning a forest. Tsing is particularly interested in 'human-disturbed landscapes' which she argues are particularly ideal places for humanist and naturalist noticing. 'Noticing as well as counting is required to know the landscape', she urges, highlighting the importance of fieldwork orientated empirical practices, such as natural history and ethnography in such a quest. ${ }^{15}$ This is not a romantic study of pristine forests and foraging activities but rather disturbed sites of global capitalism. As she writes, 'we need to know the histories humans have made in these places and the histories of nonhuman participants. ${ }^{16}$

I then incorporate Marilyn Strathern's ${ }^{17}$ exercise in figure-ground reversal, as a way to consider a more nuanced understanding of how our habits of perception are engineered. Strathern herself draws from the use of this method in visual arts, to reconsider the figure of an image, and the ground, so that the ground and figure are variably brought to the fore in different modes of interpretation. This, Strathern points out, is a very Western, or modernist tradition, of finding specifics. For Strathern, it is the oscillation between the two which is interesting. She shows how oscillating between figure and ground in photographs gives the image, what she describes as 'depth'. I extend from her insights to consider the invitation to reverse and

14 Anna Lowenhaupt Tsing, The Mushroom at the End of the World: On the Possibility of Life in Capitalist Ruins (Princeton: Princeton University Press, 2015).

15 Lowenhaupt Tsing, Mushroom at the End of the World, 30.

16 Lowenhaupt Tsing, Mushroom at the End of the World, 160.

17 Marilyn Strathern, 'On Space and Depth', in Complexities: Social Studies of Knowledge Practices, ed. John Law and Annemarie Mol (Durham, NC: Duke University Press, 2002). 
change figure ground that takes place in engineered instances of noticing our landscape. I look at how this invites a particular kind of depth through oscillation. In doing so I consider engineering as a purposeful configuring of social and material relations, and depth as a richness through attention to the histories of what is noticed.

Drawing theoretically upon these two anthropologists' work, the chapter first treads into a very digital world, that of apps and self-tracking designed to better lives through facilitating sensory awareness. These are technologies entangled in training to become more aware of not only individual experiences - our own symptoms and sensations for example - but also of our environment.

\section{Sensing and sensors}

I have suggested throughout this book that digital technologies are not the enemy of sensing but deeply entangled in sensing the world. This is hardly a new suggestion. Theorists, philosophers, sociologists and anthropologists have shown how technologies become part of who we are. Philosophers who use a mode of thought called phenomenology for example, draw on thinkers such as Maurice Merleau-Ponty ${ }^{18}$ who is interested in how tools become extensions of our sensory perception. He uses beautiful examples, such as the feather in a woman's hat being an extension of her way of sensing through space. The media theorists discussed in Chapter 3 were also very interested in the way in which media extends the senses. As John Durham Peters writes, in regards to his undergraduate students, 'their lives are much more than their phones, but they live by means of them [author's emphasis]. These devices are the narrow gate through which their mental and social metabolism passes.' ${ }^{19}$ Countless ethnographic studies in everyday settings around the world also show that the digital is part and parcel of our lives, that it does not exist besides our analogue, bodily activities. One way in which digital is entangled with sensing that I want to explore in this section, is how technologies designed for the smartphone (Figure 6.4), the now ubiquitous object in pockets, works in sensory education. I focus specifically on how the phone, including apps and other related devices, is involved in noticing landscapes and how this creates oscillations in figure-ground.

For many scholars, the smartphone and digital applications are opening up new spaces for sensing that have not been available before. There are so many examples of applications that offer sensory training of one sort or another, mostly as part of 'brain training'. I will not tread into this muddy territory but rather look at a few examples of how digital technologies

18 Maurice Merleau-Ponty, Phenomenology of Perception (London: Routledge \& Kegan Paul, 1962).

19 John Durham Peters, The Marvelous Clouds: Toward a Philosophy of Elemental Media (Chicago: The University of Chicago Press, 2015), 21. 


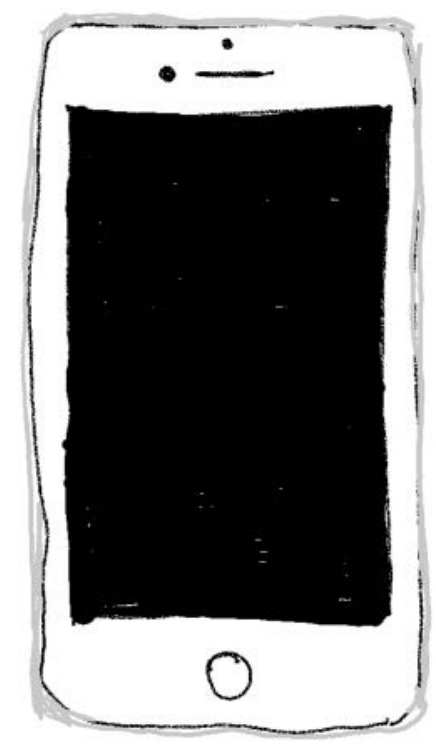

Figure 6.4 Smartphone.

have been entangled with noticing one's landscape. The sociologist Jennifer Gabrys ${ }^{20}$ and her research team looks in particular at the use of digital technologies by citizens to record flora and fauna. Ecologists and biologists use digital sensors to study many aspects of animal activity, and these often involve a public dimension that makes this data accessible to new audiences and involves citizens observing and recording aspects of their own landscape.

In her work with Helen Pritchard, Gabrys wants to get away from considering sensing as a human-centered set of perceiving and decoding practices, to look at the entities, technologies and environments of sense, including sensors used in environmental monitoring, lichens that understand air pollution and smart infrastructures that sense and adjust in real-time. ${ }^{21}$ For them, sensing is distributed across networks of which citizens form an integral part. Gabrys and colleagues' work shows that digital sensors operate through extended relations as 'environmental media'. Their work helps to expand sensory education to encompass the invisible infrastructures of sensing beyond the bodies that are often focused on in this book - the eating and medical bodies especially.

20 Helen Pritchard et al.,'Re-calibrating DIY: Testing Digital Participation Across Dust Sensors, Fry Pans and Environmental Pollution', New Media \& Society 20, no. 12 (2018): 4533-52.

21 Jennifer Gabrys and Helen Pritchard, 'Sensing Practices', in Posthuman Glossary, ed. Rosi Braidotti and Maria Hlavajova (London: Bloomsbury Academic, 2018). 
Smartphone apps also facilitate a different kind of sensory noticing in regards to how people experience their landscapes in regards to recording heart rates, stress levels, body temperatures and footsteps, apps that might be otherwise called self-tracking. While these are often criticised as digital substitutions for sensory engagement, sociologists such as Deborah Lupton and Sarah Maslen show that engaging with these systems takes a lot of sensory work too. They describe this as a connection between the 'sensory affordances and capacities of human bodies and computer hardware or software'. ${ }^{22}$ From their interview material, they found that their participants frequently described how self-tracking devices enabled them to access information about their bodies which they were unable to gain through their direct bodily sensory responses. ${ }^{23}$ They also found it a way to identify patterns and correlations, where the self-tracking technologies were imagined and used as a way to record small changes over time that supported embodied memory and sensemaking. Finally, the authors suggest that where the technology's output is accepted with little questioning, users over time incorporate the information in their bodily awareness. They learn to sense what the device tells them. For example, one woman, who regularly used a fitbit, told how she could know - or sense - after some time how much she had to move each day in order to reach the step target set by the device: 'The device had educated her about her body to the point that she was able to delegate back to her embodied sensory perceptions of how much physical activity she was achieving each day'. ${ }^{24}$ Sarah Maslen and I are now working on developing our understanding of digital sensing practices by bringing together our fieldwork in clinical situations, where clinicians (my fieldwork) and parents (her fieldwork), both used smartphones to record sounds of children's breathing. We discuss how the parents and clinicians relate their sensory expertise with the digital devices and recordings for the purposes of diagnosis and treatment.

The designers behind the inspiration for the observation exercises in Lesson 6 also promoted using the phone to collect sensory data of everyday life. Their project concerned using this technology to make recordings - notes about what was seen, photographs, sound bites - of people, things, feelings and the world. Drawing the results of observation on a postcard asked for the kind of analytical work that comes with making sense of such data - it means needing to learn to notice and to make sense and meaning from the noticing too.

Whether it means being involved in a citizen sensing project, or self-tracking your own (or child's) sensory symptoms, using these technologies

22 Deborah Lupton and Sarah Maslen, 'The More-Than-Human Sensorium: Sensory Engagements with Digital Self-Tracking Technologies', The Senses and Society 13, no. 2 (2018): 191.

23 Lupton and Maslen, 'More-Than-Human Sensorium', 194.

24 Lupton and Maslen, 'More-Than-Human Sensorium', 197. 
involves learning how to observe, read, interpret and evaluate in different ways. Noticing takes a different shape, one that brings figure/ground in movement, by highlighting aspects of sensation, then putting them in the background of data storage in the phone. As Gabrys and Pritchard, and Lupton and Maslen point out, these technologies are designed to do this (or not) in specific ways. Gabrys ${ }^{25}$ is interested in DIY, hacking and citizen engagement with digital sensors, the communities she and her research group studying, becoming part of the decisions about what counts. The apps that Lupton and Maslen studied are designed, they point out, with 'certain types of embodiments in mind, thus closing off the participation of other bodies or bodily practices'. ${ }^{26}$ They offer the example of a young mother who during pregnancy received warnings from her sleep-tracking device that her sleep had been very irregular. The technology was not designed with a pregnant body in mind. ${ }^{27}$ As other scholars have also argued in relation to technologies of sensation - one thinks here for example of sound studies scholar Jonathan Sterne's work on the mp3 for listening to music ${ }^{28}$ - these technologies are designed to shape particular kinds of perception and are also based on assumptions of that perceptive process. For Lupton and Maslen, the interactions between self-tracking devices and human embodiment of sensory knowledge and experience offers a 'more-than-human-sensorium'. ${ }^{29}$ They go on to say that

humans work with devices and data to bring sensemaking capacities into being. The affordances of devices and data may facilitate these capacities, but may also hinder or subvert them so that human users' desires or needs are not realized in ways they expect. ${ }^{30}$

Digital technologies can contribute to a specific way of sensory training (embodying the information about bodily sensations participants initially had to rely upon) and can make information about the body accessible in new ways. On the other hand, it could be argued that these devices also prevent a training of the senses by taking over practices of sensing. A mother may better train her senses by listening to her babies' cries for example, or learning what different temperatures feel like to touch, rather than relying on the device. Often the smartphone is pitted as a distraction to sensing. I

25 Jennifer Gabrys, 'Citizen Sensing, Air Pollution and Fracking: From 'Caring About Your Air' to Speculative Practices of Evidencing Harm', The Sociological Review Monographs 65, no. 2 Suppl (2017): 172-92.

26 Lupton and Maslen, 'More-Than-Human Sensorium', 198.

27 Lupton and Maslen, 'More-Than-Human Sensorium'.

28 Jonathan Sterne, Mp3: The Meaning of a Format, Sign, Storage, Transmission (Durham, NC: Duke University Press, 2012).

29 Lupton and Maslen, 'More-Than-Human Sensorium', 198.

30 Lupton and Maslen, 'More-Than-Human Sensorium', 198. 
explore this later in this chapter, in places of digital detox, where getting 'back to nature' and away from the phone is sold as a form of sensory education. Before we head into the forest though, I now turn to another site of engineered noticing, in urban environments.

\section{Design of our landscape}

In Paris, there is a beautiful garden on railway tracks above the city. You may have heard of it, or walked through it and taken time out from the business of the city, to stroll among the high arched roses. Several summers ago, my husband and I enjoyed the gardens, following it to the end of the line, sitting on the park benches with our son, grazing on baguettes and cheese as many tourists do. We sat back and soaked up the stillness, the faint buzzing of the city behind us. We felt tranquil, absorbed in the sounds and smells, loving watching our little boy tentatively step onto the grass, now with glee rather than fear, cavorting in nature (Figure 6.5).

These Paris gardens, to us, were a little bit of nature in an urban environment, the kind of landscape we often seek out as visitors to a city, following friends' recommendations to their favourite parks or wild urban spaces. ${ }^{31}$ These are landscapes that seem wild, untamed, natural. Yet as the cultural geographer Laing Ebbensgaard ${ }^{32}$ writes, these are highly designed spaces. They reflect a shift in society, he argues, from designing nature to designing the sensation of nature. That is, the landscape designers present the visitor not with as an open-ended and indeterminate experience as is often claimed, but rather a scripted 'open-ended-stability', where sensing is orchestrated. Ebbensgaard is critical of the claim that contemporary landscape designs 'embrace natural processes and function as media that in open-ended, indeterminate and unforeseeable ways enable residents to develop more intimate ways of relating to the landscape and to themselves'. ${ }^{33}$ So he went about interviewing visitors and locals of several contemporary landscape projects that are very similar to the Promenade Plantée - The High Line in New York City and Under the Crystal in Copenhagen - to find out what they thought.

The High Line in New York City is a former rail line that, after its abandonment in 1982, became covered by wildly growing plants. Between 2006 and 2013 it was redesigned into a public park. The core theme of the park is an imitation of 'wild nature', a recreational space where visitors can slow down, where they can temporarily escape from the speed of everyday life

31 Jens Lachmund, Greening Berlin: The Co-production of Science, Politics, and Urban Nature (Cambridge, MA: MIT Press, 2013).

32 Casper Laing Ebbensgaard, "'I Like the Sound of Falling Water, It's Calming": Engineering Sensory Experiences through Landscape Architecture', Cultural Geographies 24, no. 3 (2017): 441-55.

33 Laing Ebbensgaard, 'Sound of Falling Water', 442. 


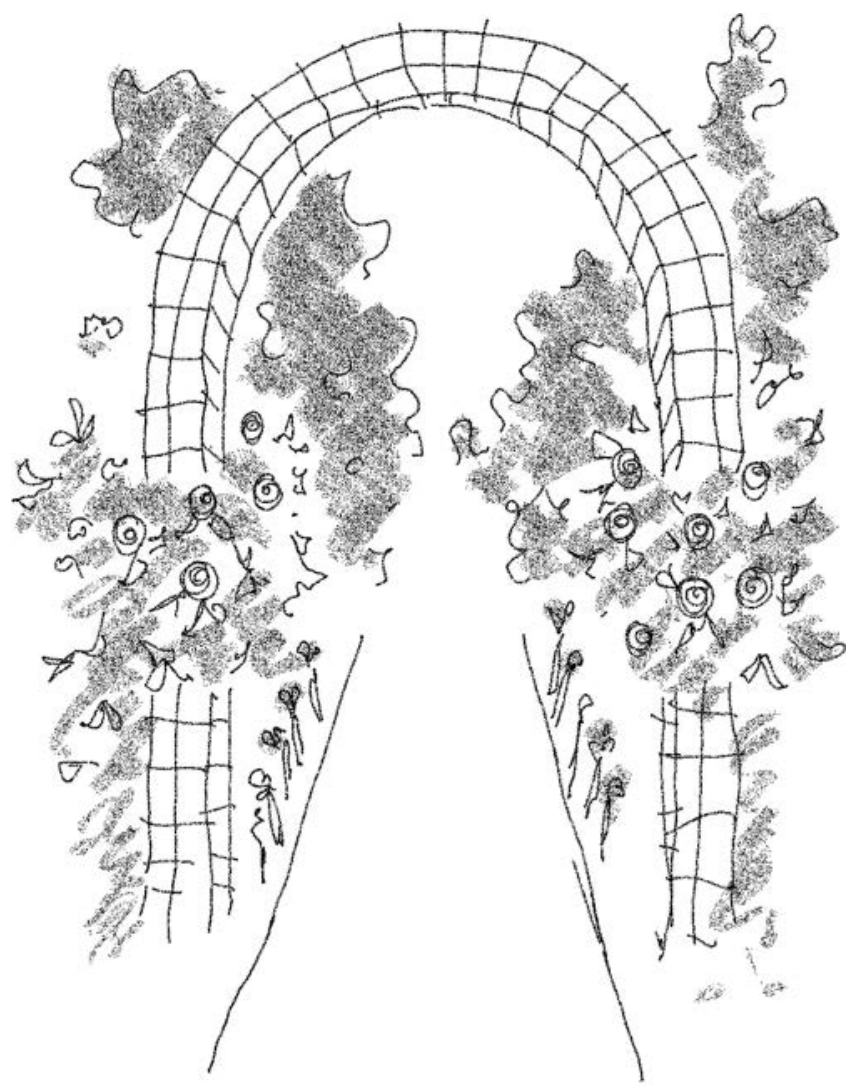

Figure 6.5 Promenade Plantée, Paris.

in the metropole, enjoy the views over the city and the Hudson River and immerse themselves in the array of sensory stimuli offered. For example, the smell-scape changes with the seasons, from flowers and pollen to the scent of decaying grass and leaves. Under the Crystal in Copenhagen is a public plaza build in 2009 within the area of the bank Nykredit. Apart from some trees and benches, its core feature are water jets that create ten water walls of varying heights (up to $2 \mathrm{~m}$ ) in irregular time intervals. From December to March the water jets are turned off. During these months, the design moves into the background, allowing the cold wind and rain to dominate the sensory experience of crossing the space. ${ }^{34}$

These projects are part of a shift in redesigning post-industrial wastelands in urban areas into environmentally friendly spaces for public leisure, which 
bring visitors 'closer to nature. ${ }^{35}$ Ebbensgaard is critical of this trend. He considers that these projects instead 'engineer' visitor's experiences. ${ }^{36}$ There is a longer history to this trend. In the nineteenth century, when parks like the Central Park were created, the aim of designers already was to provide 'breathing spaces' that counteracted the development of industrialisation within overcrowded cities. Ebbensgaard argues that landscape design today differs in its focus not on an idealised vision of nature but on one that highlights the 'sensory and aesthetic qualities of wilderness. ${ }^{37}$ Some urban projects, for example, insert mist, lighting and smells into the setting. This designing of the 'sensation of nature' Ebbensgaard writes, orchestrates and choreographs particular sensory experiences and performative practices ${ }^{38} \mathrm{He}$ writes that for visitors in the park the sensory experience of the city below them is maintained but in a controlled and purified version. They can see the city but ' $(0)$ ffensive smells are eliminated and reduced to a light deodorized breeze. ${ }^{39}$

This is in many ways similar to the orchestrated experiences of dining and shopping that I discuss in Chapter 5, where sensations are 'repackaged' in sensory lessons. In this chapter, I am interested in facilitators in the art of noticing landscapes, guides that design sensations so we notice in different ways, so that some things become figure - the birds, the flowers - and others ground - the city, the pollution - in deliberate attempts at reconfiguration. The places we inhabit are highly integrated into our sensory education. They are, as Peters reminds us, full of meaning, but this is meaning that he argues is guided by others, by the media of our lives:

Sometimes it is hard to get a full meal from natural meanings: nature can wear a blank face and the tempus can be dull. There is the miracle in the common, but also the common in the miracle. There can be nothing so boring as being. Mindfulness is never a fully sustainable program. You can't stay giddy with infrastructure forever; something else is always in the queue. Some afternoons you just need to keep chugging along; sometimes you just want to check your e-mail or see a movie. Any ecstatic philosophy needs to make friends with the inevitable fading of wonder and our inevitable hunger for the candy of human content ... human crafts reveal nature. I probably would not love the clouds so much if they had not been painted so well. For our species, nature's meaning only comes via the ships we use to navigate is being. ${ }^{40}$

35 Jens Lachmund, Greening Berlin: The Co-Production of Science, Politics, and Urban Nature (Cambridge, MA: MIT Press, 2013).

36 Laing Ebbensgaard, 'Sound of Falling Water', 442.

37 Laing Ebbensgaard, 'Sound of Falling Water', 443.

38 Laing Ebbensgaard, 'Sound of Falling Water', 444.

39 Laing Ebbensgaard, 'Sound of Falling Water', 448.

40 Laing Ebbensgaard, Peters, Marvelous Clouds, 382-83. 
In the final section of this chapter, I now want to head even further into the woods, to places which guides want followers to find unmediated, but which are, once again, highly interesting sites of lessons in noticing that are engineered and designed for this purpose. That is, I look, following from Peters, at the ships we use to navigate our sensing in landscapes.

\section{Bare feet and forest bathing}

In many urbanised places some will say that not only do smartphones intervene in living life in a sensorially rich and rewarding way but also shoes get in the way of contact with the ground and cities destroy our connection to green. If only the solution was as simple as slipping off our boots ${ }^{41}$ and walking amongst the trees. ${ }^{42}$ Habits are not easy to break, nor are creature comforts and the ease of life which such technologies bring. Yet the desire is there, to break from the shackles and engage in simple, slower lives with our environment. People will spend a lot of money on detox workshops where someone literally takes their phones away from them or does not provide Wi-Fi. Many seek inspiration and a little guidance to connect to the environments we inhabited, and it is just this that I will explore in this section, with a focus on the very earthly and green spaces that people are said to be disconnecting from.

I will start with barefoot trails, a recent fascination of mine (Figure 6.6). I first learned about barefoot trails in the area where I live from friends who went on these pathways for hens' outings or with their children. While I did not grow up with calluses on my feet, I was lucky to grow up in a country where it was not unknown to be barefoot on the sand, in the garden, in soil as a child. Thus, I was surprised to hear that there were trails for bare feet, claiming to offer cures to all modern ailments. For example, the website for one of these sites claims:

Our dress code is bare feet, so take off your shoes and socks, roll up your trousers and start walking! It's your choice whether or not you want to walk over the obstacles. Nothing is mandatory, but anything goes! It is lovely to walk around barefoot in the park. Get to know the nature in a very exciting and sometimes challenging way, by feeling with your feet. This way you can experience nature from your head to your toes! We are open in any weather. The beautiful forest is in fact the most wonderful and natural umbrella providing protection from sun and rain and it's a super air conditioning too! In this natural environment you will discover the power of greenery, health, happiness, emotion, spirit, faith and enjoyment. ${ }^{43}$

41 Tim Ingold, 'Culture on the Ground: The World Perceived through the Feet', Journal of Material Culture 9, no. 3 (2004): 315-40.

42 Williams, Nature Fix.

43 Blote Voeten Park. 'Your Walking Experience for Young and Old'. 31 May 2019. https:// barefootpark.eu/en/dresscode-blote-voeten. 

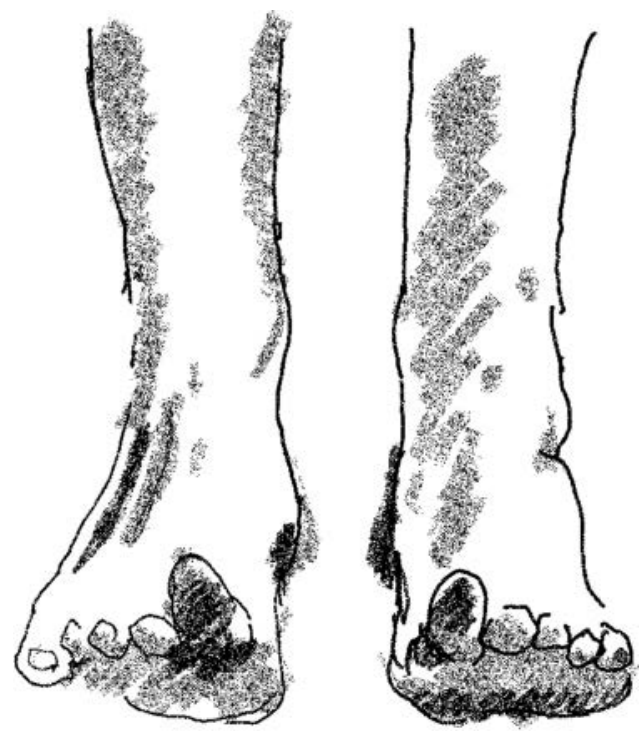

Figure 6.6 Walking with bare feet.

Curious, I tried out this barefoot trail with members of the Making Clinical Sense research team when we returned to Maastricht after an intense period of fieldwork.

It was a beautiful ride through the Dutch forests, and for the first time that year we needed sunscreen. We headed to the Brunssum Blote Voeten Park, a barefoot trail not far from our university. We started along the trail, shoes left in lockers, chatting and catching up on months apart, finding out about fieldwork adventures, new ideas and holidays. It was easy to get lost in conversation but the trail called us to attention. Smooth sand disappeared into woodchips, causing our toes to curl up a little. Soon a muddy trough greeted us, and tentatively we waded in, sensing how far we could descend into the cool water, hands out for support. We climbed wooden beams like children and looked over the park from up high. Down below we could see fellow bare footers inspecting splinters in their usually shoed feet, soft from years of woollen socks and slippers.

In his much-cited article 'Culture on the Ground', Tim Ingold suggests there has been a bias in scholarship for head over heels and that we need a more grounded approach to human movement that is sensitive to the embodied skills of footwork. Shoes, he suggests, like chairs, are a technology which privileges the intellect over instinct. Ingold argues that:

The mechanization of footwork was part and parcel of a wider suite of changes that accompanied the onset of modernity - in modalities 
of travel and transport, in the education of posture and gesture, in the evaluation of the senses, and in the architecture of the built environment - all of which conspired to lend practical and experiential weight to an imagined separation between the activities of a mind at rest and a body in transit, between cognition and locomotion, and between the space of social and cultural life and the ground upon which that life is materially enacted. ${ }^{44}$

While my young son can still squat comfortably, he has quickly adopted shoe wearing as habit as he learns to traverse the cobblestone streets of Maastricht. The first time he encountered grass he begged to be picked up, the first time in sand he tried to flick it off. We become shoe-bound so quickly that it opens up a gap in the market for footwork retraining. Barefoot trails offer the senseless feet of urban dwellers the chance to rediscover mud and woodchips and splinters all over again in a carefully designed pathway through 'nature'. The training is not through a guide or signposts but through subtle drawing of attention to change that we need to notice with our feet and hands, with our whole bodies. Visitors to such parks are guided by rails, by abrupt differences, by needing to climb or descend. The differences need to be obvious for the rusty foot feeler does not notice subtlety.

Ingold points out that we must consider more than just the tactile when it comes to barefooting, that sensing while you walk, as has constantly arisen in other examples in this book, is with the whole body. He asks:

Is it really the case for example, as intuition suggests, that what we feel with our hands, and through the soles of our feet, are necessarily related as figure and ground? In other words, is the ground we walk on also, and inevitably, a ground against which things 'stand out' as foci of attention, or can it be a focus in itself? ${ }^{45}$

The barefoot trail works to reconfigure figure and ground, to bring the ground to the forefront, so that we notice it. The pathway designers, the investors of the park, the volunteers who work there and the gardeners, all work to redesign what we need to pay attention to. Ingold draws on the work of James Gibson, who argues that the world we perceive is an environment around us, that we become familiar with, not by looking at it, but by moving in it, for example, by walking. Ingold rephrases this 'a path of observation'. ${ }^{46}$ He writes: 'Growing familiarity, however, comes not from filling in gaps in the map but from a gradual fine-tuning or sensitization of

44 Tim Ingold, 'Culture on the Ground', 321.

45 Ingold, 'Culture on the Ground', 330.

46 Ingold, Anthropology andlas Education (London: Routledge, 2018), 31. 
perceptual skills that renders perceivers ever more attentive to the nuances of the environment' 47

As I have suggested throughout this book, this fine-tuning and sensitisation is socially and materially crafted. In many ways the barefoot experience of having one's figure and ground re-shifted through designed pathways and walks is also underpinning other carefully constructed experiences with nature, such as the growing practice of Shinrin-yoku, otherwise known as 'taking in the forest atmosphere or forest bathing'. ${ }^{48}$ Starting as a Japanese practice, forest bathing has now spread internationally, with guides in many forests around the world offering meditative effects of spending time with the trees. The cultural historian Christian Ernsten, ${ }^{49}$ who practices his own ways of walking through landscapes as part of his research, directed me towards one of the Netherlands's forest guides, Didier Anthonis. Didier and his team of forest guides and wild herb experts offer a year longer educational program in forest guiding, as well as tailored workshops for groups and individuals with activities such as wild herb hunting. Foraging in the forest is framed as a lost art of noticing that is being retaught to those who have no need for such practice for sustenance, but rather for a particular experience in nature.

Forest bathing and foraging are forms of guided sensory education. Many claim for more specific, therapeutic effects - that particular trees elicit particular chemicals that can lead to specific physiological effects. Some suggest that even just a day in the forest can reduce levels of adrenalin and cortisol. Others suggest that there is a physiological resonance between the complex fractal patterns found in nature and visual processing. ${ }^{50}$ But researchers also keep coming back to the sensory details of the experience. As Florence Williams writes in The Nature Fix,

it involves cultivating your senses to open them up to the woods ... You can stroll a little, write a haiku, crack open a spicebush twig and inhale its woodsy, sassy scent. The whole notion is predicated on an ancient bond that can be unearthed with a few sensory tricks. ${ }^{51}$

Psychologists have tried to study the effects, by testing subjects in forests and in laboratories exposed to only the odor of wood, the sound of running stream water or the scenery of the forest, while other scientists have

47 Ingold, Anthropology andlas Education, 31.

48 Yuko Tsunetsugu, Bum-Jin Park, and Yoshifumi Miyazaki, 'Trends in Research Related to "Shinrin-Yoku" (Taking in the Forest Atmosphere or Forest Bathing) in Japan', Environmental Health and Preventive Medicine 15, no. 1 (2010): 27.

49 Nick Shepherd, Christian Ernsten and Dirk-Jan Visser, 'The Walking Seminar: Embodied Research in Emergent Anthropocene Landscapes', 12 December 2018.

50 Williams, Nature Fix.

51 Williams, Nature Fix, 18. 


\section{Engineering noticing}

conducted brain scans which show that 'prefrontal activity was reduced and the concentration of stress hormone was lowered in subjects exposed to a forest environment' ${ }^{52}$

Both barefoot trails and forest bathing are highly mediatised experiences there are websites, books, videos, newspaper articles leading people into the trees and on the trails. Those wishing to engage in these activities need guidance for how to navigate the forests and the earth in these particular ways, who want to cultivate their art of noticing in ways that are very different from say a child who just wants to run in bare feet. This is a different kind of noticing than what Anna Tsing writes about with her mushroom hunters, who are sensitive to changes in forest climates and how this effects mushroom growth, through careful ways of paying attention, as she describes through the mushroom hunters' manifesto on their website:

To live well with others, we need to use all our senses, even if it means feeling around in the duff. Matsiman's own words about noticing, from his matsutake website, seem particularly apt. 'Who is Matsiman?' he asks. 'Anyone who loves hunting, learning, understanding, protecting, educating others, and respects matsutake mushroom and its habitat is matsiman. Those of us who can't get enough understanding, constantly trying to determine what caused this or that to happen, or not happen. We are not limited to nationality, gender, education, or age group. Anyone can be a matsiman'. Matsiman calls up a latent commons of matsutake lovers. What holds his imagined matsipeople together is the pleasure of noticing. ${ }^{53}$

The pleasure of noticing; needing to notice things and wanting to out of curiosity, love and care. For many who commercialise, engineer and design forest bathing and barefoot trails, there is also a similar political agenda, of awareness of the very forests which are disappearing, as log trucks hurl up highways laden with cut trees. I have focused less on the practices of care, that Tsing looks at when she discusses noticing, and discovered more about how noticing is engineered and designed, how it is taught as a practice to be cultivated. The aim here, I suggest, is to offer a sensory education, an education which is imbued with particular politics, with technological infrastructures and data collection, with media and with commercial intentions.

As I have shown in this chapter, it is not only in these wild environments though that attention is given in how to sensorially educate - designers are also involved in urban and garden projects, as well as smartphone

52 Tsunetsugu, Park, and Miyazaki, 'Trends in Research', 33.

53 Lowenhaupt Tsing, Mushroom at the End of the World, 278-79. 
applications. By looking at these various examples I have not immersed myself in the debate about how natural or engineered these spaces are, but rather tried to show that there are still many sensory lessons taking place in how to engage with the landscape. In fact, I have suggested, following from Anna Tsing, that these spaces offer us particularly rich insights into how a lesson navigates human and landscape histories and interactions. For when individuals and groups rework how they consider figure and ground, when they work at what it is they notice, and the arts of noticing landscapes of living, some of the most powerful sensory lessons about the world we live in might just be taking place.

\section{Bibliography}

Blote Voeten Park. 'Your Walking Experience for Young and Old'. 31 May 2019. https://barefootpark.eu/en/dresscode-blote-voeten.

De Solier, Isabelle. Food and the Self: Consumption, Production and Material Culture. London: Bloomsbury, 2013.

Ebbensgaard, Casper Laing. "I Like the Sound of Falling Water, It's Calming": Engineering Sensory Experiences through Landscape Architecture'. Cultural Geographies 24, no. 3 (2017): 441-55.

Eliot, George. Middlemarch. London: Penguin, 1994.

Gabrys, Jennifer. 'Citizen Sensing, Air Pollution and Fracking: From "Caring About Your Air" to Speculative Practices of Evidencing Harm'. The Sociological Review Monographs 65, no. 2_suppl (2017): 172-92.

Gabrys, Jennifer, and Helen Pritchard. 'Sensing Practices'. In Posthuman Glossary, edited by Rosi Braidotti and Maria Hlavajova, 394-95. London: Bloomsbury Academic, 2018.

Ingold, Tim. 'Culture on the Ground: The World Perceived through the Feet'. Journal of Material Culture 9, no. 3 (2004): 315-40.

- Anthropology andlas Education. London: Routledge, 2018.

Lachmund, Jens. Greening Berlin: The Co-Production of Science, Politics, and Urban Nature. Cambridge, MA: MIT Press, 2013.

Lenoir, Jean. 'Le Nez Du Vin'. N.p.: n.a., 2005.

Lowenhaupt Tsing, Anna. The Mushroom at the End of the World: On the Possibility of Life in Capitalist Ruins. Princeton: Princeton University Press, 2015.

Lupton, Deborah, and Sarah Maslen. 'The More-Than-Human Sensorium: Sensory Engagements with Digital Self-Tracking Technologies'. The Senses and Society 13, no. 2 (2018): 190-202.

Majid, Asifa, Laura Speed, Ilja Croijmans, and Artin Arshamian. 'What Makes a Better Smeller?'. Perception 46, no. 3-4 (2017): 406-30.

McAlary, Brooke. Destination Simple: Everyday Rituals for a Slower Life. Carlton: Nero, 2017.

Merleau-Ponty, Maurice. Phenomenology of Perception. London: Routledge \& Kegan Paul, 1962.

Morris, Nina J. 'Dalziel and Scullion, Tumadh: Immersion'. The Senses and Society 10, no. 2 (2015): 261-66. 


\section{Engineering noticing}

Newport, Cal. Digital Minimalism: On Living Better with Less Technology. New York: Penguin Books Limited, 2019.

Peters, John Durham. The Marvelous Clouds: Toward a Philosophy of Elemental Media. Chicago, IL: The University of Chicago Press, 2015.

Pritchard, Helen, Jennifer Gabrys, and Lara Houston. 'Re-calibrating DIY: Testing Digital Participation Across Dust Sensors, Fry Pans and Environmental Pollution'. New Media \& Society 20, no. 12 (2018): 4533-52.

Purser, Ronald E., David Forbes, and Adam Burke, eds. Handbook of Mindfulness: Culture, Context, and Social Engagement, Mindfulness in Behavioral Health. Cham: Springer International, 2016.

Shepherd, Nick, Christian Ernsten and Dirk-Jan Visser. 'The Walking Seminar: Embodied Research in Emergent Anthropocene Landscapes'. 12 December 2018. https://www.christianernsten.nl/wp-content/uploads/2018/12/wandelkrant-defscreen.pdf (Accessed 1 January 2020).

Sterne, Jonathan. Mp3: The Meaning of a Format. Sign, Storage, Transmission. Durham, NC: Duke University Press, 2012.

Strathern, Marilyn. 'On Space and Depth'. In Complexities: Social Studies of Knowledge Practices, edited by John Law and Annemarie Mol, 88-115. Durham, NC: Duke University Press, 2002.

Trubek, Amy. The Taste of Place: A Cultural Journey into Terroir. Berkeley: University of California Press, 2008.

Tsunetsugu, Yuko, Bum-Jin Park, and Yoshifumi Miyazaki. 'Trends in Research Related to "Shinrin-Yoku" (Taking in the Forest Atmosphere or Forest Bathing) in Japan'. Environmental Health and Preventive Medicine 15, no. 1 (2010): 27-37.

Williams, Florence. The Nature Fix: Why Nature Makes Us Happier, Healthier, and More Creative. New York: W. W. Norton, 2017. 


\title{
Something sensible by way of a conclusion
}

\begin{abstract}
Paying attention means slowing down and accepting that intrusive interstices open up even in the midst of an urgency. ... I call it an art because it needs a ritual in order to foster this possibility. And this is very interesting when we do it well and with joy. This is not about being critical or reflexive, this is not about looking for an imperfection, about playing with arguments. It is just creating the occasion - a rather Quaker art, to "bethink," to pay attention to what may lurk. ${ }^{1}$
\end{abstract}

When Thoreau built his cabin in Walden, to work on cultivating his art of noticing and attend to the world around him, he was not, as the myth often gets told, alone. He was not engaging on an individual quest in which he acquired knowledge from his simple acts. No, his process of isolation was intensely social - there were frequent visitors to his cabin, for example, and tourists on nearby walking trails. He learned from the materials he worked with, the animals he observed and from the landscape. His learning was, as I have argued throughout this book material, meandering and social.

Sensory education is not a solitary, innate or acquired process. Throughout the chapters of this book, I have highlighted the social labour of sensory lessons, pointing out how sensory education takes care and maintenance of objects, involves set-ups and design. I have unpacked some of the elements of sensory learning that is evident across the domains of medicine and cooking, as well as other skilled practice, such as the use of reference points in learning new vocabulary; techniques of calibration as a collective social activity; the role of instructional media in re-orientating sensing; how industry repackages the senses; and how noticing is cultivated in workshops and engineered landscapes.

Why are the social and material conditions of sensory education so important to consider? Because there are consequences of how sensing is learned,

1 Savransky, Martin and Isabelle Stengers, 'Relearning the Art of Playing Attention: A Conversation', Sub-stance 47, no. 1 (2018), 136. 
as the historian Kuriyama points out so eloquently on his treatise of tactile skills in Chinese and Greek medicine, and what informs this learning:

Whether we place our hands gingerly, or grip hard, whether our fingers explore with care, or merely tap impatiently. But how we handle an object depends, in turn, on how we conceive it. The delicacy with which we hold antique china disappears when we pick up modern plastic imitations. The manner in which we cradle the face of a loved one is worlds apart from our touch when we brush, involuntarily, against someone we despise or fear. ${ }^{2}$

How the world takes shape depends on how the cultivation of sensing practices, ${ }^{3}$ practices that are learned not only through repeated experiment and activity with others but also through material encounters. The reality of bodies changes in this process - that is, there is not one 'real world' out there that learns to sense, nor is there a blank slate of a sensing singular body, but rather what is sensed (in the plural) and sensing bodies (in the plural) come about together. ${ }^{4}$ This constantly changes, with place, people, weather and so forth. What we sense is there because of the way we sense and the way we sense happens because of what we sense.

One of the central arguments made by those who offer professional guidance in sensory education, whether it be a call for digital minimalism, decluttering, mindfulness or flow, is that many currently live their lives devoid of full sensory awareness, and that being more sensorially aware will make better people, living fuller lives. Sensory education may be something celebrated as a way to attend to the world in an age of distraction, as acts of community building, expertise development, self-improvement, fulfilment and happiness. But it is also about selling products, courses, experiences and books. Sensing is linked to a vast ecology of practices, ${ }^{5}$ many of which have not been explored in this book - there are sticky threads of colonialism for example which I have not discussed in any detail and which demand attention in conversation with the growing and important literature on decolonialist politics of engagement, ${ }^{6}$ and indigenous knowledge systems, where scholars are rewriting history and urging better recognition of other worlds and ways of knowing.

There is more work to be done on how sensing is shaped by economic factors, by class, by inequalities in the world production of goods and by

2 Shigehisa Kuriyama, The Expressiveness of the Body and the Divergence of Greek and Chinese Medicine (Cambridge, MA: The MIT Press, 1999).

3 Mattijs Van de Port and Annemarie Mol, 'Chupar Frutas in Salvador Da Bahia: A Case of Practice-Specific Alterities', Journal of the Royal Anthropological Institute 21, no. 1 (2015).

4 Van de Port and Mol, 'Chupar Frutas', 175.

5 Cristina Grasseni, 'Good Looking: Learning to Be a Cattle Breader', in Skilled Visions: Between Apprenticeship and Standards, ed. Cristina Grasseni (New York: Berghahn Books, 2009), 63.

6 Sandra Harding, 'Latin American Decolonial Social Studies of Scientific Knowledge: Alliances and Tensions', Science, Technology, \& Human Values 41, no. 6 (2016). 
traditional centres of knowledge production and in conversation with disabilities studies literature. An alternative, a more revolutionary sensory education, a critical sensory pedagogy ${ }^{7}$ which invites disruption of norms and disobedience within existing dominant frameworks cries out to be written, taught, practiced. There is already some concern that sensory education may lead to a particular kind of homogenisation of the senses in the world, that sensory vocabularies are being standardised, through a global language of sensing. ${ }^{8}$ Some scholars have looked for example at how the cultivation of sensing relies on standardised and globally sanctioned sensory experiences and knowledge. ${ }^{9} \mathrm{Xiao}^{10}$ however nuances these claims by showing that while there may be attempts at global or national sensory vocabularies, that this has not erased local indigenous knowledges. Grasseni suggests that a standardised, hegemonic vision may in fact contribute to a creative way of learning skilled practice. I have also wanted to show in this book, that while there are practices of calibration and standardisation that come about in sensory lessons, that these regimes also potentially allow room for improvisation and making. As Grasseni writes: 'Paradoxically, it is a hegemonic vision, emerging out of learning processes, that maintains the qualities of social, affective and cognitive engagement, of sensuousness and creativity. ${ }^{11}$

In many ways this book is an attempt to celebrate some of that creativity, by looking at the work involved in sensory lessons. In crafting the book, I wanted to see whether by looking into personal experiences and everyday and professional practices, by looking across research in a breadth of fields, by personally engaging in sensory learning through making lessons, it may be possible to discern something interesting about how it is that humans learn as sentient beings in a sentient world. The format of the book, with practical sensory lessons and pages for observation, with invitations to read in particular ways, and conduct academic workshops by attending to the sensory and material, are attempts at opening up other possibilities for apprehension. The aim of this book has not been to forward a strong theoretical argument, as is demanded in much academic literature, or, on the other hand, to chart a manifesto, as the popular literature on this topic seems to aspire, but rather, to create an occasion, as Stengers invites, to offer a space

7 Sheila Macrine, Critical Pedagogy in Uncertain Times: Hope and Possibilities (New York: Palgrave Macmillan, 2009).

8 Jenny Elaine Goldstein, "The "Coffee Doctors": The Language of Taste and the Rise of Rwanda's Specialty Bean Value', Food and Foodways 19, no. 1-2 (2011); Steven Shapin, 'A Taste of Science: Making the Subjective Objective in the California Wine World', Social Studies of Science 46, no. 3 (2016): 436-60.

9 Yuson Jung, 'Tasting and Judging the Unknown Terroir of the Bulgarian Wine: The Political Economy of Sensory Experience', Food and Foodways 22, no. 1-2 (2014), 43.

10 Kunbing Xiao, 'The Taste of Tea: Material, Embodied Knowledge and Environmental History in Northern Fujian, China', Journal of Material Culture 22, no. 1 (2017): 3-18.

11 Grasseni, 'Good Looking', 64. 
to pay attention to 'what may lurk', and to think further about how it is that we learn how to do this.

\section{A final note on instructions}

My son has a favourite book called Aunt Amelia, which his aunt gave him as a birthday present. In the book, there are two children who are left with an unknown babysitter called Amelia. Arriving in a flamboyant hat and stripy dress, Amelia is reptilian and gorgeous. The parents leave instructions, for Amelia to follow while they are away. They include:

'They can have ice-cream, but just one each'

'They are allowed one story before bedtime ... but absolutely no television ...' 'For dinner they can choose what to have as long as it is something sensible'. ${ }^{12}$

The book outlines each of these instructions one by one and the accompanying illustrations show how Aunt Amelia and the children proceed to ignore them, one by one. They eat ice-creams with ten scoops, read stacks of books, fall asleep in front of the television and have mountains of cakes and sundaes for dinner. The instructions are ignored with glee and joy, yet they offer a way to frame the fun activities of the day at the same time. When the parents ask the children at the end of the book if they would like Aunt Amelia to babysit again, they say 'Yes please ... and perhaps you could write another list!'

So my final invitation of the book is to take the sensory instructions you find here and in life, to play with them, share then and ignore them, joyfully and with glee.

\section{Bibliography}

Brown, David, and Aspasia Leledaki. 'Eastern Movement Forms as Body-Self Transforming Cultural Practices in the West: Towards a Sociological Perspective'. Cultural Sociology 4, no. 1 (2010): 123-54.

Cobb, Rebecca. Aunt Amelia. London: MacMillan, 2013.

Goldstein, Jenny Elaine. 'The "Coffee Doctors": The Language of Taste and the Rise of Rwanda's Specialty Bean Value'. Food and Foodways 19, no. 1-2 (2011): 135-59.

Grasseni, Cristina. 'Good Looking: Learning to Be a Cattle Breader'. In Skilled Visions: Between Apprenticeship and Standards, edited by Cristina Grasseni, 47-66. New York: Berghahn Books, 2009.

12 Rebecca Cobb, Aunt Amelia (London: MacMillan, 2013). 
Harding, Sandra. 'Latin American Decolonial Social Studies of Scientific Knowledge: Alliances and Tensions'. Science, Technology, \& Human Values 41, no. 6 (2016): 1063-1087.

Jung, Yuson. 'Tasting and Judging the Unknown Terroir of the Bulgarian Wine: The Political Economy of Sensory Experience'. Food and Foodways 22, no. 1-2 (2014): 24-47.

Lowenhaupt Tsing, Anna. The Mushroom at the End of the World: On the Possibility of Life in Capitalist Ruins. Princeton, NJ: Princeton University Press, 2015.

Macrine, Sheila. Critical Pedagogy in Uncertain Times: Hope and Possibilities. New York: Palgrave Macmillan, 2009.

Savransky, Martin and Isabelle Stengers. 'Relearning the Art of Paying Attention: A Conversation'. Sub-Stance 47, no. 1 (2018): 130-45.

Shapin, Steven. 'A Taste of Science: Making the Subjective Objective in the California Wine World'. Social Studies of Science 46, no. 3 (2016): 436-60.

Van de Port, Mattijs, and Annemarie Mol. 'Chupar Frutas in Salvador Da Bahia: A Case of Practice-Specific Alterities'. Journal of the Royal Anthropological Institute 21, no. 1 (2015): 165-80.

Xiao, Kunbing. 'The Taste of Tea: Material, Embodied Knowledge and Environmental History in Northern Fujian, China'. Journal of Material Culture 22, no. 1 (2017): 3-18. 


\section{Index}

Note: Italic page numbers refer to figures.

academic workshop 120, 177

actor-network-theory 20

alignment 55, 69, 100-103; see also sensory alignment

Allison, Rachel Vaden 50, 67, 77

anthropologies: bodily concerns and 12; cognitive models and 98; education and 120; image as method 108; of learning skills 7; medical education and 84; senses and 9; sensory knowledge and 17-19; of sensory marketing 134-36; sensory skills in institutional settings 66; sensory vocabularies and 36; Slow Food movement and 106, 134, 142, 145

Appadurai, Arjun 93, 94

Aristotle 9

'arts of noticing' 2, 4, 26, 73, 98, 111, $118,160,167,171-73,175$

Atkinson, Paul 66, 77

attention workshops, for medical students 26, 115-18

Auenbrugger, Leopold 18, 116

Auscultation 53, 72, 116; learning 54, 75; teaching 55

awareness 3, 4, 6, 7, 20, 24, 25, 27, 92-94, 116, 117, 135, 141, 145, 157. $159,161,176$

bare feet and forest bathing 168-73

bodies $11,15,20,25,55,59,60,78,162$; Latour's theory 5 , 45; learning process 119-20; listening to body sounds 53 , 54, 55, 71, 116; mannequin/model 77; object/commodity 132 ; teaching 72 ; tropical fruits $61-62$ calibration practices 74-78

'Champ des Odeurs' 50

Classen, Constance 5, 21, 133, 134, 135,139

cognitive learning models 98

commodification: of bodily experience

132 ; of embodiment 133; of sensory

education 6

common sense 9-10

connoisseurship 17, 117

cookbooks 23, 26, 90, 93, 94, 97, 98, 100, $107,112,113,114,136,141$

cooking class $23,26,98,111-15,121,142$

crafts $3-4,17,91,92,100$

creative practices $78-80$

Croijmans, Ilja 43-44

cultivate/cultivation/cultivated 2, 3-4, $5-7,12,15,18,26,34,40,66,67$, 111, 117, 132, 137-39, 147, 171, 172, 175-77

cupping 42-46; 'cupping quality test' $42-43$

cyanometer 33,34 ; Alice blue to duck egg blue 33-34; dark cyan to 7.5B 1/2 38-39; periwinkle to azure 34-35; Prussian blue to Egyptian blue 36-38

Daston, Lorraine 5, 55

Dear Data project 150, 154, 155

digital minimalism 2, 159, 176

digital-sensory kind of noticing 90

digital technologies $3,8,19,21,89,150$, 161-62, 164

Ducker, John 47-48, 101

Dumit, Joe 152, 154

Dunlop, Fuschia: Every Grain of Rice 95

Dunstan, Priscilla 89 
'ear cleaning' exercise 71

ear model 70, 71

Ebbensgaard, Laing 165, 167

Edgerton, David 103

education $2-5,48,67,103,175,176$; of attention 5, 120; for children 16-17

eggs 91-92; teaching medicine with food 59,60

Eliot, George 157

Elliott, Denielle 21, 150; A Different

Kind of Ethnography 150

embodiment 12, 14-15, 20, 23, 66, 98, $119,132,133,136,164$

engineering noticing: bare feet and forest bathing 168-73; design of our landscape 165-68; digital minimalism 159; 'sense hunt' 157; sensing and sensors 161-65; sensory learning practices 158

enskillment 12, 13, 15, 17, 66, 69, 78, 91, 98, 119

'environmental media' 162

Ernsten, Christian 171

everyday design in medical schools 80

expressive instructions, designing 98-100

Fasciculus medicinae 51

Fearnley-Whittingstall, Hugh: The River Cottage Meat Book 95

The Flavor Wheel 46

Flint, Austin 54

food gatherings 106-108

food industry 14, 134, 140, 147

French craft chocolatiers 138

fried fish sandwich 107, 108

Friesen, Norm 93

Gabrys, Jennifer 162, 164

Galison, Peter 5, 55

Gibson, James 5, 170

Goldstein, Jenny 46, 131

Goodwin, Charles 50

grapes: teaching medicine with food 60,61

Grasseni, Cristina 20, 177

Guarassi, Ivana 76

Le Guide des Croqueurs de Chocolat 136

\section{Hammer, Gili 67}

handmade teaching model 79

hands-on learning 111, 119-20

Haraway, Donna 152, 154

Haring, Kristen 119, 122

Harvey, William 71
Hayward, Tim 94

Hennion, Antoine 12, 147

Howes, David xii, 5, 9, 18, 21, 133, 134, 135,139

'human-disturbed landscapes' 160

'imagistic' anthropology 108

Ingold, Tim 5, 12, 13, 17, 23, 74, $78,91,92,93,97,116-17,119-20$, $154,169,170$

innate, sensing 11-16

instructional media 18, 90, 91-93, 94, 103,175

instructions, sensory 88-103

Kabat-Zinn, Jon 159

Kneebone, Roger 71

knitting 1, 3; needles 85

knitting uterus $79,80,84$; equipment 84-86; instructions 86-87

knowledge 17-19, 89; tacit 13; see also sensory knowledge

Kondō, Marie 7

Krishna, Aradhna 135, 136

Kuriyama, Shigehisa 19, 55, 56, 57, 67,176

Lachmund, Jens 53

Laennec, René 53, 54, 73, 116

landscape: design 165-68

language 44; see also sensory language

Latour, Bruno 4-5, 20, 45

La Trappe 135

Lave, Jean 17, 74

Law, John 92

Lawson, Nigella 96

learning $3,5,6,7,8,10,11,13,15$, $18,19,25,26,41,44,48,52,54$, $57,71,77,97,111,113,116,177$; auscultation 54, 76, 116; from others 6-8; hands-on 119-20; sensing 87, 92; sensory skills $11,15,65,66,69,103$; 'learning to see' 5

leisure labour 3

Leitch, Alison 142-43

leren 6

lesson, designing 127

Lupton, Deborah 163, 164

Lynch, Michael 92

Maastricht model of education 79; see also problem-based learning

McLuhan, Marshall 89, 90, 93, 97, 102

Majid, Asifa 36, 44 
making xv-xvii, xx, 34, 38, 39, 69, 85, $87,94,95,115,123,133,136,144$, 159,177

Making Clinical Sense project 22, 24, 50 , $68,73,79,86,101,108,155$

Mak, Monica 101

Mann, Anna 146, 147

marketing 134-36; see also sensory marketing

Marks, Laura 101-102

Maslen, Sarah 52, 66, 163, 164

medical education $15,62,67,68,72,74$, $77,84,140$; attention workshops in 117-18; instructional design in 80,98 ; of senses 26

medical schools 2, 19, 21, 26, 40, 41, $52,64,66,67,72,78-80,83,98$, 100-102, 140-41; Dutch 50; everyday design in 80 ; fieldwork 23; learning of percussion in 15; models and dissection in 67, 69; pedagogical tools in 76 ; tutorials 54 ; workbook in 53 ; workshops in 116

medical students, attention workshops for $115-18$

medicine with food, teaching: eggs 59 , 60 ; grapes 60,61 ; oranges $62,62-63$; pear drops 63-64, 63; tropical fruits 61, 61-62

Merleau-Ponty, Maurice 12, 161

metaphors 51-55, 57

Miller, Daniel 103

Montessori tradition 16

'more-than-human-sensorium' 164

Munsell colour chart 38, 41, 68

new vocabularies: learning of 25 ; metaphors 51-55; new words 41-46; objectivity machines 46-48; reference sets 49-51; see also vocabularies

Noble, Ann C. 46

noticing 3, 4-6, 41, 73, 90, 98, 111, 118,175 ; see also 'arts of noticing'; engineering noticing

Nott, John 68, 69, 77, 86

objectivity machines $46-48$

observation exercises 150; equipment 151 ; instructions $152-55$

Oddell, Jenny 8

olfactory vocabulary 44

oranges, teaching medicine with food 62 , 62-63

Ottolenghi, Yotam 114 palpation technique $98-100,102$

papaya 61,62

pear drops, teaching medicine with food 63, 63-64

pedagogical set-ups 71

pedagogical tools in medical school 76

Pellico, Linda Honan 116, 117

percussion 8, 9, 10, 17-19, 22, 102; sensory experience of 10 ; skill of 8,15

Peters, John Durham 92, 93, 161, 167, 168

Peynaud, Emile: Handbook of Enology 157

Phillips, Christopher 74

Pink, Sarah 21

pleuritic rubs 54

Polanyi, Michael 13, 17, 23, 117

Prentice, Rachel 67

Pritchard, Helen 162, 164

problem-based learning 79

professional identity, development of 67

reference sets $49-51$

repackaging sensations: dining differently 143-48; old tastes, new tastes 136-41; selling slowly $141-43$; sensory marketing 134-36; 'the senses' 131,132

Rice, Tom xiii, 66, 76

sahlep 108

Saunders, Barry 66

de Saussure, Horace-Bénédict 34, 35, 39

Schwarz, Norbert 135

self-tracking technologies 163

Sennett, Richard 18, 23, 98, 111

sensations, repackaging 131-48

senses, the five $4,9,27,131,132$

sensing 4, 5, 11-16, 18, 20, 24, 45, 49, 51, $87,90,91,100,118,133,139,161-65$, 176

sensors 161-65

sensory alignment $100-103$

sensory awareness $3,4,6,7,24,25,27$, 92-94, 116, 117, 135, 141, 145, 157 . $159,161,176$

sensory connoisseurship 117

'sensory course' menu 145

'sensory disorder' 24

sensory ethnography 21,150

sensory experience $3,9-11,16,24-27$, $41,48,54,65,74,76,97,102,117$, $131,132,133,135,136,143-48,152$, $155,157,166,167,177$

sensory experiments in anthropology 150 sensory food gatherings: fried fish sandwich 107, 108; sahlep 108; Slow Food movement 106 
'sensory hierarchy' 36

sensory instructions: designing

expressive instructions 98-100; digitalsensory kind of noticing 90; Dunstan method 89; instructional media 91-93; sensory alignment 100-103; sound of recipes 93-97

sensory knowledge 11, 17-19, 65, 71, 78,89

sensory language 51 ; linguistic limitations to 44

sensory learning $3,7,19,22,118,120$, 175,177 ; practices $13,158,159$

sensory lessons $2,3,7,14,15,22,26,27$, $68,86,87,94,98,111,113,122,131$, $140,147,150,160,167,173,175,177$ sensory marketing 14, 27, 133, 134-36, 138,147

'sensory politics' 14, 19, 111, 133, 139

sensory school: calibration 74-78; creativity and improvisation 78-80; development of professional identity 67 ; learning sensory skills 65 ; sensory training of doctors 67; set-ups 69-74 sensory skills 91 ; learning $10,11,65,69$, 103; teaching 26, 59, 69, 72, 78, 98, 140 sensory training $25,41,45,48,67,90$, $102,133,150$; of doctors 67 ; and practice 24; role of television and video in 26

sensory vocabularies $36,41,44,45$, 47, 48, 51, 57, 74, 177; learning 75; training 45

Serres, Michel xvi, 19, 138

Shapin, Steven 46, 47, 48, 74, 138, 139

skills $4,13,15,17,18,25,26,41,51,53$, $59,63,66,69,71,72,78,80,91,97$. 99, 103, 115-19; see also sensory skills Skillshare 120-25

Skills Lab 22, 23, 70, 70, 79

Slow Food movement 106, 134, 141, 142-43, 145

smartphone apps 163

smell kit 48-49, 49

Smith, Delia 100

Smith-Oka, Vania 67

social labour 7, 90, 111, 175

social theories of learning 11

socio-material learning context 27

de Solier, Isabelle 3, 103, 134

Sonic Skills project 69 sound of recipes 93-97

Sounds of the Sea 143, 144

Steingo, Gavin 67, 73

Stengers, Isabelle 177

Stephens, Neil 60

Sterne, Jonathan 164

stethoscope 72

Strathern, Marilyn 5, 160

styles of listening 57

styles of speaking 57

tacit knowledge 13, 17, 91

Talley, Nicholas 9, 10

taste communities 48

'taste intersubjectivity' 48

Taylor, Janelle 66

teaching $6,16,53,55,65,66,75,78,79$, $80,83,86,98,118$; sensory skills 69 , $59,69,72,80,98,140$

Teil, Geneviève xvii, $12,49,51,57,70$, 136, 147

Terrio, Susan 16, 136, 137

training 41, 45, 48, 67, 90, 101, 133, 150

Transition Town movement 123

tropical fruits, teaching medicine with food $61,61-62$

Tsing, Anna 111, 124, 160, 172, 173

uterus, knitting: equipment 84-86; instructions 86-87

Van Drie, Melissa 17, 55, 69, 71

visual sensory cues 44

vocabularies: cultivation of 34 ; metaphors 51-55; new words 41-46; objectivity machines $46-48$; reference sets 49-51; sensory see sensory vocabularies

von Hoffmann, Viktoria 92

Wendland, Claire 67

wine tasting 47, 48, 53, 68, 74, 78, 131, 138

Wojcik, Andrea 67, 73, 77, 84

workshopping 110; 'arts of noticing'

111; attention workshops for medical students 115-18; cooking class

112-15; hands-on learning 119-20;

Skillshare 120-25

Wyatt, Sally 2

Xiao, Kunbing 14, 177 


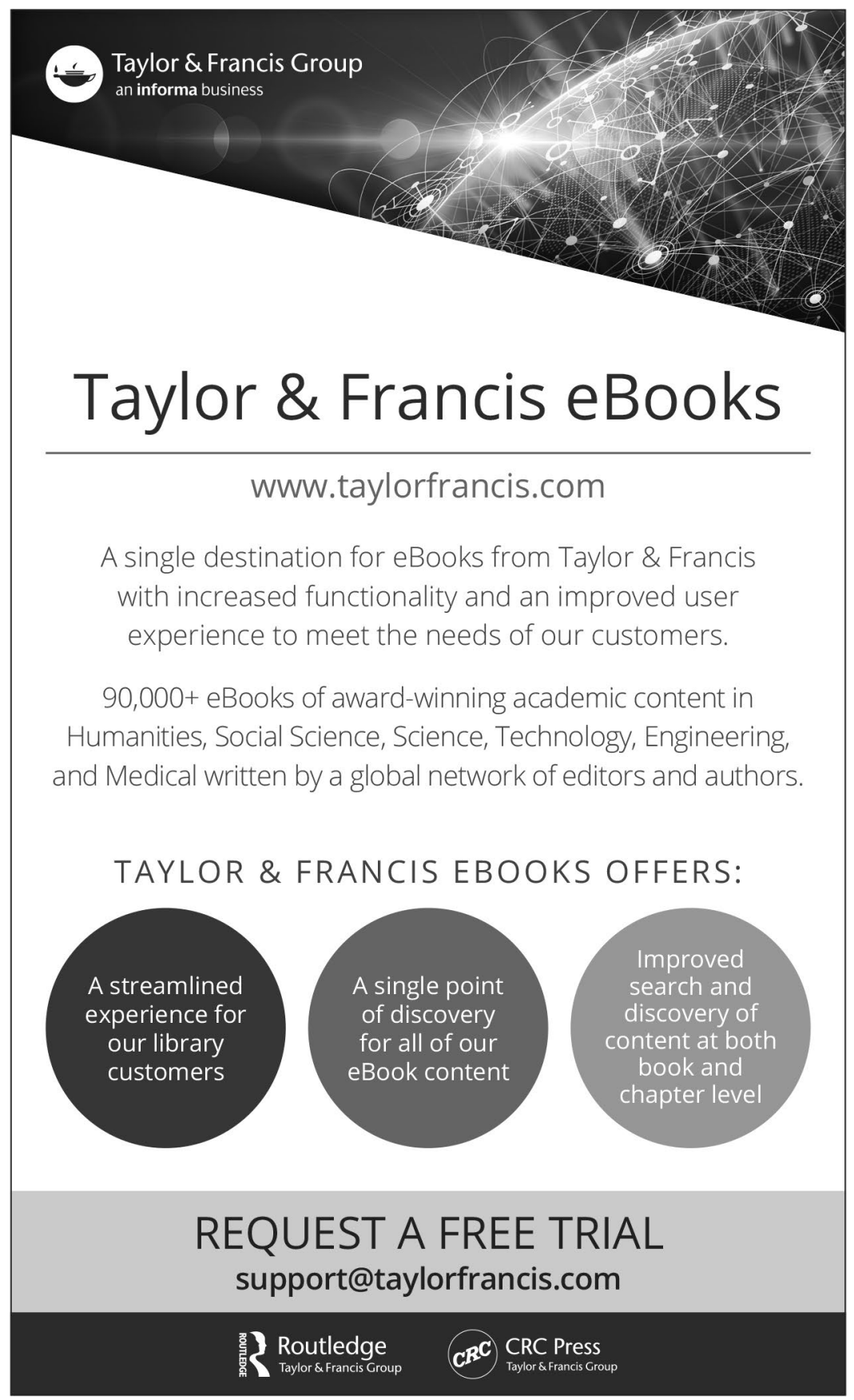

